\title{
Power to the people? : civic engagement with small- scale hydroelectric plants in India
}

Citation for published version (APA):

Höffken, J. I. (2012). Power to the people? : civic engagement with small-scale hydroelectric plants in India. [Doctoral Thesis, Maastricht University]. BOXPress. https://doi.org/10.26481/dis.20121212jh

Document status and date:

Published: 01/01/2012

DOI:

10.26481/dis.20121212jh

Document Version:

Publisher's PDF, also known as Version of record

\section{Please check the document version of this publication:}

- A submitted manuscript is the version of the article upon submission and before peer-review. There can be important differences between the submitted version and the official published version of record.

People interested in the research are advised to contact the author for the final version of the publication, or visit the DOI to the publisher's website.

- The final author version and the galley proof are versions of the publication after peer review.

- The final published version features the final layout of the paper including the volume, issue and page numbers.

Link to publication

\footnotetext{
General rights rights.

- You may freely distribute the URL identifying the publication in the public portal. please follow below link for the End User Agreement:

www.umlib.nl/taverne-license

Take down policy

If you believe that this document breaches copyright please contact us at:

repository@maastrichtuniversity.nl

providing details and we will investigate your claim.
}

Copyright and moral rights for the publications made accessible in the public portal are retained by the authors and/or other copyright owners and it is a condition of accessing publications that users recognise and abide by the legal requirements associated with these

- Users may download and print one copy of any publication from the public portal for the purpose of private study or research.

- You may not further distribute the material or use it for any profit-making activity or commercial gain

If the publication is distributed under the terms of Article $25 \mathrm{fa}$ of the Dutch Copyright Act, indicated by the "Taverne" license above, 


\section{POWER TO THE PEOPLE?}


The cover picture of this book is a copy of a woodcut print made by Jennifer Schmitt, an artist from Massachusetts, USA. For me, this woodcut print visualizes some of the key issues of my $\mathrm{PhD}$ dissertation. As you will read, my book is about the issues of civic engagement and electricity - and I see this visualized in the red snake-like curls; it is about the issue of water - the blue dots; it is about villages and power plants - represented by the house/barn; and it is about the life of indigenous people - which to me is represented by the tribal symbol on the left side. I am grateful to Jennifer for allowing me to use her print as cover picture.

(C) Copyright Johanna I. Höffken, 2012.

Cover design: Proefschriftmaken.nl || Uitgeverij BOXPress

Cover picture: "Windswept" by Jennifer Schmitt

Printed \& Lay Out by: Proefschriftmaken.nl || Uitgeverij BOXPress

Published by: Uitgeverij BOXPress, 's-Hertogenbosch

ISBN 978-90-8891-525-3 


\title{
POWER TO THE PEOPLE?
}

Civic Engagement with Small-scale Hydroelectric Plants in India

\author{
PROEFSCHRIFT \\ ter verkrijging van de graad van doctor aan de Universiteit Maastricht, \\ op gezag van de Rector Magnificus, Prof. dr. L.L.G. Soete \\ volgens het besluit van het College van Decanen, \\ in het openbaar te verdedigen \\ op woensdag, 12 december 2012 om 12.00 uur \\ door \\ Johanna Irene Höffken
}




\section{PROMOTOR:}

Prof. dr. ir. W.E. Bijker

\section{COPROMOTOR:}

Dr. T. Conzelmann

\section{BEOORDELINGSCOMMISSIE:}

Prof. dr. S. Wyatt (voorzitter)

Dr. A.M. Hommels

Prof. dr. S. Jasanoff (Harvard University, United States of America)

Prof. dr. S.M.R.L. Vanhoonacker

Dr. ir. G.P.J. Verbong (Technische Universiteit Eindhoven)

The production of this thesis has been sponsored by:

The Netherlands Graduate Research School of Science, Technology and Modern Culture (WTMC) and the Faculty of Arts and Social Sciences, Maastricht University. 


\section{Table of Contents}

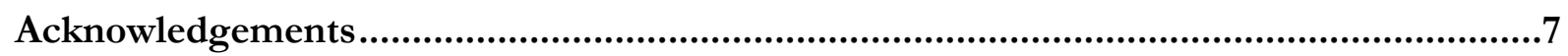

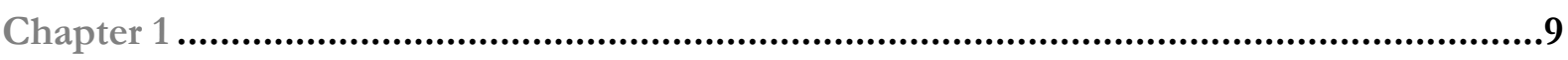

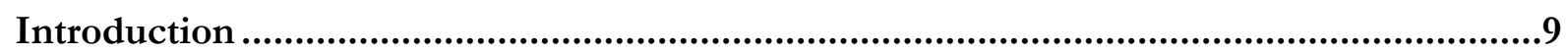

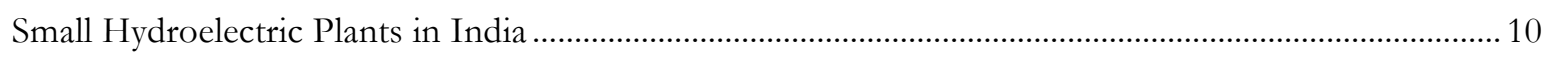

Civic Engagement in Science, Technology and Society Studies and in Political Science Studies............. 13

Studying Civic Engagement with Small-scale Hydroelectric Plants in India ...............................................18

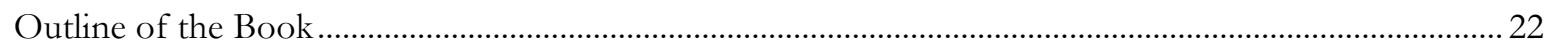

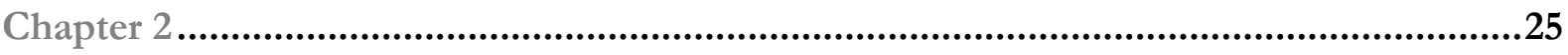

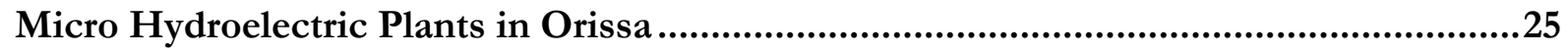

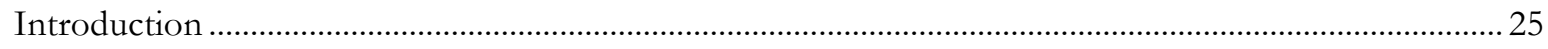

Functioning and Policy Context of Micro Hydel Plants .................................................................................29

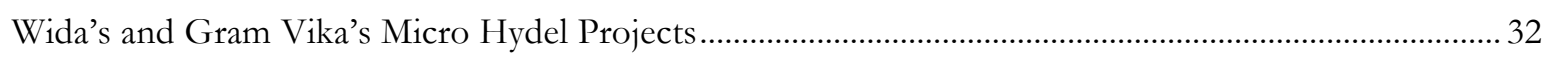

Phases of Engagement in Wida's and Gram Vikas' Micro Hydel Projects.................................................. 35

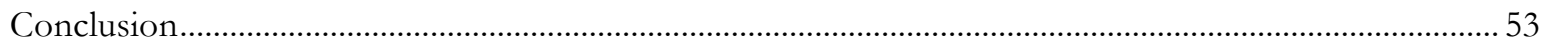

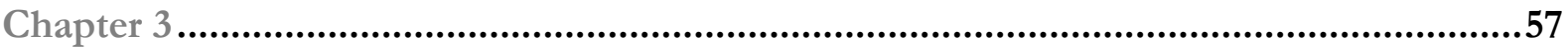

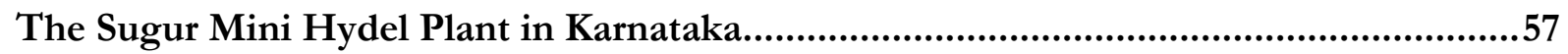

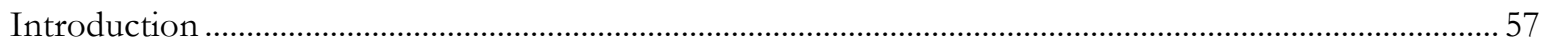

Overview of India's Electricity Sector and Policy Context ...................................................................... 58

Following the Water Flow: From Tungabhadra's Dam to Sugur's Anicut.................................................. 61

Conventional and Unconventional Forms of Engagement........................................................................ 66

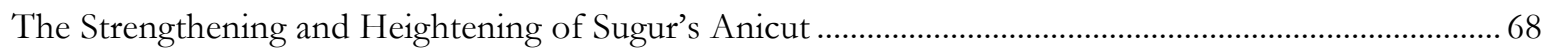

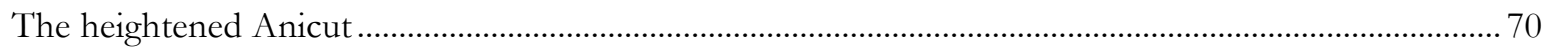

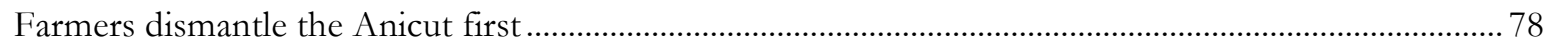

The Irrigation Department Dismantles the Anicut, Too ............................................................................. 83

The Company Dismantles the Anicut, at Last.............................................................................................. 89

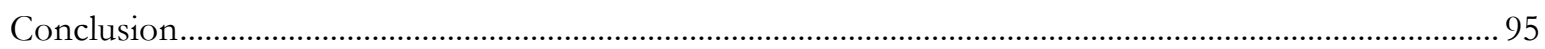




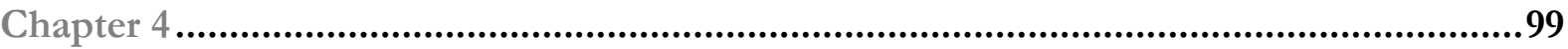

The Kenchanaguddam Mini Hydel Plant ...................................................................99

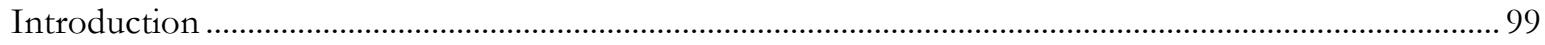

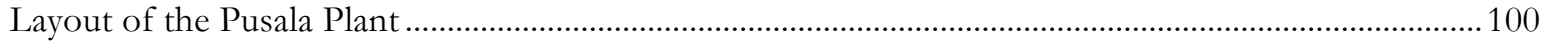

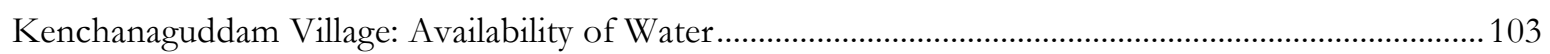

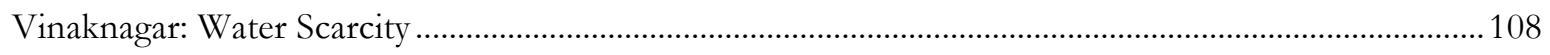

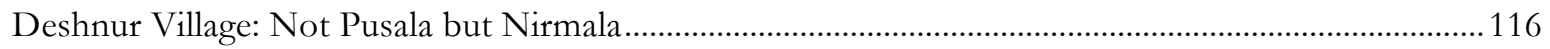

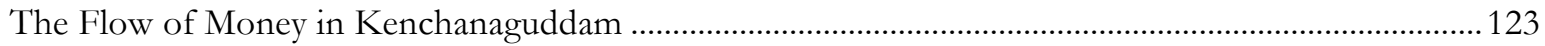

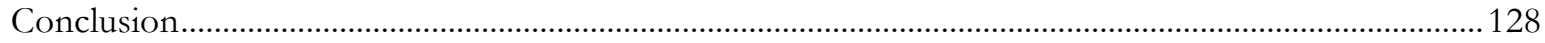

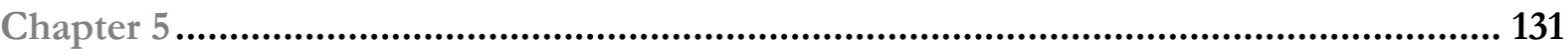

Explaining Civic Engagement with Small-scale Hydroelectric Plants .......................... 131

Forms, Contents, and Consequences of Engagement ……………………………................................ 131

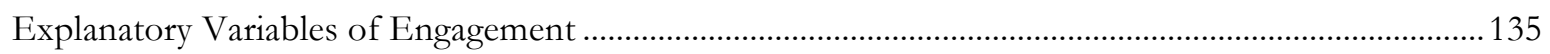

Variables of Engagement with Micro Hydel Plants in Orissa...................................................................136

Variables of Engagement with Mini Hydel Plants in Karnataka .................................................................140

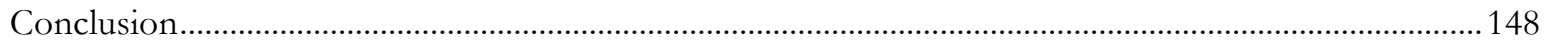

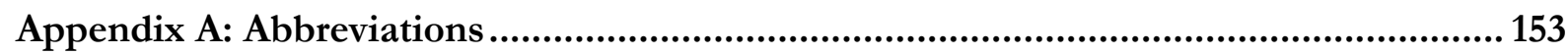

Appendix B: Chronological Overview of Key Events and Correspondence at Sugur's Mini

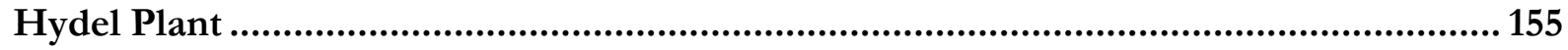

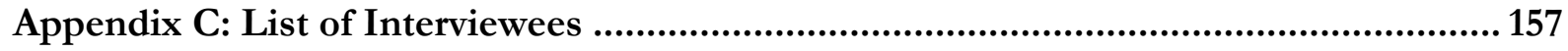

Appendix D: List of References to Specific Documentation regarding the Karnataka Case

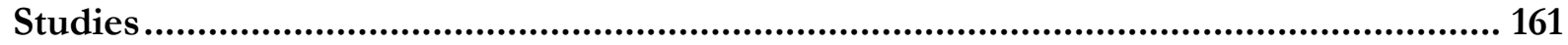

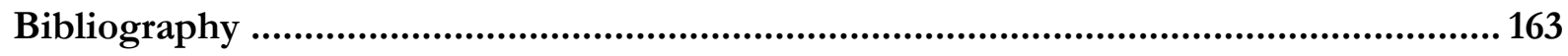

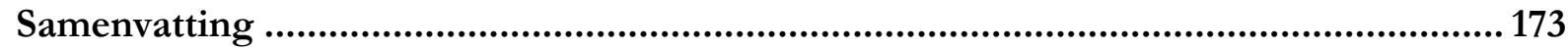

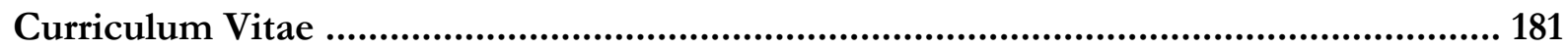




\section{Acknowledgements}

Crossroads in life sometimes turn up at strange locations. A café in the railway station of 'sHertogenbosch, where I had a meeting with Prof. Wiebe Bijker, turned out to be one of them. I had contacted Wiebe for advise about pursuing a $\mathrm{PhD}$, an ambition I had, since I had moved to the Netherlands. For me, this meeting marks the "unofficial" beginning of the project, which resulted in this book. It was during this meeting that the idea to work on a PhD project under his supervision came into life. Due to this meeting and his support I could start walking down this particular road, - and I would like to thank him for this. I would also like to thank Dr. Thomas Conzelmann who joined my project as second supervisor soon after its official start. Both supervised me in a way that was characterized by a tailor-made balance between support, guidance and freedom, by making sure that one feature never threatened the existence of the others. I truly appreciate and thank them for this.

I am also thankful for the support of my colleagues at the Faculty of Arts and Social Sciences, and especially the fellow students at the Graduate School (of whom by now there are many). My academic career was surely enriched by the trainings and workshops I could enjoy within the Netherlands Graduate Research School of Science, Technology and Modern Culture (WTMC), and I am thankful for the discussions, comments, and inspiration I received, and the people I met there.

During all of my research stays in India, I could call the Institute of Social and Economic Change (ISEC) in Bangalore my research home. I am indebted to ISEC's director, Prof. R.S. Deshpande, who kindly provided me with a research affiliation. I am also thankful for the manifold support I received from faculty and staff at ISEC, especially S. Manasi, Sunil Nautiyal, M. Mahadeva, Narayana K.S. and Umesh Babu M.S. I am grateful for having made friends at ISEC, and I will not forget the daily "evening Panchayat meetings" - thank you, Srikant, Khalid, Ananth, and Durba (to name but a few). Besides that, my time in Bangalore would not have been the same without Shanti and Ishwar, and Ganesha and Chetana - thank you for your friendship.

The case studies of this book are based on accounts of many different people across India, who agreed to share their experiences and insights with me, and I am indebted to all of them. Two persons played a key role in helping me to communicate with many of them: Subhash Bengre and Sandeep Chand, who acted as my translators and travel companions. Thank you both for your work and efforts. 
I would also like to thank Dr. Chitra Krishnan who, through her insights and support, contributed significantly to the way this project evolved - thank you, Chitra.

From the very beginning of my project, Dr. M.V. Ramana was another invaluable mentor for me. Ramana, I am so grateful for the countless discussions and reflections that took place in India, in the US, and via Skype.

During the fall semester of 2010 I had the great opportunity to join the STS Program at the Harvard Kennedy School of Government. My time at Harvard was extremely valuable and inspiring and I am thankful for the things I learnt and people I met in Cambridge. I am immensely grateful to Prof. Sheila Jasanoff for letting me join her program.

Finally, I would like to thank Angela, Rachel, Mary, Lotte, Matthijs and Alex, and all the others, who supported and inspired me during the work on my $\mathrm{PhD}$ (and beyond). My gratitude also extends to my family, especially my parents, Helga and Gert, for their continuous support.

Life is full of crossroads.

Thank you, Regina, for helping to navigate. Thank you, mijn Bram, for walking with me. 


\section{Chapter 1}

\section{Introduction}

In this book I study civic engagement through the lens of electric power generation. Given this focus, I argue for the continued importance of the voice of people in the development of science and technology. The technologies on which I concentrate in this study are small-scale hydroelectric ${ }^{1}$ plants in India, which produce electricity by converting the power of falling water. In the Indian context, looking at civic engagement with technologies that produce electricity on a small scale is rare. So far, mostly large electricity technologies have captured the attention of the public, due to the technologies' large-scale impacts on society and ecology. A well-known case involves the Narmada Bachao Andolan social movement fighting the Sardar Sarovan Dam project (Baviskar, 1995; Dwivedi, 2006). The siting of new nuclear plants has been another domain where civic engagement with large-scale electricity technologies has been documented in India (Patibanda, 2011; Ramana, forthcoming).

Since small-scale hydel plants do not rely on finite fossil fuel resources to generate power, they are qualified as renewable energy technologies. In times of steady depletion of the finite energy resources and human-induced climate change, renewable energy technologies have generally come to enjoy a positive image, by providing a clean (no greenhouse gas emissions) and green (renewable) energy alternative. This favorable image of small-scale hydel plants seems to lull interest in the relation between small hydel development and people's voice.

Along with their positive image as renewable energy technologies, their small-scale makes these hydel plants a rather unimposing candidate to study civic engagement. Especially in the case of hydroelectric projects the largeness of the technology and its impacts seems to be related to the visibility of the issue of civic engagement. Joy et al. find that "conflicts over dams ... are relatively well publicized and ... documented” (Joy, Gujja, Paranjape, Goud, \& Vispute, 2008: $\mathrm{xxv}$ ), while a broader view across India's water sector reveals "a million revolts in the making," simmering and erupting at the local level, which generally go unnoticed.

The normative importance and the empirical richness of large civic engagement activities with large-scale technologies are undisputable. Yet, with the scaling down of the technology size from large to small-scale, the visibility and recognition of civic engagement issues seem to have disappeared from the view of larger academic and other publics.

\footnotetext{
1 "Hydroelectric" is also abbreviated as "hydel." Both versions are used throughout this book.
} 
I chose to study civic engagement with small hydel plants by empirically detailing three aspects. These three aspects of civic engagement functioned as my central organizing device guiding both my empirical research and analysis. Thus, in this book I will ask about forms, contents, and consequences of civic engagement with small-scale hydroelectric plants in India. Investigating forms, contents, and consequences of civic engagement is a first step toward shedding light on a phenomenon that has not yet received much scholarly and public attention.

Choosing small-scale hydroelectric plants as research site implicitly questions common inferences suggesting the socio-technical pettiness of small-scale, renewable energy technologies. By looking at civic engagement with small-scale hydroelectric plants I show that scaling-down of the technology does neither imply the disappearance of civic engagement issues, nor does it diminish their empirical and normative relevance. Even in the case of renewable energy technologies, civic engagement continues to be important. Contrary to many studies focusing on large dams or other large-scale technologies, the choice of this study's research site is not intended as an implicit critique on such technologies per se. Rather, by focusing on small-scale hydroelectric plants I aim to show that neither their scale nor their image would justify a diminished empirical interest in their actual functioning in society.

\section{Small Hydroelectric Plants in India}

Small hydroelectric plants in India are to be associated with three broad and interrelated debates that perpetuate the positive features of these electricity projects. ${ }^{2}$ The first relates to discussions depicting India as a power-starved country. India is the second most populated country in the world and has a population of currently about 1.21 billion people, which is expected to go up (GOI, 2011a). ${ }^{3}$ Over the past several years, India's economy underwent a remarkable growth trajectory (WB, 2011). ${ }^{4}$ Along with India's demographic and economic growth, the hunger for electricity increased. Some project that between now and 2050 India's electricity supply and demand will need to increase five- or six-fold to sustain its current growth rate (IEA, 2011: 7).

In March 2010 the total power generation capacity in India amounted to 159 Gigawatt (GW) (IRESR, 2010). Most of India's electricity (64.3\%) is generated by using fossil fuels, with coal

\footnotetext{
2 The capacity thresholds, which are used to classify small hydroelectric plants, differ. While in Europe 10 megawatt (MW) is the generally accepted threshold (EU, n.d.), Government of India (GOI) classifies small hydroelectric plants as those with a capacity up to $25 \mathrm{MW}$. Small plants are further differentiated into micro (up to 100 kilowatt), mini (101 up to 2000 kilowatt), and small hydroelectric projects (2001 up to 25000 kilowatt=25 MW).

3 The world's most populated country is China, while the United States is the third most populated one. India struggles to reach its medium-term objective to bring down its fertility rate, so as to reach a stable population by 2045 (GOI, 2011a: 38).

${ }^{4}$ However, India, too, has felt the impact of the global economic crisis. In 2011 India's annual growth dropped to below 7\% (WB, 2012), which is a steep decline compared to a growth rate of around 9\% in 2009 (WB, 2011).
} 
having the largest share of installed generation capacity $(52.8 \%) .^{5}$ Nuclear power has a share of $2.9 \%$, while large hydro power has a share of $23.1 \%$. The installed generation capacity of renewable energy amounted to $15 \mathrm{GW}$, or $9.7 \%$ (ibid.).

The Indian electricity sector, however, is facing enormous challenges, including low efficiency rates of the utilities and inadequate transmission and distribution networks resulting in major electricity supply shortages. ${ }^{6}$ In view of these challenging performance deficits, renewable energy technologies have become an integral part of India's growth strategy. Currently, wind power is the largest renewable energy sector in India, followed by small hydropower. The potential of solar and biomass is still seen to be largely untapped (WB, 2010). ${ }^{7}$ Since some evaluate India's wind resource conditions as comparatively unfavorable, the trend to further develop the estimated 16 GW of hydropower potential is likely to continue (Prayas, 2009).

India's policy objective to have "sufficient power to achieve a GDP growth rate of $8 \%$ " is part of India's “Mission 2012 - Power for all” (GOI, n.d.). This title indicates another issue India is facing with regard to electricity: Not only is the availability of electricity regarded as insufficient, but over $40 \%$ of India's population, especially in rural areas, does not even have access to electricity at all (Prayas, 2009). It is generally accepted that socio-economic growth and development are linked to the availability of electricity. Hence, providing "power for all" is a key policy aim of Government of India. As a promising technology among India's renewable energy options, small-scale hydroelectric plants play a key part in Indian debates and policy initiatives, which aim to foster additional electricity generation for the grid and to contribute to rural electrification efforts.

The second debate relates to India's large-scale hydroelectric dam projects. ${ }^{8}$ Although major hydraulic interventions in rivers already played a role in India's colonial past (D'Souza, 2006), especially during the two first decades after Independence in 1947 India experienced a full-scale introduction of large dam projects. Since then, hydropower development through large-scale dam projects continues to be an integral part of India's growth and development strategy. ${ }^{9}$ The

\footnotetext{
5 Other fossil fuels are natural gas and diesel with a share of $10.7 \%$ and $0.8 \%$, respectively.

${ }^{6}$ In 2011 the grid power deficit during peak hours amounted to 10.6\% (GOI, 2011b).

7 Tax preferences, preferential tariffs, and special directives, as well as investments in research and development, have contributed to the growth of the wind sector (WB, 2010). Meanwhile the hydropower sector is witnessing similar trends.

8 According to the World Commission of Dams, which proposed guidelines for the construction of dams, a large dam has a wall height of 15 or more meters from the foundation. "If dams are between $5-15 \mathrm{~m}$ high and have a reservoir volume of more than 3 million cubic meters, they are also classified as large dams. Using this definition, there are over 45000 large dams around the world" (WCD, 2000:11).

9 The ongoing discussions about the interlinking of India's rivers is an example of the continued interest of India's government in large-scale hydropower development (TOI, 2012). The linking of 37 rivers, the construction of 3000 reservoirs, the installation of $34 \mathrm{GW}$ of hydropower capacity, the irrigation of 35 million ha, and the projected costs of 120 billion USD give an idea of the magnitude of the project (J. Gupta \& Zaag, 2008). The project is heavily criticized by civil society (e.g. Patkar, 2004; Thakkar, 2012).
} 
implementation of the dam projects did not, however, go uncontested, with displacement emerging as a central issue. ${ }^{10}$ Together with their devastating societal impacts the severe environmental effects of large multipurpose ${ }^{11}$ dams emerged as another prime ground for opposition (McCully, 1996; S. Singh, 1997), yet also their technical and economic performances have been questioned (Dharmadhikary, Sheshadri, \& Rehmat, 2005; Thakkar, 2007). Large dam critique has provided grounds for questioning definitions of development and raised questions about the role of people in this process (Khagram, 2004; Roy, 1999). Implicit in the critique against large dams is the general expectation that reducing their size goes along with downsizing their harmful impacts (IRN, 2003). Following this line of thought small-scale hydroelectric plants have emerged as an answer to the critiques against large dam projects (e.g. Singh, 1990; UNESCO, 2006: 28).

The third debate in which small hydroelectric plants figure is related to discussions on renewable energy and its economic potentialities. These discussions are paralleled by policy concerns about environmental and security aspects. India's $11^{\text {th }}$ five-year plan stresses that against the backdrop of "the growing concerns for climate change and energy security it is imperative that this energy [form] in the longer term will substantially increase its share in the fuel-mix" (GOI, 2008: 344). A recent strategy published by India's Ministry of New and Renewable Energy, highlights the important role renewable energy sources play in contributing to India's energy security, which requires "upscaling and mainstreaming their use" (MNRE, n.d.-b: 16).

The private sector is ascribed a crucial role in realizing this. As a result, environmental and security considerations provide the basis for recasting renewable energy as providing economic opportunities with promising emerging business prospects. A World Bank report on Renewable Energy in India finds that "renewable energy is seen as the next big technology industry" (WB, 2010: 7). Aspiring a high private sector participation in the development of renewable energy entailed that discussions have moved to creating an enabling financial, regulatory, and infrastructure environment. ${ }^{12}$ It is in this vein that in a time of climate change and energy insecurities, small hydroelectric plants, which are part of India's renewable energy mix, are above

\footnotetext{
${ }^{10}$ With her engagement in the Narmada Dam conflict, the Indian social worker Medha Patkar played a crucial role in drawing attention to the plight of displaced people, who lost their habitat due to the submergence caused by large dams (Sims, 2001).

${ }^{11}$ Besides electricity generation, dams are also used for flood and irrigation control, navigation and fishery.

${ }^{12}$ For example, the setting up of Renewable Energy Development Agencies in the various states, which promote private sector participation in renewable energy projects, is aimed to contribute to this.
} 
all promoted as business opportunities for entrepreneurs who are willing to invest in an emerging green market. ${ }^{13}$

The role played by small hydroelectric plants in these three debates is encouraging: smallscale hydel plants provide electricity on a small-scale, and they are green and profitable. They help to feed a power-starved country, and their small size is seen to circumnavigate contestations associated with large hydroelectric dam projects, especially since they do not entail the displacement of people. By offering an alternative to fossil fuel-based electricity generation, small hydel plants have not only come to represent a "green" way out of the "brown" electricity era, but have also become a promising green business opportunity. With the number of small-scale hydroelectric projects rising, their role in India's renewable energy future is further underlined.

The three debates outlined above sketch the role small-scale hydroelectric plants play in India. However, I will not take up these debates by directly engaging in adding, refining, or refuting their specific arguments. Rather, these debates provide the context that informed my research and analysis on forms, contents, and consequences of civic engagement with these plants. Consequently, my contribution to these debates will take place indirectly through my empirical findings on civic engagement.

\section{Civic Engagement in Science, Technology and Society Studies and in Political Science Studies}

In this section I will locate my research within different bodies of literature from the fields of Science, Technology, and Society (STS) studies and political sciences. Research in STS has stressed that technologies need to be embedded in society if they are to be effective (Bijker, 2007). Civic engagement plays a key role in this process: it is seen to correspond to the democratic claim that people should have a say in the development of science and technology in society. Although the emergence of the participatory question has a longer history (Lengwiler, 2008), Bucchi and Neriseni have characterized the issue of participation in its present form as "an emergent phenomenon with uncertain boundaries ..., [which] has simultaneously become a key focus of social mobilization, policy initiatives, and scholarly analysis" (Bucchi \& Neresini, 2008: 449). Distinguishing three broad strands of research complexes helps to navigate through the vast

\footnotetext{
13 Small hydroelectric projects in the rural electrification context, which generally are not grid-connected, lack this explicit entrepreneurial dimension. At the same time, however, entrepreneurial arguments enter the discussion here as well, as the first chapter will show.
} 
and varied body of literature within STS on the issue of civic engagement with science and technology. ${ }^{14}$

A major focal point in STS work, whereby the issue of civic engagement plays a role, is related to the notion of expertise. By showing that the boundary between scientific expertise and lay knowledge is often blurry, STS work has challenged narrowly defined notions of expertise (Bijker, 1995; Wynne, 1996). Along with broadening the notion of expertise, questions about the involvement of the public in the governance of science and technology come into focus. Just how far the extension of civic participation in scientific and technological decision-making should go is subject to a debate, which was set off by Collins' and Evans' contribution about 'The Third Wave of Science Studies" (Collins \& Evans, 2002; Jasanoff, 2003a; Rip, 2003; Wynne, 2003).

Another important line of research has concentrated on processes of knowledge production and their impact on the boundary between expertise and lay knowledge. Within this growing body of literature, Bucchi and Neresini distinguish different areas of expert and non-expert interaction, with the medical sector serving as a prominent research site (Callon \& Rabeharisoa, 2008; Epstein, 1996), even though there are many others (Bucchi \& Neresini, 2008). For example, recent work in STS about the global South has described participatory forms of knowledge production in agriculture (Quartz, 2011) and in anti-dam contestations (McCormick, 2006; Phadke, 2005).

In the first strand of STS research, the issue of civic engagement is dealt with in terms of access questions: who can play a role in the development of and decision-making on science and technology? The second main orientation of work related to civic engagement with science and technology takes up procedural questions, and resonates in a statement by Jasanoff: "The issue ... is not whether the public should have a say in technical decisions, but how to promote more meaningful interaction among policy-makers, scientific experts, corporate producers and the public" (Jasanoff, 2003b: 238, emphasis in original).

Through work suggesting the emergence of "post-normal science" (Funtowicz \& Ravetz, 1992) or identifying new modes of knowledge production (Gibbons et al., 1994), civic engagement was contextualized with reference to a changing environment, which impacts on traditionally used ways of scientific and technological problem-solving and policy-making. To facilitate civic engagement, the importance of techniques has become a focus of attention, with

\footnotetext{
14 This distinction is blurry, not only with regard to the distinction between the strands, but also with regard to the demarcation of their scope. The issue of civic engagement, for instance, is related to elemental questions about the role of science and technology in Western democracies (Ezrahi, 1990; Feenberg, 1995) and in the global South (Visvanathan, 1997a). Also, calls for civic engagement relate to specific conceptions of democracy and political theory, which caused some authors to point out the need for more reflection in this regard (Durant, 2011; Hamlett, 2003; Turner, 2001). Here, however, for the sake of conciseness and focus, I will only indicate some of the research strands with a more immediate relation to the issue of civic engagement with science and technology.
} 
the consensus conference as an especially well researched example (Joss \& Durant, 1995; Kim, 2002; Kleinman, Powell, Grice, \& Adrian, 2007; Nishizawa, 2005; Rowe, Marsh, \& Frewer, 2004), even though there are many other examples (Rowe \& Frewer, 2005).

Another research focus highlights the importance to question practices and forms as well as the framings of the issues and audiences in the process of civic engagement (Chilvers, 2008; Irwin, 2001; Wynne, 2005), leading Jasanoff to point out that we do not simply need more participation but "richer deliberation on the substance of decision-making" Jasanoff, 2003b: 240).

This relates to the third strand of research, which comprises calls to look beyond procedural approaches to issues of civic engagement with science and technology. Thorpe has noted that the assumption seems to predominate that "democratizing expertise simply involves tackling new institutional devices (such as citizen juries) onto existing political institutional structures" (Thorpe, 2008: 77). Gomart and Hajer have pointed out that civic engagement may be of relevance in settings that are "often not recognized as political but do lead to collective deliberation on public problems and, as such, seem politically important" (Gomart \& Hajer, 2003: 43). Likewise, Marres has argued, in the "The Issues Deserve More Credit," that public involvement is occasioned by issues that fall outside the existing institutional arrangements. As a consequence, "a preoccupation with procedural events of public participation may leave important aspects of public involvement practices out of the picture" (Marres, 2007: 775).

Critiques of proceduralist approaches can also be found in accounts about civic engagement outside the STS context. Looking at participation in the development discourse Cleaver criticizes that "participation has ... become an act of faith in development; something we believe in and rarely question" (Cleaver 1999: 597). In particular Cleaver disapproves of the "techniques-based participatory orthodoxy," translating "participation" into "a managerial exercise based on 'toolboxes' of procedures and techniques" (ibid: 600, 608). Discussions in development studies even went so far that authors asked about the tyranny of participation. In their book Participation: The New Tyranny?, Cooke and Kothari (2001) argue that tyranny, in the sense of an unjust exercise of power, may be "both a real and a potential consequence of participatory development, counter-intuitive and contrary to its rhetoric of empowerment though this may be" (Cooke \& Kothari, 2001: 3). It is thus not surprising that authors within STS and development studies have argued to approach civic engagement not as a static, off-the-shelf conception.

Within the field of STS, this effort to look beyond proceduralist approaches has led authors to question the notion of politics. Politics, they stress, is contingent and of dynamic nature, established in practices (Vries, 2007), so that issue formation (Marres, 2005), the object of politics 
(Vries, 2007), or matters of concern (Latour, 2004), rather than institutional foci and fixes, should be foregrounded. According to Latour, "whatever the term one whishes to use ... the key move is to make all definitions of politics turn around the issues instead of having the issues enter into a ready made political sphere to be dealt with" (Latour, 2007: 815). In this line of research, scholars concentrate on the notion of politics by focusing on what issues emerge as political and become potential candidates of civic engagement.

In the three broad research strands described above, civic engagement has emerged as an implication of particular research attention, instead of being its prime or initial focus: all three lines of research imply civic engagement but do not focus on it. In the first strand, the properties of expertise and knowledge production are center-stage, while procedure-related questions come into focus within the second orientation of research. Finally, the third strand foregrounds issues (or matters of concern or objects) that become political.

STS work on civic engagement has produced profound and ample insights with regard to the three main questions indicated above. Yet, studies in this field have been less prolific with regard to questioning the empirical properties of forms of civic engagement with technology. This book aims to contribute to mapping this rather uncharted territory. So, instead of approaching civic engagement with expertise or procedural questions in mind, or by investigating "the political" of issues, I will study civic engagement as an empirical phenomenon. Hence, throughout this book I will ask about forms, contents, and consequences of civic engagement with technologies; and I will do so by focusing on the area of small-scale, renewable energy technologies in India. I use the term "forms" to describe the specific behaviors and strategies of actors, while I employ the term "contents" to describe what the forms of civic engagement are about. "Consequences" depict the results that occur due to certain engagement activities.

While scholars in the field of STS have been rather silent on the empirical phenomenon of civic engagement, this issue has received ample attention within political science. This is hardly surprising since political participation, which is the general term used, plays a crucial role in the functioning of democratic political systems. Drawing on insights from political science when researching forms, contents, and consequences of civic engagement has proven to be of great analytical value. Calls to draw on political science theory in STS research have been issued before (Delgado, Kjolberg, \& Wickson, 2011; Hamlett, 2003; Turner, 2001; Wynne, 2007). More generally, these calls may be interpreted as stray trends within the field of STS, aiming to enlarge 
its theoretical repertoire and acknowledge and interact with insights from other disciplines. ${ }^{15}$ With this book I aim to underline the fruitfulness of bringing together different bodies of research.

By now there is a voluminous body of political science literature that concentrates on political participation. Macro studies covering large population samples and comparing them between countries have contributed decisively to the development of a theoretical vocabulary for political participation research (especially Barnes \& Kaase, 1979; Parry, Moyser, \& Day, 1992; Verba \& Nie, 1972; Verba, Schlozman, \& Brady, 1995). One theme in the literature is the continuous extension of the meaning of participation, so that the notion is seen to comprise a whole bandwidth of actions, ranging from the act of voting to voluntary activities (Norris, 2001; Putnam, 2000) and individualized forms of participation (van Deth \& Maloney, 2012). This is not the place to review this literature, however, even though its insights have also enriched this study's analysis. In order to avoid theoretical abstractions without showing empirical reference and relevance, I shall introduce relevant theoretical views when presenting my empirical analyses, instead of elaborating them at this point.

Within the field of STS, "engagement" and "participation" are the two terms generally used to describe the involvement of citizens or the public with science and technology. Delgado et al. find that both notions have been used interchangeably, but they notice "an increasing tendency within STS to favor the term 'public engagement”' (Delgado et al., 2011: 827). They explain this with reference to the prominence of the concept of "upstream engagement," which Wilsdon (2005) applied in the field of nanotechnology, thereby making this field as "the paradigmatic test field of this concept" (Delgado et al., 2011: 827). The authors find that "the need to generate an early interest and a more inclusive form of participation" emerge as key features of the engagement notion (ibid: 827).

Rowe and Frewer (2005) suggest a three-part typology comprising the two terms participation and engagement. For them, "engagement" is the umbrella notion, which encompasses communicative, consultative, and participatory forms of action. Bucchi and Neresini criticize this typology because it only includes those forms of engagement, which are “deliberately elicited by a sponsor" (2008: 461), leaving unaccounted all those activities, which fall outside the institutionalized policy-setting frame, such as public mobilization and protests.

This critique can also be extended to the understanding of "engagement" by Delgado et al.: engagement, comprising the need to generate early interest and inclusive participation, is confined to a setting in which a sponsor promotes mechanisms, which more or less satisfy these demands. The thrust of the critique resonates with arguments, which we have already come

${ }^{15}$ By now, many consider STS as an emerging discipline that is mature and independent enough to reconnect with other disciplines, without thereby fearing to abdicate itself. 
across earlier: Confining engagement or participation to the procedural policy-setting realm shuts out other sites, where potentially politically relevant issues emerge.

In the political science literature, "political participation" is the established term used to describe the involvement of people with issues, even though studies have also employed the notion of "engagement" instead (Pattie, Seyd, \& Whiteley, 2003; Zukin, Keeter, Andolina, Jenkins, \& Delli Carpini, 2006). According to some, what seems to be the "potentially important fault line" between engagement/participation is the adjective preceding the notion of “engagement" or "participation" (Zukin et al., 2006: 5). Zukin et al. define civic engagement "in contrast to political engagement, ... as organized voluntary activity focused on problem solving and helping others" (2006: 7).

The list of definitions of political participation is enormous, which rather seems to indicate that a "fault line" is difficult to demarcate and keeps changing. ${ }^{16}$ According to van Deth, common to most conceptualizations is that political participation includes four features: people participate in their role as citizens; participation is an activity; the activities are carried out voluntarily; they are aimed at the political system (van Deth, 2003: 171). It becomes clear that civic engagement as defined above by Zukin et al. could be subsumed under these four general features of political participation as well.

Nevertheless, the long history of political participation research suggests that the term "political participation" has generally been closer to procedures within the political institutionalized system than civic engagement. Taking into account these underlying connotations of the terms, I chose to use the notion of "civic engagement" throughout my research. This choice also resonates with discussions within STS outlined above, which endorse the usefulness (if not need) of not restricting engagement activities to participatory policy-setting arenas only.

\section{Studying Civic Engagement with Small-scale Hydroelectric Plants in India}

My research on forms, contents, and consequences of civic engagement with small-scale hydroelectric plants in India is framed within a qualitative research design. As most qualitative research studies, I seek to provide a rich, contextualized understanding of lived social experience through the intensive study of particular cases. Based on purposeful sampling (Patton, 1990:

\footnotetext{
${ }^{16}$ An overview of the most common definitions is provided by van Deth (2003).
} 
169), I identified three empirical case studies in India to study the issue of civic engagement with technology. ${ }^{17}$

Asking about the way people engage with small-scale hydroelectric plants, what their engagement is about, and to what consequences this leads details the politics of these artifacts. With Winner's article “Do Artifacts have Politics?” (Winner, 1980), the argument of technologies exhibiting political properties was established in the broader academic debate. Bijker has made this argument in the context of water management technologies (Bijker, 2005), finding "Dikes and Dams, Thick with Politics" (Bijker, 2007).

Technologies in the water sector thus seem a particularly compelling research site because these technologies are likely to incorporate a broad scope of issues, ranging from scientific and technical questions to social, political, economic, and environmental concerns. In India this sector is characterized by a high level of civil society organization and mobilization, which is especially documented for large dams. In many of these studies, civic engagement takes place within a context of societal conflict and unrest about the technology. My work on small-scale renewable energy technologies shows that this site offers a broader spectrum of civic engagement with technologies, going beyond the conflict dimension of civic engagement.

As outlined above, small-scale hydroelectric plants in India play a role in two electricity scenarios: they add power capacity to the grid and form part of rural electrification efforts. Both scenarios informed the selection of my case studies. One of them is located in Orissa, a state in India's East. Despite general advances of village electrification in India, Orissa remains one of the states with the lowest electrification rate, ${ }^{18}$ with its southern tribal region lagging especially far behind (Kumar, 2001). It is here where I researched civic engagement with small-scale electricity projects facilitated by two Non-Governmental Organizations (NGOs) in the Kalahandi and Koraput district, respectively.

The second research site where electricity production for the grid is center-stage is located in Karnataka, a South-Indian state. Karnataka is one of the states with the largest amount of installed small hydro capacity, as well as with the highest number of plants being in progress (IRESR, 2010:25). The two projects where I researched forms, contents, and consequences of civic engagement are located along the Tungabhadra River, which flows through the state of Karnataka to Andhra Pradesh, where it joins the Krishna River as its main tributary. Conducting

\footnotetext{
17 "The logic and power of purposeful sampling lies in selecting information-rich cases for study in depth. Information-rich cases are those from which one can learn a great deal about issues of central importance to the purpose of the research, thus the term purposeful sampling" (Patton, 1990: 169, emphasis in original).

18 A recent report by the International Energy Agency finds that by the end of March 2010, 84\% of India's villages were electrified. Orissa with $63 \%$, Jharkand with $31 \%$, and Bihar with $61 \%$ rank among the states with the lowest electrification rate (IEA, 2011: 25).
} 
research within the two overall electricity scenarios set out a broad and varied arena to study the unfolding of different forms of civic engagement.

I followed an ethnographic approach toward studying civic engagement and a variety of qualitative research techniques, including site visits and observations, listening to what people say and conducting interviews (Walsh, 2004). My empirical research is based on material I gathered during three research visits to India, taking place in 2008/2009, 2009, and 2010. In total I spent around 8 months in India, divided over one longer period of five months and two shorter periods. My extended but phased research stays in India enabled an in-depth study over a longer stretch of time. Visiting India at different times also allowed me to observe the case sites under different climatic conditions, ${ }^{19}$ which, as we will see, played an especially important role for the unfolding activities in Karnataka.

In the research setting in Orissa, NGOs, by being willing and used to reflecting and answering questions about their work, played a crucial role in providing access to information. While my research interest was met with enthusiasm and readiness to share experiences and insights about the electricity projects in Orissa, access to information proved to be much more difficult in Karnataka. The Karnataka research cases were much less hierarchically structured, marked as they were by many divergent actors and groups. Repeated visits were especially crucial, then, for developing my case studies on Karnataka because these visits gradually created a feeling of familiarity and trust, and thereby the willingness of people to share information. ${ }^{20}$

During my research time in India I could gather a range of empirical materials, including documentation about or related to the cases under study, such as detailed project reports, brochures, minutes of meetings, letters, and newspaper clippings. The main empirical source of my analysis, however, consists of over 50 interviews, which I conducted using a semi-structured interview format. ${ }^{21}$ The identification of interview partners was mainly based on the snowball sampling method, by asking the interviewee for further references. This helped to build a network of informants and gave insights into the different actor constellations and their relations to and roles in the small hydel projects. I thus held in-depth interviews with a broad range of

\footnotetext{
${ }^{19}$ I refer here to the monsoon season versus the dry season.

${ }^{20} \mathrm{It}$ is not common for a white woman to conduct research in this area. Nor is it common, regarding the topic of small-scale hydroelectric plants, to use qualitative rather than quantitative research methods.

${ }^{21}$ Semi-structured interviews are loosely structured in-depth interviews, in which the interviewer aims to learn about the worldview of the interview subject, rather than aiming to elicit preconceived information or "facts." Generally, the data generated using semi-structured interviews is seen as representing one of many possible versions of how to see the world (Byrne, 2004: 181). For each interview I prepared a topic guide (ibid: 189). In the topic guide I listed specific topics, details, and aspects, which I aimed to cover during my interview. Different to a survey format, the order of topics discussed during a semi-structured interview is flexible, so that topics are raised according to the dynamics of the interview. In addition, the format of semi-structured interviews allows the interviewer to consider new topics of interest raised by the interviewee during the conversation.
} 
actors, including farmers, politicians, civil servants, hydel developers, business people, development practitioners, and academics. ${ }^{22}$

I took notes during the interviews, many of which were held in English. Wherever possible, I recorded the interviews electronically. I spent a lot of my research time in the rural countryside, where the hydel projects are located. For the interviews conducted during this "rural" fieldwork, I used the help of translators, who translated from English into Kannada or Oriya and back. ${ }^{23}$ The majority of my interviews were transcribed and analyzed by hand-coding, whereby I identified codes and categories through ongoing comparison and interpretation. ${ }^{24}$

Since the ethnographic research process is characterized by a constant interaction between problem formulation, data gathering, and data analysis, analysis of ethnographic data is not marked by separate stages and takes place throughout the research project. Likewise, the research process, which resulted in this book, was characterized by moving between empirical data gathering in India, data analysis, and more focused data gathering. My empirical fieldwork in India was finished after the third research visit, when narratives reemerged and no blatantly new accounts or actors entered or were implicated in the cases. A statement by Clarke captures this point of saturation (Glaser \& Strauss, 1967) vividly: Saturation is reached when "you think these are the most important elements. (Of course there are many others, but they don't seem to 'make a difference' in the stories you want to tell)" (Clarke, 2003: 571).

The most common approaches of analyzing qualitative ethnographic material have been grounded theory approaches (Clarke, 2008). Originally developed by Glaser and Strauss (Glaser \& Strauss, 1967), grounded theory has now become "an umbrella covering several different variants, emphases, and directions - and ways to think about data" (Charmaz, 2009: 128). One core result that grounded theory approaches seek to accomplish is to induce theory from empirical material through the ongoing interpretation of that data. Grounded theory informed the underlying principle of my analysis, especially its emphasis on an inductive approach of data gathering and analysis. ${ }^{25}$ Thus generated insights were complemented and combined with existing bodies of theoretical and conceptual work. These were carefully selected on the basis of their conduciveness to contribute to the understanding of the theorized empirical phenomenon. This not only led to a fruitful synergy between existing theory and empirically grounded insights, but

\footnotetext{
22 Appendix C provides a list of interviewees.

${ }^{23}$ In Karnataka I conducted a number of group interviews with members of the local village governments, which were held in Kannada. Since these were often vociferous and speedy conversations, I re-listened to the recordings together with the translator the same day in order to double-check both the translation and the different opinions raised. During this process, additional information was transcribed and added to the data.

${ }^{24}$ In the few cases where I did not transcribe the interviews, because I knew they were less information-rich, I created texts in a draft manner (Gibbs, 2007).

25 In stark contrast to inductive approaches, deductive approaches are based on a series of separate stages, comprising hypothesis generation, data collection, and hypothesis testing.
} 
at times also unearthed the limitations and shortcomings of existing theoretical conceptualizations.

In my analysis I made use of different interview accounts, data sources and research methods, in order to cross-check information, insights, and interpretations. Besides this strategy of source, data, and method triangulation, discussing my work and insights with peers and stakeholders in India, the United States, and Europe further helped to ensure the validity of my research.

My analysis is rendered in "thick description" (Geertz, 1973), especially by including verbatims of interview accounts and other rich descriptive information related to the case contexts. This not only allows insights into the empirical sources on which my analysis is based but also aims to enhance the understanding of the study's context and participants. The importance (or attainability) of the generalizability of research findings is contested. Still, it can be argued that thick descriptions form part of the anthropological strategies to enable the generalizability of the findings, since they "allow readers to make inferences about extrapolating the findings to other settings" (Polit \& Beck, 2010). My book is written in this light.

\section{Outline of the Book}

My empirical analysis of forms, contents, and consequences of civic engagement with small-scale hydroelectric plants in India begins in Chapter 2, which takes us to the tribal hills of Orissa. In this first empirical chapter I will introduce the notion of "invited engagement" by describing the work of two NGOs, Wida and Gram Vikas, aiming to empower poor rural communities. The implementation of the hydel projects within the rural development framework has consequences for the civic engagement activities taking place. Civic engagement with hydel plants is related to the institutionalization of certain, pre-defined implementation phases and governance structures through which the activities of the community are aligned with the requirements of a development project. I will show how forms, contents, and consequences of civic engagement are closely linked to the conception of empowerment, which the respective facilitating actors hold.

Chapters 3 and 4 take us to another research site, the State of Karnataka. Located along the Tungabhadra River, two small hydroelectric plants close to the village Sugur (Chapter 3) and the village Kenchanaguddam (Chapter 4) serve as starting point for investigating forms, contents, and consequences of civic engagement. The context to which the two small hydroelectric projects in Karnataka relate is quite different compared to the one in Orissa. The small 
hydroelectric projects in Karnataka are private enterprises, which produce electricity for the regional grid. ${ }^{26}$ India's reforms since the 1990s aimed to liberalize the electricity sector and enabled private entrepreneurs to enter the market. Small hydroelectric plants thus form part of efforts by the Government of India to stimulate economic growth and electricity generation by enabling private entrepreneurs to tap into the promising renewable energy market.

In Sugur (Chapter 3) I will describe the unfolding events after the establishment of a hydel plant and I will show how a local inhabitant played a crucial role in the organization of engagement activities with the plant, which unfolded over a period of more than five years. The distinction between "conventional" and "unconventional" forms of civic engagement, which I introduce in this chapter, typifies the activities.

Conventional and unconventional forms of engagement also play a role in Chapter 4 about the Kenchanaguddam hydel plant, if in a hybridized way. Civic engagement with the Kenchanaguddam plant involves divergent interests among different actors, many of whom resort to disengagement. Forms of civic engagement and disengagement taking place in and around Kenchanaguddam are characterized by how local power relations are used and accepted by the different actors.

Finally, in the concluding Chapter 5 I will weave together the findings of chapters 2, 3, and 4. By seeking to identify explanations for the identified forms, contents, and consequences of civic engagement, I will distinguish different variables. These help to explain the phenomenon of civic engagement with small-scale hydroelectric plants in India.

\footnotetext{
${ }^{26}$ India does not have one national grid, but five regional grids, covering India's North, South, West, East and North-East. Karnataka is fed through the Southern grid.
} 


\section{Chapter 2}

\section{Micro Hydroelectric Plants in Orissa}

\section{Introduction}

This chapter takes us to the South of Orissa, where I visited two Indian NGOs, Wida and Gram Vikas, ${ }^{27}$ which facilitate community-based micro hydel projects in poor, rural communities (see Figure 2.1). In a community-based project, the people at which this development intervention is targeted are actively engaged in the project's implementation. Focus of this chapter is the engagement that occurs in the micro hydel projects by Wida and Gram Vikas, which are community-based. I will show how these NGOs encourage certain forms of engagement with the project to ensure that engagement takes place within pre-defined implementation phases. Wida, which only in official documents is referred to as "IRDWSI,"28 supported the implementation of three micro hydel projects in the Koraput district. Gram Vikas currently has six micro hydel projects in the Kalahandi district. Together with Bolangir, Orissa's three southern districts Koraput, Bolangir, and Kalahandi - are often referred to as "KBK region" (Kujur, 2006). This region struggles with severe socio-economic challenges such as low literacy, high poverty, and high morbidity due to malnutrition and diseases like malaria. The developmental work of both NGOs is geared to addressing these challenges. The facilitation of micro hydel projects forms part of a broader range of activities toward socio-economic development of the region.

27 "Gram Vikas" is Hindi for "village development."

${ }^{28}$ IRDWSI is the abbreviation of Integrated Rural Development of the Weaker Sections in India. 


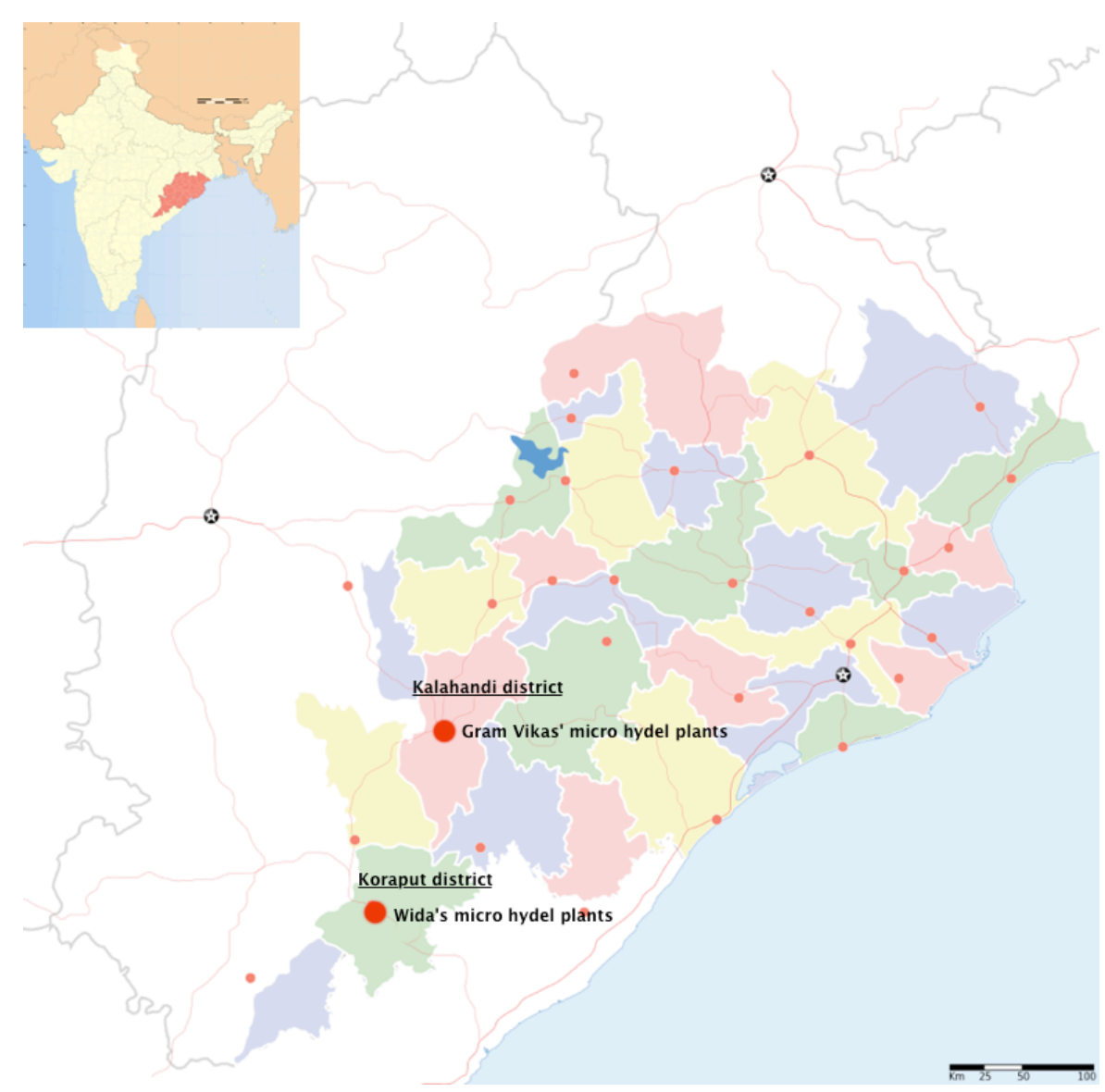

Figure 2.1: Map of India (upper left corner); the state of Orissa indicating Gram Vikas' and Wida's micro hydel plants in Kalahandi and Koraput district.

Wida's and Gram Vikas' micro hydel projects are decentralized projects, in which electricity is generated for local use and not fed into a large, centralized electricity grid. Decentralized electricity production frames the current policies relating to micro hydel projects. Yet, as we will see, there are discussions on the policy level that challenge this premise. Still, whether in a gridconnected or a decentralized scenario, the rationale for implementing micro hydel plants is their projected contribution to empower poor and marginalized communities. I will show how a specific conception of empowerment held by the NGOs is related to the forms, contents, and consequences of civic engagement enabled in micro hydel projects.

Micro hydel projects relate to discourses on "small is beautiful" and "appropriate technology." With his influential work Small is beautiful, the economist E.F. Schumacher set off a discourse emphasizing the need for small, local resource-based technologies that would be appropriate to match the needs of people (Schumacher, 1973). ${ }^{29}$ Accounts further pursuing this line of thinking stressed that appropriate technologies for rural development were to satisfy basic human needs by starting from the needs of the poorest; ensure social participation and control;

\footnotetext{
${ }^{29}$ Instead of "appropriate technology," Schumacher used the term "intermediate technology." 
and be environmentally sound (Reddy, 2006: 65). These discourses corresponded well with scholars committed to Gandhian ideas of self-rule and decentralization. According to Sharma, "Gandhi promoted a self-contained, self-sufficient village-based moral economy where people produced primarily for their own consumption and broke their dependence on the market" (A. Sharma, 2008: 13).

In the West these approaches resonated with arguments promoted by the alternative energy movement, which was rooted in the counterculture of the 1960s and 1970s. According to Glover, the movement established "the idea that social change in the developed world could be brought about by a shift to alternative energy" (2006: 250). The conventional energy system was rejected due to its centralized, large-scale, elitist, profit-oriented, militaristic, environment polluting, and antisocial characteristics. Renewable energy technologies were charged with different attributes with the promise of enabling a small-scale, locally managed, decentralized, pollution-free, and democratic alternative (ibid.).

Many of India's NGO-facilitated micro hydel projects are located in India's mountainous North. The Himalaya Mountains with their snow-fed streams offer excellent geographical conditions for the generation of hydropower. ${ }^{30}$ Nevertheless, micro hydel plants can be found all over India: for example in the Eastern Ghats range of Orissa's South, where many small streams wind through the hilly landscape. The Eastern Ghats range is part of the so-called "tribal belt" of central India. ${ }^{31}$ The central tribal belt stretches from West Bengal and Orissa in the East, through Chhattisgarh and Jharkhand up to Madhya Pradesh and Maharashtra. Most of the people living in the central tribal belt belong to a group designated by the Indian constitution as "scheduled castes and scheduled tribes." People administered within the "scheduled castes" category are usually "dalits," a group of people with a low social status, since their caste is considered to fall outside the Indian caste system. The Sanskrit term "dalit," which is not used as an official term in the Indian administration, is generally translated with "untouchable" (person) and comprises many different castes. ${ }^{32}$ Poverty and ongoing discrimination are huge challenges for scheduled castes people as well as for India's adivasi population, which fall under the "scheduled tribe" categorization. Adivasis literally means "indigenous people" or "original inhabitants" (Bijoy, 2003) and is an umbrella term comprising heterogeneous groups of ethnic and tribal people. Adivasis have developed an intricate relationship with their territories in form of a "convivial-

\footnotetext{
30 This is true for large-scale hydel projects as well as on a micro scale. In the latter case, the NGO LEDeg (ledeg.org) has much experience with the micro hydel technology implemented in the Ladakh region of Jammu and Kashmir.

31 Another tribal belt area stretches through India's Northern and Western states (Rajasthan, Gujarat, Maharashtra, Karnataka).

${ }^{32}$ Gandhi coined the term Harijan, or "child of God," to counter its discriminatory connotations.
} 
custodial mode of living" (Bijoy, 2003: 1). Yet, this way of life is seriously challenged by the advent of high modernist projects (Scott, 1998) in the tribal areas. With large dam projects and more recently the arrival of mining corporations, the tribal areas are re-conceptualized as resource-rich territories to be unlocked and tapped. ${ }^{33}$ Today, adivasi populations face huge challenges to continue their way of living and constitute, together with people from the scheduled castes, the most impoverished communities in India. The developmental work carried out by Wida and Gram Vikas in the tribal area of the Eastern Ghats aims to empower poor people from the scheduled castes and tribes.

With their emphasis on participation, community-based development projects are positioned within the broader discourse on participatory approaches to development. Participatory approaches, it is assumed, respond to the people's right to participate in development decisions and interventions that shape their lives. Furthermore, they are seen to raise the effectiveness and efficiency of development efforts by rendering people a voice and active role in the processes. Supported by these normative and instrumental arguments participatory approaches have "gained the status of development orthodoxy" (Cornwall, 2006: 62).

Although participation in development discourse became popularized in the 1990s, Cornwall (ibid.) shows that arguments supporting the merit of participation were motivated over the course of nearly all of the last century, starting in the colonial past. The meaning of participation was nuanced depending on the present development discourse of each period. In the 1990s participation came to be promoted as "people's participation" (UNDP, 1993). By then a discourse around participatory techniques had managed to enter development theory and practice. Concerned with "putting the last first," Chambers contributed to the development of participatory techniques, ${ }^{34}$ which are bottom-up methods aiming to put poor people central by including them in the knowledge production, design, and implementation of development interventions (Chambers, 1981, 1983, 1997).

People's participation was to be operationalized mainly by actors from the non-governmental sector. The 1980s and 1990s had seen an exponential growth of NGOs, fuelled by a donor funding orientation aiming to bolster NGO capacity in service delivery. With state agencies often being inefficient and corrupt, NGOs emerged as an alternative, despite accounts questioning whether this trend would impair the NGOs' performance, accountability, and legitimacy (Edwards \& Hulme, 1996). Nevertheless, in comparison to state agencies, NGOs were generally perceived to be "more participatory, less bureaucratic, more flexible, more cost-effective, with an

\footnotetext{
${ }^{33}$ In reaction to these developments adivasis have turned to (violent) organized resistance, of which the Naxalite movement is a well-known example.

${ }^{34}$ Such as rapid rural appraisal (RRA) and especially participatory rural appraisal (PRA). 
ability to reach poor and disadvantaged people" (Robinson \& White, 1997: 4, cited in Cornwall, 2006). Since the 1980s, neo-liberal ideas entered the development discourse as well, and with them the framing of participation within market mechanisms for development. In a context of "marketization of public services," people were to be enabled to own, manage, and provide their own services with the support of NGOs (Cornwall, 2006:75).

As development organizations, Wida's and Gram Vikas' activities in the South of Orissa are informed by these discourses. This brief sketch can represent the development discourses within the vast body of literature on participatory development only in a general way. It nevertheless provides some backdrop for the chapter's empirical focus on community-based engagement activities taking place in Wida's and Gram Vikas' energy projects in the South of Orissa.

\section{Functioning and Policy Context of Micro Hydel Plants}

In essence, a micro hydel plant is a scaled-down version of a small hydel plant, which will be the focus of attention in the two following chapters of this book. Although small and micro hydel plants both use the flow of water to convert it into electricity, the capacity of the two differs drastically: whereas small hydel plants generate megawatts (MW), micro plants are designed to generate only up to 100 kilowatts $(\mathrm{kW})$ of energy. ${ }^{35}$ Micro hydel plants are usually designed as a "run-of-the-river" set-up. "Run-of-the-river" or "river-off" projects do not dam the water behind a weir, but divert parts of the water flow into a channel leading into a so-called forebay tank. From here a pipe, called penstock, leads the water toward the powerhouse with its turbine and generator. The difference in height between the top of the penstock and the lower located powerhouse with its turbine is used to generate energy (see Figure 2.2).

\footnotetext{
35 A rural household with a couple of lights, a fan, and a television set would need about $250 \mathrm{~kW}$. A richer household with a refrigerator would need about $1500 \mathrm{~kW}$. The households described in this chapter have generally no technical equipment. Televisions and radio sets are rare.
} 


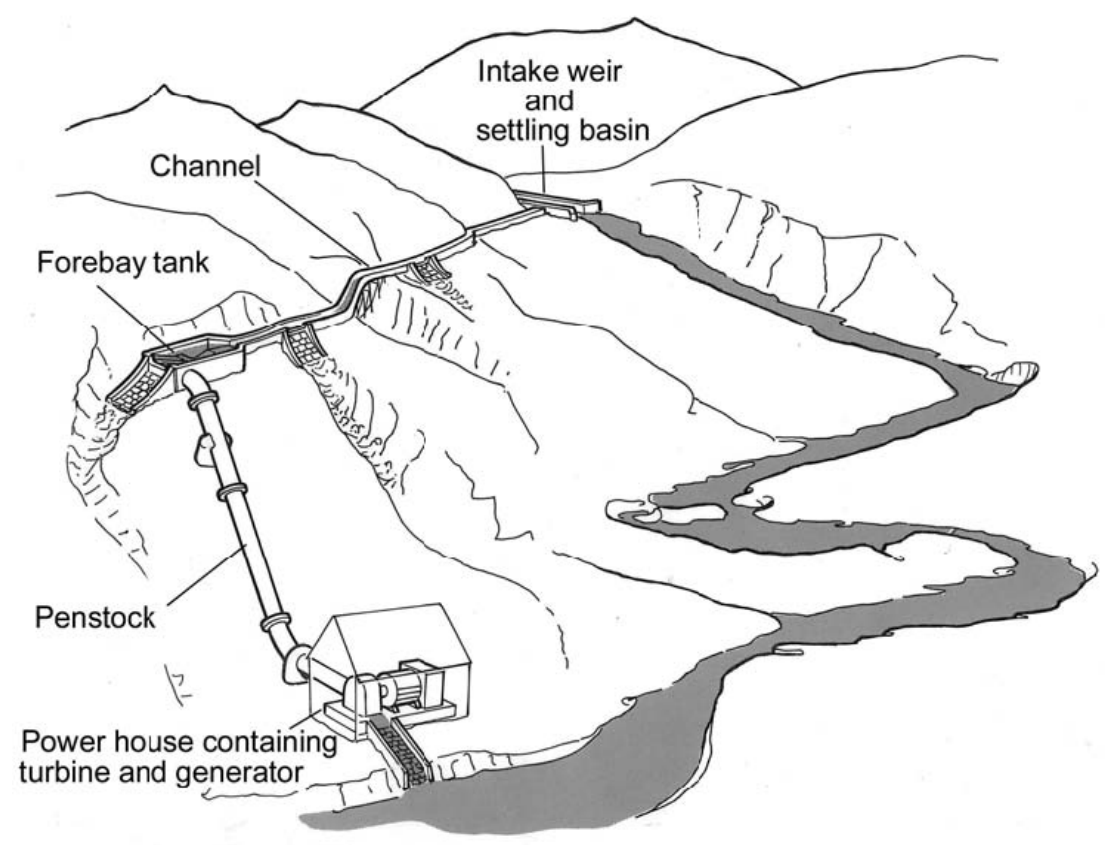

Figure 2.2: A layout with typical components of a micro hydro scheme. ${ }^{36}$

Scale and scope of the energy produced is very local. Wida's and Gram Vikas' projects generate around 10-30 kilowatts and serve only about one to three adjacent villages or hamlets. ${ }^{37}$ The energy generated can either be converted into mechanical or electrical power. ${ }^{38}$ Most of the micro hydel plants in India, including the plants analyzed here, are set up for the latter, given their role in contributing to rural electrification and enabling a versatile scope of application. Generally, the generated electricity is related to two user scenarios. The consumptive use scenario is geared to the domestic power use, such as for lighting, cooking, or radio sets. In the productive use scenario, the power generated is used in addition for income generating activities, such as charging batteries of lights intended for renting out, or driving a grinding mill. The micro hydel plants described in this study facilitate both consumptive and productive use.

Micro hydel plants play a role in India's rural electrification efforts as a means to provide decentralized power generation in remote areas, where the electricity grid has not yet reached or where grid supply is considered infeasible or not cost-effective. Government of India's Ministry of New and Renewable Energy is the main responsible government institution on the national

36 Picture found at http://practicalaction.org/practicalanswers/product_info.php?products_id=41 (retrieved 29.8.2011).

37 “Bigger" schemes such as Gram Vikas' Karlapat project provide energy to about 120 families, while in smaller settings micro hydels are used for villages with only 15 families, such as in Gram Vikas' Karnivel project.

${ }^{38}$ Mechanical energy may be used to drive grinding mills, for example. 
level relating to micro hydro. ${ }^{39}$ India's Ministry of Power is involved via its policies on rural electrification. If some of the micro plants are built for individual and private use, many of them are facilitated by NGOs and contribute to decentralized rural electrification efforts. For the implementation of micro hydel projects, NGOs try to tap international funding sources such as country or non-governmental donors, or they approach national institutions. The two main national funding schemes, the Decentralized Distributed Generation (DDG) scheme and the Watermill and Micro Hydro scheme, are issued by the Ministry of Power and the Ministry of New and Renewable Energy, respectively. ${ }^{40}$ Both schemes aim to contribute to electrification in a decentralized manner, implying that connectivity to the regional grid is generally not considered. The installment capacities of the hydro projects are restricted to $100 \mathrm{~kW}$ in the case of the Watermill and Micro Hydro Scheme, and $2 \mathrm{MW}$ in case of the DDG. ${ }^{41}$ While nationally the emphasis lies on the provision of electricity in remote rural areas, internationally, micro hydel projects have increasingly come to be funded under the climate change rationale, because of their potential for reducing emissions of greenhouse gases. ${ }^{42}$

Two main approaches can be distinguished in the implementation of a micro hydel project: the "service-" or "client-oriented" approach on the one hand, and the "community-based" approach on the other. They relate to the "tension between imperatives of delivery and community participation (process)" emerging in development projects (Botes \& van Rensburg, 2000: 50). In the "service-" or "client-oriented" approach, the provision of the service, i.e. electricity, to the clients constitutes the central aim. "Basically, the objective is to provide electricity to a set of people," as Sampath, the managing director of the small consulting company TIDE based in Bangalore, explains. He specializes on micro hydro technology and views himself as a service-provider implementing a project for interested "clients" rather than "beneficiaries as NGOs call them" (interview Sampath, 2009). In the "community-based" approach, on the other hand, not only the availability of electricity itself is seen as a means to development, but also the very process of generating and managing the electricity production is regarded as contributing to

\footnotetext{
${ }^{39}$ On the state level, different policy actors are responsible; one chief actor among them is the Rural Electrification Corporation.

40 DDG falls under the "Rajiv Gandhi Grameen Vidyutikaran Yojana" (RGGVY), or "Scheme for Rural Electrification Infrastructure and Household Electrification." It is an umbrella scheme launched in April 2005, by the Ministry of Power merging all ongoing schemes. The main funding scheme issued by the Ministry of New and Renewable Energy is the "Scheme for Development/Up-gradation of Watermills and setting up Micro Hydro Projects (up to $100 \mathrm{~kW}$ capacity)," launched in 2009.

${ }^{41}$ Most of Government of India's efforts of decentralized electrification are operationalized under the DDG policy. Some criticize the DDG for its minimalist framework, since it restricts the projects to be designed only up to certain energy levels instead of promoting to tap the full potential. Critics suggest a broader framework for rural electrification with an overall orientation away from minimal energy generation toward grid-connectivity (interview Joshi (SDC), 2010; interview Pittet, 2010).

42 In comparison, large hydroelectric projects are typically not supported under climate change related funds, since the decay of vegetation inundated by the project produces methane, a potent greenhouse gas.
} 
the overall socio-economic progress of a community. Although in both cases the engagement of the people served by the plant is required, it plays a much more explicit and refined role in the community-based approach. Here, the creation of responsible project ownership through community engagement is emphasized as the way to ensure empowerment, which goes along with the availability of electricity. Questions relate to the process of engagement in electricity generation. In the service-oriented approach, emphasis is put on the electricity output. Both approaches thus bestow different importance on the role process and output play in electricity generation.

Botes and van Rensburg describe projects with an emphasis on output as developercentered, relying on formal expertise to resolve development problems in the shortest possible time (2000). Projects with a process-focus, in contrast, are people-centered, emphasizing the importance of the problem-solving process rather than the immediate resolution of a development problem (ibid.). Both approaches, however, have their drawbacks: process without product may leave people frustrated, absorbing social energy, time, and money without any concrete results. Product without process may leave people with project outputs they do not want or cannot sustain (ibid.: 51). The empirical focus of this chapter will be on Wida's and Gram Vikas' micro hydel projects, which follow a community-based approach.

There is only a small circle of actors involved in micro hydel projects in India. Technology providers and NGOs play a leading role on the implementation level. According to a report issued by the consultant company TIDE, entitled Community Microhydro Systems in selected states, there are around 15 technology providers in India (TIDE, 2009). "One common feature in the micro-hydro space is the integrated nature of services provided by the suppliers. The services provided include project development and overall design support, civil designs and execution advise, electromechanical equipment supply ... and installation and commissioning of the system" (TIDE, 2009: 34). Most of the time, these technology providers are contracted by the project facilitating parties, which are primarily NGOs working in remote rural areas, such as Wida and Gram Vikas in the Southern part of Orissa.

\section{Wida's and Gram Vika's Micro Hydel Projects}

As NGOs, Wida and Gram Vikas originated in the Indian voluntary movements of the 1960s and the 1970s. At that time many university graduates volunteered to carry out development work in the rural countryside. Voluntary relief work after a devastating cyclone brought the founders of Gram Vikas and Wida to Orissa. Their decision to stay on and continue the 
development work went along with the official registration of their NGO, in 1979 and 1981, respectively. Different contextual factors led both NGOs to include micro hydro in their portfolio.

For Wida, the involvement with micro hydro projects was spurred by the destructive consequences brought about by the establishment of mega hydro projects in the Koraput district. In one of Wida's brochures about their micro hydro involvement the NGO explains: "[In] Koraput District of Orissa ... there are about 18 mega projects which displaced more than 250 000 people. This includes four major projects, which produce about 1000 megawatt of electricity. In contrast, this district has only about $38 \%$ of villages electrified ... The Adivasis who in general constitute about 40 per cent of the displaced persons in India and who lost their resources and livelihood because of the mega projects are the least benefited from such developments" (Wida, 2004: 6). This provided the background for Wida to look for "sustainable, community managed alternatives" to facilitate decentralized energy generation (Wida, 2007: 9). After site investigations of selected areas in the Eastern Ghats, Wida, supported by a number of Indian and international experts, "further narrowed their focus on developing community managed micro hydros" (Wida, 2004: 7). Wida's first plant in Putsil has been running since August 1999, the Bodomanjari plant was commissioned in October 2006, and the plant in Gangamaguda has been running since 2004.

For Gram Vikas, energy projects for socio-economic development have been part of their work since the very beginning. Their projects have been manifold, involving different technology options. Looking back, Gram Vikas' energy involvement can be described as one of experimentation and learning, of trial and error. Joe Madiath, Gram Vikas' director, remembers: "From the 1980s onwards we were involved with renewable energy ... [In the beginning] we were only going for biogas. If anyone wanted biogas, we were there ... It was sort of a biogas missionary" (interview Madiath, 2010). After about ten years of extensive involvement and the installation of around 54000 biogas plants, Gram Vikas moved on to install smokeless woodstoves. "But," as Gram Vikas Director remembers critically, "it was almost a total failure, not because of design or anything. It was a failure because we had no mechanism within Gram Vikas to follow up, because we were depending entirely on government funding for this" (ibid.). For Gram Vikas the importance of accompanying mechanisms were a crucial insight they drew from the woodstove projects: "Any technology meant for rural people is surely bound to fail, if there is no accompanying hand-holding, till people internalize [its working]" (ibid.). Further involvement with renewable energy technologies included photovoltaic lighting of schools. "We were quite successful, because we had the systems to troubleshoot any of those problems" (ibid.). As of 2005, Gram Vikas has added micro hydel projects to its renewable energy portfolio. The 
availability of "many streams, which have almost perennial water" spurred Gram Vikas' interest in micro hydel (ibid.). Comparable with the biogas projects, Joe Madiath describes the micro hydel work following "a learning curve, as we did not know anything about it" (ibid.). By 2010 Gram Vikas had completed four micro hydel projects in the Kalahandi district. Two more projects are currently being implemented. The commissioning of Gram Vikas' first scheme, Amtaguda, dates back to January 2006. Karlapat was commissioned in October 2006, Purnaguma started working in November 2008, and Karnivel in April 2010.

While Wida coordinates the micro hydel projects at its field office in Semiliguda, Gram Vikas maintains a program office in Bhawanipatnam. The two offices are quite different in terms of their portfolio and scale: Wida's field office in Semiliguda, in Koraput district, functions as the main executive headquarter and has two staff residential campuses and one guest house. Wida's staff, which is mostly based at the field office, comprises about 40 persons. Wida's office in Semiliguda is its central operation hub from where all the different programs and projects are coordinated. ${ }^{43}$ Wida's micro hydel projects are among several development initiatives by Wida in the villages.

Gram Vikas' office in Bhawanipatnam in Kalahandi district is one of 24 outposts Gram Vikas maintains all over Orissa. Although Gram Vikas is a large NGO with diverse programs ${ }^{44}$ and about 360 staff appointed all over Orissa, its office in Bhawanipatnam is rather small and unimposing. It merely has 4 employees, of which only one program related field staff. Gram Vikas' work in Kalahandi focuses almost exclusively on the facilitation of the micro hydel projects. ${ }^{45}$ This specific project focus is also reflected in the activity portfolio of the staff: Gram Vikas' office in Bhawanipatnam is staffed with one Energy Program Coordinator responsible for the different micro hydel projects. In contrast, Wida organizes the activities of its staff per region rather than by topic, with officers supervising different projects on different issues.

Wida's and Gram Vikas' micro hydel plants are well known development projects in India. Both NGOs enable field visits by facilitating guides, translators, and suitable vehicles to reach the remote sites. Another way to distribute information about these projects is through written communication. Apart from on its website, Wida provides information about its projects in several brochures and hand-outs. Wida's documentation zooms in on the Putsil plant. Putsil was its first project and is the oldest functioning micro hydel project implemented in Orissa's Koraput District. Successful community engagement during the plant's implementation and

\footnotetext{
43 For example, Wida is involved in activities relating to health, education, women's education, sanitation, and agriculture. Wida also maintains a solar powered village.

${ }_{44}$ Besides renewable energy and livelihood enabling infrastructure, the main programs include health, education, livelihood, and water and sanitation.

${ }^{45}$ Exceptions to this are the efforts in the field of sanitation in Karnivel village.
} 
operation as well as livelihood improvements, are the key aspects featured in Wida's communication. Putsil has attracted many people, as described in one of Wida's brochures: "Since the inception of the project, Putsil has been receiving hundreds of visitors, including people from neighboring villages, members of the community organisations, civil society institutions, government officials - from the State and even from abroad" (Wida, 2007: 10). This contributed to the public awareness about the project and its two successors, especially the Bodomanjari plant. As a result they have advanced as examples of "good practices." A study in the broad field of water management and livelihoods, commissioned by two development organizations, proposes Putsil and Bodomanjari as "an alternative development model ... based on renewable energy, resource conservation, low costs and local control” (Hoerig, 2008: 82).

Gram Vikas' Energy Coordinator responsible for micro hydel projects carries out her work in the dual role of NGO practitioner and academic scholar. She disseminates her insights within and outside the academic field. Central in her argument is the "transformative participation" of the community, especially young people, in implementing micro hydel. Learning and localization of processes play a key role in this approach. "The organisation has seen first-hand how decentralised technology cannot be sustained in poor communities, unless the hardware and technical expertise is localised and community members are involved in all phases of implementation" (Vaghela, 2010: 3).

The micro hydel projects of both NGOs have been subject to research and promoted as good practices. NGO staffs talk professionally and with ease when asked about them. Even villagers, as remote as they may live, are used to external visitors, inspecting the installations and asking questions. Central in the conversations is the community-based approach underlying the micro hydel projects. And though both NGOs set different priorities within the implementation of community-based micro hydel, projects are set up by the NGOs to pass through the same phases, which will structure the following analysis.

\section{Phases of Engagement in Wida's and Gram Vikas' Micro Hydel Projects}

The micro hydel projects by Wida and Gram Vikas can be analyzed in three phases, i.e. initializing, constructing, and operating and managing. These project phases imply certain forms of civic engagement and stand in direct relation to the approach framing the micro hydel plant as a community-based development project. NGO staff, engineers, and local community members are the main parties in the implementation of a micro hydel project. My analysis will focus on Wida's Putsil and Bodomanjari plants, as well as Gram Vikas' projects in Amptaguda, Karlapat, 
Purnaguma, and Karnivel. Yet, rather than empirically detailing the implementation of each of the micro hydel projects, I will highlight those features of the various phases in the different projects that are relevant with regard to my research interest in forms, contents, and consequences of civic engagement.

\section{Initializing}

Comparative advantages to other small, rural energy technologies, such as biogas plants, influence the decision by implementing agencies to initiate a micro hydel project. Gram Vikas' director views the versatility in use and the constant availability of the energy as factors in favor of micro hydel technology: "A biogas plant provides energy for cooking ... But micro hydro- it's like electricity on tap. You can take the energy for whatever and whenever you want" (interview Madiath, 2010). The Swiss Agency for Development and Cooperation, SDC, emphasized a different aspect related to the constant availability of energy: "The biggest advantage is that a micro hydel project has very little generation costs ... because it's the water you use" (interview SDC, 2010). For electricity generation in a biogas plant biomass is required, which has to be constantly collected. A micro hydel plant runs without any extra work, if the flow of water is ensured. Financial considerations are also seen as an advantage. Micro hydel plants constitute a "front loaded" investment, with the bulk of the investment going into the establishment of the scheme, and relatively low maintenance costs. According to Gram Vikas Director "the capital investment is quite high, ... but when you take the life cycle of a micro hydel it is one of the cheapest" (interview Madiath, 2010).

For Wida and Gram Vikas, the general decision at its management level to facilitate a micro hydel project is followed at the community level by a balancing act between suggesting without imposing and facilitating without pushing for a technology, which the NGOs consider suitable to further socio-economic development. NGOs handle this balancing act by inviting the community to engage with the micro hydel project, in which electricity generation is coupled to certain forms of community engagement. By inviting the community to engage with a micro hydel project, the question is not only whether the community wants electricity but also whether it agrees to certain engagement activities tied to it. Wynne's account of "invited" participation is instructive here. He describes invited participation as "forms of engagement ... which are in some way connected institutionally with policy making ... and have a preordained agenda and framing" (Wynne, 2007: 107). Although the relation to policymaking is rather implicit by contributing to development and rural electrification, it is especially the second characterization that describes the NGOs invitation to engage aptly. To ensure the success of the development intervention, micro hydel projects 
have "a preordained agenda and framing," since the project is only facilitated if certain forms of engagement are carried out.

Initializing a micro hydel project begins with carefully communicating the possibility to facilitate a micro hydel project to the respective community. One way to do so is to communicate indirectly by providing information to one of the community members, who would then share this information with the rest of the community. Wida could resort to village relations established in the course of its development work in the region since the early 1980s. One of these villages was Putsil (see Figure 2.3). Wida chose to approach Putsil's village leader Prem Patro in 1997. The NGO's director informed the leader about the possibility to electrify the village by using a micro hydel plant. The village leader was asked to share this information with the members of his community and to inquire about their opinion on the matter. Yet, this information seemed "so impossible" for Prem Patro that he was reluctant to share such "impossible information" with the members of his community, who might criticize him for spreading silly information and might question his credibility as one of Putsil's leaders - "so I just forgot" (interview Prem Patro, 2009). After being reminded by Wida a second time, Prem Patro called for a meeting in Putsil during which he shared the possibility of electrifying Putsil, yet only few people attended the meeting and believed him. Incredulity resonated in these accounts by Prem Patro and his community, doubting that electricity had indeed arrived in the remote tribal hills. These doubts reinforced at the same time the imagined promise of electricity as providing a plug-in to development and progress. This in turn constituted the starting point for the development work by Wida and Gram Vikas in Orissa. 


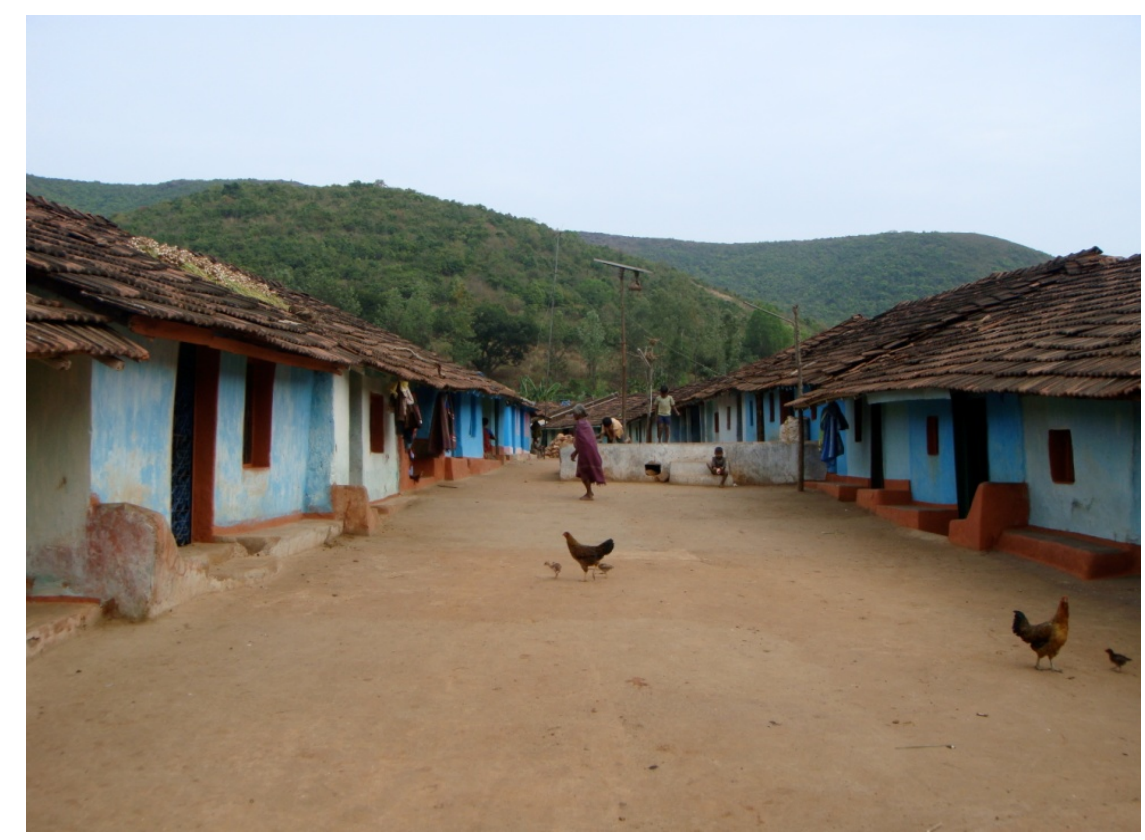

Figure 2.3: The village Putsil. ${ }^{46}$

Only when technicians and engineers came to Putsil to carry out measurements for a detailed feasibility study, village people started to believe "that it can be possible, because all the engineers and technical people came” (interview Prem Patro, 2009). Skills and expertise are required to determine whether the geographical conditions allow for the installation of a micro hydel. Such expertise is indispensable for the definition of its particular design, which needs to be tailored to a certain location. Feasibility studies on water flow measures, surface conditions, location specifications, and user demands are mostly carried out by engineers, assisted by NGO staff. Typically, engineers are being hired as external consultants to carry out this work. Rams, a micro hydel engineer, consulted by Wida for the implementation of the Putsil plant remembers: "We stayed in the village for four days and then we studied a lot: What is the consumption [pattern], what is their requirement? How much paddy is being grown? All that, plus technical details like how much water is there? What is the maximum power one can get? What are the implications on water? What other users do you have on water, like irrigation, cattle?" (interview Rams, 2009). Observing people carrying out surveys and measurements added to the credibility of the project's feasibility, since an abstract promise seemed to turn into a concrete possibility. It thereby created momentum and nourished expectations. After seeing the ongoing measurement activities, Putsil's women started lobbying for the plant. According to Wida's field staff Madhab, "they need more light [than men] who usually don't spend much time in the house" (interview Madhab, 2009). Light enables women to carry out their domestic works such as cleaning, preparing, and cooking

\footnotetext{
${ }^{46}$ I took all photographs presented here, unless where noted otherwise.
} 
food more flexibly and with more ease. The outspoken position of women is the result of Wida's long history of development efforts in Putsil, with women serving as target group. As a result, Putsil's women have learnt to voice their stake in development projects. Wida, in turn, can mobilize the interests of this group to establish the relevance of implementing other development projects.

For Gram Vikas' staff, the engineers' skills and expertise needed to carry out feasibility studies was experienced as a protected space from which non-experts were kept out. "They become protective about their terrain. So, they don't want anyone else to do their job. ... When I [Gram Vikas staff] would say [to an engineer]: 'Let the guy [from the community] measure the reading, I do not want you to measure the reading! [The engineer] just kept feeling threatened. He does not understand that he still has a job but that it would be on a different level" (interview Vaghela, 2009). To bypass this dependency on external expertise, Gram Vikas learnt how to carry out feasibility studies for its later micro hydel projects without involving external experts. "We taught [the local community] how to do the feasibility. We did that study. For almost six months we measured the [water] flow" (interview Vaghela, 2009).

Often, the volume of water in streams fluctuates with the seasons. As a result, less water will be available in summer. If a plant is to use the stream's water, its volume has to be shared between the hydel plant and other forms of water use, such as for agriculture. The installation of a micro hydel plant therefore requires villagers to compromise. The micro hydel engineer Rams explains: "In summer the flow goes down. You cannot have both [hydel plant and irrigation water] running at the same time. So, they stop [irrigation] in the evening and the powerhouse goes on. ... Nobody of the entire village is allowed to take [irrigation water]. They have to agree to that" (interview Rams, 2009).

Once a micro hydel project is being implemented the word spreads quickly to other neighboring communities: "When Putsil people got current for the first time they were very happy. Then other relatives came to see how Putsil people were getting electricity. ... And other village people are coming and requesting WIDA to extend these projects [to them], so, they can be happy" (Prem Patro, 2009). As soon as activities around the implementation of a micro hydel have started, the idea to generate electricity by using hydropower is communicated by the local villagers themselves. They thereby relieve the NGO from the task to lobby for this technology. Gram Vikas' energy coordinator remembers: “[When] we did Amptagudda, the people from Karlapat approached [us]. When we were doing Karlapat the people of Purnaguma approached [us]" (interview Vaghela, 2009). Rams, the micro hydel engineer involved in Wida's three micro hydel projects, remembers the initial challenge that an abstract idea of a micro hydel can pose in 
comparison to the tangible end-result. "In the first village it is all in our heads ... It is fantastic to see [the villagers] believe us and contribute [to the implementation]. Whereas the other two villages, they have something they can go to and visit. They see what they are getting into" (interview Rams, 2009).

The initiation process is thus eased after other micro hydel plants have already been established. Familiarity is another aspect supporting the smooth initialization of projects. Due to their long involvement with developmental work, both Wida and Gram Vikas are established actors in their respective areas of operation. Development projects following a community-based approach are not completely new to the communities. Village leaders, too, can play an important role when initializing projects. In case of Putsil, the engineer in charge remembered the important role Prem Patro played in the process: "They have a very good community leader ... His word is final, no government, nothing interferes in that. So, this leader was very understanding during this process ... He came up with all his support" (interview Rams, 2009).

The initiating phase is shaped by the NGO's efforts to invite the community to engage with a micro hydel project and its promise of empowerment. Along with consenting to engage with a micro hydel project goes the establishment of certain implementation phases, in which the community's engagement activities are expected to take place. After acceptance of the initial invitation, the phase of construction begins, which can last between four and eight months, depending on such diverse factors as weather ${ }^{47}$ and health ${ }^{48}$ conditions, the availability of the components needed, and the NGO's and the village's acquaintance with micro hydel projects. The constructing phase constitutes a core activity within the implementation of Wida's and Gram Vikas' micro hydel projects.

\section{Constructing}

In all of Wida's and Gram Vikas' projects, the actual construction of the plant is carried out by people of the respective village(s) that will be served by it. Mainly due to the remote location of the plants, no advanced construction tools such as cranes, excavators, and construction vehicles can be used. Consequently, the work is very physical, based on hard manual labor. The physical engagement by the villagers to build the plant also forms part of the micro hydel plant's character as a community-based development project. Engaging local communities in the construction of the plant is regarded as a way to create project ownership by the people rather than by the NGO. Wida's director states: "You will not hear from Wida staff saying that the hydel scheme is Wida's

\footnotetext{
${ }^{47}$ The monsoon may delay or hold up works.

${ }^{48}$ Malaria is common in the region. 
project; no, it is owned by the villagers" (interview Stanley, 2009). The community-based projects are based on the nexus between engagement and ownership. Creating ownership through engagement is believed to make projects more viable, since it shifts the main responsibility for the functioning of the plant to the villagers.

The villagers do not get paid for the labor they contribute to the construction of the micro hydel plant. This implies the need to make arrangements within a family or between the villagers to make sure that other essential works, such as agricultural activities, can be carried out. ${ }^{49}$ In Gram Vikas' Purnaguma project, arrangements were made within each family so that one person per family would contribute his labor to the plant's construction. In Bodomanjari, a village supported by Wida, some criticized the engagement of people who concentrated all their activities on the building of the plant: "Will you eat your current or what? You did not do any agricultural work!" (interview people from Bodomanjari, 2009). The village's micro hydel committee played an important role in sustaining the people's enthusiasm and support. It made arrangements for sharing agricultural duties between the community members, so the builders could continue to work on the project while their fields would be maintained by other villagers. ${ }^{50}$

During construction, engineers, who either stay temporarily in the village or visit regularly, supervise the engagement activities of the village people. Different relationships can develop between engineers and villagers. When Bodomanjari's plant was built, the engineers stayed in the village for several months. The Bodomanjari people "have a ... government school building, which is not in use and [the engineers] were staying there. And they were eating food from the people" (interview people Bodomanjari, 2009). Mentioning that food was provided by the villagers has a clear positive connotation, pointing to the closeness between engineers and the community. In another project facilitated by Gram Vikas, the physical distance of the engineer in supervising the ongoing constructions had an impact on the communication between villagers and engineers. "So, any time you have engineers [here at the construction site], they [villagers] won't say stuff. The village won't respond as much" (interview Vaghela, 2009). During the construction phase, the villagers' predominant role is to perform the work as designed by the engineers. This role allocation, however, is malleable - if NGO staff and engineers give the villagers this possibility. Gram Vikas' energy coordinator recalled an event during the construction of the Karnivel plant in which villagers moved beyond their executing role: "TThe villagers] were grumpy: 'Why are we building [the penstock] here? If we make it this way we do

\footnotetext{
${ }^{49}$ Most of the villagers are subsistence farmers, so if everybody works on the plant's construction, no food will be produced needed for their own consumption.

50 Yet, if the possibility to earn money elsewhere occurs, work on the micro hydel project may be interrupted. In Purnaguma construction work stopped when people got paid short-term jobs in government works, such as constructing streets.
} 
not have to move the rocks...' [Gram Vikas staff answered:] 'Yes, you are right!' ... I took a picture and sent it to the engineer explaining the issue. And he said it's fine" (interview Vaghela, 2009). NGO staff took over the role as mediator between the villagers and the engineers, by favorably communicating the villager's requests to the engineers.

Frequently, direct on-site interaction between engineers and villagers is complicated by language differences. As an engineer involved in micro hydel projects of both NGOs indicated: "I don't speak the language. They speak Oriya.... [The NGO] will grant me the translators, translating between us and them" (interview Rams, 2009). Yet, more profoundly, communication challenges are not restricted to different languages but also emerge due to differences in profession. Rams described how his communication between the NGO and the villagers underwent a learning process. He had to learn "how to convey ideas to people. You have something in your mind, you say something, and people understand it differently. It was very difficult because I am a technical guy. None of the other guys, neither the NGO nor the villagers, are engineers. So, I had to simplify my communication to such extent so people could understand" (interview Rams, 2009).

Adapting communication is crucial, since the engineer describes the period of construction also as a time during which training for the local people takes place: "We also train people during installation. Installation means that we are not getting in extra engineers from outside. Only I go, or one or two of us go. ${ }^{51}$ Everyone else is from the village. They know how to put a turbine, how to take it apart; what are the critical compounds; how to look after them. So, they do not have a separate training for that. It becomes part of the installation process" (interview Rams, 2009).

Implementing the construction works with manual labor makes clear how directly the design's details bear on its physical execution. "We overdid it in Karlapat. In Bodomanjari, ${ }^{52}$ the same thing [happened]: big walls... That requires more work from the community, more stress on them. But our tank here [at Purnaguma] is very simple, very small. A four-inches wall" (interview Vaghela 2009). For Gram Vikas, learning about building and managing a micro hydel project is a recurring issue in accounts about their work. This emphasis on learning was intensified in 2007 when a energy program coordinator took over the coordination of Gram Vikas' micro hydel projects. For this new coordinator, the two projects at that time, Amtaguda and Karlapat, functioned as a source of reference for Gram Vikas' newer projects in Purnaguma and Karnivel. "Yes, Purnaguma. We learnt from our first two projects, that we had too much staff, [in Purnaguma it is different:] I have been there. The driver has been there. They have managed the construction on their own" (interview Vaghela, 2009).

\footnotetext{
${ }^{51}$ Together with his colleague Punit Singh, with whom he had set up a micro hydel consultancy.

${ }^{52}$ Here, this energy coordinator refers to a project facilitated by Wida, which she had visited. 
Gram Vikas' draws on its own project experiences to learn for future projects. Localizing technical components and processes became constituent of the NGO's approach to micro hydel. Consequently, in case of Gram Vikas' projects ownership is not only created by engaging the communities in executive construction activities, but also by their explicit engagement in technical tasks. To acquire technical expertise Gram Vikas' new micro hydel coordinator chose to consult an international NGO, Practical Action, for the implementation of their third project Purnaguma. Practical Action is specialized in the implementation of micro hydel projects, by including locally fabricated components. "We used to buy the transmission line poles from outside. Practical Action told us how to make it here" (interview Vaghela, 2009). The collaboration and exchange with Practical Action specialists informed and confirmed Gram Vikas' emphasis on local instead of external component fabrication.

Localizing the processes of the implementation of a micro hydel plant is seen as empowering the communities, since it enables people to develop their own expertise and skills and thereby reduces their external dependencies. Aside from ideological considerations of empowerment, however, technology misfortune played a role in Gram Vikas' decision to localize micro hydro implementation. "We have been let down by outside developers who have brought their system and then it does not work, and we have to call them. We have now manufactured it locally, here in this [nearby] town. So, if there is a problem one hour away - they can take the bus" (interview Vaghela, 2009). Thus, a practical side-effect of localization is that it increases the manageability and controllability of the project implementation: It saves time and managerial efforts for the NGO by not being dependent on the busy time schedules of the engineers who are often based far away from the project sites.

Generally, the experiences and skills of the engineer responsible for the system's design and installation are crucial. By localizing fabrication and maintenance, however, the technology is taken out of the expert context and opened up to local people, a process that Gram Vikas refers to as "demystification" of technology: "It is our intention that [the technology] should be so demystified, that a local, that is the local town, should be able to manufacture most of it. And the village boys and girls should be able to maintain it; and not any engineers" (interview Madiath, 2010).

Gram Vikas' director finds that many engineers maintain the dependency of non-experts on their technical expertise: "You see, $90 \%$ of the engineers believe in making things as mysterious

\footnotetext{
${ }^{53}$ www.practicalaction.org, Practical Action has its headquarter in the UK, but operates worldwide. The Sri Lankan office has special expertise in micro hydel projects. The inspiration for the formation of Practical Action was provided by E.F. Schumacher's idea of "intermediate technologies," which are based on the needs and skills of people. Originally, Practical Action was named Intermediate Technology Development Group (ITDG).
} 
as possible, so that ... all the time they are on demand" (interview Madiath, 2010). According to the director, they do so due to the engineers' reluctance to share their knowledge with technically untrained people: "And very few want to really import their knowledge and say: ok, I studied five or seven years and I know this much, but within seven days I can already equip these people with knowledge so that they can manage" (ibid.). Although he acknowledges the need for expert knowledge in some fields, he stresses its exceptionality: "So, there are a few things only an engineer can do, for which you have to study engineering. But these are the exceptions" (ibid.). In cases where engineers refuse the villagers direct access by engaging them in hands-on work, the director describes how this restriction may sometimes be overcome due to the extraordinary abilities of some of the villagers: "Some people, while the engineer is working, just observe and are ultimately able to do it [themselves], even if the engineer is not there" (ibid.).

Gram Vikas has discovered that the young village residents tend to be very willing and able to engage in the implementation of micro hydel projects. According to Gram Vikas, the main motivation for them to engage is that "they are just idle. They have nothing to do" (interview Vaghela, 2009). When implementing new projects, Gram Vikas makes it possible for them to apply their acquired expertise and skills. In Gram Vikas' two newer projects, young men from other villages with micro hydel experience joined in the construction works, bringing in their knowledge and labor. This is in line with Gram Vikas' aim to build a "team of young boys who go and do micro hydel" (interview Vaghela, 2009).

The idea of a micro hydel team relates to the suggestion of forming a cluster of micro hydel projects. According to a micro hydel engineer, the geographical proximity of the sites speaks for this initiative. In addition to Gram Vikas and Wida, another NGO facilitates micro hydel plants in the Eastern Ghats range: "This is three plus three plus two: eight sites, within a radius of 100 km." The suitability of the area allows for the advance of more micro hydel projects: "In the Eastern Ghats range there is a lot of water and many remote villages. So, a couple of more [projects] are coming up next year. And in the next three, four years we will be having nearly 20 micro hydro projects in that region" (interview Rams, 2009).

The issue of scaling up the successes of the individual sites and NGOs is tackled by a regional cluster approach. According to the engineer, training NGO staff plays a central role in this endeavor. By training NGOs to carry out studies related to the feasibility of a project, the engineer can save time and costs during the preliminary stages of a project. "We also train a lot of people ... mainly NGOs, because they can do all these assessments, and see whether [a project] is doable. So that someone like me does not have to come to these remote villages, finding out whether water is sufficient to meet these demands. For that part, which we call the feasibility 
report, we will have to train enough people" (interview Rams, 2009). Links between NGOs would be strengthened, facilitating exchange and learning. "They can compile experiences, they can learn. If this guy has a problem, he can always call the other NGO" (ibid.). Besides NGO training and exchange, a cluster would also advance economies of scale for local manufacturers of components: "Local fabrication also becomes easy: Someone, who fabricates two or three [components], is interested to make more. [Whereas if] he is only making one in ten years, he is not interested" (interview Rams, 2009).

Through Gram Vikas' move to localize processes and component production, the presence and role of the engineer diminishes. Studies investigating the feasibility of a micro hydel project are carried out locally without needing the consultation and presence of an engineer. And though engineers design the actual plant, its components are as much as possible produced locally, instead of being brought in ready-made by the engineers. The construction process, too, is carried out more autonomously, with the engineers in a stand-by position, rather than being onsite supervisors. At the same time the role of the NGO has changed: Through focusing on localizing processes and production, the energy program coordinator has "technisized" the portfolio of the NGO, which now, apart from facilitating and mediating activities, also includes the supervision and execution of technical tasks.

In summary, physical engagement by the community members during the construction phase played a central role in all of Wida's and Gram Vikas' projects. This is based on the premise that engaging people in the plant's construction will create ownership, which is seen as a condition for the plant's viability. Apart from creating ownership through physical labor engagement, Gram Vikas also aims to create ownership by engaging the people in technical tasks, so that they are able to construct micro hydel projects as much as possible with local equipment and knowledge. The rationale to create ownership by engaging people is paired with the aim to thereby empower a community. One aspect of this is enabling the community to learn skills and expertise during the construction. This is explicitly encouraged by Gram Vikas, who intends to build a local micro hydel team, embedded in a regional micro hydel cluster, where the villagers can reapply their acquired expertise in other micro-hydel projects. Ownership-creating engagement activities, be it through technical or physical community involvement, do not stop with the installation of the plant but continue to be a constituent element during the management and operation of the projects. 


\section{Operating and managing}

A micro hydel project is managed by a micro hydel committee, which draws on the engagement of the community. The establishment of a micro hydel committee institutionalizes a structure through which the project is governed at the community level. In their work with the communities, the NGOs have developed certain imperatives, which have to be considered in every development project. Gram Vikas, for example, stipulates certain core values, such as 100\% community inclusion, ${ }^{54}$ social equity, ${ }^{55}$ and gender equity, ${ }^{56}$ to which all of its projects aim to comply (Vaghela, 2006). The setting up of a committee through members of the respective community is a standard procedure in the implementation of a micro hydel project and forms part of both Gram Vikas' and Wida's working methods. "[The villagers] were told to make a committee, because that's how Gram Vikas works. That's how everyone works" (interview Vaghela, 2009). A committee is set up even before construction works of the plant have started. For the NGO the committee functions as a necessary liaison in the village to implement the project. Yet, rather than assigning responsibility for the plant, NGOs aim to create a feeling of responsible ownership by the community through engagement. By institutionalizing a committee governance structure, the NGOs thus hope to ensure the plant's local management and operation, fuelled by a feeling of ownership. From the perspective of the Bodomanjari community, a committee structure eases decision-making within the community by assigning responsibility, because "if the entire community will ... decide for [the] micro hydel maintenance, it will be a little difficult. So, [it is better that] some members will be in charge and take care of the plant" (interview people from Bodomanjari, 2009).

The committee structure is rather flexible. Usually, a committee consists of around 10-15 members, though the number of persons is not fixed. There is neither a fixed meeting schedule nor a formal duration of the membership status. In Bodomanjari, decision-making takes place univocally, "because [the] committee is formed through the village, for the village and on behalf of the village ... The committee will agree to what is necessary for the whole community" (interview people from Bodomanjari, 2009). This quote shows how the community's well-being is seen as the guideline for decisions. Leadership is an oft-referred to concept in the context of micro hydel projects. Leaders, who usually inherit their role through lineage, have an influential position in their function as decision-makers for the well-being of their community. A microhydel projects impacts on the life of the community. Frequently, therefore, community leaders

\footnotetext{
${ }^{54}$ Inclusion implies that all local people may join in, so that all can profit from the development process.

55 Social equity addresses decision-making processes, so that all people are represented regardless of their social status or their caste.

${ }^{56}$ Gender equity applies to equal treatment of and equal opportunities for men and women in decision-making and control. 
are members of a micro hydel committee, as in the case of Putsil or Bodomanjari, which has "six strong leaders" and another "nine members," as people from Bodomanjari stress. Financial influence can also be a reason to play a leading role in a committee. Gram Vikas' energy coordinator remembered one incident in Purnaguma, in which money explained why a person could attain a leading position within the committee: "That guy who was elected president [of the committee] was not responding [to the task] at all. He is the richest guy in the village. People said his name because who else would it be - to be the president?" (interview Vaghela, 2009).

For the community, having specialized competences tailored to the specific theme of a committee is regarded less important than other leadership traits related to lineage or financial influence. The criteria of villagers for selecting members of a committee can thus clash with those of the implementing NGO. With the task of actually facilitating the implementation of a project, NGOs stress the need for hands-on, physical, and technical engagement by the villagers, regardless of their social position. "And now we know that you start some work like building the bricks, the poles, some basic work - and you already see who your committee is. The guys who are managing this should be the committee" (interview Vaghela, 2009). Accordingly, Gram Vikas prefers technical involvement to communicative competences of people. "Rule number one: people who are involved technically should be on the committee. They will often be the quiet ones. The usual committee [members] are very social and they can speak to people easily" (ibid.). In Gram Vikas' experience, hands-on involvement provides villagers with a technical understanding, which is crucial for the smooth management and operation of the plant. "In the other two projects, ${ }^{57}$ the social people were on the committee. They had no technical knowledge. So, they would say: 'Ah, your generator is bad.' But the generator is not bad - the water level is low! So, if they have no technical understanding how will they communicate to the rest of the community?" (ibid.). From an NGO perspective, having a technically informed committee helps to settle frustrations within the community without external interference. The creation of ownership through technical understanding of the plant's functioning is strengthened, since villagers themselves argue in favor of the plant.

Engagement activities within the committee structure aim to ensure the plant's continuous functioning. The micro hydel committee's activities include being responsible for issues of maintenance, repair, employment of plant operators, scheduling of power distribution, and tariff collection. To ensure a steady flow of water, the removal of debris and silt from the canal and check dam is a typical issue on the committee's agenda (see Figure 2.4). In Bodomanjari, the actual cleaning work will be carried out by members of the community; the committee's function

\footnotetext{
${ }^{57}$ Amtaguda and Karlapat.
} 
is to raise and discuss the issue: "The committee [will] look after the plant, the community will do [the work]. But the committee will discuss the point" (interview people from Bodomanjari, 2009).

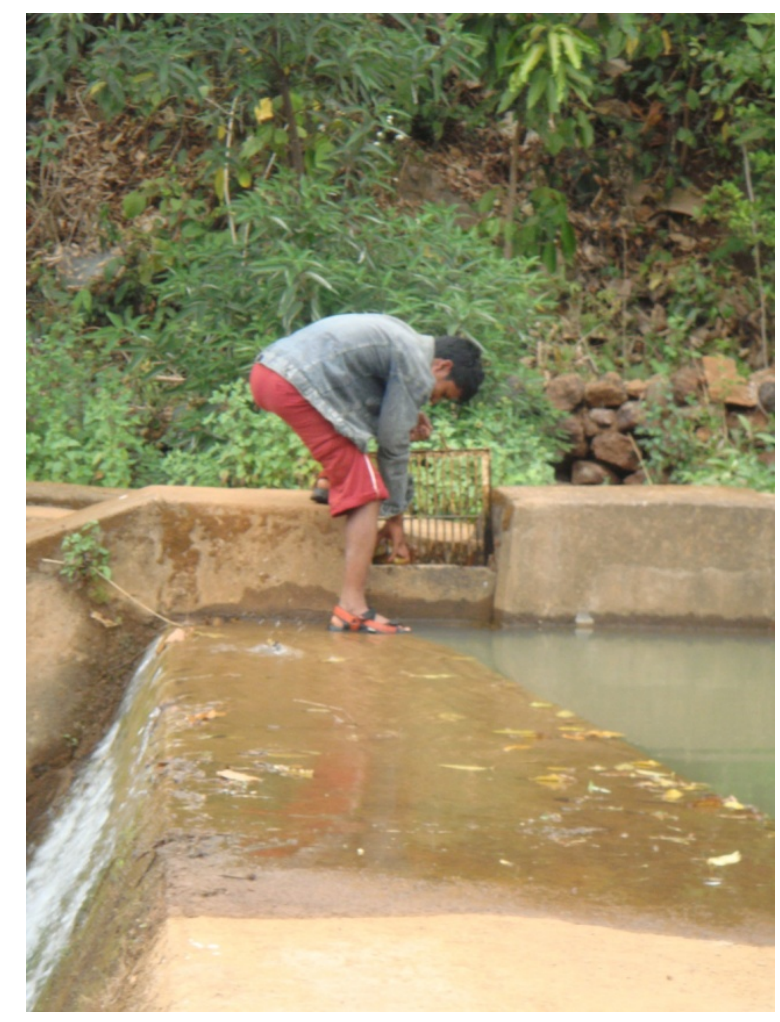

Figure 2.4: Cleaning the intake channel in Putsil.

Repair is another issue discussed by the micro hydel committee. Generally, the NGO expects the villagers, led by the micro hydel committee, to repair the damage on their own and only resort to the NGO for help if they are unable to remedy the problem themselves. When Putsil's penstock was broken due to heavy rain, Wida staff stressed positively that the villagers "repaired the pipe independently and got the current running again" (interview Wida staff, 2009). For the NGO this is an example of successful ownership, which involved financial and technical efforts by the community without resorting to the NGO for external help.

According to Gram Vikas, repairing damages of the civil works is an expertise that the villagers usually already possess. "These people build so much here. The government is always building dams and watershed. [The villagers] know how to do concreting and [work with] sand and soil. This stuff they know" (interview Vaghela, 2009). To what extent, however, community members should be enabled to take over mechanical and electric repairs depends on the methodological approach of the NGO. Training local villagers is in line with Gram Vikas' emphasis on localizing component fabrication and work processes. "In the process of doing Purnaguma we have trained a local guy, a local electrician. So, he has been coming to repair ...," as the energy program coordinator told us. Aiming to enable local people to take over the repair 
works has consequences for the choice and complexity of the plant's technology. "And [Karlapat's load] controller is very complicated. There are too many things going on. Even when we wanted to train this guy-there is no way he could learn it. Whereas in Purnaguma the load controller] is very simple, very basic" (interview Vaghela, 2009).

Questions regarding the aftercare that villagers cannot solve on their own are passed on to the project engineer, who will have left the site by then: "[After construction of the plant] we are always there for support. If there is some small problem they don't know how to fix, I will always get a call. So, we arrange it on the phone" (interview Rams, 2009). NGOs will mediate requests from the villagers, if they are not able to help the villagers themselves. Aftercare issues, implying the dependency on engineers in the solution of technical problems, have also contributed to Gram Vikas' emphasis on local fabrication and execution. Due to this, the energy coordinator evolved into a micro hydel expert herself. Gram Vikas' director describes her role as a trainer: "So, if there is a problem, which the village boys who are trained have not faced earlier ... she will be there to train" (interview Madiath, 2010).

On a day-to-day basis the micro hydel plant is usually operated by about four young men who were trained as operators and who work in rotational shifts. In Wida's terminology these operators are called "barefoot engineers" (see Figure 2.5). This term alludes to the possibility of combining the simplicity of tribal life with advanced technology. These engineers have the main responsibility for the system and their task is to switch the system on and off since none of Wida's and Gram Vikas' plants run continuously for 24 hours. Rather, the plants are switched on in the evening hours when the villagers return from work. ${ }^{58}$ Some plants run throughout the night, while others stop around midnight and start around four o'clock in the morning to enable women to finish their domestic works. The operating schedules are related to the demand of the village and the availability of water, which may be used for other purposes as well. The micro hydel committee decides on the time schedule of the power distribution. In case of festivals, sickness, childbirth, or other extraordinary events, the time schedule can be changed by the committee's decision and the operators are instructed to open and close the valves accordingly.

\footnotetext{
${ }^{58}$ Most of the villagers have agricultural occupations. During daytime, villages are almost deserted because most of the inhabitants have gone out for work.
} 


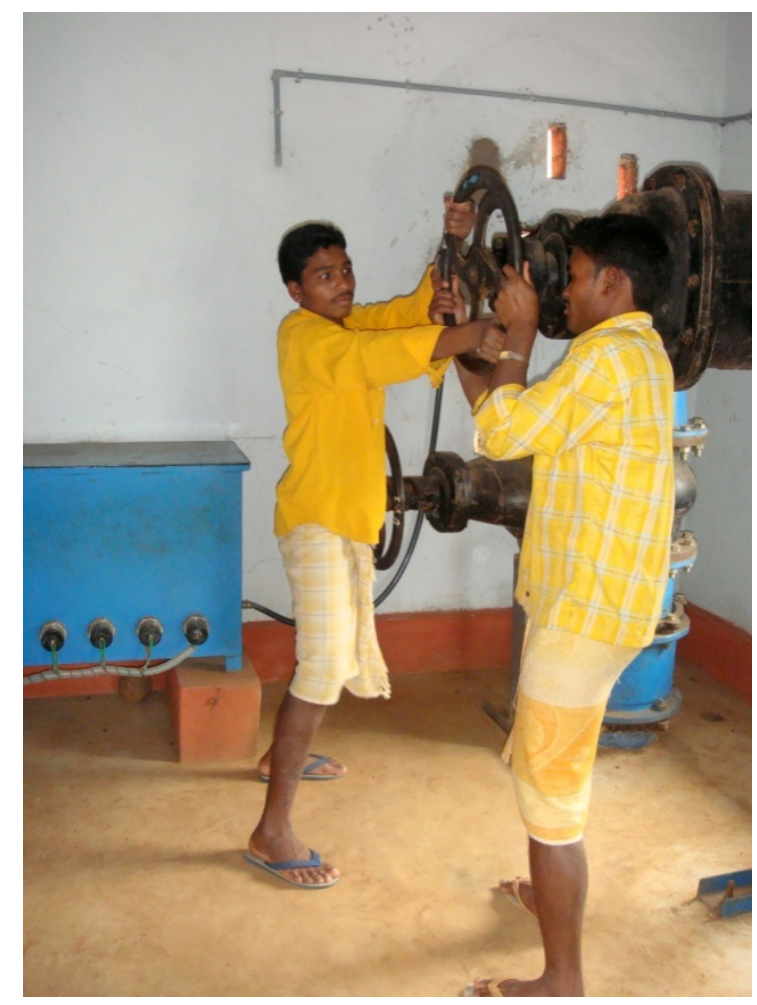

Figure 2.5: Bodomanjari's barefoot engineers (wearing flip-flops).

The power provided by the micro hydel plant is not free of charge. Every household is charged a set tariff. The charge is monthly and based on the existence of a connection, not on the actual amount of power used..$^{59}$ In Wida's and Gram Vikas' projects the tariff varies between 10 and 30 Rs. per household..$^{60}$ In Gram Vikas' projects the tariff is related to the cost of kerosene, which the villagers had to pay before they received light through electricity. The micro hydel committee is responsible for collecting the monthly rate. In case a household is unable to pay, the committee deals with this in a flexible manner. According to an engineer this is based on knowledge usually inaccessible for outsiders. "There are so many small things, which outsiders cannot know ... Because it's a social village set-up. They know each other very well. They know one guy is suffering [because] at that time maybe his ... harvest is poor. They do not press so hard for money, it's always an adjustment" (interview Rams, 2009). The monthly tariff is collected in an electricity fund, which is used for minor repair works. The fund is administered by the micro hydel committee. Gram Vikas' projects pay operators from this fund. In Wida's projects barefoot engineers carry out their work voluntarily but they are provided with free food by village members, which they bring to the powerhouse in the evening when the shift starts.

\footnotetext{
${ }^{59}$ Since both NGOs work on a policy of $100 \%$ inclusion of their projects' reach, all households have a connection and have thus to pay the monthly tariff.

6010 Rs. is about 17 Eurocent. 
As a condition to run a micro hydel plant Gram Vikas asks a clear financial commitment from the villagers going beyond the monthly tariff contribution. Villagers are expected to make a one-time payment of 1000 Rs. per family into the so called "corpus fund." ${ }^{61}$ The corpus fund is meant for any kind of major repairs. Though in practice the collection of the corpus fund is cumbersome, Gram Vikas holds on to this condition because it is seen as a way of involving villagers via the financial angle into the project (interview Madiath, 2010).

During the operating and managing phase, ownership-creating engagement activities aim to ensure the continued functioning of the projects. For Gram Vikas and Wida, the successful operation and management of a micro hydel project presupposes the engagement of villagers with regard to different issues: physically, by keeping the canals etc. clean; technically, by solving technical complications; managerially, by managing the operation issues; and financially, by paying the tariff, in the case of Gram Vikas, into the corpus fund.

Although all aspects play a role in both Wida's and Gram Vikas' projects, the NGOs prioritize them differently in the course of the implementation phases. Gram Vikas' emphasis on providing technical skills and expertise comes especially to the fore during the construction phase, while the NGO puts additional attention to financial engagement during operation and management. Wida highlights physical and managerial engagement features during construction and operation of a micro hydel project. In the approach of Gram Vikas, ownership-creating engagement activities during the different phases are not only geared to ensuring the viability of the respective project under construction; they are also related to broader efforts aimed at replicating projects elsewhere in the region.

\section{Unaccepted behavior}

Engagement in Wida's and Gram Vikas' projects takes place within pre-defined ways and phases. The NGOs carefully frame and facilitate how the community engages with the micro hydel projects. The different phases of initiating, constructing, and operating and managing imply certain engagement activities, which people are supposed to conduct. Using the typology suggested by Wynne (2007) I call this type of engagement "invited engagement." The term “invitation" captures well the NGOs' precaution to invite rather than to impose a micro hydel project. Accepting an invitation implies at the same time the agreement to certain rules implicitly or explicitly set by the inviting party. Invited engagement thus also denotes how engagement possibilities are pre-determined by the project-inviting actors: once a community decides to engage with a micro hydel project, community members are expected to engage in certain pre-

\footnotetext{
611000 Rs. are about 17 Euros.
} 
defined ways. Through regular visits the NGOs stay informed about the status of the projects. Thereby, they enable NGOs to check whether the community acts according to a certain set of behaviors regarding the micro hydel projects. Visits are a way to exert control over the activities of the communities, because they embody and underpin a frame within which activities are expected to take place.

Activities that fall outside the accepted frame relate to disengagement from and lack of commitment to the project. As we have seen, one of the expected engagement activities, which is asked from all the households in a village, is engaging with the construction works of the project, generally in the form of a labor contribution. Yet, in one of the projects, one man, who happened to be the richest man of the community, did not want to contribute any labor to the plant's construction and was not willing to compensate the days of labor financially. Since the man owns a tractor, the NGO expected him to show commitment to the project by providing the tractor for the construction works, which he was not willing to do unless being paid. Supported by the NGO, the hydel committee decided not to provide an electricity connection unless he paid for the days he did not contribute any labor. As a result of his lack of engagement and commitment, the richest man of the community has no access to electricity in his house.

Apart from not showing any material commitment, it is unacceptable to not meet one's financial obligations in the project implementation. In Karlapat the micro hydel plant was built but the corpus fund used for major repairs was not yet in place. Gram Vikas insisted on its condition of having the corpus fund in place before the micro hydel plant would start running. This led to tensions between the NGO and the community, which impacted on the community's support of the project. "We warned them: we won't turn the system on! But the community would get really angry at us because they worked this hard and we won't turn it on" (interview Vaghela, 2009). To avoid these tensions in its future projects, Gram Vikas will now start a project's construction after the collection of the corpus fund only.

Members of the hydel committee may be elected rather owing to their social or financial traits and abilities than their genuine interest in the plant. This may result in a reconfiguration of the committee member constellation. In one hydel committee the NGO supported the reelection of a president, who had accepted the position, without having any interest in the micro hydel project. "The official president has been to the site just once! So, we [Gram Vikas and people heavily engaged in the construction] made a resolution to change him" (interview Vaghela, 2009).

These incidences show that disengagement and a lack of commitment are unaccepted forms of behavior, which the NGOs aim to avert by punishment (no access to electricity), prevention 
(timely corpus fund establishment), and intervention (re-elections of committee members). Their main strategy, however, to prevent detrimental behavior is not reactive but affirmative, through ownership-creating engagement activities accompanying the project's implementation from early on. The concept of ownership is directly linked to the community engagement facilitated by Wida and Gram Vikas: if people own the project, it is assumed, disengagement and disinterest are averted, creating instead a feeling of responsibility which allows the NGO to withdraw to a stand-by position. The NGOs try to create ownership by enabling community engagement with the plant's financial, technical, managerial, and physical aspects. Based on the nexus between ownership and engagement in these four realms, Wida and Gram Vikas aim to empower the communities.

\section{Conclusion}

In this chapter I showed how several small, rural communities remotely located in Orissa's South engage with micro hydel projects, which are facilitated by two Indian NGOs. I typified the engagement activities taking place in these projects as "invited engagement." Engagement takes place within the project implementation phases of initiating, constructing, and operating and managing, and comprises physical, technical, managerial, as well as financial aspects.

Although Wida and Gram Vikas both follow a community-based approach to implement micro hydel projects, they set different emphases when facilitating community engagement in their projects. In all of the projects, community engagement is based on creating ownership, yet the content of what people are to acquire through ownership-creating engagement activities differs. Enabling the access to electricity for poor and marginalized communities characterizes Wida's framing of community-based engagement. Wida has no new or recently started micro hydel projects, nor does it have the ambition to build "a network to do micro hydro" such as that of Gram Vikas. Wida's emphasis is on the empowering possibilities the flow of electricity offers to the community, such as productive use and the availability of light to ease women's domestic work.

Gram Vikas understands community-based engagement as enabling villagers to generate equipment and expertise mainly locally, so they can implement micro hydel projects as much as possible independently. Being able to implement micro hydel projects is regarded as an empowering activity for villagers. Gram Vikas thus concentrates on the process of enabling the construction of micro hydel projects. By focusing on the process of construction, the access to knowledge comes to the fore in Gram Vikas' micro hydel projects. Enabling the access to 
knowledge is related to its aim to demystify the micro hydel technology by localizing fabrication and implementation. While this NGO's role remains important in this process, through its approach it reduces dependency on the expertise from external engineers. The creation of a regional cluster, in which NGOs facilitate and villagers implement new micro hydel projects, offers the possibility to foster knowledge application, generation, and exchange.

Through engaging the people in the project's implementation, community-based approaches inherently enable access to knowledge through hands-on involvement. In Wida's projects, enabling knowledge access therefore plays a role as well, even if less explicitly than in Gram Vikas' projects. In the approach of Gram Vikas, localizing processes and component fabrication open up access to knowledge, which goes beyond hands-on, executive involvement. Components are made locally ${ }^{62}$ or on-site, ${ }^{63}$ instead of being imported as ready-made parts. Investigation of site conditions and measurements are conducted without engineers. And though the plant's design is still an engineer's task, the engineer's role in directly supervising the implementation is reduced. Repetitive application of the knowledge gained in new projects constitutes an integral part of Gram Vikas' approach.

Through ownership-creating engagement activities, the flow of electricity takes on a central position in Wida's projects, while in Gram Vikas' project this flow is complemented with efforts to enable access to technical knowledge about the micro hydel technology. To bundle efforts and knowledge, increase visibility, and overcome isolation of projects, Gram Vikas aims to contribute to clustering and scaling up of projects by working towards a regional cluster of decentralized micro hydro projects, implemented by local people. In Wida's approach people are to be empowered as consumers and community producers of electricity. The electricity provided opens up new possibilities of socio-economic development by enabling consumptive and productive use on the local level. In the case of Gram Vikas, a central concern, apart from empowering consumers and producers, is the empowerment of local entrepreneurs who implement the micro hydel projects.

By implementing community-based engagement activities, both NGOs aim to enable the access to electricity and knowledge in order to contribute to the socio-economic empowerment of remote rural communities. Given their respective conception of empowerment, however, they enable different engagement activities: Wida relates empowerment, created through ownershipcreating community engagement, mainly to the flow of electricity, while in Gram Vikas' projects the flow of knowledge emerges saliently as a means to empower rural communities in South Orissa. Actors facilitating micro hydel projects thus determine the forms of engagement

${ }^{62}$ For example manufacturing the turbine in the near city.

${ }^{63}$ For example building the transmission poles. 
according to a certain conception of empowerment they hold. As a consequence, scenarios of empowerment are realized in which the access to electricity or knowledge enables the making of empowered consumers, producers, or entrepreneurs. 


\section{Chapter 3}

\section{The Sugur Mini Hydel Plant in Karnataka}

\section{Introduction}

The second research site, where I chose to empirically study different forms, contents, and consequences of civic engagement is located in the South Indian state of Karnataka (see Figure 3.1). The focus of this chapter as well as the next one is on engagement activities that unfolded at two hydroelectric plants, the Sugur mini hydel plant and the Kenchanaguddam mini hydel plant, built along the Tungabhadra River. Unlike the micro hydels by Wida and Gram Vikas, the plants that are center-stage in the next two chapters are grid connected and owned and managed by private companies. Yet surprisingly, we will see that electricity is not the key issue around which engagement activities unfolding at the two plants revolve. Conventional and unconventional engagement activities, which are the analytical categories introduced in this chapter, are related to the flow of water and money and have different consequences. Before analyzing how this is the case it is helpful to provide a brief overview of India's electricity sector and policy context, in order to embed the conventional and unconventional engagement activities unfolding around the small hydel plants in Sugur and Kenchanaguddam, which are privately owned and managed. 


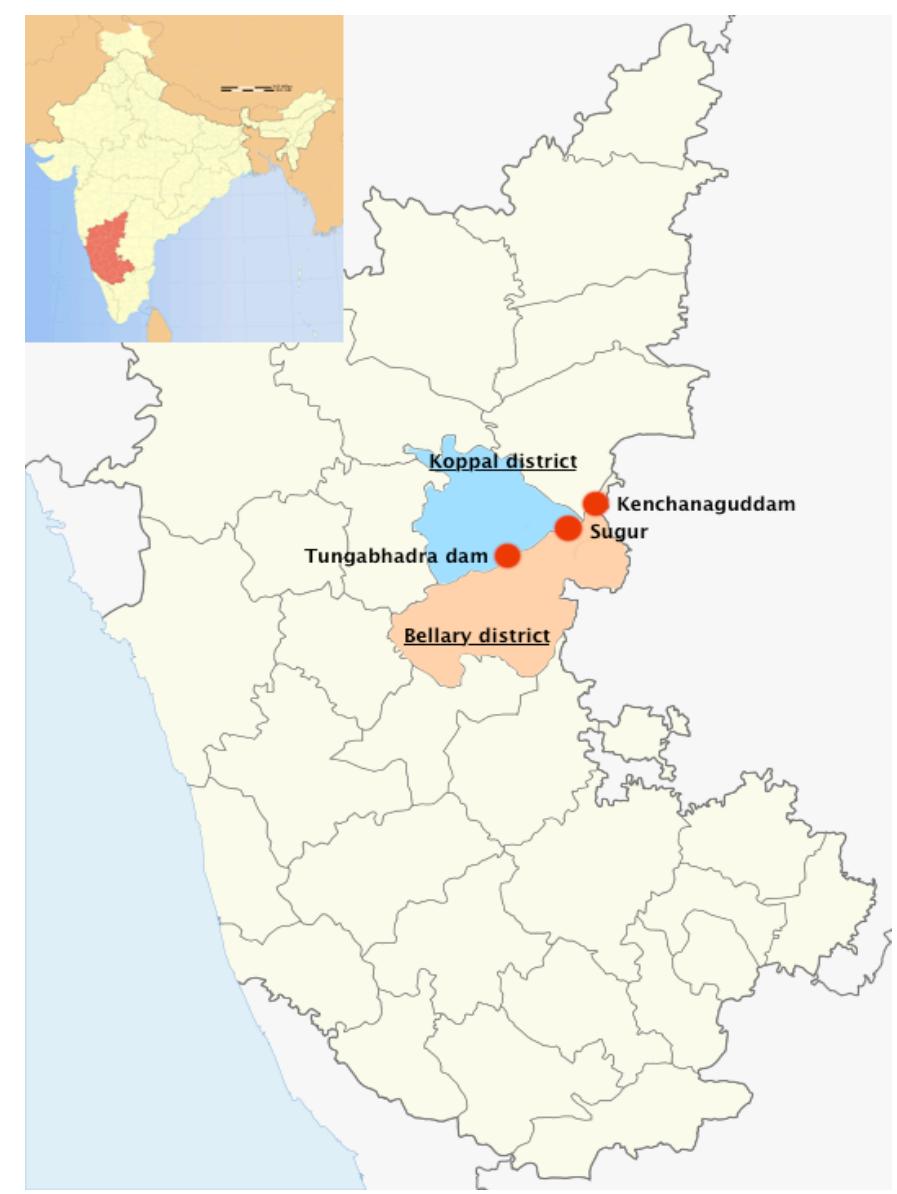

Figure 3.1: Map of India (left); map of Karnataka indicating Koppal and Bellary district with Tungabhadra Dam, Sugur and Kenchanaguddam.

\section{Overview of India's Electricity Sector and Policy Context}

The possibility for private enterprises to play a role in the electricity sector is the result of developments, which started in the 1990s. Dubash and Rajan call the year 1991 "a watershed in the history of India's macroeconomic reforms," which were triggered by a serious balance of payment crisis in 1991 (Dubash \& Rajan, 2001: 3371). The response was to initiate reforms aimed at market liberalization in diverse sectors formerly owned and controlled by the government. The extensive reforms included "measures to free currency and capital markets, reduce government controls on banks ..., [and] drastically cut back on licensing requirements for industry" (Dubash \& Rajan, 2001: 3371).

For the electricity sector the reforms paved the way for the entry of private electricity generating companies. Attracted by favorable terms and conditions, ${ }^{64}$ these so-called independent

${ }^{64}$ These included high levels of revenue guarantees to the independent power producers while the states were to bear various risks (Prayas, 2001). 
power producers (IPPs) entered into agreements with the state governments and state electricity boards. State electricity boards were important actors in the electricity sector, because they were entrusted with the responsibilities of electricity generation and supply on the state level. The response of the IPPs was indeed so tremendous that "within the first three years, different state governments signed memorandums of understandings for creating a generation capacity of approximately 90000 MW" (Prayas, 2001: 15). This is remarkable since at that time the estimated generation capacity of the entire country was estimated at only 80000 MW (ibid.: 15). But the euphoria soon ebbed away because only a fraction of the projects were actually implemented due to a combination of bureaucratic hindrances and technically and financially overstrained companies (ibid.). The IPP policy was increasingly viewed as a flawed and half-hearted approach to reforms, ${ }^{65}$ and the focus shifted to reforming the state electricity boards, in order to improve their operational efficiency and revenue collection. The demand for more comprehensive institutional reforms focusing on the state electricity boards as a key player was not new in the sector. Yet, with the adoption of competitive institutional structures for the power sector in other countries, such as the UK, Argentina, and Chile, the reforms gained momentum (Dubash \& Rajan, 2001: 3375).

The World Bank played a crucial role in reforming India's electricity sector. The Bank had been providing loans to the state electricity boards since the 1960s yet did not achieve significant performance improvements (Prayas, 2001). By the early 1990s the Bank's lending policies had embraced the so-called "Washington Consensus," the belief that development failures arose due to adverse economic policies that hindered market forces rather than because of capital shortage (Dubash \& Rajan, 2001: 3375). Influenced by the Washington Consensus and experiences of other countries with electricity reforms, the World Bank saw comprehensive privatization as the policy option to end the poor technical and operational performance of the Indian electricity sector. The first state where the Bank's reform policies were implemented was Orissa. The "Orissa model," as it came to be known, foresaw the reform of the state electricity board by unbundling the electricity generation, transmission, and distribution, and selectively privatizing these segments. Aside from unbundling and privatizing, the third major component of the model included the establishment of new institutional structures by introducing a regulatory commission (Dixit, Sant, \& Wagle, 1998).

Although the Orissa model was criticized early on (Dixit et al., 1998; Dubash \& Rajan, 2001; Kale, 2004), it had a powerful demonstration effect, since it showed that Orissa had embarked on a reform process prompting other states to follow Orissa's lead (Dubash \& Rajan, 2003). Dubash

65 Among other things, the IPP policy was criticized to favor foreign investors; to have a single focus on capacity expansions, which overlooked costs; and to offer opportunities for graft and malfeasance (Dubash \& Rajan, 2003). 
and Rajan see the "growing disenchantment with the IPP Policy" and the fact that "economic liberalization became more palatable" as important factors, which convinced states to opt for Orissa's model of reforms (Dubash \& Rajan, 2003: 177). Since 1995 many states, supported by the World Bank, have adopted some variant of the Orissa model, including large and politically significant states such as Andhra Pradesh, Haryana, Uttar Pradesh, Rajasthan, and Karnataka (Dubash \& Rajan, 2003). In 1998 the reforms implemented in different states through the Orissa model were legally recognized at the central government level. The Government of India issued the Electricity Regulatory Commission Act, which set up an umbrella framework allowing states to establish their own commissions. ${ }^{66}$ With the Regulatory Commission Act, the Indian Government recognized the significance of the reforms triggered by the Orissa model. The legislation also provided a belated template for reforms to be carried out by states that had not yet done so (Dubash \& Rajan, 2001).

The Electricity Act of 2003, including its amendments in 2007, represents the most recent effort by the Indian Government to govern the electricity sector. It replaces all existing legislation and thereby establishes an all-encompassing legal framework. The Act can be seen as bundling and continuing earlier approaches of economic liberalization. "Introducing competition in every link of the power supply chain," the main focus of the Act is seen to concentrate on increasing the commercial viability of the electricity sector (Sankar, 2004: 839). However, the Act also stimulated a renewed impetus on rural electrification (Bhattacharyya, 2006; Prayas, 2008) and the consideration of renewable energy options. According to Liming (2009), the Act marks an important legislative development toward the promotion of renewable energy sources, as it recognizes the role of renewable energy technologies for supplying power to the utility grid as well as in standalone systems. The "most important feature" of the Act concerning renewable energy, according to Liming, is the stipulation "that distribution companies must buy part of their electricity purchases from renewable sources” (Liming, 2009: 1100).

According to the National Electricity Policy, renewable or "non-conventional" energy sources comprise "mainly small hydro, wind and bio-mass" and are ascribed a role in creating "additional power generation capacity" (GOI, 2005: 5.2.20). The policy is formulated within the overall framework of the Electricity Act, which requires the provision of guidelines for the sector in the form of a National Electricity Policy. "With a view to increase the overall share of nonconventional energy sources in the electricity mix," the National Electricity Policy anticipates an important role for the private sector (ibid.). The significance of the private sector is also emphasized on the website of Government of India's Ministry of New and Renewable Energy.

${ }^{66}$ These commissions were either to be established on the basis of the central government level Act or through state level legislation as foreseen within the Orissa model. 
The Ministry is the nodal agency at the central level aiming to "develop and deploy new and renewable energy for supplementing the energy requirements of the country" (MNRE, n.d. -a). The Ministry finds that "the private sector has been attracted by these projects due to their small adoptable capacity matching with their captive requirements or even as affordable investment opportunities" (ibid.). Technical flexibility and financial affordability are thus the two features of renewable energy projects, which the Ministry highlights as particularly interesting for the private sector. It is in this line of promotion that the Ministry presents small hydro projects as "attractive business opportunities" for "private sector entrepreneurs" (ibid.). State level legislation plays an important role in detailing and facilitating this. According to the Ministry, state level governments realize "that the private participation may be necessary in tapping the full potential of rivers and canals for power generation" (ibid.).

Karnataka promotes and details its efforts in the field of renewable energy with its renewable energy policy aiming "to harness green, clean renewable energy sources for environmental benefits and energy security" (GoK, 2009). Apart from harnessing wind energy, the Government of Karnataka sees a considerable potential of small hydroelectric energy in the State and promotes its development. ${ }^{67}$ Since these efforts above all pursue participation of the private sector, the government has set up a specialized organization, Karnataka Renewable Energy Development Limited (KREDL). KREDL's main aim is to promote renewable energy projects in Karnataka through private investments (KREDL, n.d.). ${ }^{68}$

This policy context, marked by efforts towards economic liberalization, embeds the two small hydroelectric projects that will be the focus of this chapter and the following one. Facilitated by KREDL, the two grid-connected projects contribute to Karnataka's endeavors to increase the share of renewable based energy in the State's overall electricity mix through private sector participation. ${ }^{69}$ More generally, the projects also represent the outcome of reforms through which India aimed to increase the sector's performance by opening the formerly publicly owned and operated sector to privatization and liberalization.

\section{Following the Water Flow: From Tungabhadra's Dam to Sugur's Anicut}

The Sugur mini hydel plant, which will be the focus of this chapter, uses the waters of the Tungabhadra River to generate electricity (as is true of the Kenchanaguddam plant, featured in

\footnotetext{
${ }^{67}$ With $3000 \mathrm{MW}$, small hydel power is regarded as the second largest renewable energy potential in Karnataka after wind power, for which the state estimates a potential of 12950 MW. In 2009, small hydroelectric projects generated $416 \mathrm{MW}$ and by 2014 the state aims to generate another $600 \mathrm{MW}$ through small hydel projects (GoK, 2009).

${ }^{68} \mathrm{KREDL}$ also advises the government on policies regarding renewable energy.

${ }^{69}$ Karnataka aims to generate $20 \%$ of the overall electricity through renewable based energy projects (GoK, 2009).
} 
the next chapter). The Tungabhadra River is one of the major rivers in South India and a main tributary to the Krishna River ${ }^{70}$. The river is formed by the confluence of the Tunga and Badhra Rivers in Karnataka's Western Ghats. On its journey of about $534 \mathrm{~km}$ eastwards the Tungabhadra River flows through the states of Karnataka and Andhra Pradesh, its longest stretch running through Karnataka. ${ }^{71}$ It is the Tungabhadra Dam in Karnataka that forms the starting point for the subsequent analysis of civic engagement activities unfolding at a small hydel plant close to the village Sugur. ${ }^{72}$

Until 1950 there were no dams along the Tungabhadra River. This changed with the construction of the Tungabhadra Dam, a joint venture of the states of Karnataka an Andhra Pradesh. The dam is built close to Hospet, Bellary District in Karnataka damming the river on its onward journey eastwards. The Tungabhadra Dam is designed as a multipurpose dam. Apart from its two main functions, irrigation purposes and flood control, it also serves to produce electricity. ${ }^{73}$ Since the dam's construction, Tungabhadra's water is regulated by the policies of the Tungabhadra Board. This is an inter-governmental body consisting of representatives from the Central Government as well as the two State Governments. This administrative arrangement was chosen to find a balance between the competitive water interests of Andhra Pradesh and Karnataka. The Board's main responsibilities include regulation of water supply to the two states and maintenance of the dam, its reservoir, and the canals on the right bank, which serve both states. $^{74}$

With the arrival of the heavy South-Western monsoon around June and July, India's rivers start to swell. A large dam constitutes a functional demarcation point, distinguishing between the upstream catchment area and the downstream command area. Upstream of the dam all waters flowing into and down the river are to be "caught" and stored in the dam's reservoir for a controlled and regulated release from the dam into the command area. Dams are often described as "harvesting" water. Especially in view of the heavy monsoon rainfalls, this allegory describes vividly how water of a dam's catchment area is "harvested" and starts filling up the reservoir. It is a yearly spectacle when a dam's reservoir is filled to the brim and the gates are opened giving way to tons of water gushing down the dam into the command area. The moment at which the gates are or have to be opened depends on the influx of the water and the dam's and reservoir's design

\footnotetext{
70 The Tungabhadra River contributes roughly one quarter to Krishna's annual flow (Krishnan, 2008).

71 Tungabhadra runs through Karnataka for about $382 \mathrm{~km}$, then forms a border between the two states for about 55 $\mathrm{km}$, and flows another $97 \mathrm{~km}$ in Andhra Pradesh before joining the Krishna River (TB-Board, 2006).

${ }^{72}$ For a chronological overview about key events and correspondence, please see Appendix B.

73 Other functions are the development of fisheries in the reservoir and the main left bank canal.

${ }^{74}$ The Tungabhadra Dam is the starting point of two canal systems, one on the left bank and the other on the right bank of the Tungabhadra River. The right bank canal system distributes water to both states, whereas the water of the left bank canal system is distributed within Karnataka.
} 
and overall condition. ${ }^{75}$ If possible, authorities often try to parallel the opening of the dam's gate with a prestigious date. At the Tungabhadra Dam this date is set on August 15, the day commemorating India's Independence in 1947.

For a visitor of the dam this demarcation between catchment and command is nothing abstract and technical. In fact, the Tungabhadra Dam is also a tourist attraction, enabling visitors to see with their own eyes the change of the water flow. While strolling on the promenade along the reservoir's shore, one can awe at the dammed waters, which stretch out almost as far as the horizon. Turning around however, it is somewhat less obvious to grasp how exactly the huge water masses stored in the dam's reservoir are distributed in the command area. The immediate tourist attraction on the command side is the placid Nandanavana and Japanese garden with their musical fountains and light shows couched directly at the foot of the dam. Yet, the well-kept lawns, flowerbeds, and ponds are maintained by a mere fraction of the dam water. Only dull billboards inform what happens to Tungabhadra's water masses stored behind the dam. According to a precise water release-scheme, water is fed into two main irrigation canals, the left and the right bank canal, besides continuing its journey in the riverbed. It is when coming or leaving the dam site, by crossing the bridges over Tungabhadra's river bed and the left or right bank canal, that one gets a more vivid impression of how the waters are diverted over the command area.

The Tungabhadra Board regulates the waters of the Tungabhadra, but the part of the dam's command area in Karnataka falls under the jurisdiction of the State's Water Resource Department. The Water Resource Department is located in Karnataka's capital Bangalore and is assisted by local branch offices, belonging to different "zones." The Tungabhadra Command area falls under the Irrigation Central Zone and is located in Munirabad, a village next to the Tungabhadra Dam. The Irrigation Department overseeing the Irrigation Central Zone is responsible for all irrigation matters of Tungabhadra's command area within Karnataka. Its main task is to ensure and monitor the distribution of irrigation water.

Following the water flow in its riverbed, it leaves the busy dam site area with the town Hospet as its main regional centre. Onwards, somewhat $20 \mathrm{~km}$ downstream of the dam, the impressive ruins of the Vijayanagar Empire arise on the banks of the river. The Vijayanagar's legacy lasted from the mid-1400s until the mid-1700s and ruled over wide parts of medieval South India. ${ }^{76}$ Today, the Vijayanagara ruins close to the village Hampi are a well-known tourist

\footnotetext{
75 Tungabhadra Dam's reservoir was designed to have a capacity of 133 tmcft (TMC) (TB-Board, 2006). Tmcft or TMC is the abbreviation for a volumetric unit and stands for "one thousand million cubic feet." Due to heavy silt formation by 2011 the capacity is estimated to be significantly less, i.e. around $100 \mathrm{tmcft}$ (indiawaterfoundation, n.d.). ${ }^{76}$ There is a vast body of historical and archeological literature on the Vijayanagara Empire; for an introduction, see, for instance, (Stein, 1989).
} 
attraction. One can see visitors from near and far on their rented bicycles exploring the historic Vijayanagar site or enjoying a "Teppa"-trip on the river in small, nutshell-looking boats.

When following the river further downstream and leaving Hampi with its ruins and tourists behind, paddy fields stretching along Tungabhadra's banks start dominating the landscape (see Figure 3.2). The roads built parallel to the river get even more rugged and lead through small villages where people go after their daily tasks while running children, ruminating water buffalos, straying dogs, and rattling motorcycles punctuate the daily routine. Since its journey from the dam, Tungabhadra's water flow has transformed from vast water masses into a controlled and diverted flow with its scenic features coming to the fore in and around Hampi. On its journey, the flow of water has changed from being the product of an engineered marvel and a scenic tourist attraction to enabling the livelihood of farmers and peasants in the area by providing irrigation and drinking water. For these people the control of and access to Tungabhadra's waters are directly related to their lives; they depend on it.

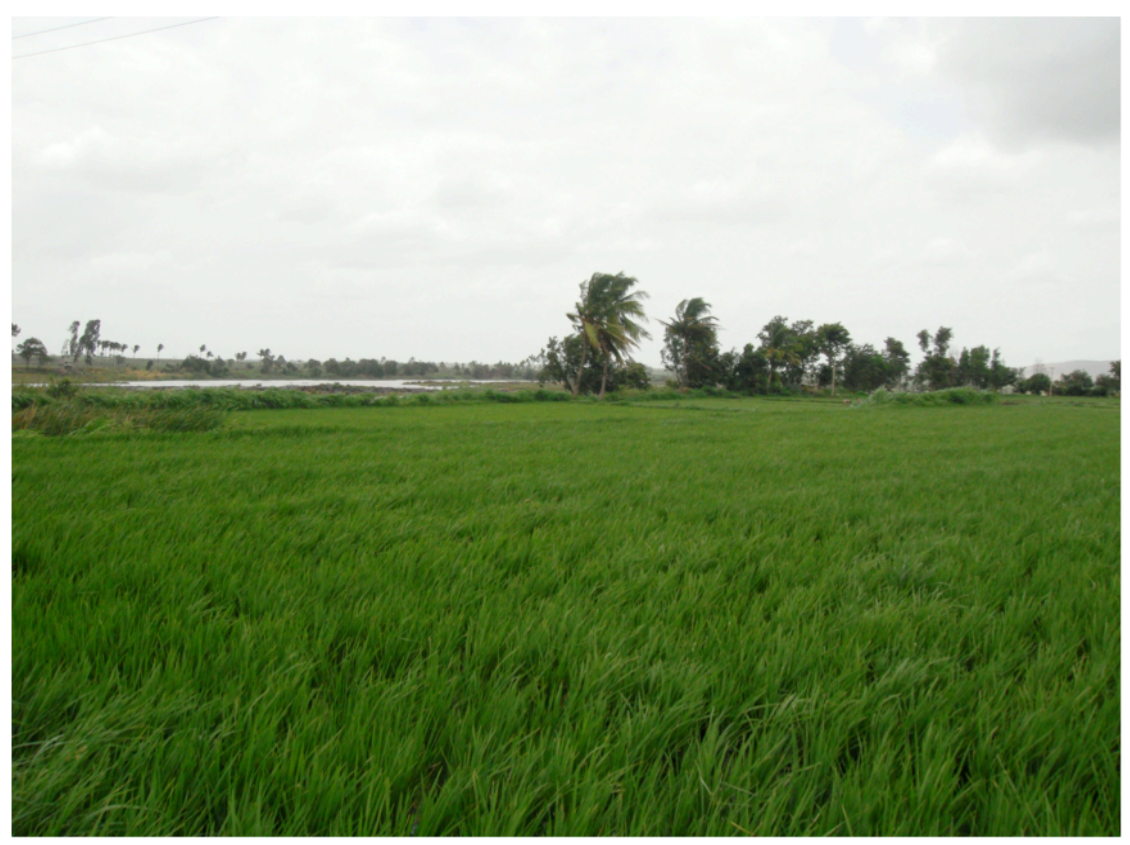

Figure 3.2: Paddy fields along Tungabhadra's shores.

About $35 \mathrm{~km}$ downstream of Hampi flanked by paddy fields along its banks, the river flow used to reach a diversion structure, called anicut, built during the Vijayanagara Empire. Today, besides temple and palace ruins in the Hampi area, a few of these curiously shaped low barriers across the river still remind one of this old Empire. In pre-colonial times these curved barriers crossing the riverbed were common and numerous (Agarwal \& Narain, 1997). The purpose of the anicuts was to slightly raise the water level thereby slowing down the river flow. Often, anicuts enabled the diversion of some of the water to a canal positioned just before the anicut. While dams are barriers blocking the water flow and creating a reservoir behind the dam, anicuts 
leave most of the river's water flowing to allow the majority of the water to spill over the structure and move downstream.

The passing of time and the flow of water had left their marks on this Vijayanagar anicut. The villages Sugur and Mannur on the right bank of the river and Bennur, Ullenoor, and Jamapur on its left bank are the main villages served by this old anicut. Originally, the anicut, stretching from one riverbank to the other, was designed to function as a check dam by slowing down the velocity of the water. Though deteriorating, the anicut still had a slowing down effect on Tungabhadra's water flow, so that it facilitated the fetching of drinking water and the installation of irrigation pump sets that pump the water to the fields inland.

It is this location that the SLS Power Industries deemed as an advantageous site for building a 4.5 MW hydroelectric plant with its powerhouse on the right bank close to the village Sugur. For the company, incorporating the crescent shaped anicut in the plant's design was of interest, as it could be used to divert water towards the powerhouse and its turbines. With the construction work starting in late 2002, the company strengthened the anicut and built an additional wall on top of it to the effect that more water was led to the powerhouse. After rushing through the turbines the water is released back to the river by being led through a tailrace canal. Rather than following Tungabhadra's water flow further downstream, we will pause at this anicut-site. By influencing the river flow, it is the shape of the anicut that proved to be the locus of contestation and the place from where the events unfolding around the Sugur mini ${ }^{77}$ hydel plant took their course. Unlike the engagement activities surrounding the micro hydel projects in Orissa, forms of engagement with the Sugur plant occur outside the project implementation frame. In fact, the dynamics of forms, contents, and consequences of civic engagement with the Sugur hydel plant are closely interlinked with the shape of the anicut, which will therefore structure the following analysis. Before beginning to describe the events unfolding at the Sugur site, however, it is useful to introduce insights derived from research on political participation. This body of literature will be helpful for the analysis of the engagement activities taking place at the plant close to Sugur, as well as those unfolding around the Kenchanaguddam hydel site described in Chapter 4.

\footnotetext{
77 There seems to be no consistent use of the classification of small hydel plants proposed by the Government of India. According to the Government, a mini hydel plant has a capacity between $101 \mathrm{kw}$ up to $2 \mathrm{MW}$. In the detailed project report of the Sugur plant, however, the plant, which has a capacity of $4.5 \mathrm{MW}$, is nevertheless called a "mini" hydel plant. Since actors and documentation about the Sugur plant refer to it as a "mini" hydel plant, I will use both terms, "mini" and "small."
} 


\section{Conventional and Unconventional Forms of Engagement}

As briefly indicated in the introduction of this book, definitions of "civic engagement" and "political participation," the prevalent term used in the political sciences, vary. The research history on political participation shows that the meaning of the concept is not static but has been informed and shaped by developments in the social context in which the studies were carried out. As a consequence, what activities are to be considered as "political participation" has changed over time. Van Deth identifies four main dimensions of political participation, which indicate the realms in which political participation unfolds. Accordingly, activities of political participation relate to voting, being involved in campaign works, contacts with government officials, and, lastly protests, including social movements (van Deth, 2003). ${ }^{78}$ These broad dimensions of political participation reflect the result of a long research history.

Until the 1960s, political participation was limited to comprising election-, party- and campaign-related participatory activities. Especially during the 1960s and 1970s a diversification of the repertoire of political activities took place. Observing these changes, Verba and Nie's influential study on Participation in America contributed to the broadening of the concept (Verba \& Nie, 1972). They argued for including participation in communal activities and engaging in direct contacts, in which citizens approached public officials to achieve a personal goal, as features of political participation. All these activities were later termed as "conventional" forms of participation.

Works by Barnes and Kaase et al. (Barnes \& Kaase, 1979) introduced the distinction between "conventional" and "unconventional" forms of political participation, which again broadened the concept of political participation. Because of the "prominence of protest in the mass politics of Western democracies during the 1960s" (Kaase \& Marsh, 1979: 27), authors took up the issue of non-institutionalized, non-electoral political action. As a result, they found that "conventional" forms of participation, as they called it, described only parts of the action repertoire falling under the concept of political participation. Different to conventional forms, "unconventional" forms of participation describe behavior that "does not correspond to the norms of law and custom that regulate political participation under a particular regime" (Kaase \& Marsh, 1979: 41). The distinction between conventional and unconventional forms will inform the analysis of the activities taking place at the mini hydel sites in Sugur and Kenchanaguddam.

\footnotetext{
78 Opinions differ whether a fifth dimension should be added, comprising voluntary activities, which have increasingly been researched since the 1990s (van Deth, 2003).
} 
Since their introduction, unconventional and conventional forms of political participation have become an accepted distinction in the literature on political participation (Gabriel, 2009). Many subsequent studies took up this distinction and developed and modified it further (Parry et al., 1992; Topf, 1995; Verba et al., 1995). One of the consequences is that the categorization, which forms of activities are considered as conventional and unconventional activities, has changed due to its application and embedding in specific social contexts. Protesting against an issue by joining a citizen initiative or a demonstration used to be seen as an unconventional form of activity in the 1970s; today it is not uncommon to identify these acts as conventional forms of participation (cf, Nohlen, Schultze, \& Schüttemeyer, 1998; Schultze, 1995).

One predominant distinction used to delineate conventional from unconventional forms of participation is made on the basis of their respective institutionalization (Kaase, 2003). Unconventional forms of participation are non-institutionalized. Kaase defines noninstitutionalized forms of actions as those that occur during a planned or spontaneous process of mobilization outside an institutionalized framework. ${ }^{79}$ Institutionalized forms of action are those that are embedded in a clearly defined institutional context, such as in a constitution or a municipal code (Kaase, 2003). Conventional forms are institutionalized or comprise activities that can be related to and accommodated by the institutionalized framework.

The ongoing research on political participation led to a further differentiation of unconventional engagement activities into legal and illegal activities (Uehlinger, 1988). The question of the legitimacy of activities, which from the outset played an important role in the analysis of unconventional engagement (Kaase, 2003), is related to this legal-illegal differentiation. As the Sugur and Kenchanaguddam cases will show, it is the legitimacy of the unconventional engagement activities, which seems to be a significant reference point for the people. Its meaning is socially constructed, by being the result of a social process, embedded in the local context.

The evolving definitions of the notions of "conventional" and "unconventional" engagement show their adaptability to and accommodation of different temporal and spatial contexts. This underpins my decision to apply them in the Indian context and thereby add to a body of engagement literature, which has mainly concentrated on the global North.

\footnotetext{
${ }^{79}$ Squatting is an example of an unconventional form of participation, which is non-institutionalized.
} 


\section{The Strengthening and Heightening of Sugur's Anicut}

With the start of the hydel plant's construction the landscape around the site changed. A "kutcha" road $^{80}$ deviating from Sugur village towards the river was strengthened and paved enabling construction machines to reach the project site. A large powerhouse ${ }^{81}$ was built and excavation blasts were executed for the $700 \mathrm{~m}$ long tailrace canal downstream of the powerhouse discharging the water back to the river (TCE, n.d.). The heightening and strengthening of the anicut stretching across the river complemented these changes on the river's right bank. With the company's construction work starting, the anicut changed from laying in broken, partly unconnected pieces into one solid cement-wall stretching across the river with a height of about 5 meters.

Five villages are located in the vicinity of the hydel plant. Administratively, these five villages fall under two different districts. The Tungabhadra River forms the district border. Whereas Bennur, Ullenoor, and Jamapur on the left bank belong to Koppal District administration, Sugur and Mannur fall under the administration of Bellary District. The focus of this analysis will be on Bennur and Ullenoor village because people from these villages were most active in their engagement activities with the Sugur hydel plant. Besides attaining administrative clearances from state authorities, SLS received permission to construct the plant from the Gram Panchayat of Sugur-Mannur. ${ }^{82}$ The company approached this body because the powerhouse situated close to Sugur village falls under Sugur-Mannur's Gram Panchayat jurisdiction. ${ }^{83}$

For people from Bennur and Ullenoor watching the construction works taking place at the other riverside, information about the plant remained vague. When they went to the site to inquire about the plant and the alterations of the anicut, the site management answered their questions only reluctantly and evasively. To prevent any further queries by the people it referred to the plant as a government project (interview Rao-I, 2009; GP Bennur, 2010). By concealing the private ownership of the project the site management aimed to discourage villagers' inquiries by building on the argument of the alleged infallibility of government projects. ${ }^{84}$

For a while this strategy seemed to be successful. Bennur Gram Panchayat members remembered "[if we had known] that the power plant was built by a private company ... [we]

\footnotetext{
80 A "kutcha road" is a ramshackle road; from Hindi kachcha, "raw, unripe."

$8131.5 \mathrm{~m}$ width $\mathrm{x} 33 \mathrm{~m}$ length and $30 \mathrm{~m}$ height (TCE, n.d.).

82 The two villages Sugur and Mannur fall under one Panchayat.

83 Besides the local Gram Panchayat level, the procedure to attain construction clearances involves state authorities such as the Irrigation Department, Pollution Control Board, Environmental Department, and Power Transmission Corporation.

${ }^{84}$ The interview accounts of local people around the Sugur site point to a deep mistrust in the private sector, while comparatively the public sector is generally regarded as more trustworthy, if clearly not without fail, as we will see.
} 
would have kept an eye on the construction" (interview GP Bennur, 2010). People from the left side began to become more skeptical about the project when the heightening works on the anicut began. Drastically heightening the anicut meant that the water flow would be altered and with it its established characteristics. In the end it was the argument of increased water storage pleaded by the plant management and leaders from Sugur village that reassured Bennur and Ullenoor people about the usefulness of the heightened anicut (interview GP Bennur, 2010). The occurrence of a drought in 2003 granted this argument even more urgency and plausibility (interview Rao-I, 2009).

In Karnataka 18 of a total of 27 districts are drought prone, so that in terms of geographical area Karnataka is India's second most drought prone state (Biradar \& Sridhar, 2009: 124). During the years 2001 until 2003 Karnataka faced a period of consecutive drought, with the year 2003 being especially severe (ibid: 124). The impacts affected the agricultural harvest in almost all parts of Karnataka, including the area along the Tungabhadra River in the Koppal and Bellary district, where the SLS company decided to build its plant. Under these circumstances the prospect of water storage due to a heightened anicut seemed an attractive option.

Yet, SLS had no government permission to heighten the anicut. In a construction approval letter, Bangalore's Secretariat of the Water Resource Department determined certain conditions under which the 4.5 MW plant was to be built. The letter addressed to the Chief Engineer in Munirabad ${ }^{85}$ stipulated that "for no reason should the height of the anicut be increased" and "the basic structure of the anicut should not be changed" (Approval letter, 2002). Yet, with the construction of a concrete layer on top of the anicut, which more than doubled its initial height, the company flouted the conditions set by the Water Resource Department.

In the beginning villagers, only being sparsely and reluctantly informed by the plant's site management, were not aware of these conditions set by the government. The combination of two main factors caused initially skeptical villagers to consent to the changes done at the anicut. First, the period of a lasting drought made the prospect of being able to store water seem very useful. Second, the trust in it being a government project convinced them about the reasonableness of the project with its heightened anicut.

So, by 2003 the anicut had been turned into a solid, small dam changing Tungabhadra's water flow when passing Ullenoor and Bennur on the left bank and Mannur and Sugur on the right bank. When earlier "the water used to flow easily down the river" (interview GP Bennur, 2010) it now hit an approximately 5 -meter high concrete wall built across the river, which diverted the water towards a newly built powerhouse and its turbines before being led back to the river. But,

\footnotetext{
85 The Chief Engineer oversees the small hydel plants built in the Irrigation Central Zone.
} 
as Gram Panchayat members from Bennur recalled, "it did not happen the way [we] expected it, that the [stored] water would be useful" (interview GP Bennur, 2010). And with the rainy season of 2004 approaching initial doubts about the anicut's height resurfaced again.

\section{The heightened Anicut}

Conventional forms of civic engagement were the predominant activities farmers resorted to when the anicut was heightened. People from Bennur and Ullenoor expressed their complaints and requests about the power plant first orally, by visiting two different types of government authorities, the local Irrigation Department and the District Authority. Visiting the authorities in person allowed people to make sure that the issue actually reached the officers, made it possible for people to express and explain the issue and its urgency more extensively, and implied that they would receive a first reaction from the officer involved.

Yet soon, conventional forms of engagement went beyond these individual contacts with government authorities. Early on, an influential person from Ullenoor, Subramaniam Rao supported the complaints and efforts by left bank farmers to receive information about the hydel project and its design. Farmers from Ullenoor had approached Rao, whose family owns a lot of land along Tungabhadra's left bank, close to Ullenoor. Rao himself lives and works in Gangavati, the taluq's ${ }^{86}$ municipal and commercial center where he runs an oil company. ${ }^{87}$ Furthermore, his appointment as Koppal District-Secretary of the KRRS underpinned his strong engagement for farmers' interests.

The Karnataka Rajya Raitha Sangha, KRRS, is the most prominent farmers' organization in Karnataka. Founded in August 1980 it is based on the belief that "the interests of urban, industrial 'India' have systematically undermined the interests of agrarian and rural 'Bharat"' (Shah, 2012: 5). On its "agricultural" agenda, the KRRS lists economic demands, which are generally addressed to the State and which mainly focus on tax, price, and subsidy issues (Mollinga, 2003: 356). As a populist rural mobilization of farmers, the KRRS has been able to draw on a large supporters' base, which cut across class and caste lines. Nevertheless, the influential Lingayat/Vokkalinga caste dominates the organization's leadership, meaning that distributional issues such as agricultural wages or interests rates on private loans are hardly addressed (Assadi, 1995; Nadkarni, 1987).

\footnotetext{
${ }^{86} \mathrm{~A}$ taluq is an administrative unit. The State of Karnataka is divided into different districts, which in turn comprise of different taluqs. The villages Bennur and Ullenoor belong to the taluq Gangavati, which falls under the Koppal District.

${ }^{87}$ Rice bran oil is the oil extracted from the inner husk of rice. 
To voice and enforce its demands the KRRS organizes mass demonstrations and protests mobilizing people and awareness. The KRRS became internationally known due to its antiglobalization agenda, which it has voiced since the early 1990s. Based on its confrontational style of protests the movement carried out a series of high-profile direct actions against Cargill, Monsanto, and Kentucky Fried Chicken, and it organized mass demonstrations against GATT ${ }^{88}$ negotiations (Pattenden, 2005). It was in the name of the KRRS that Rao began his engagement with the Sugur mini hydel plant.

In his function as KRRS District Secretary, he wrote a letter in which he officially voiced the uneasiness of left bank farmers about the heightened anicut to local government authorities in a written format. In this letter, dated 30.6.2004, Rao warned the District Commissioner (DC) of Koppal District about a possible inundation of adjacent lands due to the heightened anicut. “Therefore," Rao wrote, "you should personally visit this project and ... identify by expert opinion the area which might be submerged and to secure compensation for the farmers through your mediation. If you do not take suitable action ..., struggles will be organized under the aegis of KRRS” (Letter Rao, 2004). Through Rao's engagement individual actions were bundled and clearly placed within the protest dimension of engagement.

As a result of the visits and Rao's letter, both the Irrigation Department and the District Authorities started to attend to the matter by inspecting the site and producing reports about it. By the beginning of August 2004 the threat of submergence due to the plant and the need to act in order to avoid flooding of fields was officially recognized by the Irrigation Department. After visiting the site on August $12^{\text {th }} 2004$ the Chief Engineer stated in his report that the "height of the anicut has been raised ..., thereby water is stored in the river course. Because of this storage ... the adjacent lands are being affected and the concerned MLA's ${ }^{89}$ of the area and the affected people are urging for dismantling the anicut" (Inspection CE, 2004). As a result, he instructed "the Power Plant authorities ... should see that there shall be no stagnation of flood water in the river course at the barrage. The conditions stipulated in the Government order and the agreement entered into should be strictly adhered to" (ibid.). In view of the approaching flood induced by the opening of the Tungabhadra Dam, he set a time limit so "that the instructions issued are complied by the SLS power Plant immediately [in order to] report compliance within a week's time" (ibid.).

\footnotetext{
${ }^{88}$ The GATT, General Agreement on Tariffs and Trades, is a multilateral agreement, which covers international trade in goods. It is anchored within the institutional system of the World Trade Organization.

${ }^{89}$ MLA is the abbreviation for Member of Legislative Assembly. MLA's are directly elected representatives to this assembly on state level, which is also called Vidhan Sabha or lower house. Karnataka's Legislative Assembly has 224 members, who are elected from constituencies across the state.
} 
Yet, despite these instructions, the anicut remained unchanged. In mid August 2004 after the opening of the Tungabhadra Dam, farmlands got flooded around the Sugur site, causing just the situation of submergence Rao had cautioned against in his letter. The heightened anicut had dammed up the water flow released from the dam so that it flooded the riverbanks, entering into the paddy fields and destroying the standing crop.

While farmland close to the riverbank got drowned, left bank farmers cultivating paddy inland, away from the river, suffered from water shortage. "[Bennur and Ullenoor] people are at the tail end of distributing channel no. 36 of the Left Bank Canal. Since they are at the tail end of distribution, they do not get water from the distributory. ${ }^{90}$ So, they have been watering their fields by drawing water directly from the river using pumps. This is how the situation was in 2003" (interview Rao-I, 2009). With the flood water of 2004 damming up behind the heightened anicut pump sets installed at the riverbanks had to be removed or were flooded and could not be used to pump river water inland to irrigate the fields. Dammed by the heightened anicut, the flood thus produced two sorts of water effects: submergence at the riverbank side as well as water scarcity inland. Due to the heightened anicut, an area of about 500 acres along the river became prone to submergence depending on the duration and the volume of the water released at the Tungabhadra Dam. At the same time, the dammed water jeopardized many pump sets installed for drawing river water to irrigate the fields. Heightening the anicut thus had repercussions going far beyond the immediate riverbank surroundings, affecting also a "hinterland" area of a much larger scope. ${ }^{91}$

In response to these events, public water authorities initiated two lines of investigations about the incidents at Sugur power plant. One was employed by the Chief Engineer in Munirabad, the other line of investigation was prompted by the Water Resource Department in Bangalore. Both lines overlapped and decisions how to deal with the dispute around the Sugur plant built on each other. The request from Bangalore to inquire about the events at the Sugur plant site meant that the issue had climbed up high the hierarchical ladder. Yet, despite of this, the Chief Engineer in Munirabad reported back only six months after the Water Resource Department's instruction to investigate into the matter. In his report to Bangalore, the Chief Engineer concluded that "the approval given to the ... SLS company for setting up of a minihydel plant can be cancelled" (Letter CE, 2005). To back up this advice he made reference to earlier neglected instructions in which his office had ordered the company to promptly remove the extra height built on the anicut. However, it seemed that just as the company did not abide by

\footnotetext{
${ }^{90}$ Water scarcity for tail-enders is a well-known problem in canal irrigation. For a detailed study on water distribution in Tungabhadra's Left Bank Canal, see (Mollinga, 2003).

91 Members of Bennur's GP estimate the affected acres to be around 2400 acres. 
the orders of the Irrigation Department, so the Chief Engineer's advice to revoke the plant's permission was not followed up by Bangalore. The recommendation got lost in the long bureaucratic lines between Bangalore and Munirabad: neither of the Departments pursued the issue and the plant kept operating with the anicut unchanged.

By writing the warning letter to the DC Koppal, Rao had formalized farmers' reservations against the plant with its heightened anicut under the aegis of the state-wide farmers' organization KRRS. That he was the Secretary of the KRRS in the Koppal District resorting to this organization seemed practical and obvious. Due to his work at the KRRS he was familiar with advocacy processes of farmers' interests and interacting with authorities. Also, by formalizing the query under the KRRS Rao could make use of the organization's state-wide reputation and its large membership, which both potentially increased the urgency and leverage of the matter.

However, these considerations could not convince farmers affected by the Sugur plant who were skeptical about the KRRS' involvement in the case. Rao realized that to gain the support of the local farmers he had to distance himself from the KRRS: "The KRRS is quite a political organization [active] in various districts in Karnataka. So, if I needed the support of the farmers in my area, I had to form another organization that would fight this case. Otherwise it would have got too political" (interview Rao-I, 2009). Especially the international, national, and statewide agitation history of the KRRS was seen by the people as a burden in their own struggle, since it bestowed their efforts with a political legacy that they did not regard as helpful. Moreover, the issues at Sugur seemed too local and specific to fit into the broader agenda of the KRRS, so that an organizational detachment from the KRRS seemed sensible to Rao.

Rao formed a new organization, the Raitha Hitarakshana Samiti (RHS), an organization especially set up to fight for the farmers' interests in the Sugur case. At the end of August 2004, he founded and registered the RHS together with around 15 other people mainly from his home village of Ullenoor, which elected him president. In principle, membership was open to all people affected by the Sugur mini hydel plant, regardless from which village they came, whether situated on Tungabhadra's left or right bank. Most of the members, however, came from Bennur and Ullenoor on the river's left bank. The river demarcates not only different administrative districts, Koppal and Bellary, but, with the closest bridge across the river far beyond walking distance, ${ }^{92}$ also separates areas of life and engagement. Aside from affectedness, proximity thus influenced the memberships of the RHS.

92 Due to the rather rough roads, it takes about an hour by car to get to the closest bridge, built upstream near the town of Kampli. 
The constituency of the RHS was twofold. ${ }^{93}$ On the one hand it was composed of about 30 members, who worked lands close to the riverbank and were affected due to the submergence of their paddy land. In addition to these 30 "riverbank farmers," the RHS had a broad hold of about 200 sympathizers, mainly from Ullenoor and Bennur. These sympathizers were farmers who got affected since they could not use their pump set installations due to the water dammed by the heightened anicut. "[Pump sets] will be filled with water. We will not get water for 15-20 days. ... Earlier our problem was only for two days, before the anicut was heightened. Now it is a 15 days problem" (interview Bennur farmers, 2009). The aim of the RHS was twofold, encompassing past and future events: ensuring financial compensation for the accrued crop loss and avoiding financial loss caused by future submergence of fields. The RHS' compensation efforts for accrued loss only encompassed demands of riverbank farmers. "Inland farmers" could not demand compensation, either because they had no permit from the Irrigation Department to draw water with their pump sets, or the permit excluded any liability in case of flooding (interview Mohan, 2011). In legal terms they were thus not affected by the power plant, since they fell beyond the official conceptualization of "affectedness." Although they could not hope to receive any financial compensation, they supported the RHS because avoidance of future submergence was in the interest of both riverbank farmers and inland farmers who had pump sets installed at the riverbank (see Figure 3.3).

\footnotetext{
${ }^{93}$ In contrast to Pattenden (2005) I use the notions "farmers" and "peasants" interchangeably throughout this book. Yet, I follow his classification when he describes that rich farmers "produce a consistent surplus, which can be reinvested, and cultivate in part with family labour"; middle farmers "use a larger proportion of family labour and hover on either side of surplus and deficit, unable to invest in expanded productive capacity"; marginal farmers "are largely dependent upon selling their labour and almost exclusively use family labour" (2005: 1984). Most of the people joining the RHS were middle farmers. Farmers with land along the shore were mostly richer farmers.
} 


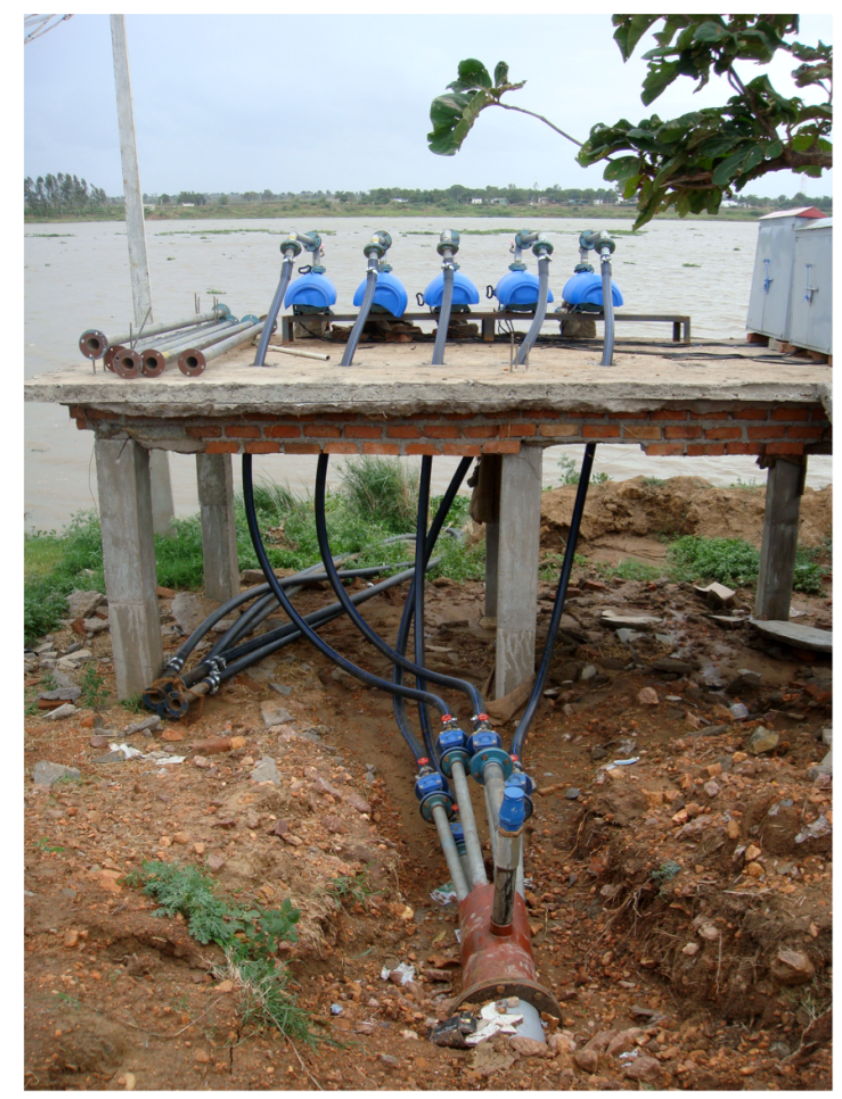

Figure 3.3: Lift irrigation pumps installed along Tungabhadra River at Bennur.

Before we move on to follow farmers' engagement activities, it is time for a recap. With the heightening of the anicut we have seen the unfolding of conventional engagement activities, beginning with visits of individual farmers to the public authorities. With Rao's letters the concerns about a possible submergence were not only formalized in written form, but also combined under the aegis of the KRRS. After the rejection of the KRRS and its legacy as the formal frame for engagement, the formation of the RHS led to the localization of the activities. The new organization offered the opportunity to concentrate the efforts locally and to detach them from any political affiliations and state-wide actions associated with the KRRS. Despite the warnings of submergence, and despite inspections and instructions of public authorities, the anicut remained unchanged, even after the flood of 2004 caused crop loss.

One of the first opportunities for farmers to express their demands was at a meeting in March 2005 between representatives from the RHS farmers and the company. Under the chairmanship of the Thasildar ${ }^{94}$ of Gangavati taluq, 31 affected riverbank farmers from Bennur and Ullenoor village and the company's managing director along with an in-house engineer came together. The inspection reports, instructions, and internal communications of the Irrigation Department had stayed within the realm of paperwork, and did not change anything in the

${ }^{94}$ A "Thasildar" is an official of the Revenue Department in charge of the collection of revenues. 
farmers' situation. The meeting, however, offered the possibility to finally undertake concrete steps to tackle the issue of compensation and address the threat of future submergence, which became increasingly urgent in view of the approaching floods of August 2005. Yet, it was only the issue of future submergence on which the parties came to an agreement. In the meeting's minutes the company committed to building a 2-3 km long wall to strengthen the river's left bank against floodwater. Most importantly, however, the company agreed to install floodgates into the anicut to release excess floodwater. The compensation of accrued loss could not be solved, even though the company generally assured that it would compensate in case of future submergence.

The installation of floodgates discussed during the meeting shows that there were two options on how to deal with excess floodwater to avoid future submergence. One option was the removal of the added concrete layer on top of the anicut. The other option was to install floodgates into the heightened anicut, which would let excess water through to avoid submergence. The Irrigation Department stipulated the removal of the added concrete layer in its inspection reports from early on, the company, however, pursued the installation of floodgates to solve the problem of submergence. While the RHS initially pleaded for the removal of the added concrete layer, during the March meeting the organization agreed to the floodgate option. Generally, the RHS' aim was to avoid submergence; whether this was accomplished by installing floodgates or lowering the anicut's height was a secondary matter, at least for the time being.

The building of the floodgates had only progressed rudimentarily when the monsoon floods of 2005 brought once again submergence and crop loss for farmers in Ullenoor and Bennur. Yet, despite the company's announcement during the March 2005 meeting to be willing to accommodate compensation claims, no payments were made. In fact, there seemed to be a prolonged interruption in communication, because none of the actors recalled decisive meetings or correspondence between the RHS, the company or government authorities after the monsoon floods of 2005.

In October 2005, Rao resorted to yet another form of conventional engagement in order to endorse RHS' interests. As President of the RHS he filed a Court case at the High Court of Karnataka. To pay for the lawyer's fee, the RHS had collected 30000 Rs $^{95}$ from its members. By October it was clear that neither of the two options proclaimed by the Irrigation Department or the company, namely anicut dismantling or floodgate installation, had actually been realized. After the heightening of the anicut, farmers had witnessed several Irrigation Department inspections during which they could articulate their complaints about it. Irrigation Department reports all clearly stipulated the removal of the extra concrete layer. Yet, the Irrigation

\footnotetext{
${ }^{95} 30000$ Indian Rupees is about 453 Euro. 
Department's instructions were not followed up and the anicut remained unchanged. The company with its approach to tackle the issue of submergence with the installation of floodgates did not meet its commitments as announced during the March meeting in 2005. The building of floodgates progressed extremely slowly and the loss accrued during the flood in 2005 was not compensated, despite earlier announcements in this regard. Farmers were left with one solid cement-wall and the loss of their Kharif crops in two consecutive seasons. ${ }^{96}$

The petition filed at the High Court of Karnataka, in which the petitioner Rao detailed the events at the Sugur site, showed how the RHS made sense of the events unfolding at the Sugur site: Rao accused the involved offices of the Irrigation Department, the District Authorities and the company of collusion. "[They] chose not to act to implement the government orders and their own orders and except assurances and meetings, no action was taken" (Petition, 2005).

By the time Rao filed the petition he had managed to acquire different official documents and orders relating to the power plant, of which the approval letter was crucial. In the approval letter different conditions were stipulated under which the plant had to be built and operated. Central was the first clause stating that "for no reason should the height of the anicut be increased" (Approval letter, 2002). By referring to the plant's approval letter and different inspection reports of the Irrigation Department, Rao endorsed the fact that the anicut was illegally heightened. In the petition Rao accused the company and the government authorities of deliberately ignoring this illegality: "[The company] being aware of the terms and conditions of the government order and also the consequences of violating it, increased the height of the Ancient dam changing its original form causing the water stagnation resulting in spreading of the river which entered the agricultural lands" (Petition, 2005). The government authorities on their part "have committed illegality by deliberately ignoring the government orders and inspection reports, being fully aware of the [company's] illegal activity" (ibid.). Rao suspected that the two government authorities were paid off by the company, since "no official would have kept quite [sic] for such a long time if they are not under political pressure and money pressure from the [company]" (ibid.). Based on these assessments Rao petitioned the Court to issue a writ, which would order the parties to comply to orders and rules, "preserve the Ancient Dam in its originality", and "pay compensation to farmers for loss caused to them" (ibid.).

I will return to the issue of corruption at a later point in this chapter and the following one. For now, it is important to highlight Rao's legalistic approach, which underpinned his engagement activities. Filing a court case was as much part of this as his initial framing of the

\footnotetext{
${ }^{96}$ Monsoon or summer crop is also referred to as "Kharif" crop. It is planted with the beginning of the first monsoon rains starting in July.
} 
activities under the organization of the KRRS and later under the officially registered RHS. The legalistic approach connected engagement to a formal, rules-based framework.

Filing the case at the Court did not induce any action on the part of the company or the government authorities. Only after nine months, in July 2006 with the floods of 2006 closing in, a meeting was held between farmers' and company's representatives under the chair of the DC. While the company had sent high-level management representatives to the first meeting with farmers in March 2005, to the second meeting a year later it sent an on-site engineer who was not authorized to take any decisions. This implied procrastination of action from the outset and endorsed the impression of unwillingness to tackle the matter decisively. During the meeting the RHS urged to undertake immediate action to dismantle the extra layer on the anicut in order to prevent the third consecutive submergence of fields, which was about to take place. And though the DC instructed the Irrigation Department to dismantle the anicut and warned with disciplinary measures if his command was not followed, the anicut remained unchanged.

Engagement activities, which unfolded when the anicut was heightened, included conventional forms, such as individual visits to public authorities, correspondence, and attending meetings. With the formation of a dedicated farmers' organization, efforts were formally concentrated and an organization endorsing the interest of farmers was established. Engagement activities took place in what the participation literature categorizes as the "protest dimension" of participation and they were significantly influenced by Rao, who followed a legalistic approach in the advancement of the RHS' interests. By 2006 farmland along Tungabhadra's shores at the Sugur site had been flooded twice, during both monsoon seasons, and despite meetings and correspondence with public authorities and the company, the anicut remained unchanged.

\section{Farmers dismantle the Anicut first}

In August 2006 protest activities changed and took the form of unconventional engagement. Frustrated by the perpetual inaction and the prospect of the approaching flood destroying their Kharif crop for the third time in a row, RHS farmers and sympathizers from Ullenoor and Bennur went to the anicut equipped with axes, mattocks, and spades. Starting from the left bank side at Bennur village, they began destroying the anicut using their hand workshop tools. They broke the top layer of the massive concrete dam for some meters until the arriving police stopped them (see Figure 3.4). 


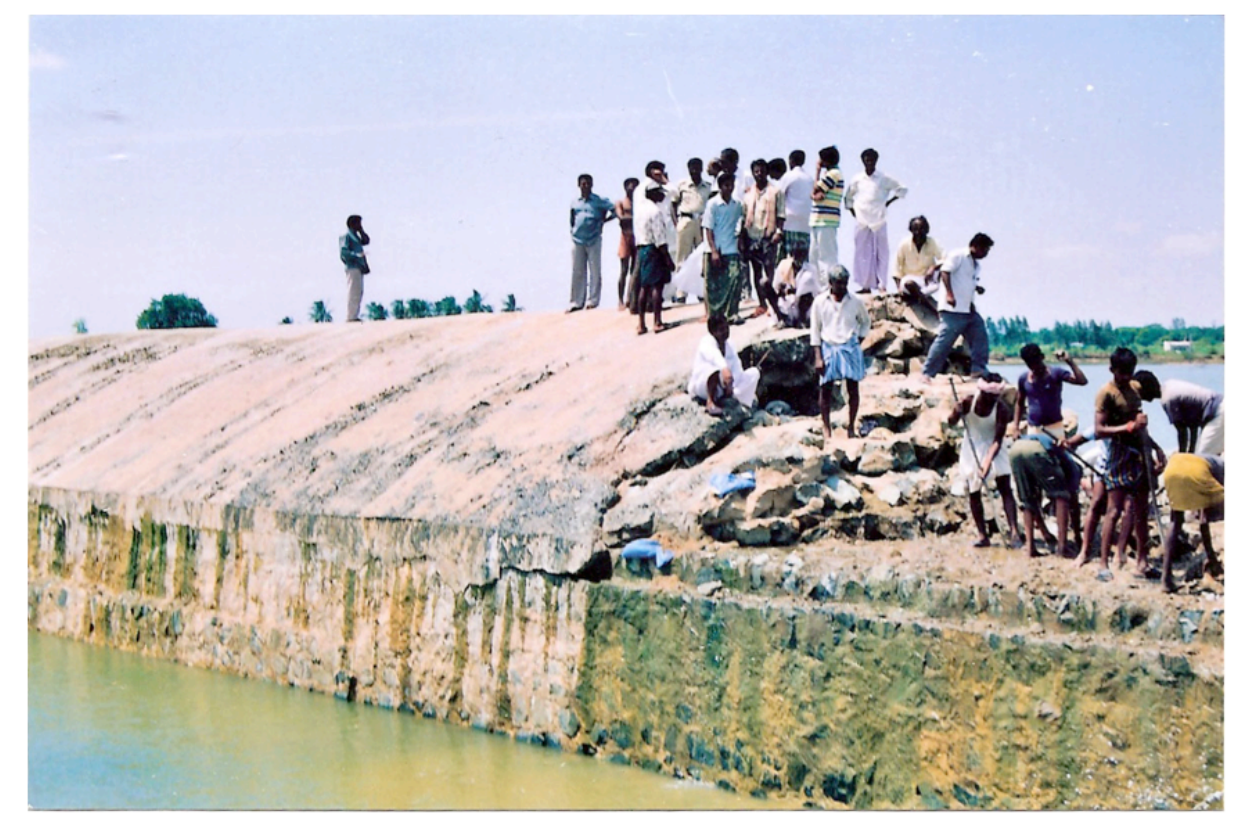

Figure 3.4: Farmers destroy parts of the anicut in August 2006. (Picture credits S. Rao.)

Rao motivated their action by referring to the illegal heightening of the anicut by the company: "They are the ones who built this illegally. What we are doing is not illegal" (interview Rao-I, 2009). Rao's statement is interesting because it introduces a frame of reference, with which engagement activities were explained. As we will see in this and the following chapters, different frames of reference will be appealed to, in order to legitimize activities. The reference to legality, as Rao did when destroying the anicut, describes one of them.

The company assessed the situation quite differently. The Managing Director wrote a letter of complaint addressed to the DC Koppal after farmers had destroyed parts of the anicut. In the letter he denied the company's responsibility for the damage caused by the floods in 2006, destroying the crop for the third time, and he referred to the exceptionally high floods that year: "You may be aware that there is excessive flood all over and especially in the River Tungabhadra where it had exceeded $2.5 \mathrm{lakh}^{97}$ cusecs $^{98}$ for no fault of us. However, the reason for the submergence is not understood by the villagers and they think as if we are responsible for the damage to their fields" (SLS letter, 2006). The Managing Director made clear that the farmers were not the only victims of this flood: "We are also suffering from reduced production due to the excessive water and the bankers are asking us to repay the loans by whatever means" (ibid.).

For the company, RHS' trespass was an act of contradictory behavior: "As if add oil to the fire the villagers of Ullenoor, near Bennur had forcibly entered our premises and began to

\footnotetext{
${ }^{97}$ In India, the number 100000 is referred to as "1 lakh."

98 "Cusecs" is a volumetric unit measuring the flow of liquids. One cusec is equal to the flow of about 28 liter per second.
} 
damage the structures. On one side these people have gone to the High Court and on the other they themselves are damaging the anicut" (ibid.).

While the company viewed the acts of destroying the anicut and filing a court case as incompatible, for RHS farmers the one did not foreclose the other. According to them, the illegality of the anicut provided the justificatory base for both forms of engagement. Just as the act of filing a petition at the Court aimed at restoring a legal situation, so did the destruction of the anicut. The destruction did not result in any penal consequences for the farmers involved. This suggests the broad level of acceptance of the RHS action, not only among the local village people, but also among the local police authorities. The police only stopped the actual destruction, but subsequently did not arrest any of those involved.

Though the company denied responsibility for the damage caused by the 2006 floods, in a report issued by Gangavati's Thasildar the submergence of 450 acres of farmland was ascribed to the power plant. For the first time, a report presented a detailed ascertainment of the damage by detailing the number of affected acres per village. The importance of the report for the RHS was that it combined damage and cause in one document. By relating detailed numbers of damage to the heightened anicut, the company was officially called to account. For Rao the report fit well within the legalistic approach underpinning his engagement efforts. Yet, neither the anicut's partial dismantling by the RHS farmers nor the official confirmation of damage and cause induced actions by either the Irrigation Department, the District Authorities, or the company.

The situation changed when in November 2006 the management of the Sugur mini hydel plant was taken over by the Bangalore-based company Bhoruka. When Bhoruka acquired the Sugur power plant it claimed not to have been aware of the depth of the ongoing problems occurring due to the floods. According to Bhoruka's General Manager of the Civil Works Department, the advantageous circumstances for power generation created by the raised anicut contributed to the decision to take over the power plant: "Based on that only, we took it. Because the head is so much and generation is so much" (interview Manager-Civil, 2010). In the decisionmaking process, Bhoruka's Managing Director explained, emphasis was put on assaying the technical aspects: "So, we got into the project report, whether generation was possible, the head, the tailrace ... But there are certain things the developer does not calculate. You do not know much about it ... like: what are the farmers' issues?" (interview Managing Director, 2010). The Managing Director referred to time constrictions during take-over negotiations, as a reason for not being fully informed about all the problems at the site. "I don't think that any company can get into all the nitty-gritty during the short time span of three to four weeks [of negotiations]" (ibid.). 
During the take-over technical details and practicalities were given priority over other considerations, such as the importance of the trustworthiness of the selling party: "You have to evaluate the seller, more than the profit" (ibid.). For the Managing Director the trustworthiness is related to the willingness to look beyond profit-making: "Responsible developers, while they like to maximize their generation and profit, they also take care of the environment and the society around. They won't like to maximize the generation at the cost of somebody, they would never do that" (ibid.). It seemed that with this statement the Managing Director intended to convey several messages: on the one hand the statement implied that the developers, who managed the Sugur site thus far, did not live up to these standards: on the other hand, it stressed Bhoruka's adherence to and promotion of these standards; and lastly, the comment let Bhoruka appear as an innocent victim of irresponsible developers.

Bhoruka puts emphasis on its image as a socially responsible enterprise. The Managing Director stressed that from the very beginning Bhoruka always sought to complement profit making with social commitment. The company's founder established the idea "that the organization should always give back to society, in the form of charitable activity" (ibid.). ${ }^{99}$

Aside from the company's history of social commitment, the Managing Director of Bhoruka Power looks back on a personal involvement in social charity activity. He helped setting up one of Bhoruka's charitable projects in connection to a power project at Tungabhadra's Left Bank Canal. "In 1990 we started a project, which got commissioned in 1991. We saw that in the rural areas, education is definitely a big challenge. So, we started a school some time in 1990 in one of our project sites" (ibid.). Being engaged in charity was for Bhoruka Power's Managing director not an aim in itself: “I won't say our charitable activities are altruism. It is not. It is always a policy of live and let live. ... If I have to be comfortable, the people around me have to be comfortable. ... I can't be comfortable in isolation" (ibid.).

When Bhoruka took over the Sugur plant at the end of 2006 the situation was anything but comfortable. Early 2007 it came to what Rao described as a "hostage situation" (interview Rao-II, 2009). Due to routine workplace-rotation a new District Commissioner had taken office in Koppal. During a scheduled plant site visit, and accompanied by Irrigation Department engineers, he was to inform himself about the situation regarding Sugur's power plant. Yet, in the last moment he decided not to attend the site inspection personally. Anxious to make the new DC aware of the situation at the Sugur site, RHS members and sympathizers forced Irrigation engineers who had come to the scheduled meeting to stay at the site. They were not allowed to

\footnotetext{
99 The growth of the company entailed a clustering and decentralization of the four different types of business activities in the steel, IT park development, gas and power sector. Today, $5 \%$ of the generated profit of the Bhoruka Group of Companies Ltd. is donated to Bhoruka's own charity organization, Bhoruka Welfare.
} 
leave until they had convinced the new DC to come and inspect the Sugur plant site personally. The hostages were released when the DC finally arrived at the scene and farmers could personally express the urgency of the matter. "Taking the engineers hostage" (interview Rao-II, 2009) was another form of unconventional engagement by RHS farmers. Detaining public officers to enforce a collective demand is not uncommon in the rural area where farmers have been reported to resort to this act especially due to water and electricity scarcity (Hindu, 2007, 2010; msn-news, 2011; TOI, 2010). In the case of Sugur farmers resorted to this action in order to make themselves heard, hoping this would elicit action on the side of the District Authorities.

Meanwhile, with the change of the plant's ownership, the installation of floodgates resurfaced as option again. Wary of the Court's involvement and eventual verdict the SLS company had stopped the works on the gates when the petition was filed at the Court. Yet, the new company placed the option again on the agenda. Investing into floodgates was considered comparatively cheaper since "there is no need to pay compensation every year. It is only the expenditure during the installation” (interview Manager-Civil, 2010).

In March 2007, soon after the take-over, the company informed the RHS in a letter about its plans to install 10 floodgates and a protecting sidewall along the riverbank. The new company management signified an opportunity for the RHS to re-endorse the unresolved issue of compensation, which the company seemed inclined to discuss. In its letter the company agreed to a meeting with "the [District] Commissioner along with Irrigation Department officials ... and with farmer's representatives to solve this issue amicably as early as possible" (Bhoruka letter, 2007).

The RHS seized the opportunity to be able to enter into negotiations by collectively preparing a compensation proposal foreseeing a "one-time compensation" payment by the company to affected farmers. The proposal was based on a scenario in which floodgates would be built into the anicut to avoid future submergence, while a one-time payment would compensate past losses that had occurred due to the plant. In the agreement the company would commit itself to pay "a ONE-TIME COMPENSATION calculated at the rate of Rs. 100 000/(Rupees one lakh only) per acre of affected land, whereafter [sic!] the President of the Samiti shall withdraw the Writ Petition" (RHS Draft Agreement, 2007, emphasis in original). By offering to withdraw the petition, if affected farmers would receive compensation, the pursuance of the petition at the Court emerged as a bargaining chip of the RHS. Withdrawing the petition also implied that the RHS discarded its insistence on lowering the anicut. In fact, in the proposal drawn up by the RHS the installation of floodgates played an integral role, since future submergence was to be avoided not by lowering the anicut but by installing floodgates. The RHS, 
then, adopted a flexible attitude with regard to the anicut's shape: rather than insisting on the anicut's low shape as an end in itself, the RHS embraced the goal of avoiding floods. This outcome-oriented position, which the compensation agreement entailed, did not undermine Rao's legalistic approach. The formal agreement between farmers and the company would indeed replace the Court's verdict but at the same time it would establish another rules-based framework backing his activities.

In this section we saw how farmers under the aegis of the RHS resorted to unconventional forms of engagement, when realizing that the activities they had engaged in so far did not induce any action. Destroying parts of the anicut and the taking of hostages were activities carried out collectively by RHS farmers in order to make public authorities aware of the illegal shape of the anicut. But neither the anicut's partial dismantling nor the hostage-taking gave rise to penal consequences. This indicates the actions' high degree of legitimacy, not only in the eyes of the people, but also in the eyes of the officials, who condoned them. This also underscores that what is considered to be acceptable behavior is locally embedded.

The frame that Rao, in the name of the RHS, invoked to justify the activities relates to the legal status of an issue. According to the RHS' president, the unconventional engagement activities were legitimated by the illegality of the anicut's shape. Invoking this normative, justificatory frame forms part of Rao's legalistic approach, which underpins the activities of the RHS, and in which anicut destruction, hostage taking, and drafting a compensation agreement are all legitimized with reference to a formal, rules-based framework. The prospect of entering into negotiations with the new plant management opened new opportunities for the RHS farmers to endorse their interests.

\section{The Irrigation Department Dismantles the Anicut, Too}

While the plant management change heralded a rapprochement between the company and the RHS, for the Irrigation Department the take-over induced a re-thinking of its approach, since it started to substantiate its long proclaimed positions with action. Shortly before the monsoon floods of 2007 were released at the Tungabhadra Dam, the Irrigation Department dismantled the concrete top-layer on a stretch of about $1 / 3$ of the total length of the anicut. ${ }^{100}$

In the Court petition the RHS had accused the Irrigation Department of accepting bribes from the company to remain inactive. Work by Robert Wade has revealed the deep-rooted system of administrative and political corruption in the context of South Indian irrigation (Wade,

\footnotetext{
100 The anicut has a length of about 300 meters.
} 
1982, 1984, 1985). Wade found that Irrigation officials have to pay for favorable posts, or pay to avoid being sent to less favorable ones. During his tenure, which lasts about two to three years, an officer "will want to recoup what he paid out to get it, plus whatever extra he has to pay to senior officers and politicians during the tenure, plus his own profit - which has to include some of what he is to bid for his next post" (Wade, 1982: 304). Irrigation officers mainly use the allotment of construction and maintenance contracts to generate the money, since they receive a percentage of the money allotted in the respective contracts. Being aware of this source of income, the elected MLA of the region, for which the irrigation officer is responsible, exercises leverage by manipulating the compulsory routine transfer of officers. In turn, the money, which the MLA receives from the officer as a payment for the transfer, finances his own electoral process.

This context embeds the statement by the new Managing Director who, too, alluded to corruption when explaining the events unfolding at the Sugur site. When asked about the Sugur case, he carefully stated: "In Sugur what happened: [the previous plant owner] wanted to maximize his generation. ... He put [the anicut] like that, so, when the floods came it submerged quite something. So, they were all up and arms.... But [the previous plant owner] managed it in a political manner, not in a technical manner" (interview Managing Director, 2010). When challenged to explain how he thought the previous plant manager managed the case in a political manner, the answer was more reluctant: "You get the politicians and all the right people and then... So people keep quiet. So, go and talk to the MLA and tell him: Don't worry, Sir... So, some way you find out some methodology or something" (ibid.). The "methodology," as the Director discretely puts it, comprises the act of bribing.

The case of the Sugur plant is different to the fairly well documented situation of corruption in the context of canal water distribution, in which influencing the transfer of office posts (by MLAs) and allotment of construction contracts (by officers) are the driving forces of the system (aside from Wade (see above), cf. (Molle, Mollinga, \& Wester, 2009; Mollinga, 2003). In Sugur, the source of the money did not stem from construction and maintenance contracts, but was established by the hydel company, which paid both MLA and Irrigation Department officers to remain inactive. The checks and balance system between MLA and officers, which holds the cycle of corruption in place in the case of canal water distribution, gave way to a constellation in which the MLA and the officers were both manipulated by the company.

The rapprochement between the new company management and the RHS changed the established relations in the Sugur case. The new management's approach to deal with the Sugur case "technically rather than politically" and to discuss the issue of compensation ended the 
relation the Irrigation Department had hitherto maintained with the previous company management and strengthened the role of the RHS. Officially, the Irrigation Department's position, which it had stipulated in diverse communications, did not change; practically, however, the Irrigation Department decided to act by following up on the stipulations it had endorsed for more than two years. Although it undertook action and dismantled the heightened anicut for a substantive part, the monsoon water released in 2007 still submerged riverbank land and caused subsequent crop loss.

Meanwhile the discussions between farmers and the new company management continued. In a letter sent by Bhoruka to the RHS, shortly after the submergence of 2007, the company detailed how it planned to tackle both the issue of past compensation claims and future submergence. With the letter Bhoruka argued for the distinction of the submergence area into two categories, "regular" and "exceptional." Only for the regular submergence area, which got flooded regularly, the company assumed responsibility. For the area that only submerged when an exceptionally high flood occurred, it referred to force majeure and thus waived any responsibility for providing future protection and compensation of accrued loss. Accordingly, the company was "ready to extend the compensation for two years to the farmers and we are not considering compensation for the year 2007 ... Also, there is flooding due to natural calamity and not just because of our power projects. Hence considering compensation for 2007 is not possible" (Bhoruka letter, 2007). The company thus made it clear that it was not willing to compensate damage following from this exceptionally high flood caused by force majeure. Future submergence was to be avoided by the installation of floodgates: "The 45 number of gates [sic!] will take care up to the level of 2.2 lakh cusecs" (Bhoruka letter, 2007). The company thus defined the regular submergence area. "After installation of floodgates we will be responsible only up to 2.2 lakh cusecs of water, over and above we will not take any responsibility" (ibid.). Accordingly, high floods exceeding 2.2 lakh cusecs and destroying farmlands fell into the exceptional submergence category and were beyond the company's liability.

In October 2007, to settle the unresolved issues of the newly acquired power plant, Bhoruka's management invited farmers' representatives of affected villages on both sides of the river - Bennur, Ullenoor, and Jamapur, as well as Mannur and Sugur - to its premises in Bangalore. Up to that time, the different forms of conventional and unconventional engagement activities that took place at the Sugur site fit rather well within the protest dimension of political participation described in the literature. ${ }^{101}$ Although engagement in the Bangalore meeting was still related to the broad framing of protest, the issues were to be settled without involving the

101 As described earlier, van Deth (2003) distills a different dimension from the body of participatory research literature. 
Irrigation Department or the District Authorities. Thus far, engagement activities had always included or were aimed at involving public authorities, but the meeting between farmers and company initiated a different approach. The failure of public authorities to contribute to a solution led farmers to turn towards the company as the sole negotiation partner to solve the problem of submergence and outstanding compensation.

And though the RHS had established itself as the main actor to fight for farmers' rights in the Sugur power plant case, RHS representatives were not the only ones to go to Bangalore. Rao explained: "From each village that is suffering there are elders from whom you should take advice. And the organization is not only depending on my opinion and ideas" (interview Rao-III, 2010). Aside from Rao as the RHS' president, 14 other people from the five affected villages went to meet Bhoruka's management. "Once all go together and meet Bhoruka and they come to a conclusion, it will be easier to convince the people in the villages back home" (interview RaoIII, 2010). In this way, a delegation of farmers' representatives from different villages not only ensured more representation of farmers' views; it was also crucial in legitimizing the outcomes of the meeting back home.

For farmers the meeting in Bangalore was a chance to finally settle the long-lasting issue of receiving financial compensation for the accrued crop loss they had suffered in four consecutive years. Their representatives entered the negotiations with a common position, which they had agreed upon beforehand: for every acre that got submerged on account of the heightened anicut, they would ask 1 lakh Rs. compensation. This position evolved from the 2007 compensation proposal the RHS had worked out and introduced in the discussion when Bhoruka took over and indicated a willingness to tackle the issue. ${ }^{102}$

Not just the issue of past compensation but also that of floodgates was discussed between the two parties meeting in Bangalore. For Bhoruka it was attractive to propose the installation of floodgates because it gave the company more flexibility in water storage and water discharge than a solid dam. By having more stored water available, more water could be let through its powerhouse and Bhoruka's electricity production would increase. In case of floods, which threatened to submerge the riverbank, floodgates could be opened to discharge the excess water. For farmers the issue of floodgates was related to the avoidance of future submergence of their fields. Bhoruka proposed to install floodgates, which would be capable of discharging a flood

102 Farmers had settled on the amount of 1 lakh Rs. by basing their proposition on the land price at the time the first submergence took place in 2004. "At that time the land value was about 2 lakh Rs. per acre. ... The reason why we agreed on 1 lakh Rs. per acre [was that] during summer we can grow crop, and we are only loosing that rainy season crop" (interview Rao-III, 2010). In the farmers' view, this was a low amount of money because over the years land prices had risen significantly, so that by 2008, when the meeting took place in Bangalore, the land value per acre had doubled. Yet, to enhance the possibility to finally receive compensation for the accrued loss over the years, 1 lakh Rs. seemed to be a reasonable negotiation position for them. 
volume of 1.8- 2.0 lakh cusecs. A demand by farmers' representatives to install floodgates with a much higher discharge of 2.7 lakh cusecs was rejected by Bhoruka earlier during the meeting. Bhoruka argued that at around 2 lakh cusecs the water carrying capacity of the river was exhausted, and water levels up- and downstream of the gates would equalize. Consequently, at around 2 lakh cusecs submergence would inevitably occur. Bhoruka planned to build floodgates taking into account this tipping point of 2 lakh cusecs when regular floods turned into high floods. Any flood volume above 2 lakh cusecs would enter the exceptional submergence area and its occurrence would lie beyond Bhoruka's responsibility.

Farmers acknowledged that before the power plant was built, fields submerged at a flood volume of around 2 lakh cusecs as well (interview Bennur farmers, 2009; GP Ullenoor, 2010; Rao-I, 2009). The previous threshold of 2 lakh cusecs at the time before the power plant was built would thus be the same after the installation of floodgates. This implied that floodgates would not result in additional benefits for farmers, because in case of flooding of more than 2 lakh cusecs farmers could not claim any compensation from Bhoruka. The additional advantage potentially gained from floodgates was thus one-sided: while the company could raise its output, there was no additional benefit for the farmers. Significantly, this shows that the farmers were not simply out to create a situation of mere coexistence, whereby the plant's existence did not interfere in the lives of the farmers. Rather than returning to a situation similar to the one before the power plant was built, farmers also wanted to benefit from it.

This explains their demand for "permanent compensation" during the meeting. Permanent compensation entailed that with every occurring flood the company was to be liable for compensating the damage. The farmers thus wanted the entire submergence area, beyond the 2 lakh cusecs threshold, to be under future compensation protection. "In this way," the RHS argued, "a compensation for the farmers' Kharif crop can be ensured and losses due to natural calamities can be avoided" (Letter RHS, 2007). The RHS' demand for "permanent compensation" shows similarities with a newer goal currently articulated by the KRRS, namely crop insurance (Shah 2012). Crop insurance aims to protect farmers financially against the risk of losing their crop and thus their income. Permanent compensation is a sort of crop insurance because it promises farmers the benefit of complete planning reliability by protecting them financially against any flood, be it a regular or exceptional one.

The Bhoruka management objected to this demand: "How can the private sector be held responsible for [something, which] comes once in a while due to nature's fury? That's a natural calamity" (interview Managing Director, 2010). Countering the farmers' demand for permanent compensation, the company's Managing Director referred not only to force majeure but also to 
the inherent unpredictability of the occurrence of high floods: "And then, we can't even predict it. If it happens once in a [while], then I cannot be held responsible for that" (ibid.). While permanent compensation would have introduced planning reliability for farmers, it would have had the reverse effect for the company, as it established unpredictable compensation expenses.

From the farmers' point of view the meeting ended somewhat ambiguous. It was agreed that floodgates were to be installed in the anicut, with a discharge capacity of up to 2 lakh cusecs. The anicut's height was decided not to exceed 4.72 meters, a variable on which the project's technical design and financial calculations were based. Lowering the height would negatively affect the generation capacity and thus the power plant's financial profitability. In contrast, maintaining this parameter by adding floodgates made it still possible to achieve the calculated output as foreseen in the project's technical and financial blueprints. Regular flooding of up to 2 lakh cusecs and subsequent compensation claims could be avoided by discharging excess water through floodgates. Although the famers agreed to floodgates, they did not reach any concession concerning their demands for permanent compensation, protecting them financially against exceptionally high floods beyond a volume of 2 lakh cusecs. Their long lasting calls for past compensation claims were finally heard, however, and an agreement about a compensation proposition was found. After a four-year struggle for compensation, for a total area of 350 acres the company was ready to pay an average amount of 1 lakh Rs. ${ }^{103}$ per submerged acre.

The conflict, which began with the increasing uneasiness farmers expressed about the heightened anicut in 2004, finally seemed to have come to an acceptable end for the company as well as for the farmers. In a letter addressed to the Executive Engineer, the RHS communicated the outcomes of the Bangalore meeting to the Irrigation Department shortly upon its return from Bangalore. The Irrigation Department, however, did not endorse the agreement, and less than two weeks later the Executive Engineer issued a notice ordering to recuperate Tungabhadra's water flow. "The additional wall built on the anicut" was to be dismantled (Notice, 2007). The notice set a clear time limit for action. If the company did not dismantle the anicut "within ten days," the Irrigation Department would withdraw the permission given to the company to operate the power plant. The notice left "no scope for letter correspondence in this regard" (ibid.). The company interpreted the issuance of the notice as implicitly rendering the arrangements agreed with the farmers in Bangalore as void.

The dismantling by the Irrigation Department showed that relations in the Sugur case had changed. The source of income, which the power plant under the former management provided for the Irrigation Department, had vanished. With the new management, a rapprochement

1031 lakh Rs. is about 917 Eur. 
between farmers and Bhoruka took place culminating in the agreement of Bangalore. By issuing the notice to dismantle, the Irrigation Department reinforced its control and re-aligned its practice with the stipulations it had issued since the beginning of the conflict. The Department thus had an interest in complying with the orders and stipulations it officially voiced since the beginning of the conflict. By excluding public authorities, the direct negotiations between farmers and Bhoruka showed that collective activism of the RHS (and) farmers took a new form. The negotiations also made clear that farmers intended to benefit from the plant, rather than being interested in the creation of a situation in which they were merely unaffected by it.

\section{The Company Dismantles the Anicut, at Last}

By rejecting the Bangalore agreement the Irrigation Department continued the course it had more actively enforced since August 2007. In the notice the Irrigation Department made its position and consequences of noncompliance unmistakably clear. While earlier stipulations by the Irrigation Department passed without subsequent action, this time the notice was obeyed. In the beginning of January 2008, though with a delay of about a month, the new company management demolished the remaining part of the heightened anicut (see Figure 3.5).

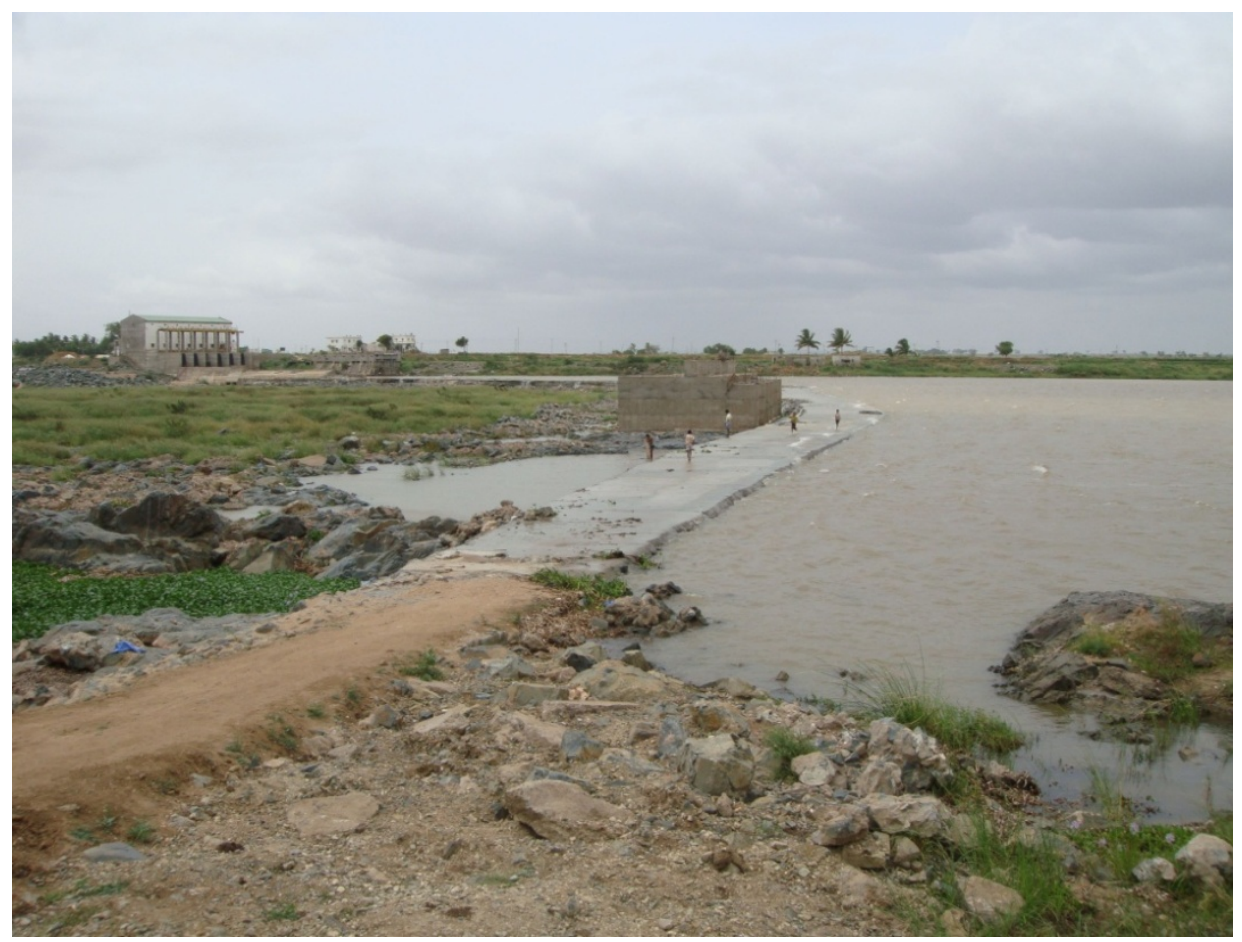

Figure 3.5: View from Tungabhadra's left bank of the anicut and powerhouse after the dismantling by the company.

Bhoruka treated the Bangalore agreement about past compensation payments and future protection through floodgates as a package deal. The dismantled anicut changed the 
circumstances under which Bhoruka had initially accepted the Bangalore agreement and thus, according to the company, rendered it void. This meant for the RHS that the issue of compensation claims returned on the agenda. In early 2008 with the anicut dismantled and the agreement annulled, the farmers turned to the Irrigation Department for compensation claims. Faced with compensation requests the Irrigation Department acted quickly to forward these demands to the company. Without reacting explicitly to the farmers' claims, with its urging letters to the company the Irrigation Department made it clear that it denied responsibility for the farmers' compensation.

In reaction to these requests, the company's management met Irrigation Department officers and farmers' representatives during a meeting at the District Commissioner's office in February 2008. During the meeting the company agreed to compensate 350 acres of land at a price ranging between 0.85 till 1 lakh Rs. per acre (Minutes, 2008). Yet, again, an agreement, which would have finally settled the issue of compensation, was forestalled. A group of farmers from the right bank downstream of Sugur village felt left out; they believed their claims relating to 80 affected acres were not appropriately considered in the proposal, which was based on the failed Bangalore agreement. Realizing the company's willingness to pay compensations, they, too, sought to seize the opportunity by demanding a compensation of about 1 lakh Rs. per acre, even though their lands lay downstream of the plant and were not submerged due to the raised anicut. As a consequence, compensation claims soared up and Bhoruka backed out of its initial commitment to compensate due to the volume of the newly tabled demands (interview Rao-III, 2010).

The unity of the farmers' position had dissolved due to the disaccord between farmers from the left and right bank who agreed to the Bangalore-agreement based compensation proposal, and a group of farmers who felt excluded. The RHS, which until then managed to represent the different farmers' interests in the Sugur case, did not accommodate the interests of a group of farmers from the right bank side, which claimed compensation for land located downstream of the power plant. With the emergence of a new set of interests, the collective negotiation position hitherto upheld through the engagement activities in negotiations with third parties fell apart.

Bhoruka used the disaccord by farmers to again procrastinate the compensation issue and instead introduced the acquisition of farmland as a new issue into the discussions. The company indicated its willingness to purchase the lands, which were prone to be submerged by regularly occurring floods up to 2 lakh cusecs. The blatantly different views on the value of the land became clear when the company's offer to pay 2.5 lakh Rs. per acre was rejected by the farmers, who demanded 10 lakh Rs. per acre (Minutes, 2008). In cases of land acquisition, Bhoruka takes government indications on land value as basis for price negotiations. "But that is all the basic. 
Every farmer will take an advantage of that because we are private people. So, they try to extract more money." Bhoruka feels that the farmers often have unrealistic expectations about the company's financial scope during negotiations. "We have some limitations. Somebody asked 10 lakh per acre! But our limitation is four, five, or six lakhs. So, we have to see that also" (interview Manager-Civil, 2010).

The February meeting ended without any concrete decisions or action points. The DC who presided it merely stressed the importance to settle past compensation claims and offered his support for the lawful acquisition of farmlands once farmers and company had come to an agreement on the price.

According to Bhoruka's General Manager from the Civil Department, negotiations with farmers have become more complicated, since "nowadays, slowly, people are getting more aware about what is happening around them" (interview Manager-Civil, 2010). Education is seen to play a key role in this trend: "They have become more knowledgeable and more interested. Now, a farmer has at least one son who is literate. This son is studying in a good place. And then he knows all what is happening. Then he will interfere" (ibid.). As a consequence of this increased education, young people have become more self-reliant and have gained more confidence regarding decisions about their property. "[The young, educated son] has got his own ideas. And he has got the right of the property, he is a stakeholder in that" (ibid.). And while their voice gained influence, the leading role of other institutions diminished. "See, earlier, what was happening 10 years ago, the farmer was listening to the local Panchayat, all these leaders. ... But today it is not like that. There is a new generation" (ibid.).

For Bhoruka this meant that the company had to change its strategy in negotiations about setting up power projects. "[Earlier] if we had convinced the Gram Panchayat leader, [and] he would have convinced the farmer. [Yet, nowadays] the villages' Gram Panchayat is unable to convince the people" (ibid.). Accordingly, Bhoruka has to conduct more negotiations with more parties, which takes more time, while "[earlier] it was very easy and within a short time we used to complete everything" (ibid.).

Increasing bureaucratic requirements for the setting up of a hydel projects also contribute to the longer time span between project initiation and commissioning. "There are so many meetings, so much involvement from the government...For a project you require permission from the Panchayat, permission from the village people, permission from the Irrigation Department, permission from the Forest Department... So many things are there" (ibid.). This statement is in line with recommendations of a recent World Bank study about Unleashing the Potential of Renewable Energy in India (WB, 2010). Apart from problems of financial viability and the 
lack of functioning support infrastructure, the report identifies bulky regulatory approval mechanisms as one of the three main barriers to unleash the potential of renewable energy. To overcome regulatory hurdles the World Bank recommends to "streamline bureaucratic processes for clearances and approvals through the use of light-touch regulation" (WB, 2010: 10). Lighttouch regulations include "accelerated environmental and social clearances and package deals" (ibid.: 12).

This might ultimately also ease and speed up social interactions, involved when starting a project. Similar to the initiating phase of micro hydel projects described in Chapter 2, Bhoruka's General Manager-Civil describes the first encounters in the process of the establishment of a power plant as very time-consuming, requiring delicate and strategic behavior. "First you have to study them. If you come straight from Bangalore from this company ... with all the researchers, then it never matches their mindset. So, we have to become one of them" (ibid.). The way Bhoruka's engineers try to do so is by "meeting frequently, talking casually" (ibid.). The aim in these encounters is to "make them understand what we are doing; how it helps the society, how it helps the state, how it helps the country" (ibid.). Building trust thus provides the basis for convincing the people about the usefulness of the project, which goes far beyond the local setting, by contributing to the development of the Indian nation. Skill is required in these first encounters with the people, which last about three to four days. According to the General Manager-Civil, not everyone can do this: "most project developers show their smartness, [but] that will not work in the rural sector" (ibid.). In his view, combining sensitivity, strategy, and skill will finally lead to a successful project. "Who succeeds to do that will start the project easily. But who fails in that he will put himself and the company into complications" (ibid.). This is why Bhoruka's Managing Director emphasizes that "by and large we don't believe in buying completed power stations. We believe in doing it ourselves" (interview Managing Director, 2010). This enables Bhoruka to stay in charge of the project's implementation and design. At the same time this statement also enabled Bhoruka to shift the responsibility of the social complications caused by the Sugur plant to the previous plant management.

After the failed meeting in February the RHS submitted the request for compensation payments again to the Irrigation Department, which in turn, forwarded the requests to the company. The issue remained pending until Bhoruka communicated to the government authorities as well as to the RHS that "consideration of the compensation to the farmers will be taken up only after the court verdict" (Bhoruka letter, 2008). Thus Bhoruka managed to disengage itself from the compensation discussions by making its actions dependent on the Court's ruling. This effectively adjourned the issue of compensation payments indefinitely. In 
response to the unsuccessful price negotiations with the farmers, Bhoruka indicated that it would base its eventual compensation payments on official records from the Revenue and the Irrigation Department, ruling out the possibility to come to more individually negotiated compensation agreements with farmers, as was the case in the Bangalore agreement or during the February meeting in 2008.

With the issue of compensation payments put on hold, the anicut's original height became prominent in the conflict. For farmers the anicut's height is crucial because it determines at which flood volume farmland along the riverbank will be inundated. Before the power plant was installed, fields got flooded at about 2 lakh cusecs. Consequently, the final decision - that the additional part of the anicut had to be demolished - received careful attention from the farmers.

The question of the anicut's original height was hardly a new point of discussion, however. Since the beginning, the RHS had questioned measurements by the Irrigation Department determining the anicut's height at seven feet. ${ }^{104}$ Rao explained the wrong measurements of the Irrigation Department by referring to the anicut's particular shape: “The anicut was built in a Ushape. At the sides of the river it was seven feet and then the height decreased to four feet right in the middle. ... But the engineers say it is seven feet because towards the right side [of the river] they found ruins of the anicut that were seven feet ... [So,] engineers think that it was a straight structure of seven feet across the river" (Rao-III, 2010). Just as the Irrigation engineers, the project report detailing technical and financial aspects relating to the Sugur power project, too, assumed a straight structure, yet, with an even higher crest level. "The crest level of the existing anicut is [determined at] approximately EL ${ }^{105} 375$ m" (TCE, n.d.: 10). A consequence of this complex circumscription of the anicut's height was that the actual height of the anicut was not directly evident by only consulting the report. Only when knowing the elevation of $369.98 \mathrm{~m}$ at this stretch of land, it became clear that the report and all the calculations relating to the power plant started from a five-meter high anicut.

Even though the anicut was dismantled following the notice issued by the Irrigation Department, according to the RHS the anicut was not yet back to its original shape. Established by the Irrigation Department's measurements, a height of seven feet had been used as the benchmark. Consequently, in its letter from March 2008 the RHS urged the Irrigation Department to ensure that the anicut is brought back to its original condition, which Rao, in the name of the RHS detailed as followed: "When the anicut in 2002 is recalled, the anicut was seven feet tall at the river banks and four feet tall (371.20 EL) on the inside and crescent shaped and in

1047 feet are equal to $2.13 \mathrm{~m}$.

$105 \mathrm{EL}=$ elevation. 
order to prevent accumulation of silt at the bottom and behind, sluices were present and on the left side the anicut was crumbling" (RHS letter-a, 2008)

Studying the design of traditional anicuts formed part of Krishnan's engineering analysis on tank and irrigation systems in South India (Krishnan, 2003). Krishnan put the curious shape of anicuts in connection with the problem of dealing with sediments, which are carried along by the water flow. ${ }^{106}$ In particular, she argued that "having depressions in the crest" enhances the ability of sediment transport (Krishnan, 2003: 40ff, 143), also (Krishnan \& Veeravalli, 2006). Krishnan's findings corroborate the description Rao gives of the anicut before the company heightened it. Serving as a check dam, this U-shape design allowed for sediments to be transported downstream, while at the same time slowing down the water flow. The detailed project report defined the shape of the anicut as a $5 \mathrm{~m}$ high structure. This clearly contrasts even the basic characteristics of anicuts as being water diversion structures rather than small dams (Agarwal \& Narain, 1997).

In order to determine the original height of the anicut the RHS had long been demanding to consult government records, yet the Irrigation Department denied possessing any records relating to the anicut's shape (interview Rao-I, 2009). Consequently, in March 2008 the RHS wrote the Chief Engineer in Munirabad to determine the anicut's features by comparing gauge data of the last 35 years taken at Ullenoor. By requesting the re-calculation of the benchmarks the RHS hoped to confirm the parameters of $7 \mathrm{ft}$ at the outside and $4 \mathrm{ft}$ on the inside, because with this shape of the anicut "even a flood of 2.2 lakh cusecs ... only [caused] minor losses" (RHS letter-c, 2008). The straight height of seven feet, however, entailed submergence of farmlands close to Ullenoor and Bennur "even when a flood of only 1.7 lakh flows in the river" (ibid.). And though the company confirmed about three months later in a letter that "demolition of the Anekatte is under progress" (Bhoruka letter, 2008), the works were not carried out.

Rao stopped pursuing the issue vigorously because the straight height of seven feet turned out to be beneficial for farmers. "Because right now, the pump sets are being helped by the slightly raised height" (interview Rao-III, 2010). Since then, the struggles at the Sugur site have calmed and even though the RHS "is still active, we are not working right now" (interview RaoIII, 2010). With the current height profiting the farmers, Rao saw no reason in further pursuing the issue. This points to another frame of reference invoked to justify actions: the benefits of the slightly raised anicut justify the disengagement of the RHS from the issue.

"Now the only thing that is pending between us and the company is the compensation, and that is in the court" (ibid.). By 2010 the president of the organization had decided to leave the

${ }^{106}$ Many irrigation structures deteriorate due to deposits of sands, which do not get transported down the water flow but clog the scheme. 
remaining issue of compensation, for which the RHS had been fighting since 2004, to the discretion of Karnataka's High Court.

After the Irrigation Department's notice had induced the third stage of the anicut's dismantlement by Bhoruka, the anicut's height and shape came to be central in the engagement activities of the RHS. The focus on the anicut's shape was also due to the fact that Bhoruka outsourced the compensation questions to the Court's ruling. The cause for Bhoruka to resort to this move, which effectively stalled all compensation claims, was triggered by the discordance of farmers' interests. During the February meeting of 2008, the united position of “the farmers" on compensation demands broke because of differences between farmers who supported the Bangalore-agreement based compensation proposal and those who did not.

The focus shifted to the anicut's height, about which Rao in the name of the RHS corresponded with the Irrigation Department. According to the RHS, the anicut, despite several rounds of dismantlement, was not brought back in its original condition. However, when it became clear that the current height of the anicut benefited the farmers, the RHS' engagement in the form of letter correspondence stopped.

References to benefits that a certain situation creates relate to the frame of legitimacy. Apart from referring to legality, legitimacy thus serves as another normative frame invoked by the RHS to legitimize its actions. Rao's legalistic approach, which he followed during the conflict, made way for other justifications, which underpinned the conduct of the RHS in the conflict. The legalistic approach was thus not a matter of principle but a flexible approach, which was abandoned when other considerations about the situation were regarded as more beneficial for farmers.

\section{Conclusion}

In this chapter I argued that protests unfolding in response to the Sugur hydel plant took the form of conventional and unconventional engagement. Within this scenario of protests, Rao played a crucial role in organizing civic engagement under a newly formed farmers' organization. Formalization of activities under the RHS, or the demand for permanent compensation are examples of how the KRRS influenced the organization and objectives of RHS' engagement activities. Yet, while it is generally the state that is addressed by the KRRS to provide supportive measures for farmers, for the RHS the company was the main addressee of their demands.

Due to the general neglect of public authorities to decisively engage in the case, the RHS turned to a new form of interaction, in which it decoupled its efforts from public authorities. The 
agreement of Bangalore foresaw a solution to the issues, yet its coming into force was forestalled by the Irrigation Department's notice to dismantle the anicut. The role of the Irrigation Department was underpinned by two approaches during the conflict, which both were not oriented towards taking up the interest of the local people. Irrigation officers first remained inactive and indecisive about the conflict since this behavior ensured them kickbacks. After the management change, and the end of the bribes, they enforced the dismantling of the anicut according to what they considered to be the original level and subsequently took a hands-off approach.

In the beginning of the conflict, activities comprised different forms of conventional engagement, which were later complemented by unconventional forms of engagement. Though unconventional engagement in the form of destroying the anicut or taking hostages conflicted with formal laws, they possessed a high level of legitimacy in the eyes of the local people. This shows that legitimacy, rather than an abstract given, is the result of a social process that is locally embedded. Actors appealed to normative frames of reference to justify their engagement activities. The RHS, with Rao as its spokesperson, invoked legality to legitimize their unconventional engagement activities. Overall, this fitted into Rao's legalistic approach underpinning the engagement activities, which all had reference to a formal, rules-based framework. Towards the end of the conflict the unitary negotiation position of farmers broke, which went hand in hand with the adjournment of the compensation payments by Bhoruka. Subsequently, engagement activities shifted to correspondence about the anicut's height, before Rao decided to leave the issue due to its beneficial effects for farmers. By pointing towards the beneficial situation the slightly raised anicut brought about, a new frame of reference was invoked, with which Rao justified the organizations' disengagement from the issue and which is tied to the frame of legitimacy. The following chapter will show that legality and legitimacy are not the only frames of reference actors appeal to in order to legitimize their forms of engagement.

The content of the conventional and unconventional engagement activities unfolding around the Sugur Mini hydel plant revolved around issues related to water. Compensation payments, the installation of floodgates, and the anicut's height - all were related to Tungabhadra's water flow, which was changed by the establishment of the power plant. This is surprising because at the outset one would expect engagement activities related to hydroelectric power plants to be related to issues of electricity, for example including its quality, pricing, transmission, or distribution. The demand for permanent compensation or the acceptance of a slightly raised anicut show that in this case the farmers did not merely expect a project to blend into the surroundings without 
further interference. In fact, they expected that the plant provided them with benefits. These are related to the issue of water rather than electricity. Having a longer water availability or receiving a standard compensation in every case of submergence constituted desirable benefits of the plant for the farmers. Benefits brought about by a hydel plant also figure in the next chapter, in which civic engagement activities unfold in and around the Pusala mini hydel plant near the village Kenchanaguddam. 


\section{Chapter 4}

\section{The Kenchanaguddam Mini Hydel Plant}

\section{Introduction}

About $20 \mathrm{~km}$ downstream of Bhoruka's power plant close to Sugur, Tungabhadra's waters are again used for the generation of electricity. The company Pusala Power Projects Pvt. Ltd. built a $6 \mathrm{MW}$ hydroelectric plant on the river's right bank in Bellary District. Close to the plant is the village of Kenchanaguddam, which is located about $2 \mathrm{~km}$ inland. Apart from obtaining the permissions of the relevant State government departments, Pusala acquired the permission to build the plant from the Gram Panchayat (GP) of Kenchanaguddam village, which holds the local jurisdiction of the area. Subsequently Karnataka's Water Resources Department authorized the building of the power plant near Kenchanaguddam in 2002, while in 2005 the plant was commissioned.

Compared to the situation in Sugur we will see that in the Kenchanaguddam case farmers' interests pursued with different forms of engagement are more divergent. The farmers' respective location with regard to the plant's site plays an important role in this. Thus, in this chapter I follow a multi-sited approach to analyze forms, contents, and consequences of civic engagement. This is echoed in the structure of this chapter, in which civic engagement will be analyzed per location. Accordingly, the analysis starts in Kenchanaguddam, then moving downstream to look at the situation in Vinaknagar Camp and Deshnur Village, before returning again to Kenchanaguddam. In this case, like in Sugur, anicuts will again figure prominently. Due to their complex siting, the importance of the different village locations, and Tungabhadra's branched water flows, I included photos in order to enhance comprehensibility of the case.

In this chapter, the analytical categories introduced in Chapter 3 will be put under tension. We will see how engagement activities in Kenchanaguddam and its surroundings lead to a distortion of the concepts of conventional and unconventional engagement with the analytical result of the emergence of hybrid forms. In the Kenchanaguddam case, engagement activities lead to different forms of disengagement from the mini hydel plant. I find that references to legitimacy and justice are invoked, which provide normative frames for the people to justify forms of engagement and disengagement.

Different forms of disengagement occurred only after engagement activities had taken place, 
which all revolved around the flow of water. Just as in Sugur the installation of the hydel plant changed the local water flow, yet with different consequences for the local people in Kenchanaguddam and its surroundings. Engagement activities in and around Kenchanaguddam revolve around water, but also around money. As we have seen in the Sugur case, compensation payments figured centrally in the activities organized under the aegis of the farmers' organization RHS, yet the mini hydel plant built close to Kenchanaguddam raises different financial queries.

The context in which I carried out my interviews about civic engagement in and around Kenchanaguddam was often very tense. A lot of the interview accounts are permeated by mistrust and anger, or my interviewees were very reluctant and cautious. In most of the cases this can be explained by the existence of a powerful farmers' lobby, which significantly influences forms of engagement and disengagement taking place around the Kenchanaguddam mini hydel plant.

In a way the complexity of the Kenchanaguddam case is a reflection of the complexity of Indian (rural) society, which I do not claim to be able to penetrate completely. Having said this, the case offers a condensed peek into some of the varied facets that characterize rural society, as well as complements those we have already come across in Orissa and in Sugur.

\section{Layout of the Pusala Plant}

In the construction of its plant, Pusala made use of a series of existing, old diversion structures, or anicuts - built during the Vijayanagar Empire - to divert Tungabhadra's waters towards its powerhouse. The Gangammana anicut near the powerhouse is the last of a series of 7 successive anicuts, built along a stretch of about $2 \mathrm{~km}$ upstream of the powerhouse. Even further upstream before the beginning of the anicut series, Tungabhadra's riverbed becomes veined, splitting into three main arms. The right arm splits again into three smaller arms at a distance of about $2 \mathrm{~km}$ away from the powerhouse. It is at this second bifurcation that the anicut series starts (see Figure 4.1). By strengthening the existing old anicuts, which were "dilapidated and leaking profusely" (TCE, 2003: 21), the water was diverted toward the righter arm along which Pusala built the power plant. As a consequence of the strengthened anicuts, the left and middle arm receive less water since they divert the water flow toward the right arm. 


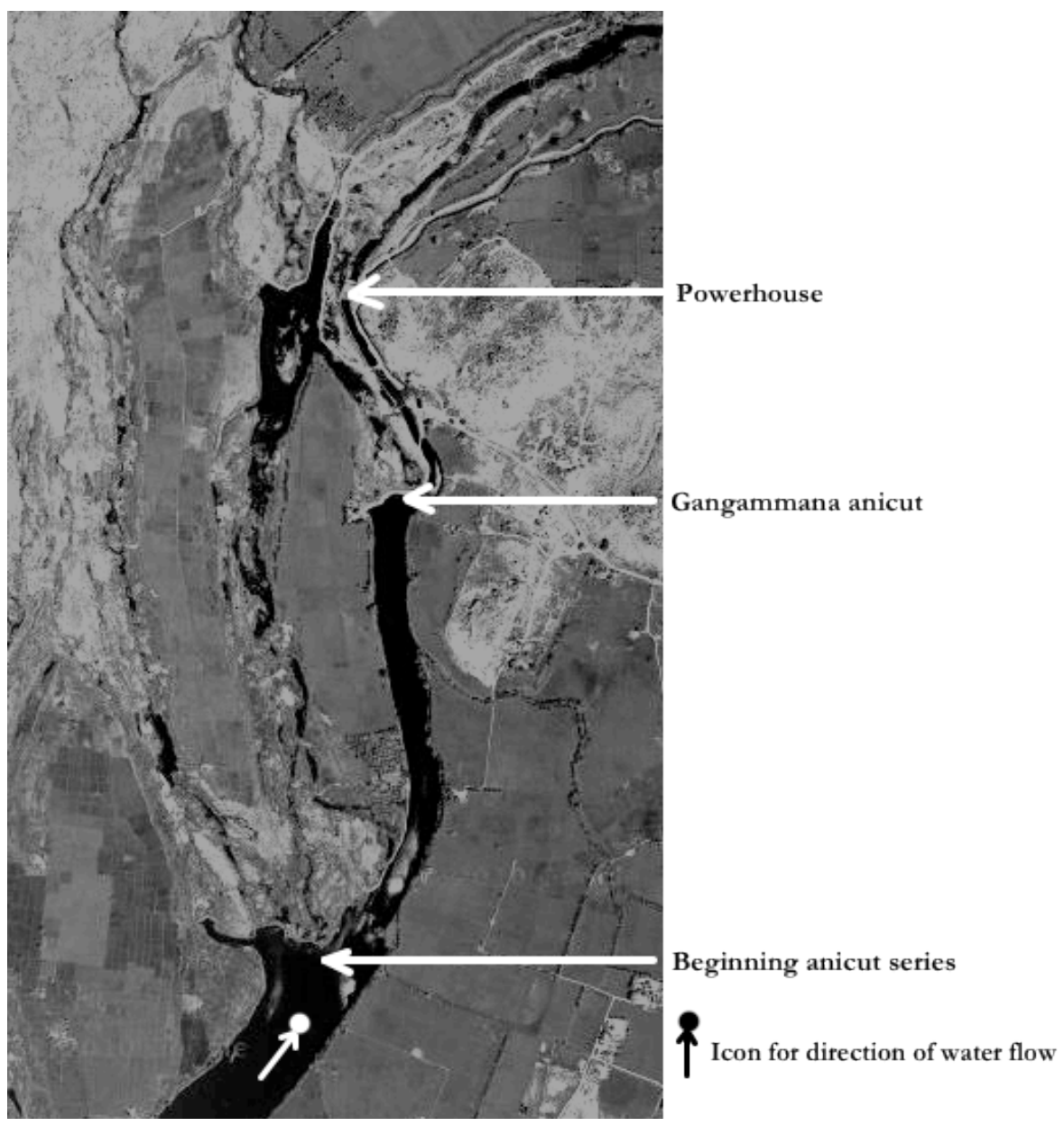

Figure 4.1: Bird's-eye view of Tungabhadra's three arms and built infrastructure. (All bird's-eye pictures are adapted from Google Earth.)

The Gangammana anicut is the closest to the powerhouse and Pusala used it to divert the water into an about $380 \mathrm{~m}$ long intake canal before the water reaches the powerhouse, runs through the turbines and is released back into the river. The water inlet of the plant's intake canal is built right next to the inlet of an irrigation canal, the Sirguppa canal. Just downstream of the plant another irrigation canal departs, the Deshnur canal. Deshnur canal and Sirguppa canal are referred to as the "Vijayanagara Channels" and are part of the "Medieval irrigation systems of the Tungabhadra River with Sirguppa Channel on Right Side and Deshanur Channel on left side" (Department, n.d.: 1). Not without pride is it mentioned that "work [on these Vijayanagar Channels] was taken up during 1509-1530 A.D. in the regime of reputed king of Vijayanagara Sri Krishnadevaraya" (ibid.: 1). Both irrigation canals are still in use today.

Due to the strengthened Gangammana anicut, more water is diverted toward the river's shores where the inlets for the intake canal of the plant as well the Sirguppa canal are located. The irrigation canal runs parallel to the plant's intake canal for about $380 \mathrm{~m}$ before it bends inlands heading toward the taluq's capital Sirguppa (see Figure 4.2 and 4.3). 


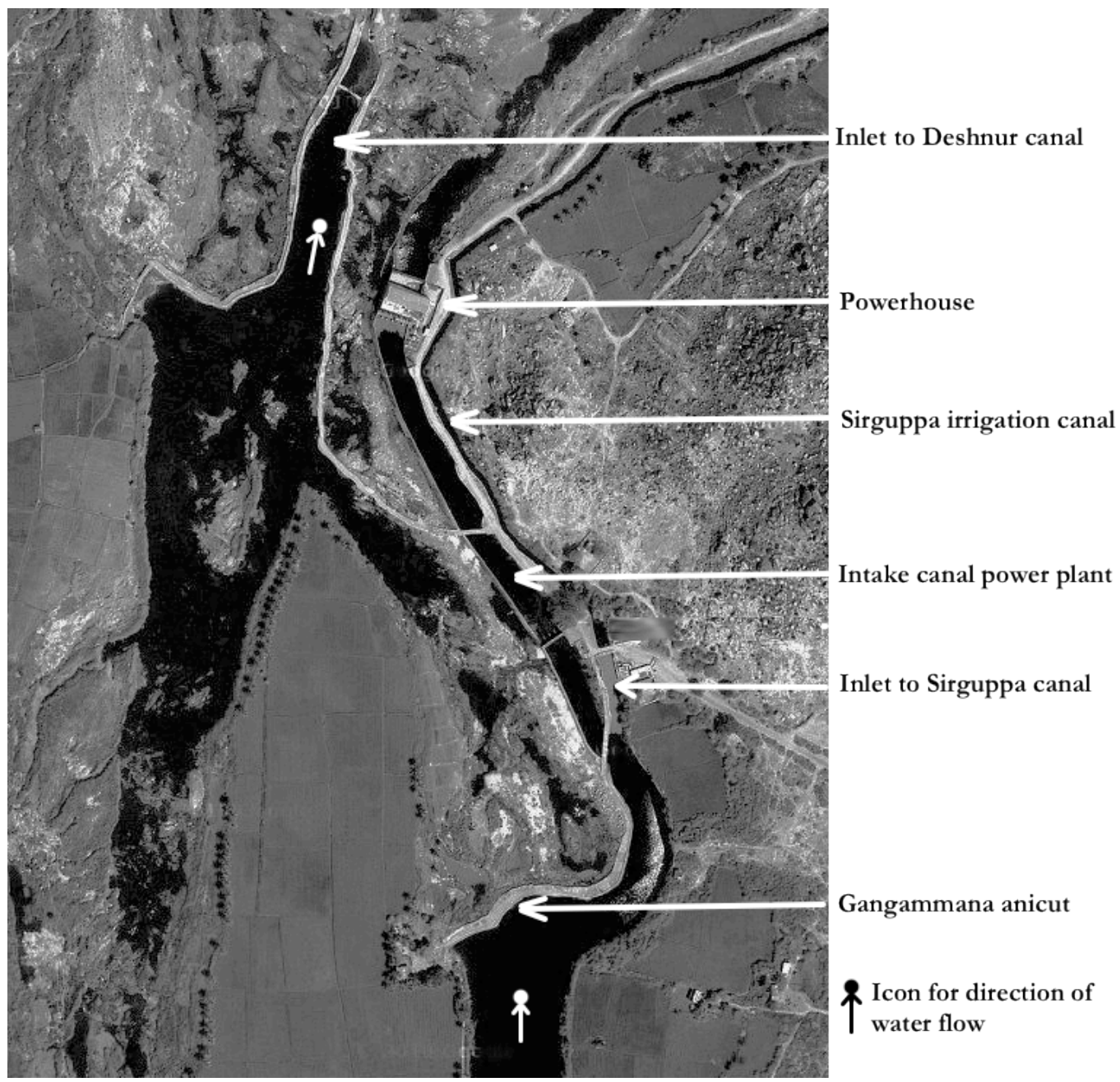

Figure 4.2: View from above displaying Tungabhadra's (dark) waters as well as built infrastructure at the Kenchanaguddam plant site.

Compared to Bhoruka, Pusala Power Projects, based in Hyderabad, is a small, family-run company with only a couple of small hydel projects, which are managed by father and son. Whereas an in-situ manager who lives close to the powerhouse is responsible for the day-to-day business and supervision of the Pusala plant, its general and executive management takes place in the head office in Hyderabad by the Managing Director and his son in the function of Executive Director. 


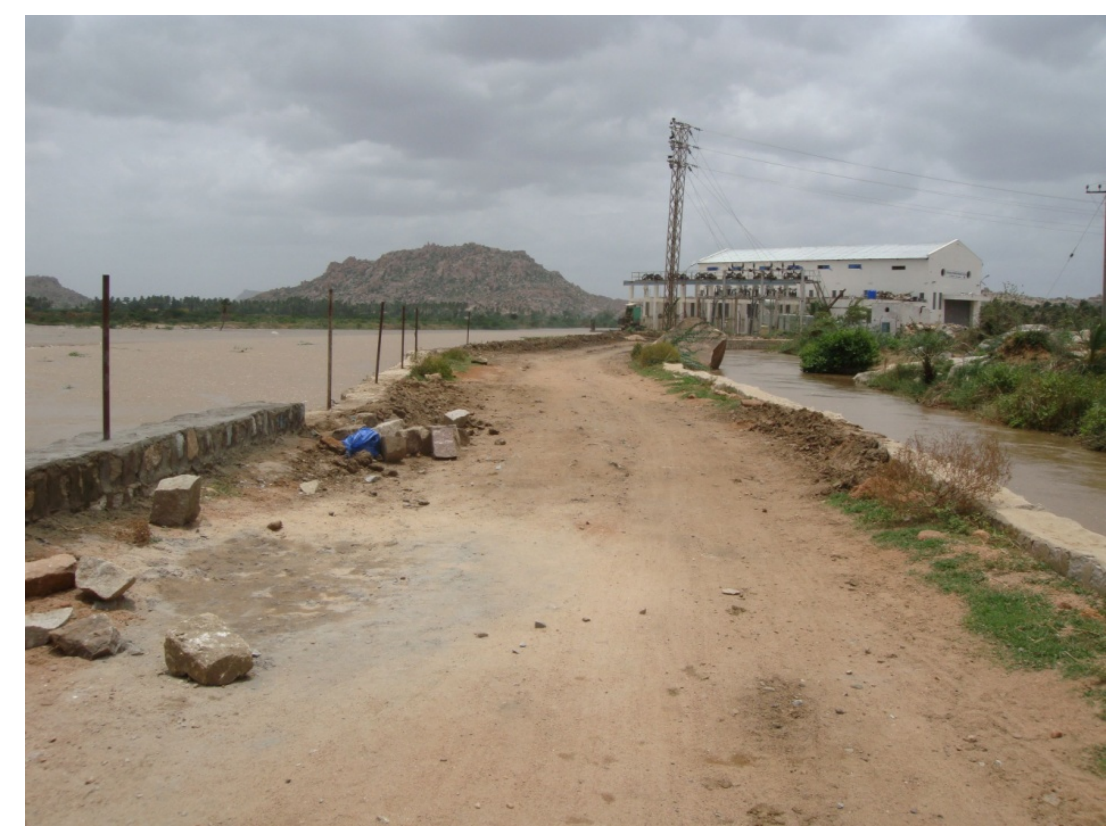

Figure 4.3: In the rear Pusala Power Plant; to the left the plant's intake canal and to the right Sirguppa irrigation canal.

\section{Kenchanaguddam Village: Availability of Water}

The strengthening of the anicuts diverting waters toward the plant changed Tungabhadra's flow of water. The seven anicuts were strengthened by "a) arresting the leakages through the anicuts; and b) providing a suitable capping for effective discharge" (TCE, 2003: 21). Changing the flow of water had a direct impact on the livelihoods of farming households in the area. For Kenchanaguddam village, located about $2 \mathrm{~km}$ off Tungabhadra's right arm, the plant's construction entailed that more water was led through the river's right arm along which the plant was constructed.

Not surprisingly, when asked about the situation after the construction of the plant Kenchanaguddam's Gram Panchayat members stressed "the plant is helping us because more water, which we use for cultivation of land, is stored" (interview GP Kenchanaguddam, 2010). Especially the strengthened Gangammana anicut, the last anicut of the diversion series in combination with the fairly long intake canal leading the water towards the turbines, slow down Tungabhadra's water flow and have a water storage effect. The water slowing and storing feature makes the water easier accessible and longer available for cultivation and drinking water purposes. According to Pusala's Executive Director, the plant had even another positive impact by changing the local cropping pattern significantly: "Earlier [people] used to get only one or two crops a year. Because of this project, now, they get three crops a year" (interview Executive Director, 2010). This was possible due to the water storing effect, since "by ... putting this 
project here, the water will stop for one or two months more" (ibid.).

Some GP members, however, qualified the advantage of water storage by describing another effect the construction of the plant on the water flow: "When the flood comes, there is a problem due to submergence" (interview GP Kenchanaguddam, 2010). GP members were thus not unanimous in their evaluation of the impact of the plant. Yet, during the discussion the issue of submergence was generally toned down and argued against by foregrounding the advantage of water storage.

This is closely related to the specific anicut shape. In Kenchanaguddam, by stretching across three quarters of Tungabhadra's right arm, the Gangammana anicut plays a crucial role in altering the water flow around the plant's site. Many GP members stressed that the anicut did not play a role in aggravating the floods because its overall shape was retained: "The anicut ... was built ages back and Pusala has not made any changes to it, they only strengthened the anicut" (interview GP Kenchanaguddam, 2010). The company's role is seen as being confined to the mere strengthening of the anicut, while the structure itself is described as preexisting. In the eyes of GP members, the works on the anicut undertaken by Pusala are therefore only a reconstruction of an ancient old and thus time-tested water management structure.

In any case, GP members stressed "when the flood comes the only people who get affected are the ones having land close to the river bed and those having pump sets [while] 3000 acres profit from the plant” (interview GP Kenchanaguddam, 2010). Moreover, GP members regard the bureaucratic procedures in case of flooding as effective. "When the $\mathrm{TB}^{107}$ Dam's gates are opened, the Irrigation Department informs the District Commissioner about possible floods due to the opening of the gates" (ibid.). While it is the Irrigation Department's task to inform about, to ensure, and to control the water flow, the Revenue Department deals with financial queries: "In case of loss due to flooding it] comes to the village, does some surveys and compensates" (ibid.). Three arguments were presented to counterbalance the issue of submergence: the retained shape of the anicut, the fact that only a certain group of farmers are affected while many profit, and, lastly, the existence of effective bureaucratic procedures of information and compensation.

Another statement, which punctuated the dominant narrative of the advantage of water storage, was given by several GP members who attributed the enduring problem of submergence to the fact that "the company has increased the anicut by a foot" (interview GP Kenchanaguddam, 2010). According to some members, the anicut's shape was not just reconstructed but changed, which explained the submergence problems: "If these people [from Pusala] would have just strengthened the anicut, the people having river bed land as well as pump

107 TB is the common abbreviation used for "Tungabhadra." 
sets would not have faced any problems due to flooding" (ibid.).

While GP members did not further elaborate on the fact that the anicut was heightened by one foot, the MLA ${ }^{108}$ claimed it to be a result of an agreement, which he had helped to bring about. This agreement reverted a situation, which had emerged in early 2006, when the Pusala company had significantly heightened the anicut to be able to lead more water through its turbines and thus increase its electricity production. Referring back to this time, the MLA recalled: "In the beginning, just by seeing it, farmers thought it was good, because they could collect a lot of water" (interview MLA, 2009). For two years farmers enjoyed the extra water storage until the flood occurring in 2008 caused major submergence, affecting " $400-500$ acres" of farmlands along Tungabhadra's shores (interview GP Kenchanaguddam, 2010). This triggered "lots of protests; 200-300 farmers went to the Pusala plant" (ibid.). In the event a similar scenario as in Sugur emerged, when "masses of farmers came with axes and spades and demolished the extra height" (interview MLA, 2009). This resulted in the demolition of the additional layer, which Pusala had built on the anicut. In their protests farmers had requested their MLA to attend to the matter, since "if anything happens farmers are turning to me [for help]" (ibid.).

Mollinga describes contacting the MLA for issues of water as a "deviation" for farmers, because it is the Irrigation Department that is responsible for water distribution and control (Mollinga, 2003: 239). However, since there are "virtually no formal accountability mechanisms between water users and Irrigation Department," farmers often resort to their MLA to lobby for their water interests (ibid.: 239). For the MLA, eager to be re-elected, this is a chance and challenge to prove himself to his constituency. Yet, different to the roles described for MLAs in issues of (canal) irrigation (Molle et al., 2009; Mollinga, 2003), in Kenchanaguddam the MLA's role went beyond being the promoter of his constituents' interests. The MLA used his involvement as an opportunity to profile himself as a broker between the company management and the farmers: "Under my leadership the farmers and the managing director came together and made the agreement to build again one more foot [on the anicut since] if they build one foot, it is beneficial for the farmers as well as for the power plant project" (ibid.). Aside from satisfying his constituents, the MLA gained leverage over the company because his mediation made it possible for the anicut to have an additional layer, which ensured increased electricity production.

In the words of a GP member, the conflict was resolved "due to the protest and the support [of the MLA]" (interview Kenchanaguddam, 2010). GP members represented the anicut incident, which happened "two years back"109 (ibid.), as resolved and settled. Remarks about its course remained brief and the topic was ended by referring to the current status: "Because they [Pusala]

${ }_{108}$ Member of the Legislative Assembly. For a brief explanation of the acronym, see footnote 89 on page 69.

109 i.e. in 2008. 
have strengthened the anicut there is no leakage of water, so almost all the water is stored and farmers from Kenchanaguddam can use it. That's how we make use of the plant" (ibid.). By referring to the current situation, the case was presented as closed, shifting the emphasis away from the past to the present advantage of water storage. Thereby, the issue of the anicut's heightened shape, which according to some caused submergence, was glossed over as well, again accentuating the advantage of water storage instead.

During both interviews, both the MLA and the members of the GP stressed the illegality of the anicut's heightening by Pusala: "There was no permission to heighten the anicut, the government's permission was only given to use the existing anicut" (interview GP Kenchanaguddam, 2010). Illegality in connection with the current shape of the anicut having an additional height of one foot was, however, never brought up. In fact, the MLA who brokered the agreement presented it as an achievement through which the conflict between farmers and the company was turned into a win-win situation. In the GP discussion in which the narrative of water storage was dominant, the anicut's shape was only tentatively questioned in terms of its potential to aggravate submergence, not in terms of its illegality. Some GP members presented the anicut even as unchanged: "Till today the anicut is not heightened" (interview GP Kenchanaguddam, 2010). With this comment GP members seemed above all to divert the discussion away from the anicut's shape to foreground its usefulness.

For the farmers, acceptance of the anicut's height is related to the advantages it entails. When Pusala initially raised the anicut, it could remain heightened until the advantage of water storage had turned into a disadvantage due to submergence. Consequently, farmers destroyed the additional height. There were no reports that their collective activism in the form of trespassing and destruction of property entailed legal consequences. Similar to the case in Sugur this points to the local acceptance of this form of unconventional engagement. The current status of an additional height of one foot was accepted because a majority of farmers from Kenchanaguddam and people served by the Sirguppa canal profit from the availability of extra water.

In Sugur the destruction of the anicut by farmers and hostage-taking were legitimized with reference to the illegality of the anicut's shape. Destroying the heightened anicut in Kenchanaguddam and the agreement mediated by the MLA point to legitimacy as a frame of reference, with which activities leading to certain situations are justified. The legitimacy frame is invoked for measures that are regarded to ensure the benefits of people. The destruction of the Gangammana anicut was seen as an act to ensure people's benefits endangered due to submergence. The agreement in Kenchanaguddam legitimated a permanent social arrangement that conflicted with construction stipulations for the plant issued by the government. The 
legitimacy of the agreement was justified by invoking the benefits it brings about for farmers and the company.

The agreement mediated by the MLA distorts the categories of conventional and unconventional engagement, introduced in Chapter 3. In the Sugur case we have already come across the conventional engagement form of conducting a meeting to find a solution to submergence. In Kenchanaguddam this conventional form of engagement entailed an illegal dimension, by agreeing to the heightening of the anicut, which is at odds with government stipulations. This makes the engagement a hybrid of the two categories: its form of engagement is conventional, but its content is illegal.

Unconventional engagement and a hybrid of a conventional form of engagement, the latter mediated by the MLA, led to an additional height of the anicut, which was accepted by the majority of the farmers. With the establishment of the Pusala power plant, which entailed the strengthening of the anicut series and heightening Gangammana anicut, Tungabhadra's water flow changed, diverting more water toward the river's right arm. Water is slowed down and stored for a longer period of time, enabling easier and longer accessibility of water. In a region where the availability of water is not perennial, these advantages are significant and seem to outweigh negative consequences potentially caused by the plant by aggravating submergence.

With the advantage of water storage and increased water availability, forms of engagement with the mini hydel plant gave way to forms of disengagement. For the majority of farmers disengagement is related to the utility of the plant for their livelihoods: the plant and the anicut in its current shape is beneficial for the people, which contributes to its legitimacy. Aside from affecting people from Kenchanaguddam, the change of the water flow also affects the Sirguppa irrigation canal and thereby the people served by it. With its inlet right next to the plant's intake canal, the Sirguppa canal can be fed with more water due to the diversion of water through the strengthened anicuts and Gangammana's additional height. Those few who see the additional height as a potential cause of submergence do not receive much attention. For too many, the advantage of the extra height is too sizable, and the potential damage caused by it too small, to mobilize interests against the raised anicut. For people from Kenchanaguddam the evaluation of the plant is related to the availability of more water - and, in the eyes of few others, to the availability of too much water. Yet, as we will see, for some farmers in the vicinity of the plant it is not water but the lack of it that shapes their experiences and their form of engagement with Kenchanaguddam's mini hydel plant. 


\section{Vinaknagar: Water Scarcity}

"Some people are having advantage, some people are having disadvantage," as one farmer, named Venkat, summarized the situation after the construction of Pusala's power plant (interview Venkat, 2009). Venkat lives in Vinaknagar Camp on Deshnur ${ }^{110}$ Island, which is situated just downstream of the power plant. Tungabhadra's left and right arm form this island with a total surface area of about 2800 acres, most of which are used for cultivating paddy. ${ }^{111}$ The main village is Deshnur, which is located in the middle of the island, about $6 \mathrm{~km}$ downstream of the power plant. Vinaknagar is situated on the upper part of the island, about $2 \mathrm{~km}$ downstream of the plant and consists of only three large farmhouses, owned by wealthy farmers.

At the southern tip of the island, located just downstream of the power plant, is the inlet for a small irrigation canal, ${ }^{112}$ the Deshnur canal (see Figure 4.4). Documents of the Water Resource Department describe the canal as "another medival (sic!) irrigation system under Tungabhadra River [that] is situated just below Sirguppa Channel system." The canal is fed based on a funnel system. "The system consists of [an] anicut formed with big boulders packed close.... The anicut is of ' $\mathrm{V}$ ' shape connecting right Bank of River and one of the Islands [located above Deshnur island.] The Deshanur Anicut takes off from the apex of the 'V'" (Department, n.d.: 3).

110 "Deshnur" is also referred to as "Deshanur"; just as my correspondents I will use both versions.

111 Some sugar cane is grown as well.

${ }^{112}$ My correspondents also use the word "channel" for "canal." 


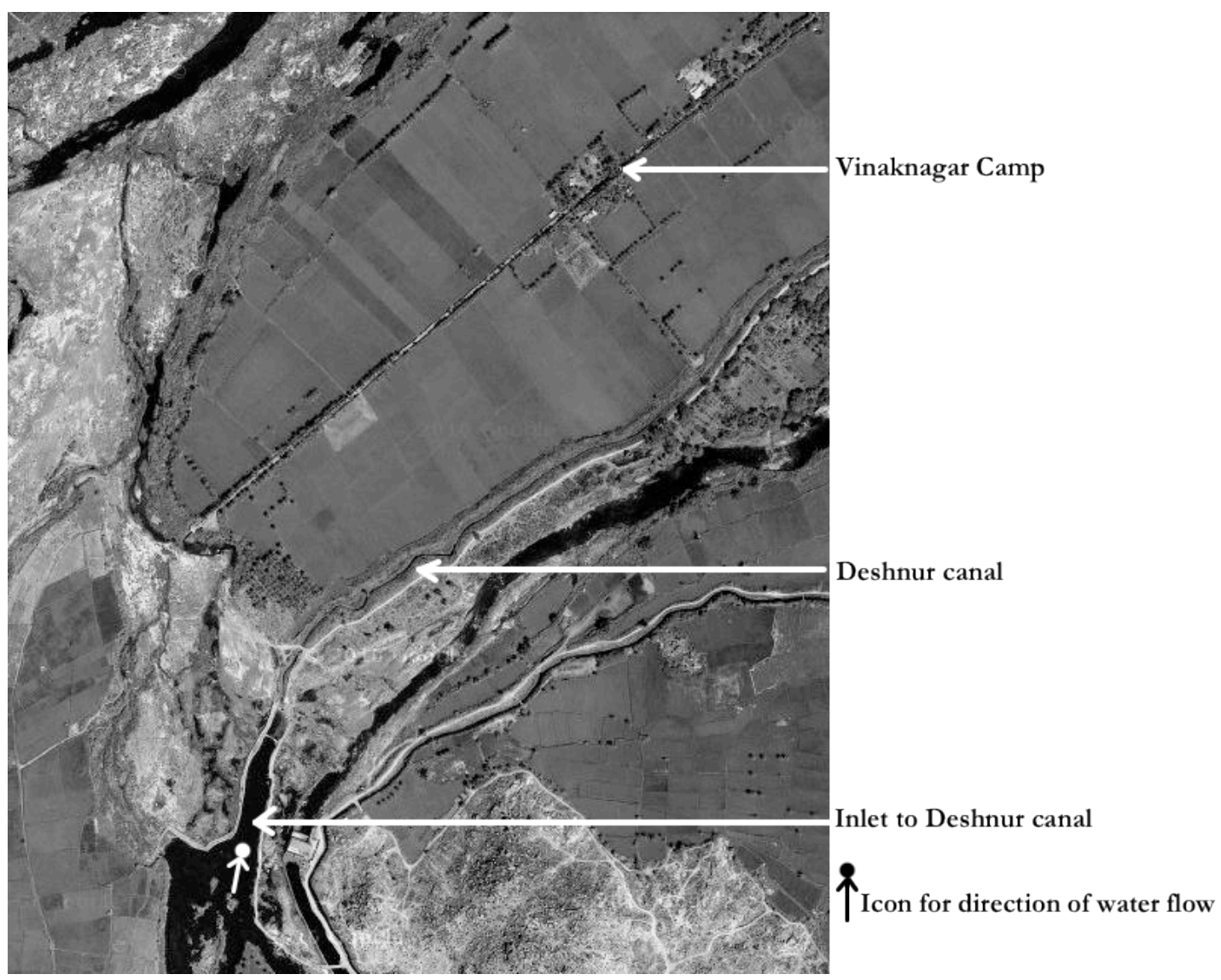

Figure 4.4: View of the southern tip of Deshnur island, displaying the inlet to the Deshnur canal and Vinaknagar Camp.

Before the establishment of the Pusala plant, Tungabhadra's waters used to reach Deshnur canal by leaking through the anicuts or, in case of high water level, by overflowing the diversion structures. "Hundreds of years back, our ancient people built these anicuts. They built these anicuts by using not a single bag of cement! But these people [Pusala] have spoilt the anicuts by using cement" (interview Venkat, 2009).

Deshnur canal used to be fed by water overflowing and leaking through Arelli anicut as well as Gangammana anicut. Arelli anicut is the first of the anicut series and is built across the middle arm, diverting the water towards the right arm. Gangammana anicut is the last of the anicuts and diverts the water into the Sirguppa canal and Pusala's intake canal. Before the establishment of the Pusala plant, water used to flow down Tungabhadra's middle as well as right arm and reached Deshnur canal. Yet, by strengthening the anicuts, Venkat explained, "they [Pusala] have obstructed the water for Deshnur Channel [since] Pusala has diverted water from the very top" (interview Venkat, 2009). The "top" refers to the location where the anicut series begins and where Tungabhadra splits into the left, middle, and right arm (see Figure 4.5). Implementing the "plugging of leakages at the existing 7 anicuts" (TCE, 2003: 2) as foreseen in the Detailed Project 
Report of the Pusala plant, changed Tungabhadra's water flow.

With the construction works ongoing and the anicuts strengthened, Venkat realized that the plant's design significantly impacted on the water flow supplying Deshnur canal. Venkat started to protest: "When Pusala came here, we asked them: 'How is the water going to Deshnur canal? Show me!"' (interview Venkat, 2009). Venkat turned to the Irrigation Department to voice his objection to the plant's design: "I have called all the Departments ... Even the Chief Engineer came to that place. ... They came, I asked them, you show me, where is the way for the water to this channel? This project, this man has obstructed all the water for that canal ... Pusala has spoilt all the natural stream" (ibid.).

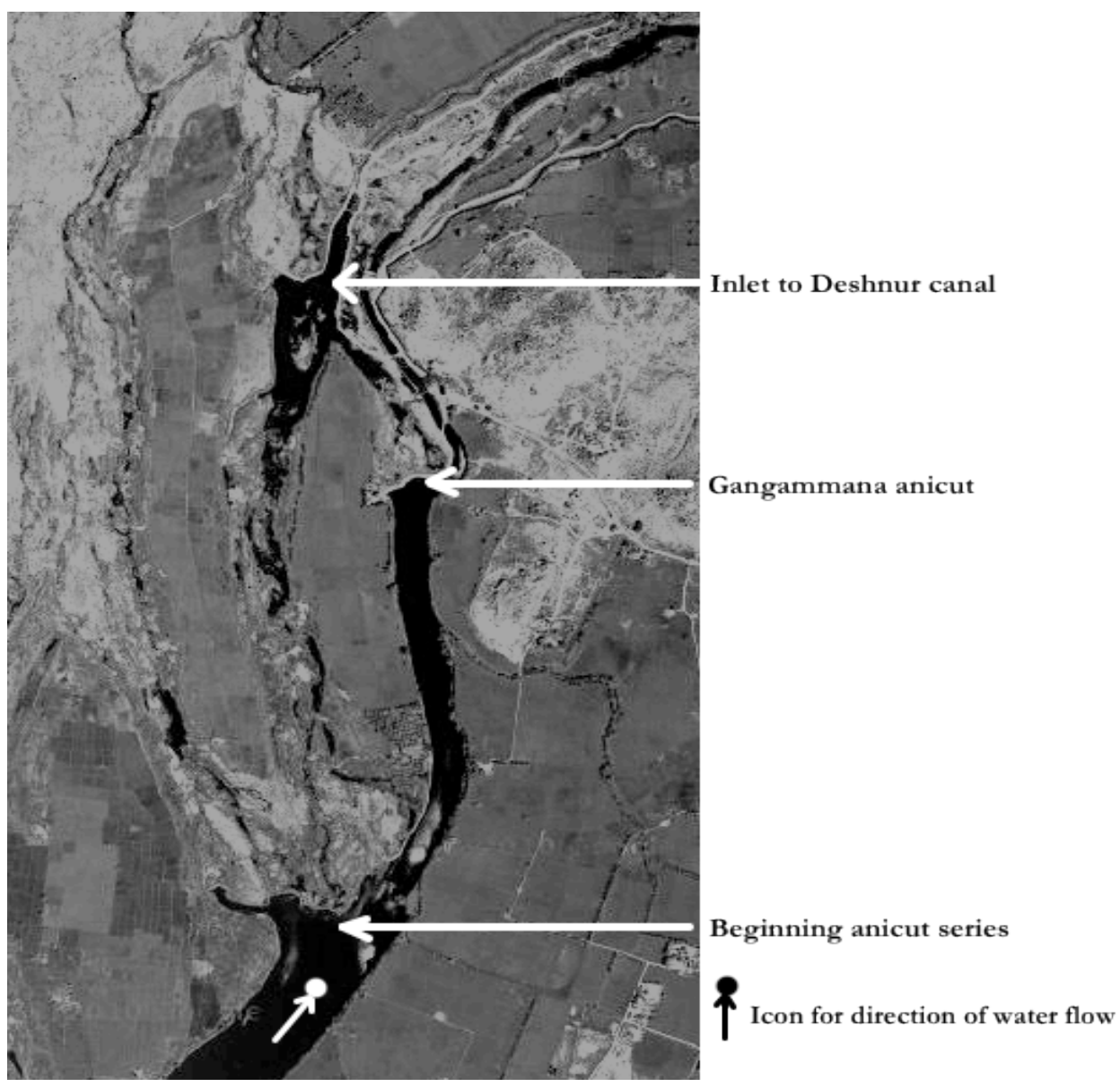

Figure 4.5: View of river stretch from beginning of the anicut series to the inlet of the Deshnur canal. 
Venkat's statements implied that a characteristic design feature of the anicut series consisted of their leakage ensuring a small water flow even during low water tables. Detailed research on anicuts is scant and Krishnan's exceptional study of these structures in South India is "a first step in conducting an engineering analysis of traditional irrigation systems" (Krishnan, 2003: 4). In her research she focuses on the anicuts' diverse shapes and their relation to bed sediment transport effects but does not elaborate in detail on the masonry of the anicuts. ${ }^{113}$ Agarwal and Narain mention in their overview and compilation of India's traditional harvesting structures that "anicuts on the Tungabhadra River ... were all constructed by the Vijayanagar kings [and] all of them are made of large boulders and rough masses of stone piled upon the other without mortar or cement" (Agarwal \& Narain, 1997: 205). Yet, neither Krishnan nor Agarwal and Narain are concerned with leakage as an intended feature of anicuts. Local sources in the form of interview accounts and government and survey documentation about the anicuts series describe their packed, yet permeable boulder-structure. Furthermore, the placement of the anicut series speaks for a design that allowed some water to leak through the anicuts. This underlines that despite their underlying engineering principles the design of traditional anicuts was varied and adapted to local circumstances. ${ }^{114}$

Venkat's protests took the form of conventional engagement activities. In letters written to the Irrigation Department he proposed to install extra sluice gates to ensure the water flow toward Deshnur canal. The power plant's detailed project report did not foresee extra sluice gates. As a result of Venkat's engagement in the form of letter correspondence as well as direct interactions with Irrigation officials at the site, two sluice gates were installed. However, the location of the gates was not the one Venkat had proposed: "They should have provided sluice gates to Deshnur canal at the Gangammana anicut" (interview Venkat, 2009). Instead, two "very small gates" were installed at the upper part of the intake canal's wall (ibid.). The local Irrigation Department is in charge of operating these gates, which discharge water to the Deshnur canal. The gates are operated between March and June. During this hot and dry summer period Tungabhadra's water tables are low and water is scarce. The anicuts strengthened with "random rubble masonry" hinder the little water, which flows in the river during this period to trickle through the anicuts (TCE, 2003: 21). Water cannot overflow the anicut because of too low water tables, nor can it leak through the anicuts because they were turned into solid barriers. Consequently, the anicuts located at the upper part divert the available water away from the middle arm towards the right arm where Gangammana anicut diverts the water finally into the

\footnotetext{
113 She suspects that a certain plaster might have enhanced sediment transport (Krishnan, 2003:40). ${ }^{114}$ In fact, this variety of design features led Krishnan to start investigating into common, underlying principles of anicuts.
} 
plant's intake canal and the Sirguppa irrigation canal. During July and September, ${ }^{115}$ however, when the monsoon-rain-waters and dam releases fill Tungabhadra's waterbed, the water tables are so high that they overflow the anicuts reaching Deshnur canal. The availability of water during the periods of the advancing and retreating monsoons is thus not an issue for the farmers served by Deshnur canal.

Venkat had proposed to the Irrigation Department to install gates in the Gangammana anicut, but "these Kenchanaguddam people, these canal people objected it" (interview Venkat, 2009). For people profiting from the Sirguppa canal, installing gates in the Gangammana anicut only meant that less water would reach "their" Sirguppa canal, because part of the water, which the Gangammana anicut diverted toward the plant and irrigation canal inlet, would be discharged through the sluice gates. The Irrigation Department decided that the two sluice gates were to be installed in the wall of the intake canal. Water is thus first led toward the irrigation and the intake canal. Only from there it can be released through the wall into the riverbed where the Deshnur Anicut's right leg diverts the water toward the inlet of the Deshnur canal (see Figure 4.6).

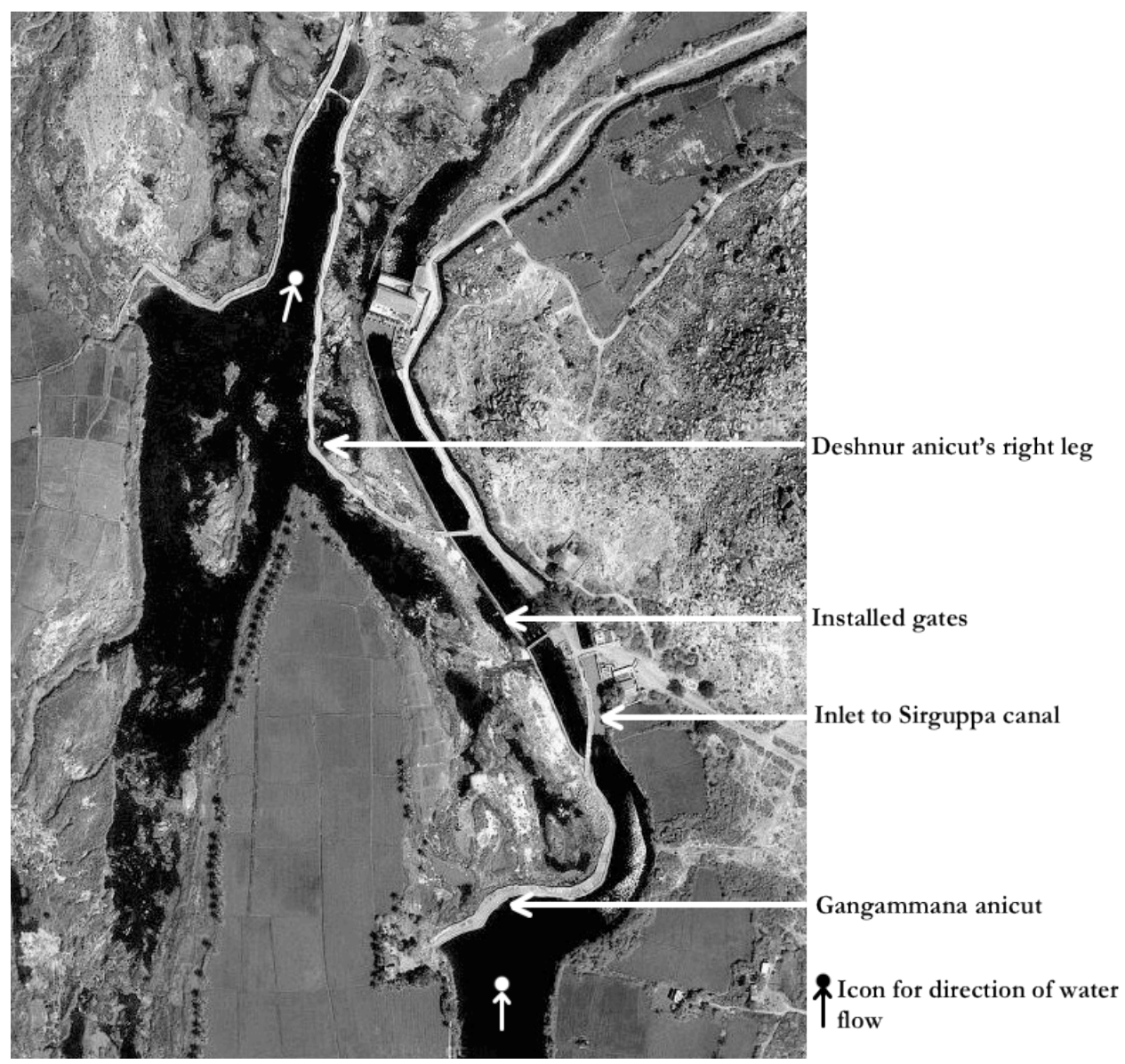

Figure 4.6: Bird's-eye view of the built infrastructure at the plant.

115 These months fall within the advancing monsoon period, taking place around June until September; the retreating monsoon period occurs around September until November. 
Venkat did not blame the local Irrigation Department for the approval to install gates in the intake wall: "It is not their [Irrigation Department] mistake. These farmers are there, Kenchanaguddam farmers, they obstructed the officials!” (interview Venkat, 2009). In his view, Kenchanaguddam has a group of influential farmers who could pressurize the local Irrigation Department, so that the gates were eventually put in the intake wall rather than in the Gangammana anicut. This ensured that the water flow first passed the Sirguppa irrigation inlet before being released toward Deshnur canal. Before we move on to see how Venkat dealt with this issue, his statement about farmers capable ofo influencing local decisions needs closer theoretical contextualization.

Studies investigating Indian power structures have related the rising influence of peasants after India's Independence to the abolishment of the feudal landlordism, or "zamindari" system (Frankel, 1990: 506; Rudolph \& Hoeber-Rudolph, 1987: 50). The rising middle peasants who often used to be tenants under zamindars ${ }^{116}$ could acquire increasing economic and political control on local level. ${ }^{117}$ And though landownership is an important feature of peasant's dominance (D. Gupta, 2005 citing Srinivas, 1972), "the new dominants of rural India are not necessarily those who are economically at the top. They must, of course, have a viable economic standing, but they should also have sufficient numbers as well as political connections (ibid: 416 citing K. L. Sharma, 1997) .

The phenomenon of the rising power of peasants broadened the look beyond the category of caste for understanding rural power relations. It thereby augmented explanations of social power structures in rural areas based on the "dominant caste theory" (MacDougall, 1979). The latter found that there exists a dominant caste in many villages, which has access to most of the local power resources. Although the dominant caste theory is not neglected, it is now an accepted finding that there has been a decline of power of the traditional elite castes in India (Rudolph \& Hoeber-Rudolph, 1987). According to Manor, there is still not yet a full understanding of the reasons for the decline of caste power (Manor, 2007). Looking at Karnataka, he sees the decline of the "jajmani" system, ${ }^{118}$ which provided the material underpinning of caste hierarchies, and government policies after 1972, which favored disadvantaged groups as factors contributing to undermine caste lines (ibid.: 656).

With the ascendants of peasants and the decline of caste hierarchies, the notion of "faction"

\footnotetext{
116 A zamindar was a quasi-feudal landlord who "stood between the state and the cultivator by acting as revenue agent... and performing some local government function" (Rudolph \& Hoeber-Rudolph, 1987: 50).

${ }_{117}$ Rudolph and Rudolph (1987) introduced the often-cited notion of "bullock capitalists" for small to medium selfemployed independent agricultural producers, whom the authors found to be the principal beneficiaries of the abolition of the zamindari system (p.50).

118 Bluntly, the "jajmani system describes upper and lower caste relations, in which the lower castes are obliged to deliver free services to upper castes." For a more detailed conceptualization, see Miller (1986).
} 
emerged to account for political processes of conflict at rural level (Bailey, 1969); (Dumont, 1970). And though there are different definitions of the term, "factions usually refer to informal, spontaneous, leader-follower groups organized for a particular purpose which disband when that purpose has been accomplished" (Tenhunen, 2003: 514). The strong farmers' group in Kenchanaguddam bears resemblance to a faction, as the following accounts further elucidate.

With the installation of the two gates, the controversy about Tungabhadra's water flow did not end, because, as Venkat put it, "now, they are not regulating these gates. They have kept it to a certain extent: [at] one, one and a half foot they left it" (interview Venkat, 2009). During the summer months when the water tables get low Venkat together with other farmers served by the Deshnur canal has "to go to the Irrigation officers, and request them ... to come and lift the gates. ... Once they open the gates ... 100-200 or more farmers [from Kenchanaguddam] will come to fight" (ibid.). The farmers' lobby from Kenchanaguddam "comes automatically" and gathers at the intake canal and protests against the opening of the gates by officers of the local Irrigation Department (ibid.).

The informal structure and the temporary amassing of many people with a certain purpose underline the factional character of the Kenchanaguddam lobby. Hardiman writes that "factions are fighting for merely a bigger piece of the cake, their conflicts are not on ideological grounds" (Hardiman, 1976) referring to Bailey, 1969). The leader-follower relationship explains group mobilization; followers, after all, support leaders, hoping to get favors in return.

In Kenchanaguddam these favors seem to have been related to money stemming from the Pusala plant: the sluice gates are located in the wall of the plant's intake canal, downstream of the inlet to the Sirguppa canal. Consequently, for people served by the Sirguppa canal the opening of the sluice gates to Deshnur canal does not impact on their availability of water. Their objection to the opening of the gates is therefore unexpected. Venkat accuses the Pusala plant management of "instrumentalizing" leaders of Kenchanaguddam by paying them to show up and protest when the sluice gates to Deshnur canal are to be opened. According to Venkat, the powerful lobby explains the weak role of the local Irrigation Department: "They [Irrigation Department] are helpless, because of the strong leaders in Kenchanaguddam" (interview Venkat, 2011). Intimidated by the mass of angry protesters the local Irrigation Department officers leave without "properly opening" the sluice gates to Deshnur canal (interview Venkat, 2009).

"He [Pusala] does not want to open [the gates] more, because he will generate less" (interview Venkat, 2011). Venkat observed that the plant only runs at a water flow below 50000 cusecs. "More than ... 50000 [cusecs], once the water comes, they cannot generate. Their turbines don't run. [So], when the heavy water is coming they cannot generate" (interview 
Venkat, 2009). As a consequence, Pusala is generating electricity using the water flow available during the drier months, so that during this lean water period the need for water by farmers using the Deshnur canal conflicts with the need for water by Pusala.

Only due to Venkat's engagement the issue of extra sluice gates for Deshnur canal became an action point on the agendas of the Irrigation Department and Pusala's management. Gates were installed, though not in the Gangammana anicut, but in the intake canal's sidewall. This achievement, however, was frustrated by the activities of the farmers' lobby, which agitates against their opening. Due to that, Venkat and others served by the Deshnur canal stopped their engagement. "No, we left it ... Why should we fight? If we have justice, we fight, [but] if there is no justice... we left it" (interview Venkat, 2009). Venkat's reference to “justice” is intriguing because by referring to justice he invokes a "just higher order" and thereby questions the legitimacy of the current situation, which is dominated by the interests of the farmers' lobby. Thus, justice seems to be another frame of reference, which is invoked to justify forms of engagement - and, in Venkat's case, disengagement.

For Venkat and others served by the Deshnur canal, the establishment of the Pusala power plant in 2005 aggravated the water scarcity faced during the dry summer months. The installation of sluice gates did not alleviate the situation. The conflict over the opening of the sluice gates by the Irrigation Department is a repeating event. Every year when Deshnur canal dries out and the local Irrigation Department is contacted to open the sluice gates, people from Kenchanaguddam start massive protests.

Several reasons may explain why Deshnur canal people conceded to this situation. The canal is small, serving only a few hundred acres, so, the number of affected farmers is low compared to those located at the other side of the river who benefit from the plant. The small number of affected farmers cannot keep up with the strong and numerous farmers' lobby from Kenchanaguddam. Clearly, the creation of legitimacy is related to the strength of support one can amass for an issue.

But apart from resigning for lack of support, the availability of pump sets installed downstream of the powerhouse in the right and left arm of the river account for the disengagement by Deshnur canal people. "We have installed pump sets, which we use all the year, 360 days" (interview Venkat, 2009). Consequently, Venkat and others are not dependent on the water flow of the Deshnur canal, because pump sets pump the water from the river toward the fields. The disengagement from the plant's impact on the local water flow is based on a combination of resignation and the availability of alternatives. Not being able to create legitimacy for his cause, Venkat decides to resign from his engagement activities. Since Venkat and others 
can resort to alternatives, which prevent them from experiencing any crop loss, their disengagement does not entail damage for them.

The form of disengagement taking place in Vinaknagar differs from the one in Kenchanaguddam village and surroundings, where Kenchanaguddam people and Sirguppa canal people disengage owing to the advantageous water flow created through the power plant. However, some of them interrupt this disengagement by temporarily resorting to unconventional engagement activities in the form of intimidating and threatening public officials not to open the sluice gates for the Deshnur canal.

That the Irrigation Department conceded to this is likely to be a result of the power constellations between farmers' leaders, local elected politicians, and local irrigation officers. Farmers' leaders can mobilize their followers to support a local politician, and withdraw their support in case the politician does not act in their interest. Local politicians, in turn, interested in a broad support-base for their re-election, instruct irrigation officers to condone the activities of their support-base. They can do so because they are aware of the influential role they can play in the routine transfer of irrigation offices. This system of dependencies builds on the deep-rooted system of administrative and political corruption described by Wade (1982) and discussed above. It also has some resemblance with Frankel's notion of "competitive populism," which describes the phenomenon of groups gaining access to resources in exchange for political support (1990: 511). Frankel uses the notion in the context of the political mobilization of backward castes in Karnataka. Yet, if applied to the situation in Kenchanaguddam, competitive populism seems apt to describe the phenomenon that a group of farmers receives political patronism, which they are likely to have gained in exchange for their votes.

Disengagement in Vinaknagar occurs due to the inability to mobilize sufficient support for a cause. The availability of alternatives enabled Venkat and others to circumvent the disadvantages brought about by the plant. As we will see in the case of Deshnur Village below, the immediacy of damage that a plant might cause is another feature that influences engagement with or disengagement from the plant.

\section{Deshnur Village: Not Pusala but Nirmala}

Deshnur is the main village on Deshnur Island, located about $6 \mathrm{~km}$ downstream of Pusala's power plant (see Figure 4.7). GP members from Deshnur were very clear when asked to evaluate the power plant's impact on the local water flow. "The way it changed was really good, because it is helping us, because water is stored. Every time Pusala releases water, Deshnur makes use of it" (interview Deshnur GP, 2010). At the same time, GP members put the advantage Deshnur 
people have through water storage into perspective, arguing that "more than Deshnur people, the people from Kenchanaguddam and villages from Sirguppa taluq use the stored water due to the strengthened anicut" (ibid.). Nevertheless, they stated that the strengthened anicut contributed to their supply of water that they "can use one month more" (ibid.). In an area where the water flow is perennial but rather scarce than abundant this is a significant benefit. The availability of more water has a direct impact on farming livelihoods because it allows for cultivating more water intensive cash crops, like paddy. ${ }^{119}$ In Deshnur, like in Kenchanaguddam village and surroundings, water storage emerges as a major advantage, allowing people "to make use" (ibid.) of Pusala's power plant.

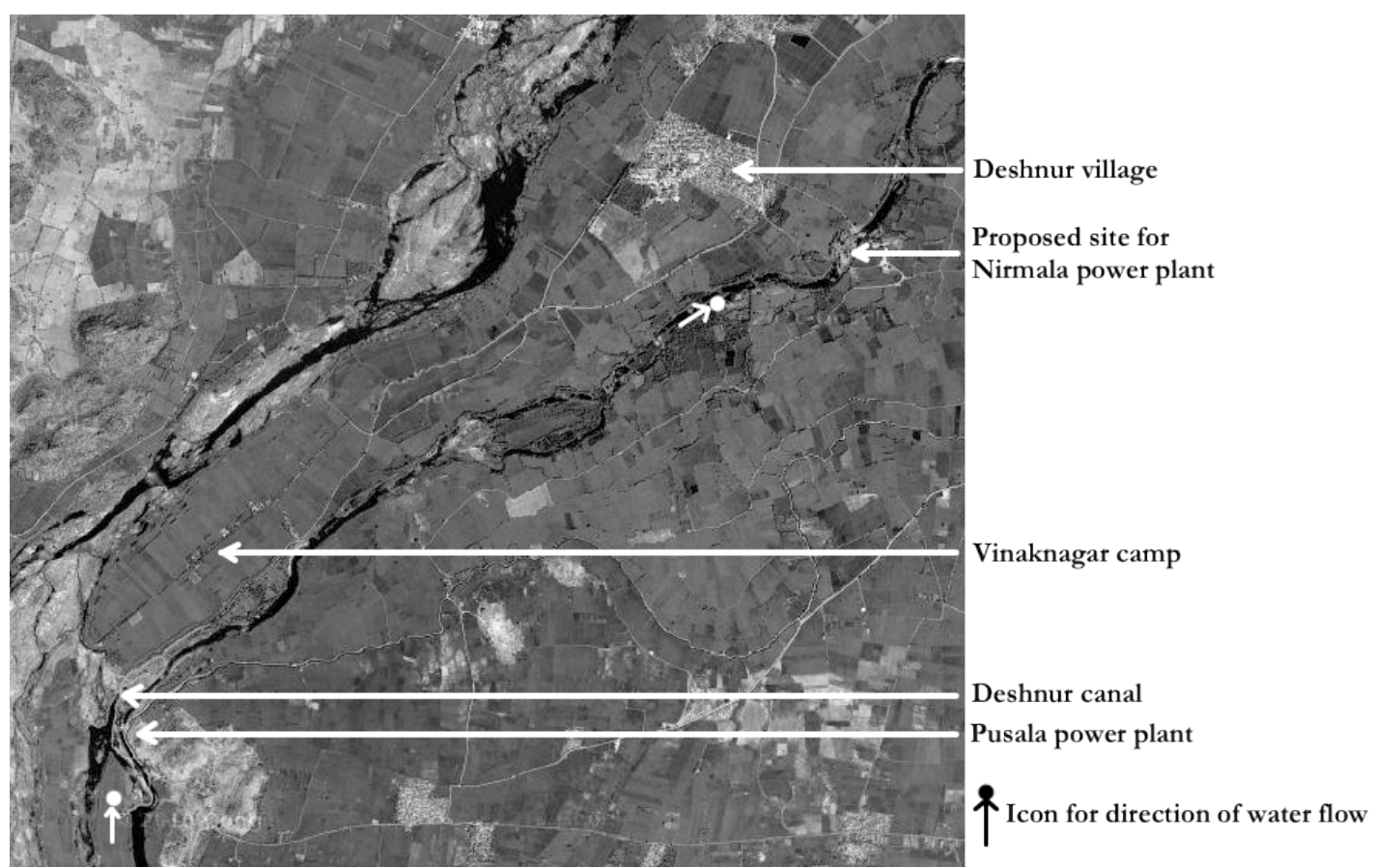

Figure 4.7: Bird's-eye view of Deshnur island.

While the Pusala power project was not a point of concern for members of the Deshnur GP, another power project was considered potentially troublesome. In June 2002, Nirmala Power Pvt. Ltd. from Bangalore received the allotment from Karnataka's Government to build a 4.5 MW mini hydel plant "downstream of existing Vijayanagar Anicut on Tungabhadra river, $6 \mathrm{Km}$ from Siraguppa ${ }^{120}$ Village in Bellary District" (KREDL, n.d.). GP members elected at that time consented to the project; yet, current GP members explained that the company has "not started the construction, because the owner's son is in Australia. The father is building the power plant for his son" (interview Deshnur GP, 2010). The statement seemed to underline that the physical

${ }^{119}$ In contrast to subsistence crops, cash crops are grown for profit. The common cash crop in the Tungabhadra area is paddy.

120 "Sirguppa" is also referred to as "Siraguppa." 
distance of the prospective manager caused it to be set on hold.

A farmer having land adjacent to the proposed project site recalled that when the previous GP granted the permission to the Nirmala company, farmers along the riverbed were not given any information about it. The farmer, whom we will call Mahadesh, only learnt about the project by chance: "When Nirmala ... bought land next to my land, then I got to know about the project" (interview Deshnur farmer, 2010).

Officially, villagers are informed about decisions of their GP during so-called Gram Sabha meetings or village meetings. A Gram Sabha is called in by the elected GP and comprises all registered voters within the jurisdiction of the respective Panchayat. ${ }^{121}$ Issues discussed during such meetings include reports about the GP's activities, the approval of plans and development schemes, and the consideration of budget and tax proposals. However, a government report by the "Special Task force on Panchayati Raj Institutions"122 found that "the Gram Sabha, by and large, has been given very little importance ... There is a tendency to view Gram Sabha meetings as a mere formality, [so that often] suggestions and recommendations by the Gram Sabha can be ignored by the Gram Panchayat" (Task-Force, 2001: 13).

In Deshnur Village the decision about the approval of the hydel plant was not shared via the Gram Sabha but "spread by word of mouth" (interview Deshnur farmer, 2010). When farmers with land along the river learnt about it, they started to object the approved project plans. "20-30 farmers protested by writing a letter to the DC, telling that the land selected for the power plant is not suitable, because farmlands, which are close by will be flooded" (interview Deshnur farmer, 2010).

For Mahadesh, bribing was the reason why the GP member at that time approved the Nirmala project without consulting the village: "The Nirmala company gave the previous GP money" (interview Deshnur farmer, 2010). He assumes that "the GP might have called four to five farmers to agree to the power plant," to ensure support for the GP's approval. Manipulating the Gram Sabha is an acknowledged problem (deSouza, 2003). DeSouza sees "the main deficiencies [in] non-attendance or low-attendance at the gram sabha, because this allows village oligarchs to claim that they are speaking on behalf of the village and to pass off their self-interest as public interest" (ibid.: 114). In the case of Deshnur Village, not village oligarchs but the GP Deshnur seems to have subjected the Gram Sabha to their interests, for villagers were selectively chosen on the basis of their approval of the GP's plans. Vijayalakshmi describes this activity of

121 The institution of Gram Sabhas has constitutional status, by being anchored in India's Constitution under Article 243.

122 "Panchayat" literally means "assembly" and "raj" government. The Panchayati Raj Institution (PRI) involves a system of governance that comprises three levels: the village, block (taluq), and district level. 
GP members as fixing: "Fixing ... involves the circumventing of rules and procedures, and misuse of the official position to fulfill this" (Vijayalakshmi, 2005: 7).

Mahadesh's accusations point to a discrepancy of interests between potentially affected farmers and members of the GP. "The GP will not lose anything if the power plant gets constructed. Those who will face problems will be the farmers who have land there" (interview Deshnur farmer, 2010). At village level the tasks of Gram Panchayats typically comprise two areas of responsibility: GPs select beneficiaries for development schemes funded by the State or through the Central Government, and they are responsible for the construction and maintenance of village public goods ${ }^{123}$ (Besley, Pande, \& Rao, 2007). For the GPs to be functional, they enjoy a certain fiscal autonomy, in particular the power to levy taxes. ${ }^{124}$ Important areas of taxations, which most of the GPs have tapped, include tax on buildings and land, market fees, or tax on industries or factories established within their jurisdiction (Babu, 2004). The establishment of a hydroelectric power plant is a possibility for GPs to increase their budget, by levying tax. At that time, GP members also seemed to raise their personal budget by accepting bribes to manipulate or "fix" the approval of the project.

Deshnur river-land farmers were aware of the experiences other farmers had to go through due to the establishment of a power project. Alluding to submergence events caused by hydel plants, Mahadesh said: "We have seen people suffering upstream of Tungabhadra river. After seeing that, we do not want to face similar problems, that's why we protested" (interview Deshnur farmer, 2010). Consequently, farmers who felt potentially affected by the plant "went to a literate person, who wrote the letter, which was then signed and submitted personally to the District Commissioner." This statement indicates that the means to engage in the conventional form of correspondence are not for everyone straightforward. A multiple indicator survey conducted in Bellary District ${ }^{125}$ finds that less than $50 \%$ of the population above the age of 7 is literate (Centre, 2002). Although correspondence is a form of engagement conventionalized in the broader political system, for many people this form of engagement is not conventional or a standard procedure as it is only possible through intermediation.

In the farmers' protests, the manipulation of the project approval or accusations of corruption were not an issue. Vijayalakshmi describes a similar observation when investigating the issue of corruption at the Gram Panchayat level in Kerala and Karnataka: "Accepting commissions while carrying out the functions of the panchayats was viewed as normal" (2005: 10). Normality also resonates in Vishvanathan's provocative observation "today in India to be, is

\footnotetext{
${ }^{123}$ Such as streetlights, road maintenance etc.

124 The panchayats at the taluq and district level cannot levy tax. GPs cannot levy individual taxes.

${ }^{125}$ Deshnur Village is part of the Sirguppa Taluq, which is in Bellary District.
} 
to be corrupt" (Visvanathan, 1997b: 2378).

Therefore, instead of concentrating on the corruptive practices of the GP members, the farmers' objections focused on the proposed project. Farmers criticized the project on the basis of its location and its design. In particular, their criticism targeted the insufficient depth and the width of the river around the proposed hydel project site. "They'll have to build an outlet canal with a total length of $1.5 \mathrm{~km}$... because the riverbed is so shallow" (interview Deshnur farmer, 2010). While downstream of the proposed plant a tailrace canal has to be dug into the shallow riverbed, Mahadesh projected that water flowing toward the plant will cause flooding: "In case Nirmala will build a power plant, even when they store water by a four to six feet ${ }^{126}$ high barrier, fields will get flooded on both sides. Even the temple might get flooded!” (ibid.). This statement elucidates how fundamentally a potential establishment of the plant interferes with the life of farmers having land along the site. This project would not only threaten to change the landscape dramatically by blasting a canal into the river; it would also potentially affect the economic basis of farmers due to the submergence of their fields and serve as a religious encroachment through the risk of flooding their temple.

By comparing the proposed site to the conditions found at the Pusala site near Kenchanaguddam, the width of the riverbed and the existence of an anicut emerged as important features, which the proposed plant lacked. "When the power plant was built in Kenchanaguddam they used an existing anicut and the river is very broad near Kenchanaguddam. This means that flooding is unlikely. But near Deshnur the river is narrow, one side is Sirguppa taluq, the other side is Deshnur. There is no existing anicut to make use of. The power plant would have to construct a new structure, which would cause flooding on both sides" (interview Deshnur farmer, 2010).

The way anicuts were incorporated into the design was stressed as important: "What Pusala did was they used the existing anicut by the Vijayanagar Empire, but they have not heightened the anicut ... That is the reason why no one is facing problems ... In Sugur-Mannur they have also used the existing anicut from Vijayanagar Empire but have heightened the anicut that's why surrounding farmers face problems" (ibid.). According to Mahadesh, not changing the design of the anicuts ensures the same favorable conditions, which were once engineered during the Vijayanagar Empire. "In Kenchanaguddam, there are no problems because the same amount of water in the times of the Vijayanagar Empire is collected now as well. But in Sugur-Mannur they have heightened the anicut that's why flooding occurred" (ibid.).

We have come across accounts stressing the provenness of anicuts before, so that the

\footnotetext{
1266 feet are around $1.80 \mathrm{~m}$
} 
reverence of the time-tested anicuts is not only reminiscent in Mahadesh's statement. These accounts relate to debates in the academic literature, which are often labeled as "new traditionalist." The essentially uncontested nature, both socially as well as ecologically, of traditional water management systems lies at the heart of new traditionalist discussions. Mosse identifies three key themes in new traditionalist discourses: Firstly, "water systems were subtly adapted to the monsoon system micro-ecologies, and managed by users to a degree unimaginable today"; secondly, there has been an erosion of traditional village-centered management of the schemes; and lastly, "the past of community control and sustainable water resource management is explicitly a goal or model for the future" (Mosse, 2003: 10ff.).

Although the general thrust of the themes has been mostly acclaimed, new traditionalists accounts are mainly criticized because of their tendencies to romanticize the system's community-governance and overlook power relations (Shah, 2003), and because they portray a simplified image of the social context, suggesting stability and control, rather than change, risk, and uncertainty (Mosse, 2003).

The accounts we have come across in Kenchanaguddam and Sugur do not delve into the community governance dimension so central in the new traditionalist debates. But they stress the trustability and provenness of the traditional designs, and the importance of the artifacts' particular shape and location, which both underpin new traditionalist discourses. The cases suggest that disregarding these features, as happened in Kenchanaguddam as well as Sugur, turns these anicuts into contested structures.

The engagement of farmers eventually led to changes in the plant's project proposal. In reaction to the farmers' concerns about submergence, Nirmala proposed walls protecting the riverbank as a measure to avoid flooding. Yet, according to Mahadesh, the relation between the sidewalls and the barrier, blocking river water for the plant, is ill measured, which will result in submergence: "The Nirmala power plant [people] say that they will build a side protection wall on river bank with the height of 10 feet. ${ }^{127}$ But the barrier will be up to 15 feet. ${ }^{128}$ The problem is, even without any power plant, if we get five feet ${ }^{129}$ of water, our fields get flooded. But now, with a barrier of 15 feet and sidewalls of 10 feet - just imagine how much will be flooded!” The concessions farmers could attain were thus regarded as useless.

During the interview with Deshnur's GP, the newly elected GP members made a point of distinguishing themselves from former members, who were responsible for approving the proposal to construct a power plant. Among others, the newly elected members stressed that

\footnotetext{
12710 feet are around $3 \mathrm{~m}$.

12815 feet are around $4.5 \mathrm{~m}$.

1295 feet are around $1.5 \mathrm{~m}$.
} 
when acquiring the agreement of farmers to the plant, they would also consider the opinion of farmers not falling within the jurisdiction of their own GP Deshnur: "We would ask for the majority of the farmers along the riverbank ... on both sides of the river. When [they] agree, that's when we would give permission" (interview GP Deshnur, 2010). The point is of relevance because it reiterates the importance of considering the effects of a plant beyond its administrative realms. As we saw in the Sugur case, a plant has potential impact on both sides of the river, irrespective of administrative borders.

In Deshnur Village, engagement is related to the immediacy and urgency of a matter, so that organized action takes place if “any problem” occurs (interview GP Deshnur, 2010). "We don't have any organization for Nirmala power plant, because the power plant as of now is not being built" (ibid.). When farmers heard about the project details for the first time, their reaction came in the form of a common letter, in which they expressed their objections to the District Authorities in 2008. With this letter the farmers' conventional engagement activities with the plant had peaked. After that farmers disengaged from the issue. As Mahadesh stated: "I do not want to get involved, since right now the power plant is not under construction" (interview Deshnur farmer, 2010). The farmer was sure, however, that "in case ... the construction starts, more people will join to oppose the plant ... [Given that] right now they [Nirmala] do not construct, everybody is quiet and nobody gets involved" (ibid.). Leadership of the resistance against the plant had not yet crystallized: "Right now, we do not have leaders, but once construction starts, someone will take up the responsibility in opposing the plant" (ibid.). This shows that it is not considered to be worthwhile to engage if the matter stays in the abstract realm of proposed plans.

The elusiveness of the Nirmala plant was intensified by the fact that Nirmala company seemed willing to sell the land they acquired for the project. During my inspection of the site, led by Mahadesh, a Jeep arrived and four men dressed in business clothing, rather than wearing the common dhoti, ${ }^{130}$ got out, looking around the site. This was accompanied by Mahadesh's remark to me: "Already 2-4 parties have come to see the land [potentially] to buy [it]" (interview Deshnur farmer). His statement seemed to imply that the unsuitability of the plant's proposed location led Nirmala to abandon its plans and sell the land, which elicited the need to find a new buyer. $^{131}$

\footnotetext{
${ }^{130}$ A dhoti is a traditional men's garment and very common in Southern India, especially in the countryside. The cloth is wrapped around the men's waist. Its length can be adjusted to the ankles or to the knees.

131 Recently, at the very end of my research time for this PhD project, KREDL overhauled its website. (In fact, its new website's name still indicates the testing and updating mode: www.kredltest.in). Detailed information about hydel projects was removed, while other information was added that had not been made public before. So, I learnt in May 2012 that, apparently, the Nirmala Power project was cancelled in June 2010. This information had not reached
} 
Given the unclear status of the plant, riverbed farmers disengaged for the time being from the plant. Their disengagement takes the form of a "suspended engagement," because they relate their engagement to the plant's construction. Until then, people from Deshnur enjoy the advantages of water storage brought about by what is still the only nearby plant, the mini hydel plant located just upstream of their island.

\section{The Flow of Money in Kenchanaguddam}

The change of the local water flow due to the establishment of a hydel plant has been at the heart of engagement activities of people in and around Kenchanaguddam as well as downstream of the Pusala plant. As I have shown, for different reasons their engagement eventually made way for different forms of disengagement, which, however, were disrupted by yearly protests of Kenchanaguddam's farmers' lobby. In this section I will also detail how the establishment of a power plant seems to be paralleled by the flow of money, and how it triggers engagement activities.

For the Kenchanaguddam GP the flow of money is related to the industrial tax, which the GP is entitled to levy on industrial projects established under their jurisdiction. During the GP meeting in Kenchanaguddam, which I requested to discuss issues related to the power plant, an animated discussion between GP members and the local plant manager broke out. GP members invited the local on-site manager of the power plant to join the meeting because they "thought it would be interesting” (interview GP Kenchanaguddam, 2010). The loud and vigorous discussion followed a comment by the manager when he joined the meeting's conversation. In his comment he turned to the GP members affirming them they had no problems due to the plant, rather, that they "make use of it due to storage of water" (interview on-site manager at GP meeting, 2010). A GP member reaction, provoked by the manager's intervention, sheds light on the issue of contestation triggered by the plant manager. Turning towards the plant manager, a GP member responded angrily: "You tell me whether you have paid tax this year or not!" (interview GP Kenchanaguddam, 2010).

The exchange between the plant manager and the GP member developed into a vociferous crosstalk between the plant manager and all GP members. They accused the Pusala Power plant

the people in Deshnur village when I was conducting my fieldwork and interviews there one month after the project's cancellation. While the project was canceled for Nirmala, the location will remain a potential site for hydel power generation. KREDL handles a policy that allows companies a maximum time span of five years to complete a project. Nirmala received the allotment of the project in June 2002, and after eight years KREDL apparently considered it reasonable to cancel the project for Nirmala and thereby opening up opportunities for other interested companies. 
management of delaying the agreed tax payment of 93.000 Rs., ${ }^{132}$ which the company has to pay yearly to the GP: "Whenever we ask for tax, Pusala pays 10.000 to $15.000 \mathrm{Rs}^{133}$ and never pays after that. ... Now the debt is almost up to 4 lakhs" ${ }^{\text {"134 }}$ (interview GP Kenchanaguddam, 2010). By providing such precise details about the financial amounts of tax payments and accrued debt, GP members stressed not only the significance and urgency of the issue but implicitly also invoked the legality of their claims, which were based on their right to tax industry projects.

According to the GP members the inaccessibility of the plant's executive managers makes it difficult for them to directly voice their demands: "it is difficult for us to contact them ... We have never spoken to them, because the Managing Director comes in the night and leaves by day" (interview GP Kenchanaguddam, 2010). Withholding tax payments in combination with the absence of direct communication is for the GP an indication of the plant owners' lack of commitment to village matters: "Pusala's owners are not bothered about what is happening in the village. ... Only when the power plant faces problems the Managing Director comes. When farmers face problems and call for him a hundred times, he won't come" (ibid.). The accounts of Kenchanaguddam's GP members present the GP as a victim of the managers' behavior, since the managers circumvent tax agreements, are inaccessible for communication, and not interested in village matters.

Pusala's Executive Director ${ }^{135}$ sketched a very different picture of the relations between the local people and the plant's management: "So, all the people are very cunning people here. They always look for money and bribes... If you do not bribe them regularly they'll start blackmailing you in any other way" (interview Executive Director, 2010). For Pusala, the flow of money is not about taxes but about aggression and blackmailing.

Pusala sees itself affected by aggressive civic engagement carried out by people from Kenchanaguddam. The victim of the most recent aggression, which happened in May 2010, was the plant manager, who "was just sleeping in his room ... They attacked him very rudely. There were something around 10-15 people who just came to the room with sticks and everything" (interview Executive Director, 2010). The Executive Director traced this and other attacks back to "a few, four to five, big people in the village," which also have connections to the GP (ibid.).

It is not clear whether the people to whom the director referred were the same as the influential leaders of the strong farmers' lobby, who played a role in determining the location of the sluice gates leading water to Deshnur canal and who yearly mobilize their followers to

\footnotetext{
132 About 1400 Eur.

133 About 160 Eur. to 230 Eur.

1344 lakh is about 6100 Eur.

135 I interviewed the Executive Director, who is the Managing Director's son, a few days earlier than the GP Kenchanaguddam.
} 
intimidate Irrigation officers, when they try to operate them. The Executive Director would neither specify the reason for the aggression nor the names of the alleged perpetrators.

I could not further inquire about the issue during my interview with the GP members, which took place a few days later. Just before I started the interview, the attending local plant manager took me aside and requested me not to mention any of the issues the Executive Director had told me when I interviewed him a few days earlier. This suggests his distress about the matter and his desire to keep precarious issues fueling adversary feelings among GP members out of the discussion. More generally, it underlines the power of "a few big people in the village," which can create an atmosphere infused by mistrust and suspicion, if not threats.

After the assault of the plant manager the director went to the police, but "he never does anything. We bribed the police ... thinking that he might do something - but he never does anything" (interview Executive Director, 2010). As discussed earlier, the decline of caste hierarchies in the rural areas gave way to the rise of other elites, most notably the group of richer peasants. Jeffery writes that the emerging elites "have come to occupy positions of leadership in civic society and are adept in exerting political pressure on the state" (Jeffrey, 2002: 22). In order to do so, powerful "elites shore up their positions through forms of political rent-seeking, for example by creating links with the police and politicians" (ibid.). These findings could explain why the assaults carried out by and under the leadership of some "big people" from Kenchanaguddam were never prosecuted.

Another way in which Pusala sees itself being affected by civic engagement activities is related to collaborative blackmailing. The Executive Director accused an engineer of the local Irrigation Department and people from Kenchanaguddam of working collaboratively to extort money from the company. Pusala's Executive Director described an incident in which he blamed the local Irrigation Department to "provoke the village people" so that they would disturb the maintenance works (interview Executive Director, 2010). "I had to do some maintenance work on the anicuts ... But the village people used to stop me" (ibid.). The protesting villagers hindered the execution of the work, so the Director went to the local Irrigation Department, which is in charge of matters related to water distribution and control, to complain about the issue. Expecting the visit of the complaining Director, the engineer already had a solution to settle the commotion. The Executive Director recalled the conversation with the engineer, who proposed the following to him: "Why don't you call the village people ... and we'll sit here and we'll do some eating and ... we'll settle the amount" (ibid.). After having paid the engineer, "who will give half the money to the village people" (ibid.), the Executive Director could take up his maintenance work again. 
These accounts underscore that Pusala perceived itself hassled by the interests of local inhabitants and by those of the local bureaucracy. According to the director, local people and the Irrigation Department colluded by playing out their respective stereotypical roles to strategically extort money from Pusala. Farmers, concerned about water, acted as protestors, while the public authority got involved in the context of its responsibility for water distribution and control. But instead of supporting Pusala's request to carry out its work without being hindered, the Department profiled itself as negotiator of the bribe.

Leaders from Kenchanaguddam occupy key positions in these rent-seeking activities. They gain access to Pusala's flow of money by strategically mobilizing their followers to engage in protests. By means of protest mobilization leaders engage in shifting temporary coalitions, which are always aimed at extorting funds from the company. At times protests are aimed against the opening of sluice gates, which enables the power plant management to have more water available to run through its turbines; at other times protests are aimed to frustrate the smooth operation of the Pusala plant by threatening staff or hindering maintenance works.

The director's descriptions of the ways in which he sees his company affected depicts Pusala as victim of a context in which "everybody is lying, everybody; everybody eats money" (interview Executive Director, 2010). Mistrust resonates in his accounts of "the people here," who are "cunning," "not trustable" and "not so good as we think" (ibid.). The way Pusala deals with this situation is by bribing: to avoid being press-ganged by local people and to ensure that his plant keeps running, he resorts to the strategy of routine bribing.

In order to contextualize the statements by Pusala's director, it makes sense to briefly pause and have a closer look at the issue of corruption in Indian society. Investigating the issue of political corruption since India's Independence, Singh has found that early on "political corruption moved from the level of folklore to becoming an integral part of national political culture" (G. Singh, 1997: 631). The shift, which began under Nehru, was accelerated during the ensuing terms of offices of Mrs. Gandhi and her son Rajiv. According to Singh, because of Mrs. Gandhi's "quest for absolute power, [she] not only centralized power in New Delhi but also ensured that opposition -both within and outside Congress- was destabilized through the use of 'briefcase politics' and legal, constitutional, and unconstitutional methods” (ibid.: 632). ${ }^{136}$

At the end of her term she left a decaying political and economic system, which led her son Rajiv, who took over her office, to embark on a "programme of political renewal and economic liberalization" (ibid: 633). His reform efforts remained halfhearted, however; selective liberalization was not accompanied by structural adjustments and the fiscal deficit grew. Rajiv,

136 Briefcase politics encompassed "the transfer of vast amounts of black money in the form of cash into the coffers of the Congress party” (Kochanek, 1987: 1290). 
who set out to profile himself as "Mr. Clean," ended his term by being enmeshed in a major scandal of corruption in connection with a Swedish arms manufacturer (ibid.). ${ }^{137}$

The elections of 1989 marked the end of the Nehru-Gandhi dynasty, it giving way to different national coalition governments. As a consequence of increased political competition at the state and national levels, corruption increased: "As political parties have become less centralized, less corporate and more provincial, their sources of funding - business, foreign contracts, 'black money' - have also become less secure” (ibid: 634). Parties increasingly turned to build patronage relationships to secure local vote banks. With the mobilization of lower castes, supported by affirmative action policies since 1989, lower castes emerged as important electorates, courted by parties and demanding favors of them in return (ibid.).

At the same time, corruption, rather than being confined to the political party arena, permeates India's bureaucracy and can be detected "in the system all across the public services" (Transparency, 2005: 1). For most people, the issue of corruption plays out in interaction with public services. This corroborates Visvanathan's observation that "in fact the bribe is the fundamental transaction of the Indian state" (Visvanathan, 1997b: 2378). With the recent passage of the Lokpal and Lokayuktas Bill 2011, the issue of corruption again soared up high on India's political agenda. The passage of the Bill was accompanied by massive protest all over India and can be seen as a reaction to the anger, mainly expressed by the middle class, about the ubiquity of the issue of corruption in Indian life. ${ }^{138}$

Though sketchy, these outlines provide a backdrop for the comments of Pusala's director who resorts to the strategy of bribing. By having to bribe local leaders in order to avoid getting press-ganged and be able to run the power plant, local leaders emerge as another actor in the system of corruption. Recipients of bribes are not confined to the "classic" actors, namely elected government officials and appointed bureaucrats, but local people, exerting their local power, are able to siphon off money for their own advantage.

Pusala's director has described this as "very common over here." To him, "the only solution is that the whole village people have to change. There is no other way that this problem can be solved. The village people should be educated. They should be changed" (interview Executive Director, 2010). He has little hope that this approach will bear fruit, however, as "nobody will like to change them, because they do not listen to what you say. They say that whatever they say is

\footnotetext{
137 Rajiv's precise involvement in the Bofors scandal could never be confirmed, however.

138 The bill can be translated as “citizens' ombudsman bill.” Passed by India's Lok Sabha in December 2011, it sets out "to provide for the establishment of a body of Lokpal [ombudsman institution] for the Union and Lokayukta [ombudsman institution] for States to inquire into allegations of corruption against certain public functionaries and for matters connected therewith or incidental thereto" (Sabha, 2011: 1). The anti-corruption activist Anna Hazare played an influential role in the mobilization of protests when resorting to a hunger strike to exert pressure on the government to pass the anti-corruption bill (Times, 2012).
} 
correct ... Everybody is a king of himself here" (interview Executive Director, 2010). Not being able to counter the power of local leaders, Pusala's director has to operate in a context, in which he feels his voice is not heard. Thus he justifies his strategy of bribing, which ensures him a modus vivendi; it is a way to maneuver through what he experiences as the arbitrariness and selfinterestedness of local people. Generally, he seems to regard this strategy as effective, since he does not attempt to change the situation by resorting to any institutions beyond the local level. Seeking help at institutions higher up the hierarchical ladder does not seem to be preferable to the modus vivendi he found with bribing.

The establishment of the Pusala plant was paralleled by a flow of money. The GP Kenchanaguddam aims to access the flow of money by levying industrial tax on the plant, though with varying success because Pusala exercises control over the flow of money by procrastinating the payments. The connections between the GP and powerful leaders, which might make up for this dependency, are unclear but probable. The phenomenon of local dominant groups influencing public decision-making and behavior of elected representatives of the local government bodies is a recognized problem in India (Vijayalakshmi, 2005). Such an influence seems to be also traceable in the case in Kenchanaguddam, where local leaders, who seem to be well connected with the local government as well as with bureaucratic institutions, play a powerful role. Their unconventional engagement activities are unchallenged so that they use their influence to tap into the flow of money established by Pusala by means of shifting coalitions. Pusala submits to the interests of Kenchanaguddam's influential leaders by resorting to a strategy of bribing, which ensures the plant's profitable operation.

\section{Conclusion}

The establishment of the Pusala power plant changed the local water flow, which brought about advantages as well as disadvantages for the surrounding villages. While for people of Kenchanaguddam and those served by the Sirguppa irrigation canal the water accessibility and availability improved, for farmers served by the Deshnur canal the plant caused water scarcity. Further downstream, people from Deshnur profit from water storage; but their attention is geared to plans of another plant, which would cause significant changes of the water flow in Deshnur's vicinity.

In all cases the flow of water is the reference point for the people to eventually turn to different forms of disengagement. In Kenchanaguddam village disengagement is not due to indifference but due to the useful advantages caused by the changed water flow. In the case of Vinaknagar Camp, disengagement takes place due to resignation coupled with the availability of 
alternatives: Kenchanaguddam's strong farmers' lobby overrides the demands of farmers served by Deshnur canal, but the use of pump sets counters the disadvantage of water scarcity. Farmers from Deshnur disengage from the Pusala plant for the same advantageous reasons as people from Kenchanaguddam and surroundings. Their disengagement related to the Nirmala plant, however, is based on a form of engagement, which is suspended until construction works start. The forms of disengagement in Kenchanaguddam, Vinaknagar, and Deshnur illustrate that besides mobilizing sufficient support, another aspect of not taking up engagement is related to the immediacy of the damage potentially caused by a plant. Considerations to disengage thus encompass a scale dimension as well as a temporal dimension.

Three important actors can be distinguished that play a significant role in shaping people's engagement and disengagement with the (prospective) power plant. First, in Kenchanaguddam, the local MLA used his involvement to broker an agreement between farmers and the company about the anicut's height, upon which people disengaged from their engagement. Secondly, Kenchanaguddam's farmers' lobby holds a powerful position in the conflict, which it displays by intimidating Irrigation officers. The lobby's unconventional engagement resulted in the installation of sluice gates in the intake canal, rather than in the anicut, as proposed by Venkat. Moreover, due to the lobby's intimidating protests, it can influence the distribution of water to the Deshnur canal. The farmers' lobby has a powerful position by being able to determine water distribution without being challenged by public authorities. This may be explained by its rootedness in a system of power dependencies within the faction and between farmers (as voters), MLA's and Irrigation officers. Venkat's disengagement is fueled by his resignation in view of the lobby's power, but can circumvent these disadvantages by resorting to alternative ways to water his fields.

Thirdly, the events in Deshnur Village showed the important role GPs play in information and approval processes related to a hydel plant. In these processes the GP's office-related and personal interests might intertwine. A new industrial project will increase the GP's tax income and thus the GP's ability to spend money on public goods, which in turn increases the public credits the GP receives for his work. The GP members' personal budget goes up when they accept money for manipulating a project approval. The acceptance of bribes points to the shortterm and profit-oriented approach GP members in Deshnur at that time seemed to have been committed to. When hearing about the approval of the project by the GP, potentially affected farmers started to protest against the plant by writing a letter to the district bureaucracy. With this form of conventional engagement, their protest was at its height, but quite soon they disengaged from their activism owing to the standstill of the project's construction. 
The establishment of the Pusala plant brought about a flow of money, which actors tried to control and tap into. The influential role of Kenchanaguddam leaders in demanding bribes underlines their powerful local position. In shifting coalitions they emerged as driving forces for exerting pressure to extort money from the Pusala plant. By resorting to a strategy of routine bribing, the Pusala management sought to ensure a modus vivendi, allowing the company to run a profitable plant.

We have seen that the legitimacy of a situation is created by both the mobilization of people and the immediacy of damage caused by the plant. In the Kenchanaguddam case, the absence of these factors provided grounds for disengagement from the plant: Venkat could not amass support for his critique on the design of the plant and the anicuts and he resorted to ending his engagement. In Deshnur the lack of immediacy and urgency of the potential damage the plant might cause led farmers to suspend their engagement.

As we have seen, different frames of reference were appealed to in order to justify certain forms of engagement and disengagement. Invoking the creation of benefits was a way to claim the legitimacy of an action or situation. Based on the support of many, the agreement mediated by the MLA was legitimated with reference to the benefits for farmers and company alike. Justice is another frame that was invoked to justify forms of engagement, including disengagement: Venkat was confronted with a situation legitimated by many. He referred to the absence of justice as a way to question the legitimacy of the current situation, thereby justifying his disengagement from the plant.

The agreement mediated by the MLA and the farmers' lobby's unchallenged behavior influencing the flow of money and water are examples of the creation of social arrangements, in which legitimacy is permanently prioritized over legality. As a result a new local order is legitimated, which exists in parallel to the overarching law and order. In contrast to the Sugur case, in Kenchanaguddam no attempts were undertaken to try and align local legitimacy with the overarching system of law and order.

Analytically, the permanent misalignment of local legitimacy and overarching legality distorts the categories of conventional and unconventional engagement introduced in the previous chapter. The MLA's conventional engagement has an illegal dimension, and the unconventional engagement activities by the farmers' lobby are unchallenged and ongoing, which de facto legitimizes its behavior permanently. Hybrid forms of conventional and unconventional engagement are the result. 


\section{Chapter 5}

\section{Explaining Civic Engagement with Small-scale Hydroelectric Plants}

\section{Forms, Contents, and Consequences of Engagement}

My research to investigate into forms, content, and consequences of civic engagement with smallscale hydroelectric plants took me to the tribal hills of Orissa, where I visited Wida's and Gram Vikas' micro hydel projects, before I followed Tungabhadra's water flow in Karnataka to study the engagement activities unfolding at the plant close to Sugur and further downstream at the plant close to Kenchanaguddam. In this chapter I will weave together the different findings of my studies in Orissa and along the Tungabhadra River, before I will look for answers, which can help to explain forms, content, and consequences of engagement.

In order to demonstrate the specific characteristics of the respective cases, I structured each empirical chapter differently, rather than applying the same structure throughout. This approach enabled me to disclose salient features that I found to be important and specific in each case, while the continued angle on forms, contents, and consequences of engagement guided me through each case. In Orissa, phases of engagement rendered an intelligible structure, which helped to highlight the predetermined ways along which engagement is expected to take place. In the Sugur case the anicut's shape proved to be an obvious starting point to structure the chapter, because on the basis of the anicut's shape different forms of engagement took their course. In the Kenchanaguddam case, eventually, the forms of engagement, which people resorted to, were connected to their respective location with regard to the plant. Depending on their location, different issues emerged as salient and triggered various forms of engagement and disengagement. The structure that I chose to use in the chapter on people's engagement in Kenchanaguddam and surroundings caters to this.

\section{Forms}

In all three cases, small-scale hydroelectric plants triggered different forms of engagement, which I typified as invited engagement, conventional engagement, and unconventional engagement. Wynne's (2007) concept of "invited" engagement was helpful to conceptualize the engagement activities with micro hydel plants in Orissa. The concept aptly captures how the NGOs invited 
communities to engage in their projects. For the communities, accepting the invitation went along with the commitment to engage in certain predefined ways, comprising, physical, technical, managerial, as well as financial aspects.

Different traits of engagement emerged in the activities of people engaging with small hydel plants along the Tungabhadra River. Protests shaped the activities, ranging from contacting and corresponding with government officials, via founding an interest group, to aggressive behavior. The resemblance of these forms with those described in the political participation literature prompted me to adopt analytical insights from this field of studies. Especially the analytical distinction between "conventional" and "unconventional" (Barnes \& Kaase, 1979) forms of engagement proved helpful in understanding the engagement in Karnataka. I distinguished between conventional from unconventional forms of engagement on the basis of their institutionalization. Implicit in the institutionalized status of conventional engagement forms is the assumption of their legality. Unconventional engagement activities can both be legal and illegal.

In the analysis of the Karnataka cases, two interesting findings regarding the distinction between conventional and unconventional engagement categories emerge. One is related to the tension within a category, the other to the distortion of the engagement categories. First, the identified unconventional forms of engagement in Sugur and Kenchanaguddam revealed a misalignment between official legality and local legitimacy, because the activities violated against legal rules, while locally they were considered to be legitimate. This shows how the creation of legitimacy is the result of a social process that is locally embedded. Kaase and Barnes stressed from the outset the important role legitimacy plays with regard to analyzing unconventional forms of engagement (Barnes \& Kaase, 1979; Kaase, 2003), and my analysis confirms this.

Second, as the Kenchanaguddam agreement mediated by the MLA has shown, a conventional form of engagement was used to legitimate a permanent social arrangement, which conflicted but coexisted with the official law and order. The farmers' lobby's ongoing behavior, which remains unchallenged, shows how this unconventional form of engagement is de facto legitimated permanently. Both incidents result in a permanent misalignment between legality and legitimacy. Analytically, this led to the distortion of the categories of conventional and unconventional engagement activities, which turned into hybrid forms.

\section{Contents}

The different forms of engagement analyzed in this book revolved around different issues. In Orissa, the engagement with micro hydel projects facilitated by the NGOs Wida and Gram Vikas 
was not only about the generation of electricity; the physical, technical, and managerial engagement of the people also provided access to knowledge.

The dominant issues around which engagement activities with the two hydel projects along the Tungabhadra River in Karnataka revolved were related to water and money. As we have seen, changing the water flow, which the establishment of the plants brought about, was a trigger for engagement activities as well as disengagement. Moreover, in Kenchanaguddam, the plant is seen as a source of money and this triggered continued engagement mainly under the leadership of influential lobby leaders.

In the Sugur case farmers, company, and public authorities were all aiming to influence the flow of water, which among other things led farmers to physically destroy parts of the anicut, prompted the company to consider the option of floodgates, and eventually caused the Irrigation Department to issue a final notice of dismantling. In Sugur the flow of water was mainly determined by both the Irrigation Department and the company, while the company could retain control about the flow of money: until the end it determined whether compensation payments were paid - or not paid. In Kenchanaguddam, the farmers' lobby played a significant role in directing both flows of water and money. Under the leadership of influential farmers the lobby engaged in shifting coalitions to extort money from the plant and to limit the water flow feeding Deshnur canal.

In Orissa, the efforts by Wida and Gram Vikas are aimed at empowering poor rural communities, so they can influence the flow of electricity and knowledge. The way and extent people are enabled to access and shape these flows depends on the NGOs' conception of empowerment.

\section{Consequences}

The engagement activities in Orissa and Karnataka gave rise to different consequences. Depending on the conception of empowerment, the engagement activities of people in Orissa lead to scenarios of empowerment, which center on access to electricity or knowledge. As a result, people are empowered as consumers, producers, or entrepreneurs. Each scenario anticipates a different geographical scope. In Wida's projects it becomes clear that the empowerment of people as consumers and producers of electricity is achieved at the local level: electricity is produced and used in and for the villages. Gram Vikas' focus on building a micro hydel team to implement projects follows a regional approach. Through the implementation of decentralized micro hydel projects, a regional cluster is to be built by young entrepreneurs from tribal villages who are supported by NGOs. 
In the Sugur case engagement activities took predominantly shape in the form of protests. The engagement activities of the farmers, formalized under the RHS, were aimed to induce action both on the part of public authorities and the company in order to avoid further submergence and to receive compensation payments. Frustrated by the continued inaction of public authorities, farmers eventually turned to negotiations with the company, not including public authorities. Their engagement led to the Bangalore agreement, which constituted a new approach, tackling both the compensation and submergence issue. Fearing the loss of its influence, the Irrigation Department restored its control by declining the agreement and issuing the notice to dismantle. Although this notice contributed to the avoidance of further submergence, for farmers the decline of the agreement meant that the prospect to eventually receive compensation payments was again deferred to the distant future. With the submergence issue solved and the chances for receiving immediate, directly negotiated compensation payments dwindling, engagement activities slowly ebbed away.

As a result of the long-lasting engagement of farmers under the aegis of the RHS, they eventually succeeded in averting future submergence, which constituted one of the organization's goals. And though this was only a partial victory, a consequence of the farmers' engagement was that they experienced that their engagement activities made some difference. This optimistic note is surely ambiguous, however, because the duration of the farmers' engagement, the amount of crop loss, and the receptiveness with which their claims were met are disproportionate to the results.

In Kenchanaguddam and surroundings, engagement activities led to a scenario of mistrust, with accusations of corruption at its core. Influential farmers' leaders, being able to mobilize many followers, played a key role in this. According to Venkat, these leaders were willing to collaborate with the company in exchange for bribes. Venkat accused the company to instigate leaders from Kenchanaguddam to engage in massive protests when the sluice gates feeding the Deshnur canal are to be opened. The company blamed influential leaders to collude with the Irrigation Department and to use their powerful position to blackmail the company to extort money. In Deshnur, mistrust does not emerge as an issue in connection with the Pusala power plant located upstream, but in connection with the possible establishment of the Nirmala plant close to Deshnur Village. Farmers having land at the river's shore blamed their GP for fraudulent behavior by manipulating an agreement to the plant's construction in exchange for bribes.

Both the ongoing engagement activities by the farmers' lobby and the disengagement to which Venkat and farmers from Deshnur resorted to perpetuated the status quo. This situation is permeated by mistrust between villages (of Kenchanaguddam and Vinaknagar), between villagers 
(in Deshnur), between the company and villagers (from Kenchanaguddam, and from Vinaknagar). The engagement activities of the farmers' lobby led to the establishment of power structures, which exist alongside public government institutions. As a result, public government institutions are weakened and thereby people's possibility for demanding accountability and redress.

After having detailed the different forms, contents, and consequences of engagement in Orissa and Karnataka, I will now move on to the question: what explains the forms, contents, and consequences of engagement with small-scale hydroelectric plants in India?

\section{Explanatory Variables of Engagement}

In this section I will look at different variables, which help explain forms, contents, and consequences of civic engagement in Orissa's hilly South, and at the two small hydel plants close to Sugur and Kenchanaguddam along the Tungabhadra River in Karnataka. Explanations for the occurrence of engagement activities described in the literature on political participation are diverse and tailored to the studies' respective focus, resulting in different emphases and refinements. An important factor, which has been confirmed by many influential participation studies, is people's access to resources in order to act (Barnes \& Kaase, 1979; Milbrath \& Goel, 1977; Parry et al., 1992; Verba \& Nie, 1972). In addition, explanations of engagement by citizens commonly relate to "situational elements such as mobilizing events and conflicts, integration in networks, and institutional framework conditions" (van Deth, 2003: 184). ${ }^{139}$

The identification of the variables, which help to explain forms, contents, and consequences analyzed in this book, is based on a combination of my analytical findings and established insights from the participation literature. As a result, when explaining forms, contents, and consequences of engagement in Orissa and Karnataka four factors emerged as significant explanatory variables. Together, these four variables use recognized insights from the participation literature and enrich them with inductively derived findings from my own research.

The first variable looks at how engagement activities were triggered and relates to the idea that some change or event in the life of people leads them to engage. I will refer to this variable as "situational elements." The variable "organization" of engagement expresses the assumption that certain structures and resources are needed for the organization of engagement. "Framework conditions" as the third variable address policy-related aspects as well as other contextual factors that embed engagement activities. This variable thus addresses broader context factors that play a

\footnotetext{
${ }^{139}$ My own translation.
} 
role in the emergence and shape of the engagement activities. The fourth and last variable, "technology design," investigates the relation between design of the technology and engagement. The specific focus of my research on civic engagement with technology underpins this last variable. It is based on the assumption that the design of a technology shapes the forms, contents, and consequences of engagement with this specific technology.

In principle, each explanatory variable can shape forms, contents, and consequences of civic engagement. However, as we will see, the variables "situational elements" and "technology design" seem to relate mostly to the content of engagement. The variable "organization," which looks at whether and how engagement can be and is organized, and what strategies the actors choose, is the salient variable which relates to forms and consequences of engagement. By influencing the strategies and behavior of engaging actors, the variable "framework conditions" plays a significant role in explaining forms of engagement.

\section{Variables of Engagement with Micro Hydel Plants in Orissa}

In the following section the four explanatory variables will be detailed for the case study in Orissa.

\section{Situational Elements}

Certain basic geographical conditions have to be met in order to generate electricity using hydroelectric technology. Aside from a preferably constant flow of water, there needs to be the possibility to make use of a certain head, or difference in height, so that the water can pick up speed before hitting the turbines, which in turn drive the generator. Issues concerning the geographical suitability, financial means and the NGOs' managerial capacities need to be considered or settled before NGOs start a project.

Yet crucially, and apart from geographical, financial, and managerial issues, Wida and Gram Vikas made the start of a micro hydel project dependent on the approval of the local communities. In the NGOs' strive for a balance between suggesting without imposing and facilitating without pushing a technology for socio-economic development, they invited the community to engage in a project. The acceptance of this invitation by the people, or the people's own request asking the NGO to facilitate a micro hydel project in their village, formed an integral part in the advance process leading to project implementation.

Trust and familiarity with the NGOs' work played a supportive role in the people's decision to accept a project invitation or to approach the NGO to request a project. Both NGOs are 
established development actors in the region with a record of development work in the villages. For example, Wida's earlier work with women in Putsil encouraged women to voice their interests and lobby for a micro hydel plant. Besides existing development work relations, completed projects functioned as a trigger for villagers to get engaged with micro hydel projects. Visiting a plant of a neighboring village caused people to desire the ability to generate electricity in their own village, too. Both these requests, in turn, relieved the NGOs from having to lobby for a technology and instead enabled them to take on the role of responsive facilitators.

\section{Organization}

In the facilitation of micro hydel projects Wida and Gram Vikas address the community of a village or of several villages. Thereby the community emerges as the general organizing unit at which the NGOs' development efforts are directed. In the literature on political participation the relation between community and participation is underpinned by "the view that where people are highly integrated into the local community, and where they identify strongly with it, participation would be greater" (Parry et al., 1992: 12ff.). Parry et al. find that investigations about communitarian approaches to participation are complicated by the fact that the term "community" is simultaneously used in a descriptive and a prescriptive way (ibid: 13).

The difficulty also shows in the field of development studies, where communities play a role in participatory development approaches. An oversimplified conceptualization of the community as one homogeneous entity endowed with certain qualities contributes to the creation of what Cleaver calls "the myths of community" (Cleaver, 1999: 603). ${ }^{140}$ These myths are created when communities are not seen as a site of both solidarity and conflict; when their real structural and resource constraints are neglected and an uncritical belief in their resourceful capabilities is upheld; when tensions between cultural traditions and modernizing projects are disregarded; and when oppressive features of local cultures are overlooked (ibid: 603ff.). Nevertheless, despite these complications the concept of community is valuable precisely because it describes "the case that most people's lives are conducted within the confines of the locality in which they reside" (Parry et al., 1992: 14).

Community engagement in Wida's and Gram Vikas' micro hydel projects was related to the phases through which each project runs. The organizing principle of the community's activities consisted of phases. In the initiating phase, people were invited to attend informative meetings about the project and discuss their opinions and concerns. In all of the projects facilitated by

\footnotetext{
140 The simplistic conceptualization of "communities" was questioned before, for example by Guijt and Shah in their book The Myth of Community, in which they analyzed the use of the "community" concept in approaches using participatory rural appraisal (1998).
} 
Wida and Gram Vikas, the initializing phase led to the communities' approval and acceptance of the engagement duties accompanying each project. The construction phase foresaw that, generally, each household engaged by contributing labor and tools in order to build the plant. Once the plant was built, the community's engagement continued in the form of activities related to the plant's management and operation.

Another important institution to organize engagement consisted in the early establishment of a micro hydel committee, which governs the project at community level. The role of leaders who are usually part of the committee played an important role in mobilizing the community. In Putsil, Prem Patro was crucial for convincing people about the possibility to generate electricity for the village and to obtain their support. In Bodomanjari, another project facilitated by Wida, leaders in the hydel committee ensured that engagement was sustained during construction works. Besides the key role of leaders in providing access to and mobilizing the village community, Gram Vikas also identified the village youth as motivated and motivating actors in the project implementation.

The decision for a hydel project entailed that a division of labor had to be ensured. In Bodomanjari, leaders of the micro hydel committee convinced the community to share essential tasks, so that both agricultural and the plant's construction works could be carried out. The division of labor went beyond the construction phase: in Putsil the daily work by the "barefoot engineers" is compensated with food that is prepared for them by each household on a rotational basis. With the implementation of a micro hydel plant, diffuse reciprocity norms emerged (Keohane, 1986). People invested in a collectively used good in the expectation that this will somehow pay off in the future, by receiving electricity, acquiring skills, or improve the social status by showing commitment.

From the beginning of each project the micro hydel committee was involved in the project's governance on the village level, ensuring that engagement activities were carried out in the anticipated phases. Early transfer of responsibility to the committee, appointed by the community, reflects the NGOs' aim to create project ownership by the people. Wida and Gram Vikas find that project ownership is created and sustained by a process of engagement throughout the project. Since the success of a project is seen to be dependent on ownershipcreating engagement activities by the community, organizational efforts by the NGOs are tailored toward mobilizing and sustaining these forms of community engagement within the pre-defined phases. 


\section{Framework Conditions}

Learning plays an important role in the implementation of micro hydel projects. Especially Gram Vikas emphasized the value of learning processes in the different micro hydel projects, which the NGO facilitated. Learning was not confined to the villagers, who learnt skills related to the construction, management, and operation of the plant. Gram Vikas' involvement with energy projects in general, and in particular its move toward localizing component fabrication and activating local expertise when facilitating micro hydel projects was itself a learning process that the NGO actively pursued. The idea of a regional cluster of micro hydel projects fits well into this approach: it broadens the scope of learning by fostering reflection and knowledge exchange between different NGOs.

From a policy perspective Wida's and Gram Vikas' micro hydel projects contribute to India's decentralized rural electrification efforts. Government of India foresees decentralized electrification in cases where the electricity grid has not yet reached or where grid supply is considered as not feasible or not cost-effective (GOI, 2009). In the context of decentralized electricity production, community engagement fits within the functional necessity to generate electricity off the grid.

The community-based development approaches by Wida and Gram Vikas are well embedded in the international development aid and funding context, where participatory development projects have become the standard format. So ubiquitous has participation become in development work that some even questioned it as "the new tyranny" (Cooke \& Kothari, 2001). Nevertheless, for Wida and Gram Vikas participatory development approaches offer a "technology of governmentality" (Cornwall, 2006: 79) with which they aim to create ownership by the people and thereby empower marginalized communities. Instrumental and normative considerations underpin Wida's and Gram Vikas' participatory approaches. While engaging the community is not only seen to make the projects more efficient, Wida and Gram Vikas also aim to empower local people by giving them a voice in decisions which affect their lives.

\section{Technology Design}

Wida's and Gram Vikas' micro hydel plants are designed in a spirit of "small is beautiful" and "appropriate technology," and relate to ideas of self-sufficient village communities in a Gandhian sense. Small-scale, social participation and control, environmental soundness, self-rule and decentralization are key aspects. Essentially, the plants are to cater to the local needs of people in a socially, economically, and ecologically sustainable way. To do so, the engagement of local people is regarded as the lynchpin of the plants' functioning, and it informs the design of the technology: the plants are designed to enable people's engagement in the building, operation, and 
maintenance processes. The whole community is expected to participate in the construction of the plant by contributing labor and tools. Because generally no advanced tools or motorized equipment are available, hard manual labor is needed for its construction. ${ }^{141}$

The technology is designed in such a way that no external experts are needed for its daily operation and maintenance, instead, during the construction phase "barefoot engineers" learn how to operate and maintain the plant. The technology design enables NGOs to shift the responsibility of the project implementation to the community. Nevertheless, Gram Vikas and Wida remain in a stand-by position, so communities can fall back on the NGOs in case difficulties arise that the people cannot solve on their own. The technology is thus embedded in mechanisms of hand-holding by the facilitating NGOs.

There are different approaches as to what extent a micro hydel technology should be "demystified," so that the technology is taken out of the expert context and made intelligible for local people. Wida does not emphasize the importance of technology demystification beyond the realm of routine operation and management, whereas Gram Vikas' approach clearly aims to open up the micro hydel technology as much as possible by localizing fabrication processes and acquiring components locally. The NGO's aim to build a team for implementing new micro hydel plants in the area is a logical continuation of this approach.

Through the conceptualization of the micro hydel projects as community-based, engagement is built into project design and implementation. In Wida's and Gram Vikas' micro hydel plants, engagement is a sine qua non condition of project implementation, so that the acceptance of a project inevitably goes along with certain engagement activities. The lack of engagement has direct consequences for the availability of service, since electricity only flows if the community is committed to its construction and if it ensures the plant's continued operation and maintenance.

\section{Variables of Engagement with Mini Hydel Plants in Karnataka}

The following section discusses the variables in the Karnataka cases. Since the framework conditions and the technology are very similar in the Sugur and the Kenchanaguddam case, these variables will not be described separately for each case. The "situational elements" variable and the "organization" variable, however, will be detailed separately.

\footnotetext{
${ }^{141}$ For this reason, Gram Vikas for instance tries to minimize the concrete used in designs: the leaner the design of
} the civil works layout, the less concrete has to be used and carried up the construction site. 


\section{Situational Elements at the Sugur Plant}

Engagement activities at the Sugur mini hydel plant were started by the heightening of the anicut stretching across the Tungabhadra River. The SLS company had incorporated the anicut structure into its plant design and considered it profitable to significantly increase its height in order to increase electricity production. Initially, farmers believed that an increased anicut would ensure more and longer availability of water, yet with the approaching monsoon season doubts emerged, since the heightened dam threatened to submerge their lands.

With the occurrence of the flood in 2004, causing submergence and crop loss, two rationales crystallized that were to underpin conventional and unconventional engagement at the Sugur plant site. First, engagement activities aimed to avoid future submergence. The two options discussed to achieve this were the lowering of the anicut and the installation of floodgates. As we have seen, after years of engagement the anicut was ultimately dismantled and with its lowering the floodgate option was discarded. Besides the avoidance of future submergence, the second rationale underpinning engagement was the experience of crop loss. The submergence during the 2004 floods was the first of a series that caused crop loss and, with it, loss of financial income for the farmers near the Sugur plant. Hence from the beginning, engagement activities aimed to receive financial compensation for the accrued loss of farmers having land close to the river's shores.

Local government authorities dealt with the issue of repetitive submergence and crop loss due to the raised anicut only reluctantly and slowly. Sustained engagement activities were carried out to publicize the issues and push the urgency of their consideration by public authorities. The intensity of written correspondence but also the destruction of the anicut by farmers and the hostage taking are examples of this. Aside from raising awareness and demanding the handling of the issue, continued engagement activities also led to discussions in alternative actor constellations: for example, during the Bangalore meeting, farmers' representatives and the new plant management of the Bhoruka company discussed the option of floodgates and compensation payments.

The heightened anicut changed Tungabhadra's water flow causing yearly submergences, which triggered engagement activities. Only when the issue of submergence was settled by lowering the anicut, and compensation claims were to be sorted out by the court's verdict, farmers' engagement faded.

\section{Organization at the Sugur Plant}

Rao played a leading role in organizing engagement activities at the Sugur plant. Several aspects underpinned his leadership in the unfolding conventional and unconventional forms of 
engagement. Rao is a well-off businessman based in the taluq's capital Gangavati. His work gave him the time and the means to become engaged. Though Rao does not cultivate the land he owns along Tungabhadra's shores close to his home village Ullenoor himself, he has family ties and contacts in the village. He is thus no outsider but known in the villages around the Sugur plant. As other farmers of the area, he, too, is affected by the submergence due to the raised anicut. By being the KRRS' District's Secretary, Rao fills a high office in this organization and is familiar with representing farmers' interests and the formalities and procedures involved in representation and organization. When forming the RHS, going to court and interacting with the different authorities, he could draw on the skills and expertise acquired during his work at the KRSS. So, the combination of having time and means to engage, being known in the villages and being himself affected by the plant, as well as having skills and expertise in representation underpinned his role as leader in the engagement activities with the Sugur plant.

Realizing that farmers evaluated the KRRS as being too general as well as too politically tinted in its work, Rao soon organized engagement under the aegis of the newly founded RHS, which seemed more suitable as an umbrella for engagement. The RHS is an issue-oriented organization, formally registered in August 2004 and created with the double aim of avoiding future submergence and receiving financial compensation. For three and a half years these aims were not challenged by other competing interests of farmers within or outside the organization.

The two goals served the interests of a broad constituency, since they represented the interests of left bank farmers with riverbank land as well as those farmers affected through submerged pump sets. The RHS stood open to anyone having a stake in the issue. This openness implied the conflation of being affected with supporting the case of the RHS. As a consequence, the RHS could claim to speak for all the farmers who were (potentially) affected by the plant. By representing all affected farmers the RHS established itself as an interest organization with a wide support base in the conflict about submergence and compensation. The RHS did not, however, insist on being the only voice of the farmers. Rather, it embraced other influential farmers' leaders with whom it lobbied for its demands. This not only ensured a broad representation of farmers' views, but also helped in legitimizing the results negotiated during meetings with public authorities and the company. The homogeneity of the demands made this possible, because the demands expressed by individual leaders and by the RHS were congruent.

Only in February 2008, after the anicut was dismantled by Bhoruka and discussions concentrated on compensation payments, the unanimity of the farmers' position on compensation demands broke up between left bank farmers and a group of right bank farmers downstream of the plant. This disaccord gave the company the possibility to again procrastinate 
the issue of compensation, ultimately linking it to the court's long pending verdict. With the avoidance of submergence sufficiently tackled and the compensation demands linked to the court's verdict, the RHS stopped to actively engage in the compensation issue.

In Sugur key organizational elements of engagement related to the role Rao could assume during the conflict. Rao had access to recourses, which enabled him to lead engagement activities at the Sugur plant. Engagement activities were organized under the RHS, which could for long maintain a unanimous interest position. Yet, after the goal to avoid future submergence was realized, the unanimity of the farmers' position broke on the financially laden issue of compensation.

\section{Framework Conditions of the Plants close to Sugur and Kenchanaguddam}

The mini hydel plants built along the Tungabhadra River close to the villages Sugur and Kenchanaguddam can be seen as manifesting the outcomes of policy efforts, which aim to liberalize India's electricity sector by unbundling generation from transmission and distribution, and subsequently privatizing these segments. Private sector participation is viewed as promising in particular regarding the generation of electricity with renewable energy. Together, these efforts set out a policy frame that enables private entrepreneurs such as Bhoruka and Pusala to operate their small hydel plants and generate renewable electricity for the grid.

Light-touch regulations proposed by the World Bank for unleashing the potential of renewable energy relate well to India's overall regulatory framework for electricity, which focuses on enabling the liberalization and privatization of the sector. "Accelerated environmental and social clearances and packages deals" (WB, 2010: 10) might be in line with efforts of economic market liberalization. However, the Sugur and Kenchanaguddam cases highlight that these policy proposals should be complemented by provisions ensuring the interests of those who live next to these renewable energy projects.

In contrast to Orissa, where civic engagement was indispensable for the plant's approval, construction, and operation and management, in Karnataka engagement beyond the approval of the plants' construction was not incorporated in the projects. Instead of being invited, engagement activities in Karnataka took place mainly by contesting the plant's operation.

Persistent references to the ubiquity of corruption and bribes provided the overall backdrop that embedded unfolding engagement activities. In the Sugur case, corruption was seen to explain why engagement activities were long ignored by government authorities. While in Sugur corruption seemed to be confined to the interactions between the company and the Irrigation Department, in the Kenchanaguddam case the issue emerged much more saliently. Corruption 
was much more presented as an all-encompassing condition, permeating the deeds of most of the actors. Corruption is a known malady in India's administrative and political system, including the South Indian irrigation bureaucracy. With the construction of the plants a new source of money was established and accessing it constituted a great part of the engagement activities, which took place around the plants in Sugur and Kenchanaguddam.

We have seen that different frames of reference were invoked to justify the engagement activities and situations thus created. These frames relate to the appeals to legality, legitimacy, and justice. Rao followed a legalistic approach with his engagement activities: the foundation of the officially registered RHS to represent the farmers' interests and his appeal at Karnataka's High Court exemplifies this. The resort to unconventional forms of engagement with a high degree of legitimacy in the eyes of the people also formed part of this approach. Demolishing parts of the anicut and taking engineers hostage were justified by appealing to the frame of legality. In Kenchanaguddam the frame of legitimacy was invoked to permanently legitimize a situation that benefited the majority of people. If not foreseen in the construction specifications set by Karnataka's Water Resource Department in Bangalore, the agreement mediated by the MLA, which foresaw to raise the anicut by a foot, was supported by many.

The third frame of reference that emerged is the appeal to justice. By appealing to the frame of justice, a higher order is invoked that may question a situation that many people find legitimate. Venkat appealed to justice, when the majority of the people accepted the placement of the extra sluice gates in the intake canal wall rather than in the Gangammana anicut, and when improper opening of the gates was enforced by Kenchanaguddam's farmers' lobby.

To sum up, policies relating to the liberalization and privatization of the electricity sector constitute important framework conditions for the establishment and operation of the small hydel plants close to Sugur and Kenchanaguddam. Within this policy framework, civic engagement activities shape, and are shaped by, local networks with their relationships of corruption and their endemic norms of legitimacy. The corruptive practices of different local networks - which include the business, public, and civic sector - render the regulatory framework void. Within this sheath of regulations, endemic norms of behavior are legitimated that locally frame the working of the plants.

\section{Technology Design of the Plants close to Sugur and Kenchanaguddam}

Different to what we have witnessed in Orissa, the technology used in the mini hydel plants in Karnataka is not tailored towards engagement of local inhabitants. People are neither involved in the construction, operation, or management of the plants, nor do the plants provide the villages 
with more electricity. In fact, for local people the plants are more about the flow of water and money than they are about the flow of electricity. Rather than stimulating engagement and enabling local use, the plants are conceptualized within the policy rationales of promoting private entrepreneurship with renewable energy options and electricity generation for the grid.

Taxes paid by the hydel company to the GP are a way to ensure that the local community is compensated for the establishment of a plant. However, this exchange is only convincing if the taxes are actually paid by the company, and if they are spent accordingly by the GP so that they do not end in the private purses of GP members. This points to a more general issue that emerged from the analysis. The Karnataka cases have shown how corruption influenced the design and implementation of the plants. These practices of corruption, which penetrate every sector of society, constitute a huge challenge for the local functioning of small hydel projects.

A specific characteristic of the plants in Sugur and Kenchanaguddam is that both incorporate anicuts in their layout. From the point of the hydel developers, incorporating existing anicuts in the design of a power plant seems convenient because using these structures reduces time and costs needed if new barriers were to be built. In the respective detailed project reports, the anicuts were presented as "old and dilapidated" implying that they were out of use and function. In effect, however, the incorporation considerably changed the characteristic features of the anicuts: due to the changed shape of the anicut at Sugur farmland inundated, and the amended water permeability of the anicuts at Kenchanaguddam caused a significant change of the water flow. The effect of the anicuts' incorporation in Sugur and Kenchanaguddam's mini hydel scheme was that the structures turned into contested objects. Importantly, contestation focused on the way the anicuts were incorporated into the scheme, rather than questioning the overall existence of the hydel plants. This suggests that small-scale hydroelectric plants are much more likely to become socially accepted technologies than large hydro dams.

\section{Situational Elements at the Kenchanaguddam Plant and Surroundings}

For people from Kenchanaguddam engagement with the Pusala plant became only an issue when the advantages of water storage brought about by the raised anicut turned into a disadvantage due to submergence. Consequently, the occurrence of damage led people to destroy the anicut's raised layer. Mediated by the MLA, a generally accepted height was found, which ensured extra benefits for both the people from Kenchanaguddam and the company.

For Venkat from Vinaknagar, having lands located at the southern end of Deshnur Island, the construction of the plant - especially the strengthening of the anicuts - implied that the water supply of the small Deshnur canal was threatened to run dry. This significant change of the water 
flow was the trigger for his engagement, which he conducted in the interest of the farmers from Vinaknagar. In letter correspondence and meetings with public authorities he expressed his discontent and proposed to install sluice gates in the Gangammana Anicut. Yet, he could not counter the influence of the strong farmers' lobby in Kenchanaguddam, so that the gates were eventually placed in the wall of the plant's intake canal. But despite the installation of gates, water supply to Deshnur canal remained contested, as Venkat complained that the gates were not properly operated. He nevertheless disengaged from the issue, mainly due to the inability to mobilize enough supporters for his case and especially because he could resort to alternative ways of watering his fields.

Downstream of the Pusala plant at the northern part of Deshnur Island people enjoyed the advantages of extra water availability due to the plant built close to Kenchanaguddam. Farmers from Deshnur Village with land along Tungabhadra's right arm became only concerned when they heard about another small hydel plant, which Nirmala Ltd. planned to build on Deshnur Island. These plans triggered the engagement of potentially affected farmers, who started to voice their concerns about the project's location and design in a common letter to the District Authorities. After sending the letter, farmers disengaged from the issue, due to the lack of urgency, since there were no indications of an immediate start of construction. In fact, Nirmala seemed itself inclined to disengage from the project, by trying to sell the acquired land.

Venkat's engagement, demanding the installation of extra sluice gates in the Gangammana anicut, led the farmers' lobby from Kenchanaguddam to engage with the plant. Gates in the anicut threatened the water interests of farmers from Kenchanaguddam and surroundings, since gates would potentially lower the water channeled toward the inlet of the Sirguppa irrigation canal. This potential disadvantage triggered their unconventional engagement by pressuring the local Irrigation Department officials to install the gates in the inlet canal. Faced with a demand, which catered to the multitude of water users of the Sirguppa irrigation canal, the officers conceded to this. With the gates installed in the inlet canal, engagement activities by the lobby shifted to agitations against the gates' opening. Venkat blamed that these protests were instigated by the Pusala company, which bribed lobby leaders to organize these agitations. The company, too, accused leading figures of the lobby that selfish financial interests motivated their continued engagement with the plant: the company claimed that by colluding with local Irrigation officers the lobby used routine maintenance works carried out by the company as an opportunity to extract money.

Engagement activities described in the Kenchanaguddam case study took place during different instances. While Venkat's engagement unfolded during the construction of the plant, 
the activities of people from Kenchanaguddam including those under the leadership of the lobby, took place when the plant was operating. Engagement from farmers in Deshnur Village, concerned about plans of the Nirmala company, took place during the planning phase of this project. Different situational elements related to the flow of water and money thus triggered engagement during different temporal stages.

\section{Organization at the Kenchanaguddam Plant and Surroundings}

Similar to the case study in Sugur, in the Kenchanaguddam case leaders played an important role in the organization of engagement activities too. With the beginning of the construction works at the Pusala plant, Venkat, one of the well-off farmers from Vinaknagar, realized that the design would block the water supply to the Deshnur anicut, which in turn fed the small Deshnur canal. This change of water flow meant that in lean water months, the Deshnur irrigation canal would be deprived of water. Venkat took the lead in protesting against the plant's design. In his protests, comprising letter correspondence and meetings, he made use of his contacts in the Irrigation Department, enabling him to draw the attention of high-ranking irrigation officials to the matter. Although it turned out that the sluice gates were to be sited in the wall of the intake canal and their opening would be continuously obstructed by Kenchanaguddam's farmers' lobby, it was due to Venkat's protests that extra sluice gates were at least considered and added to the plant's layout. Just as Rao in the Sugur case, Venkat had the time, means, skills, and contacts to lead and organize engagement activities. What Venkat lacked was a critical mass of people supporting his case. This, together with the availability of alternatives, led him to disengage from the issue.

Offe speaks about the "organizability" of issues as one condition for the organized representation of public interests (2003: 21). ${ }^{142}$ "Organizable" are issues if sufficient motivational and material resources can be mobilized by a specific group of people with a sufficient interest in pursuing the issues. The second condition Offe identifies for the organized representation of public issues is the "conflict ability" of interest, so that a group can make a plausible threat to withhold certain system-relevant activities (ibid: 22). While Venkat had enough material resources to organize interests, he could not mobilize sufficient motivational support, which impacted on the "organizability" of interests. The lack of motivational resources also reduced the "conflict ability" of the interests, since there were not enough people who could plausibly threaten to inflict costs on their opponents. So, in addition to the unanimity of interests, Offe's

${ }^{142} \mathrm{My}$ own translation. Although Offe introduces these conditions in the context of unions and syndicates, it is useful also in the similar case of interest organizations. 
"organizability" and "conflict ability" are confirmed as important factors for organizing civic engagement.

A large number of supporters underpinned the influence Kenchanaguddam's farmers' lobby could exercise when engaging with the hydel plant. Client-patron ties provide an explanatory background for the ability of leaders to call up people's engagement. Neher finds that these patron-client based relationships "form the basis of the political and social structure of South, Southeast, and East Asia" (Neher, 1994: 950). Based on these "exchange bonds ... a person who has command over resources attains power over others who need those resources but have only limited access to them" (ibid.). In Kenchanaguddam a number of lobby leaders were able to use their "exchange bonds" when organizing engagement of farmers to enforce their water and financial interests.

Both case studies in Karnataka suggest a relation between the availability of resources and the organization of engagement activities with the mini hydel plants. Rao, Venkat, and Kenchanaguddam's lobby leaders are well-endowed actors, determining how activities around the plants take shape. ${ }^{143}$ These findings are in line with what in the literature on political participation is discussed with reference to the socio-economic status model, which sees a positive relation between individual resource endowments and the individual capacity and willingness to employ conventional and unconventional forms of participation. ${ }^{144}$ The Karnataka case studies of this book suggest that well-endowed individuals not only engage in the activities but can also take a leading role in the organization of this engagement.

\section{Conclusion}

As I have shown in this book, engagement activities in Orissa and Karnataka took different forms, revolved around different contents, and led to different consequences. To explain why this is the case, I introduced different variables - situational elements, organization, framework conditions, and technology design - and detailed them for each case study. The explanatory power of each of the variables is differently weighted in every case, so that in each case different variables emerge saliently.

\footnotetext{
143 The protest that formed around the issue of the proposed Nirmala plant close to Deshnur Village, too, indicates the importance of resources in engagement. We learnt that for many people the ability to express concerns and interests in written form is not straightforward, since not everyone is literate. Writing a letter made the author the first contact point for correspondence and information exchange, and thereby implicitly endowed him with an important role in the process of engagement, if it were to be maintained.

144 This correlation is especially well documented for studies concentrating on the global West, generally finding that white male men who enjoyed more higher education, have higher income, and occupy higher social positions are more likely to participate (Verba \& Nie, 1972) (Milbrath \& Goel, 1977) (Barnes \& Kaase, 1979).
} 
In Orissa, the technology design emerges as key variable for explaining forms, contents, and consequences of engagement. The chief rationale along which Wida's and Gram Vikas' micro hydel projects are conceptualized is the idea of community-based engagement. The technology is designed in such a way that it enables people to engage in the plant's construction, operation, and management.

Although the change of the water flow through the construction of a hydel plant was the starting point for engagement activities in Sugur and Kenchanaguddam, different variables dominate explanations of why the activities unfolded the way they did. The engagement taking place in the Sugur case was chiefly influenced by the way Rao organized the activities. Consequently, engagement under the aegis of the RHS shaped the course of events.

In Kenchanaguddam framework conditions of corruption and bribes, in combination with the existence of powerful leaders organized in a farmers' lobby, provided the key backdrop for the unfolding of engagement. By using their patron-client ties influential lobby leaders could summon and organize engagement not only to determine the flow of water, but also to access the flow of money established with the plant.

To sum up, while the "technology design" is dominant in the Orissa case study, the variable "organization" dominates explanations of engagement in the Sugur case. Lastly, both "framework conditions" and "organization" emerge as important explanatory variables in Kenchanaguddam. Identifying the saliency of some variables should not be understood as implying the unimportance of the others. In fact, as the elaboration of the different variables during the main part of this chapter underscores, it is precisely the interplay of the variables, which together help to explain forms, contents, and consequences of civic engagement with small-scale hydroelectric plants in India.

In this book I have approached civic engagement as an empirical phenomenon that I researched in the area of small-scale, renewable energy technologies in India. By choosing this research focus I aimed to show that neither scale nor image of technologies needs to diminish empirical interest in their functioning in society. Studying the empirical properties of civic engagement has received less attention within the field of STS, where questions have concentrated on issues of expertise and knowledge production, procedures, and objects of politics. In this literature, rather than constituting the main focus, civic engagement emerged as an implication.

To study civic engagement as an empirical phenomenon, I chose to use forms, contents and consequences as heuristic. Insights from the field of political sciences, where civic engagement is mainly conceptualized as political participation and an established field of research, informed my 
analysis. A major focus within the political science literature on political participation is on the repertoire of manifestations of engagement activities on an aggregated level and its implications for conceptualizing the notion. ${ }^{145}$

A consequence of this aggregated focus is the conflation of "forms" with "contents" of engagement. With the analysis of the three case studies I have shown the value of disentangling both notions. The Orissa case underpinned the empirical importance to distinguish forms from contents. The content of the invited, community-based engagement in the projects of Wida and Gram Vikas differed and led to different consequences. Wida stressed the issue of electricity to empower poor communities, while Gram Vikas foregrounded the issue of knowledge in its development efforts, so that different scenarios of empowerment emerged. The Karnataka case studies draw attention to the finding that contents of engagement may be counter-intuitive. Civic engagement with small-scale hydroelectric plants in Karnataka does not revolve around the issue of electricity; instead, water and money come to the fore. What is more, the overall existence of small hydel plants - unlike that of large dams - went unquestioned, so they seem much more likely to become socially accepted technologies. Both findings provide important insights for policy approaches governing small hydel plants in India.

The forms of engagement taking place at the Kenchanaguddam plant put pressure on the analytical categories of conventional and unconventional forms of engagement. The agreement mediated by the MLA and the lobby's ongoing behavior permanently misaligned legality and legitimacy, with no attempts being undertaken to change this situation. In the literature on political participation, legitimacy has been recognized as an important reference point for distinguishing conventional and unconventional engagement activities (Kaase, 2003; Kaase \& Marsh, 1979). As a result, engagement activities, which have once been labeled as "unconventional," have over time been re-conceptualized as "conventional" engagement. Empirical evidence motivated in this literature confirms a dynamic that is based on an alignment of legitimacy and legality over time. The Kenchanaguddam case questions this dynamic and draws attention to a scenario in which a legitimated local order conflicts, yet coexists, with an official law and order over time. Analytically, this resulted in the emergence of hybrid forms of unconventional and conventional engagement, which express this tension.

My book has shown that civic engagement with hydroelectric plants opens up questions of power, both in terms of electricity and in terms of people's social power to influence a development. We have seen that small-scale hydroelectric plants are not only about electricity as a technical property but are inextricably linked to issues of social power. This links to the

${ }^{145}$ For an overview, see Parry et al. (1992) or van Deth (2003). Influential studies expanding the repertoire and notion of political participation include Verba and Nie (1972), Kaase and Marsh (1979), and Putnam (2000). 
constructivist understanding that the development of science, technology, and society is coproduced (Jasanoff, 2004). Neither is technology exclusively technological nor is society merely social; instead, we live in a technological culture (Bijker, 2006). By focusing on civic engagement, my book provides an argument for the continued importance of the voice of people in the development of science and technology in society. 


\section{Appendix A: Abbreviations}

\begin{tabular}{|c|c|}
\hline Cusec & Cubic feet per second (about 28 liters per second) \\
\hline DC & District Commissioner \\
\hline DDG & Decentralized Distributed Generation \\
\hline GATT & General Agreement on Tariffs and Trade \\
\hline GOI & Government of India \\
\hline GP & Gram Panchayat \\
\hline GW & Gigawatt \\
\hline Hydel & Hydroelectric \\
\hline ITDG & Intermediate Technology Development Group \\
\hline IPP & Independent Power Producers \\
\hline IRDWSI & Integrated Rural Development of the Weaker Sections in India \\
\hline KREDL & Karnataka Renewable Energy Development Ltd. \\
\hline KRRS & Karnataka Rajya Raitha Sangha (Karnataka State Farmers' Association) \\
\hline $\mathrm{kW}$ & Kilowatt \\
\hline lakh & $\begin{array}{l}\text { A unit in the South Asian numbering system equal to one hundred } \\
\text { thousand }(100,000) \text {. }\end{array}$ \\
\hline MLA & Member of the Legislative Assembly \\
\hline MW & Megawatt \\
\hline NGO & Non-Governmental Organization \\
\hline PRA & Participatory Rural Appraisal \\
\hline PRI & Panchayati Raj Institutions \\
\hline RHS & Raitha Hitarakshana Samiti (farmers' organization) \\
\hline RRA & Rapid Rural Appraisal \\
\hline Rs. & Rupees; common name for currency in India. \\
\hline SDC & Swiss Agency for Development and Cooperation \\
\hline STS & Science, Technology \& Society \\
\hline TB & Tungabhadra \\
\hline Tmcft or TMC & One thousand million cubic feet \\
\hline WB & The World Bank \\
\hline
\end{tabular}




\section{Appendix B: Chronological Overview of Key Events and Correspondence at Sugur's Mini Hydel Plant}

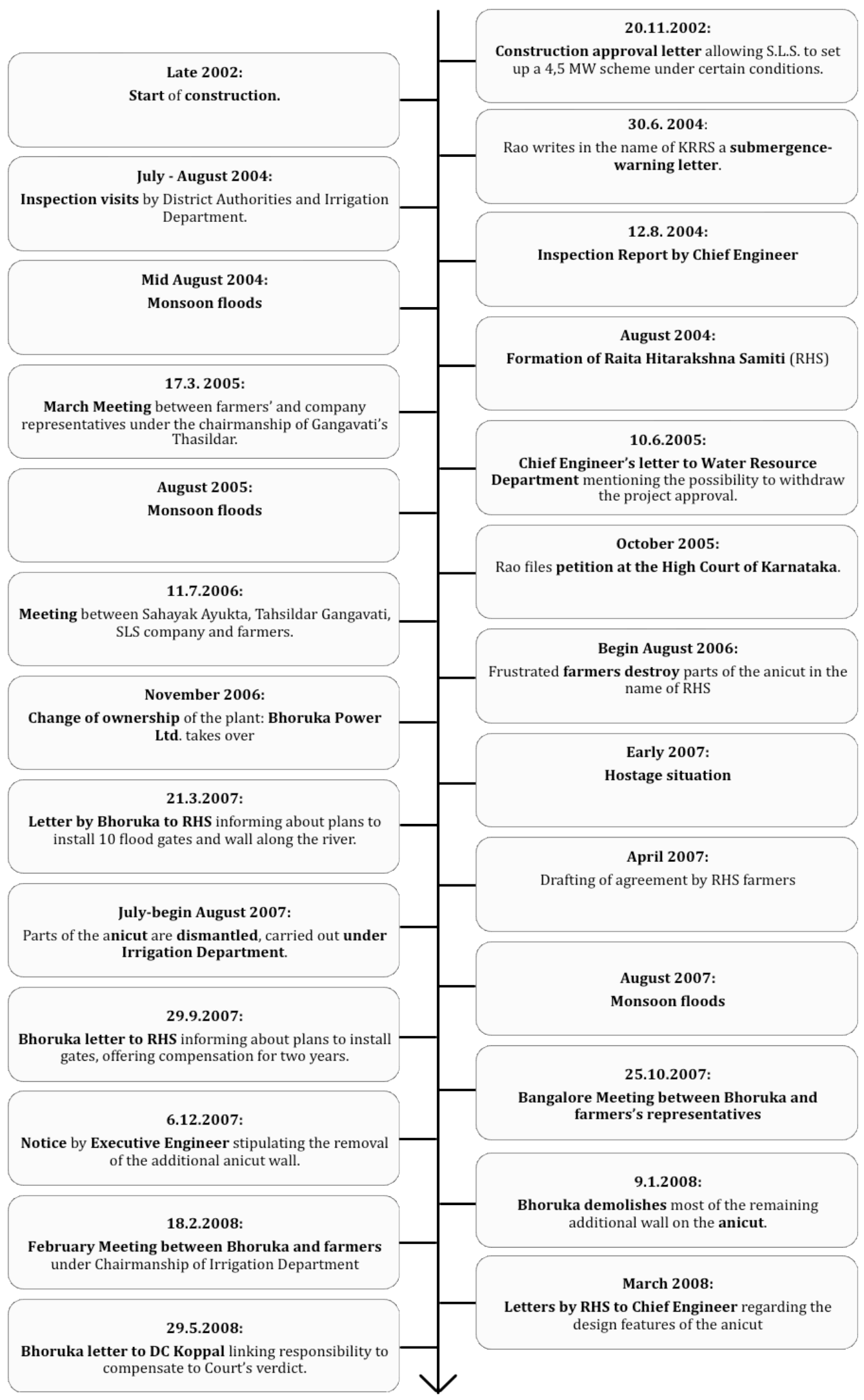




\section{Appendix C: List of Interviewees}

\begin{tabular}{|c|c|c|c|c|}
\hline Name & Function/Occupation & Date & $\begin{array}{l}\text { Location of } \\
\text { interview }\end{array}$ & $\begin{array}{l}\text { Interview } \\
\text { language }\end{array}$ \\
\hline $\begin{array}{l}10 \text { Gram Panchayat } \\
\text { members }\end{array}$ & Bennur GP & 3.8 .2010 & Bennur & $\begin{array}{l}\text { Kannada, } \\
\text { translated by } \\
\text { Sandeep Chand } \\
\text { Kannada, } \\
\text { translated by }\end{array}$ \\
\hline $\begin{array}{l}\text { members } \\
\text { memant Panchat }\end{array}$ & Ullenoor GP & 4.8.2010 & Ullenoor & $\begin{array}{l}\text { Sandeep Chand } \\
\text { Kannada, }\end{array}$ \\
\hline $\begin{array}{l}13 \text { Gram Panchayat } \\
\text { members }\end{array}$ & GP Kenchangudda & 5.8 .2010 & $\begin{array}{l}\text { Kenchanagu } \\
\text { ddam }\end{array}$ & $\begin{array}{l}\text { translated by } \\
\text { Sandeep Chand } \\
\text { Kannada, }\end{array}$ \\
\hline $\begin{array}{l}14 \text { Gram Panchayat } \\
\text { members }\end{array}$ & GP Sugur & 7.8.2010 & Sugur & $\begin{array}{l}\text { translated by } \\
\text { Sandeep Chand } \\
\text { Kannada, } \\
\text { translated by }\end{array}$ \\
\hline 3 male villagers & Farmers & 21.7.2009 & Bennur & $\begin{array}{l}\text { Subhash Bengre } \\
\text { Kannada, } \\
\text { translated by }\end{array}$ \\
\hline 4 male villagers & Farmers & 21.7.2009 & Bennur & Subhash Bengre \\
\hline 5 villagers (male) & Inhabitants Bodomanjari & 10.3.2009 & Bodomanjari & $\begin{array}{l}\text { Oriya, translated } \\
\text { by Madhab } \\
\text { Kannada. }\end{array}$ \\
\hline $\begin{array}{l}7 \text { Gram Panchayat } \\
\text { members }\end{array}$ & Deshnur GP & 6.8 .2010 & Deshnur & $\begin{array}{l}\text { translated by } \\
\text { Sandeep Chand }\end{array}$ \\
\hline Adappa S. & $\begin{array}{l}\text { Assistant Executive Engineer, } \\
\text { No.2 L.L.C. Subdivision, } \\
\text { Sirguppa }\end{array}$ & $\begin{array}{l}\text { Several } \\
\text { meetings }\end{array}$ & Sirguppa & English \\
\hline Annand $\mathrm{H}$. & $\begin{array}{l}\text { Assistant Engineer, } \\
\text { Munirabad Central Zone, } \\
\text { Kampli }\end{array}$ & $\begin{array}{l}\text { Several } \\
\text { meetings }\end{array}$ & Kampli & $\begin{array}{l}\text { Kannada, } \\
\text { translated by } \\
\text { Subhash Bengre } \\
\text { Kannada, } \\
\text { translated by }\end{array}$ \\
\hline Anonymous male & Farmer & 7.8.2010 & Sugur & $\begin{array}{l}\text { Sandeep Chand } \\
\text { Kannada, }\end{array}$ \\
\hline Ashoq & $\begin{array}{l}\text { Panchayat Development } \\
\text { Officer } \\
\text { Council of Management }\end{array}$ & 7.8.2010 & Sugur & $\begin{array}{l}\text { translated by } \\
\text { Sandeep Chand }\end{array}$ \\
\hline Bhogle, Svati & TIDE (NGO) & 10.7.2009 & Bangalore & English \\
\hline Chandrashekar S. & $\begin{array}{l}\text { Bhoruka Managing Director } \\
\text { Director International Energy }\end{array}$ & 24.7.2010 & Bangalore & English \\
\hline D'Sa, Antonette & $\begin{array}{l}\text { Initiative (NGO) } \\
\text { Chief Engineer, Irrigation } \\
\text { Department, Irrigation }\end{array}$ & 3.3.2009 & Bangalore & English \\
\hline $\begin{array}{l}\text { Devaraj K.B. } \\
\text { Gouda, Pampana; }\end{array}$ & Central Zone (ICZ) & 4.8.2010 & Munirabad & English \\
\hline Palakshappa K.; & Representatives of Water & & & Kannada, \\
\hline Balappa Harapur; & User Association, Gangavati & & & translated by \\
\hline Sharanappa Upnal & $\begin{array}{l}\text { Taluq } \\
\text { Senior Advisor-Energy, Swiss } \\
\text { Agency for Development and }\end{array}$ & 24.7.2009 & Kartagi & Subhash Bengre \\
\hline Joshi, Dr. Veena & Cooperation & 19.08 .2010 & Delhi & English \\
\hline Krishnan, Dr. Chitra & $\begin{array}{l}\text { Free-lance researcher, organic } \\
\text { farmer }\end{array}$ & $\begin{array}{l}\text { Several } \\
\text { meetings }\end{array}$ & Bangalore & English \\
\hline
\end{tabular}




\begin{tabular}{|c|c|c|c|c|}
\hline Name & Function/Occupation & Date & $\begin{array}{l}\text { Location of } \\
\text { interview }\end{array}$ & $\begin{array}{l}\text { Interview } \\
\text { language }\end{array}$ \\
\hline $\begin{array}{l}\text { Kumar, Mohan; } \\
\text { Yelappa, Gulige }\end{array}$ & $\begin{array}{l}\text { Representatives of Water } \\
\text { User Association, Sirguppa } \\
\text { Executive Director Pusala }\end{array}$ & 22.7.2009 & $\begin{array}{l}\text { Sirguppa } \\
\text { Kenchanagu }\end{array}$ & $\begin{array}{l}\text { Kannada, translated } \\
\text { by Subhash Bengre }\end{array}$ \\
\hline Kumar, Pramod & $\begin{array}{l}\text { Power Projects } \\
\text { Managing director TIDE }\end{array}$ & 2.8.2010 & ddam & English \\
\hline Kumar, Sampath & Technocrats Pvt. Ltd. & 11.7.2009 & $\begin{array}{l}\text { Bangalore } \\
\text { Kalahandi }\end{array}$ & English \\
\hline Madhab & Wida field staff & 10.3.2009 & District & English \\
\hline $\begin{array}{l}\text { Madiath, Joe } \\
\text { Male villager }\end{array}$ & Gram Vikas, Director & 16.8 .2010 & Berhampur & English \\
\hline $\begin{array}{l}\text { (referred to as } \\
\text { "Mahadesh") }\end{array}$ & $\begin{array}{l}\text { Farmer } \\
\text { Assistant Professor at Indian }\end{array}$ & 6.8 .2010 & Deshnur & $\begin{array}{l}\text { Kannada, translated } \\
\text { by Sandeep Chand }\end{array}$ \\
\hline $\begin{array}{l}\text { Malghan, Dr. } \\
\text { Deepak }\end{array}$ & $\begin{array}{l}\text { Institute of Management, } \\
\text { Bangalore } \\
\text { Director of the Centre for } \\
\text { Education and }\end{array}$ & 23.1.2009 & Bangalore & English \\
\hline Mendoza, Walter & $\begin{array}{l}\text { Documentation } \\
\text { Joint Director Livelihood, }\end{array}$ & 15.1.2009 & Bangalore & English \\
\hline Mohan, Rama & Center for World Solidarity & 31.7.2009 & Hyderabad & English \\
\hline Mohandas, Manish & $\begin{array}{l}\text { SDC, Research Associate } \\
\text { Engineer at Soham }\end{array}$ & 19.08.2010 & Delhi & English \\
\hline Narayan N.K. & Renewable Energy & 11.12.2008 & $\begin{array}{l}\text { Bangalore } \\
\text { Bhubanesh- }\end{array}$ & English \\
\hline Pattnaik, Sudhir & $\begin{array}{l}\text { Editor Samadrusti } \\
\text { Chief Technical Advisor, } \\
\text { Centre for Electronics, } \\
\text { Design and Technology, } \\
\text { Indian Institute of Science, }\end{array}$ & 14.8.2010 & war & English \\
\hline Pittet, Dr. Andre & $\begin{array}{l}\text { Bangalore } \\
\text { Professor for Rural } \\
\text { Management at Indian }\end{array}$ & 14.6.2009 & Bangalore & English \\
\hline Prasad, Dr. Shambu & $\begin{array}{l}\text { Institute of Management, } \\
\text { Bhubaneshhwar }\end{array}$ & 13.8.2010 & $\begin{array}{l}\text { Bhubanesh- } \\
\text { war }\end{array}$ & English \\
\hline Prem Patro & Tribal Leader & 10.3.2009 & $\begin{array}{l}\text { Kalahandi } \\
\text { District }\end{array}$ & $\begin{array}{l}\text { Oriya, translated by } \\
\text { Madhab }\end{array}$ \\
\hline Ramana M.V. & $\begin{array}{l}\text { Senior Fellow CISED } \\
\text { Director of Village }\end{array}$ & $\begin{array}{l}\text { Several } \\
\text { meetings }\end{array}$ & Bangalore & English \\
\hline $\begin{array}{l}\text { Rams } \\
\text { (Ramasubramaniam) }\end{array}$ & $\begin{array}{l}\text { Renewable Energy Systems } \\
\text { (India) Pvt. Ltd. }\end{array}$ & 4.4.2009 & Bangalore & English \\
\hline \multirow[t]{3}{*}{ Rao Subramaniam } & President RHS & 20.7.2009 & Gangavati & $\begin{array}{l}\text { Kannada, translated } \\
\text { by Subhash Bengre }\end{array}$ \\
\hline & & 21.7.2009 & Gangavati & $\begin{array}{l}\text { Kannada, translated } \\
\text { by Subhash Bengre }\end{array}$ \\
\hline & & 3.8.2010 & Gangavati & $\begin{array}{l}\text { Kannada, translated } \\
\text { by Sandeep Chand }\end{array}$ \\
\hline Rao, Subramaniam & & 17.3.2009 & Gangavati & $\begin{array}{l}\text { Kannada, translated } \\
\text { by Chitra Krishnan }\end{array}$ \\
\hline Rao, Surendra & $\begin{array}{l}\text { Assistant Executive Engineer, } \\
\text { ICZ } \\
\text { Bhoruka General Manager- }\end{array}$ & 4.8.2010 & Munirabad & English \\
\hline Shashidar B.M. & Civil & 24.7.2010 & Bangalore & English \\
\hline
\end{tabular}




\begin{tabular}{|c|c|c|c|c|}
\hline Name & Function/Occupation & Date & $\begin{array}{l}\text { Location of } \\
\text { interview }\end{array}$ & $\begin{array}{l}\text { Interview } \\
\text { language }\end{array}$ \\
\hline $\begin{array}{l}\text { Sheshadrinath, } \\
\text { Sandeep }\end{array}$ & $\begin{array}{l}\text { Research Associate, Centre } \\
\text { for Budget and Policy Studies }\end{array}$ & 20.10 .2010 & Bangalore & English \\
\hline Singh, Dr. Punit & Micro Hydel Engineer & $\begin{array}{l}\text { Several } \\
\text { meetings }\end{array}$ & Bangalore & $\begin{array}{l}\text { English } \\
\text { Kannada, } \\
\text { translated by }\end{array}$ \\
\hline Somalingappa M.S. & MLA & 17.2.2009 & Sirguppa & Subhash Bengre \\
\hline Sreekumar N. & $\begin{array}{l}\text { Energy Group member, } \\
\text { Prayas (NGO) }\end{array}$ & 27.7.2010 & Hyderabad & English \\
\hline Stanley, William & Director Wida & 11.3.2009 & Semiliguda & English \\
\hline Thakker, Himanshu & Director SANDRP (NGO) & 28.7.2010 & $\begin{array}{l}\text { Delhi } \\
\text { Koraput }\end{array}$ & English \\
\hline Vaghela, Dipti & Energy Program Coordinator & 12.3.2009 & District & English \\
\hline Vaidyanathan, Geeta & CTex GreEn (NGO) & 16.8.2010 & Berhampur & $\begin{array}{l}\text { English } \\
\text { Kannada, } \\
\text { translated by }\end{array}$ \\
\hline Venkat K.R. & Farmer & 23.7.2009 & Vinaknagar & Subhash Bengre \\
\hline
\end{tabular}




\section{Appendix D: List of References to Specific Documentation regarding the Karnataka Case Studies}

\begin{tabular}{|c|c|c|c|}
\hline Reference & Type of document/title & Author & Date \\
\hline Approval letter, 2002 & Letter & $\begin{array}{l}\text { Water Resource } \\
\text { Department, Bangalore }\end{array}$ & 20.11 .2002 \\
\hline Bhoruka letter 2008 & Letter & Bhoruka & 29.5 .2008 \\
\hline Bhoruka letter, 2007 & Letter & Bhoruka company & 21.3.2007 \\
\hline Department, n.d. & $\begin{array}{l}\text { Note on Right Bank } \\
\text { Vijayanagara Channels }\end{array}$ & $\begin{array}{l}\text { Water Resource } \\
\text { Department, Bangalore }\end{array}$ & n.d. \\
\hline Inspection CE, 2004 & Inspection report & Chief Engineer, ICZ & 13.8.2004 \\
\hline Letter CE, 2005 & Letter & Chief Engineer, ICZ & 10.6.2005 \\
\hline Letter Rao, 2004 & Letter & S. Rao & 30.6 .2004 \\
\hline Letter RHS 2007 & Letter & RHS & 19.11.2007 \\
\hline Minutes 2008 & Minutes of meeting & DC Koppal & 18.2.2008 \\
\hline Notice 2007 & Notice (Order) & Executive Engineer, ICZ & 6.12 .2007 \\
\hline $\begin{array}{l}\text { Petition } 2005 \\
\text { RHS Draft Agreement } \\
2007\end{array}$ & $\begin{array}{l}\text { Petition } \\
\text { Draft agreement }\end{array}$ & $\begin{array}{l}\text { R.B. Deshpande } \\
\text { (Advocate) } \\
\text { RHS }\end{array}$ & $\begin{array}{l}23.10 .2005 \\
\text { April-March } \\
205\end{array}$ \\
\hline RHS letter-a, 2008 & Letter & RHS & 8.3.2008 \\
\hline RHS letter-c, 2008 & Letter & RHS & 8.3.2008 \\
\hline SLS letter, 2006 & Letter & SLS company & 4.9.2006 \\
\hline TCE, 2003 & $\begin{array}{l}\text { Detailed Project Report: } \\
\text { Kenchanaguddam Mini Hydel } \\
\text { Scheme }(3 \times 2 \mathrm{MW}) \\
\text { Detailed Project Report: S.L.S. } \\
\text { Power Industries LTD: Sugur } \\
\text { Mini Hydel Scheme }(3 \times 1.5 \\
\text { MW) }\end{array}$ & $\begin{array}{l}\text { TCE Consulting } \\
\text { Engineers Limited, } \\
\text { Bangalore } \\
\text { TCE Consulting } \\
\text { Engineers Limited, } \\
\text { Bangalore }\end{array}$ & $\begin{array}{l}2003, \\
\text { Bangalore }\end{array}$ \\
\hline
\end{tabular}




\section{Bibliography}

Agarwal, A., \& Narain, S. (Eds.). (1997). Dying Wisdom: Rise, fall and potential of India's traditional water harvesting systems (Vol. 4).

Assadi, M. (1995). Peasant Movement in Karnataka 1980-1994. Delhi: Shipra.

Babu, M. D. (2004). Finances of Panchayats in Karnataka: A policy paper ISEC Working Paper Series, 143.

Bailey, F. G. (1969). Stratagems and spoils : a social anthropology of politics. Oxford: Blackwell.

Barnes, S., \& Kaase, M. (Eds.). (1979). Political Action: Mass Participation in Five Western Democracies. Beverly Hills: Sage Publications.

Baviskar, A. (1995). In the Belly of the River: Tribal Conflicts over Development in the Narmada Valley. New Delhi: Oxford University Press.

Besley, T., Pande, R., \& Rao, V. (2007). Political Economy of Panchayats in South India. Political \& Econmical Weekly, 42(8), 661-666.

Bhattacharyya, S. (2006). Energy access problem of the poor in India: Is rural electrification a remedy? Energy Policy, 34, 3387-3397.

Bijker, W. (1995). Democratization of Technology: Who are the Experts? Extended version of paper presented at seminar "Expertenkultur und Demokratie", Aachen, 23.3.1995.

Bijker, W. (2005). The Politics of Water: A Dutch Thing to Keep the Water Out or Not. In B. Latour \& P. Weibel (Eds.), Making Things Public: Atmospheres of Democracy. Cambridge, MA: MIT Press.

Bijker, W. (2006). The Vulnerability of Technological Culture. In H. Nowotny (Ed.), Cultures of Technology and the Quest for Innovation (pp. 52-69). New York: Berghahn Books.

Bijker, W. (2007). Dikes and Dams, Thick with Politics. Isis, 98, 109-123.

Bijoy, C. R. (2003). A History of Discrimination, Conflict and Resistance. (February), 1-10. Retrieved 23.2.2012, from www.pucl.org/Topics/Dalit-tribal/2003/adivasi.htm .

Biradar, N., \& Sridhar, K. (2009). Consequences of 2003 Drought in Karnataka with Particular Reference to Livestock and Fodder. Journal of Human Ecology, 26(2), 123-130.

Botes, L., \& van Rensburg, D. (2000). Community Participation in development: nine plagues and twelve commandments. Community Development Journal, 35(1), 41-58.

Bucchi, M., \& Neresini, F. (2008). Science and Public Participation. In E. J. Hackett, O. Amsterdamska, M. Lynch \& J. Wajcman (Eds.), The Handbook of Science and Technology Studies (Third Edition ed.). Cambridge: MIT Press.

Byrne, B. (2004). Qualitative interviewing. In C. Seale (Ed.), Researching Society and Culture (2nd ed., pp. 179192). London: Sage Publications.

Callon, M., \& Rabeharisoa, V. (2008). The Growing Engagement of Emergent Concerned Groups in Political and Economic Life: Lessons from the French Association of Neuromuscular Disease Patients. Science, Technology \& Human V alues, 33(2), 230-261. 
Centre (Population Research Centre), (2002). Bellary District, Karnataka: Multiple Indicator Survey Report No. 126. Dharwad: JSS - Institute of Economic Research.

Chambers, R. (1981). Rapid Rural Appraisal: rationale and repertoire. Public Administration and Development, 2(2), 95-106.

Chambers, R. (1983). Rural Development: Putting the Last First. Harlow: Longman.

Chambers, R. (1997). Whose Reality Counts? Putting the first last London: ITDG Publishing.

Charmaz, K. (2009). Shifting the grounds: Constructivist grounded theory methods. In J. Morse, P. Stern, J. Corbin, B. Bowers, K. Charmaz \& A. Clarke (Eds.), Developing Grounded Theory: The Second Generation (pp. 127-154). Walnut Creek: Left Coast Press

Chilvers, J. (2008). Deliberating Competence: Theoretical and Practitioner Perspectives on Effective Participatory Appraisal Practice. Science, Technology \& Human Values, 33(2), 155-185.

Clarke, A. (2003). Situational analyses: Grounded theory mapping after the postmodern turn. Symbolic Interaction, 26(4), 553-576.

Cleaver, F. (1999). Paradoxes of Participation: Questioning Participatory Approaches to Development. Journal of International Development, 11, 597-612.

Collins, H. M., \& Evans, R. (2002). The Third Wave of Science Studies: Studies of Expertise and Experience. Social Studies of Science, 32(2), 235-296.

Cooke, B., \& Kothari, U. (Eds.). (2001). Participation: The New Tyranny? . London: Zed Books.

Cornwall, A. (2006). Historical Perspectives on Participation in Development. Commonwealth and Comparative Politics, 44(1), 62-83.

D'Souza, R. (2006). Drowned and Dammed, Colonial Capitalism and Flood Control in Eastern India. New Delhi: Oxford University Press.

Delgado, A., Kjolberg, K. L., \& Wickson, F. (2011). Public engagement coming of age: From theory to practice in STS encounters with nanotechnology. Public Understanding of Science, 20(6), 826-845.

deSouza, P. R. (2003). The Struggle for Local Government: Indian Democracy's New Phase. Publius, $33(4), 99-118$

Dharmadhikary, S., Sheshadri, S., \& Rehmat. (2005). Unravelling Bhakra: Assessing the Temple of Resurgent India. Badwani: Manthan Adhyayan Kendra.

Dixit, S., Sant, G., \& Wagle, S. (1998). WB-Orissa Model of Power Sector Reform: Cure Worse than Disease. Economic and Political Weekly, 33(17), 944-949.

Dubash, N., \& Rajan, S. (2001). Power Politics: Process of Power Sector Reform in India Economic and Political Weekly, 36(35), 3367-3390.

Dubash, N., \& Rajan, S. (2003). Electricity Reforms in India: Political economy and implications for social and environmental outcomes. In N. Wamukonya (Ed.), Electricity Reform: Social and environmental challenges. Roskilde, Denmark: United Nations Environment Programme

Dumont, L. (1970). Homo hierarcbicus: An essay on the caste system. Chicago: University of Chicago Press.

Durant, D. (2011). Models of democracy in social studies of science. Social Studies of Science, 41(5), 691-741. 
Dwivedi, R. (2006). Conflict and Collective Action: The Sardar Sarovar Project in India. New Delhi: Routledge.

Edwards, M., \& Hulme, D. (1996). Too Close for Comfort? The Impact of Official Aid on Nongovernmental Organizations. World Development, 24(6), 961-973.

Epstein, S. (1996). Impure Science: AIDS, activism, and the politics of knowledge. Berkeley: University of California Press.

EU. (n.d.). Hydropower Retrieved 24.4.2012, from

http://ec.europa.eu/research/energy/eu/research/hydropower/index_en.htm

Ezrahi, Y. (1990). The Descent of Icarus: Science and the Transformation of Contemporary Democracy. Cambridge, MA: Harvard University Press.

Feenberg, A. (1995). Alternative Modernity: The Technical Turn in Philosophy and Social Theory. Berkely: University of California Press.

Frankel, F. (1990). Conclusion: Decline of a Social Order. In F. Frankel \& M. Rao (Eds.), Dominance and State Power in Modern India (Vol. II). Mumbai: Oxford University Press.

Funtowicz, S., \& Ravetz, J. (1992). Three types of risk assessment and the emergence of post-normal science. In S. Krimsky \& D. Golding (Eds.), Social Theories of Risk (pp. 251-274). Westport: Praeger Publishers.

Gabriel, O. (2009). Politische Partizipation. In D. Fuchs \& E. Roller (Eds.), Lexikon der Politik: Hundert Grundbegriffe (pp. 224-226). Stuttgart: Philipp Reclam jun.

Geertz, C. (1973). The Interpretation of Cultures. New York: Basic Books.

Gibbons, M., Limoges, C., Nowotny, H., Schwartzman, S., Scott, P., \& Trow, M. (1994). The New Production of Knowledge: The Dynamics of Science and Research in Contemporary Societies. London: Sage.

Gibbs, G. (2007). Analyzing Qualitative Data. In U. Flick (Ed.), The SAGE Qualitative Research Kit (Vol. 6). London: Sage Publications.

Glaser, B., \& Strauss, A. (1967). The Discovery of Grounded Theory: Strategies for Qualitative Research. Chicago: Aldine Publishing Company.

Glover, L. (2006). From Love-ins to Logos: Charting the Demise of Renewable Energy as a Social Movement. In J. Byrne, N. Toly \& L. Glover (Eds.), Transforming Power: Energy, Environment and Society in Conflict (Vol. Energy and Environmental Policy Series 9). New Brunswick: Transaction Publisher.

GOI. (2005). National Electricity Policy. New Delhi: The Gazette of India.

GOI. (2008). Eleventh Five Year Plan (2007-2012): Agriculture, Rural Development, Industry Services and Physical Infrastructure. New Delhi: Government of India.

GOI. (2009). Guidelines for Village Electrification through Decentralized Distributed Generation New Delhi: Government of India.

GOI. (2011a). Census of India 2011. New Delhi: Office of the Registrar General \& Census Commissioner.

GOI. (2011b). Economic Survey 2011-12. New Delhi: Ministry of Finance.

GOI. (n.d.). Mission 2012 - Power for All Retrieved 6.4.2012, from http://powermin.nic.in/JSP_SERVLETS/internal.jsp 
GoK. (Government of Karnataka) (2009). Karnataka Renewable Energy Policy 2009-2014. Bangalore: KREDL.

Gomart, E., \& Hajer, M. (2003). Is that Politics? In B. Joerges \& H. Nowotny (Eds.), Social Studies of Science and Technology: Looking Back, Ahead (pp. 33-61). Dordrecht: Kluwer Academic Publishers.

Guijt, I., \& Shah, M. K. (1998). The Myth of Community: Gender Issues in Participatory Development. London: IT Publications.

Gupta, D. (2005). Caste and Politics: Identity over System. Annual Review of Anthropology 34, 409-427.

Gupta, J., \& Zaag, P. v. d. (2008). Interbasin water transfers and integrated water resource management: Where engineering, science and politics interlock Physics and Chemistry of the Earth, 33(1-2), 28-40.

Hamlett, P. W. (2003). Technology Theory and Deliberative Democracy. Science, Technology \& Human Values, 28(1), 112-140.

Hardiman, D. (1976). Politicization and agitation among dominant peasants in early twentieth century India. Political \& Econmical Weekly, 11(9), 365-369.

Hindu. (The Hindu) (2007). Irate farmers lock up Tungabhadra HLC office. Retrieved 30.1.2012, from http://hindu.com/2007/12/12/stories/2007121261390800.htm

Hindu. (The Hindu) (2010). CADA engineers locked up in office. Retrieved 30.1.2012, from www.hindu.com/2010/02/03/stories/2010020352800300.htm

Hoerig, U. (2008). Water to the People: Drinking Water and Water for Livelihoods. Bonn: Evangelischer Entwicklungsdienst.

IEA. (International Energy Agency) (2011). Technology Development Prospects for the Indian Power Sector. Paris: International Energy Agency.

indiawaterfoundation. (n.d.). News: November 28, 2011, Retrieved 24.1.2012, from indiawaterfoundation.org

IRESR. (2010). Indian Renewable Energy Status Report: Background Report for DIREC 2010. Oak Ridge and Springfield: U.S. Department of Energy.

IRN. (International Rivers Network) (2003). Twelve Reasons to Exclude Large Hydro from Renwables Initiatives (Vol. November). International Rivers Network (and other co-publishers).

Irwin, A. (2001). Constructing the scientific citizen: science and democracy in the biosciences. Public Understanding of Science, 10, 1-18.

Jasanoff, S. (2003a). Breaking the Waves in Science Studies: Comment on H.M. and Robert Evans, The Third Wave of Science Studies. Social Studies of Science, 33(3), 389-400.

Jasanoff, S. (2003b). Technologies of Humility: Citizen Participation in Governing Science. Minerva, 41, 223-244.

Jasanoff, S. (Ed.). (2004). States of knowledge: the co-production of science and social order. New York: Routledge.

Jeffrey, C. (2002). Caste, Class, and Clientelism: A Political Economy of Everyday Corruption in Rural North India. Economic Geography, 78(1), 21-41.

Joss, S., \& Durant, J. (Eds.). (1995). Public Participation in Science - The Role of Consensus Conferences in Europe. London: Science Museum. 
Joy, K. J., Gujja, B., Paranjape, S., Goud, V., \& Vispute, S. (Eds.). (2008). Water Conflicts in India: A Million Revolts in the Making New Delhi: Routledge.

Kaase, M. (2003). Politische Beteiligung/Politische Partizipation. In U. Andersen \& W. Woyke (Eds.), Handwörterbuch des politischen Systems der Bundesrepublik (5 ed.). Opladen: Leske + Budrich.

Kaase, M., \& Marsh, A. (1979). Political Action: A Theoretical Perspective. In S. Barnes \& M. Kaase (Eds.), Poltical Action: Mass Participation in Five Western Democracies (pp. 27-56). Beverly Hills: Sage Publications.

Kale, S. (2004). Current Reforms: The Politics of Policy Change in India's Electricity Sector. Pacific Affairs, 77(3), 467-491.

Keohane, R. (1986). Reciprocity in International Relations. International Organization, $40(1), 1-27$.

Khagram, S. (2004). Dams and development: transnational struggles for water and power. Ithaca: Cornell University Press.

Kim, M. (2002). Cloning and deliberation: Korean consensus conference. Developing World Bioethics, 2(2), $159-172$.

Kleinman, D. L., Powell, M., Grice, J., \& Adrian, J. (2007). A Toolkit for Democratizing Science and Technology Policy: The Practical Mechanics of Organizing a Consensus Conference. Bulletin of Science, Technology \& Society, 27(2), 154-169.

Kochanek, S. A. (1987). Briefcase Politics in India: The Congress Party and the Business Elite. Asian Survey, 27(12), 1278-1301.

KREDL. (n.d.). Karnataka Renewable Energy Development Limited, Retrieved 23.2.2012, from http://www.kredl.kar.nic.in

Krishnan, C. (2003). Tank and Anicut Irrigation Systems: An Engineering Analysis. (PhD), Indian Institute of Technology, New Delhi.

Krishnan, C. (2008). Irrigation Infrastructure - a view from below: The Case of the Tungabhadra River. In C. f. E. a. D. (CED) (Ed.). Bangalore.

Krishnan, C., \& Veeravalli, S. (2006). Tanks and Anicuts of South India: Examples of an Alternative Science of Engineering. In A. V. Balasubramanian \& T. D. Nirmala Devi (Eds.), Traditional knowledge systems of India and Sri Lanka (Vol. 5, pp. 220-226). Chennai: Centre for Indian Knowledge Systems.

Kujur, R. K. (2006). Underdevelopment and Naxal Movement Economic and Political Weekly, 41(7), 557-559.

Kumar, S. (2001). Adivasis of South Orissa: Enduring Poverty. Economic and Political Weekly, 36(43), 40524054.

Latour, B. (2004). Politics of Nature: How to bring the Sciences into Democracy (C. Porter, Trans.). Cambridge, MA: Harvard University Press.

Latour, B. (2007). Turning around Politics: A Note on Gerhard De Vries' Paper. Social Studies of Science, 37(5), 811-820.

Lengwiler, M. (2008). Participatory Approaches in Science and Technologu. Science, Technology \& Human Values, 33(2), 186-200. 
Liming, H. (2009). Financing rural renewable energy: A comparison between China and India. Renewable \& Sustainable Energy Review, 13(5), 1096-1103.

MacDougall, J. (1979). Dominant Castes or Rich Peasants? Political \& Econmical Weekly, 14, 12-13(March 24-31), 625-634.

Manor, J. (2007). Change in Karnataka over the Last Generation: Villages and the Wider Context. Political \& Econmical Weekly, 42(8), 653-660.

Marres, N. (2005). No Issue, No Public. (PhD), University of Amsterdam, Amsterdam.

Marres, N. (2007). The Issues Deserve More Credit: Pragmatist Contributions to the Study of Public Involvement in Controversy. Social Studies of Science, 37(5), 759-780.

McCormick, S. (2006). The Brazilian Anti-Dam Movement: Knowledge Contestation as Communicative Action. Organization and Environment, 19(3), 321-346.

McCully, P. (1996). Silenced Rivers: The Ecology and Politics of Large Dams. London: Zed.

Milbrath, L. W., \& Goel, M. L. (1977). Political Participation: How and Why Do People Get Involved in Politics? Chicago: Rand Mc Nally College Publishing Company.

Miller, D. (1986). Exchange and Alienation in the "Jajmani" System. Journal of Anthropological Research, 42(4), 535-556.

MNRE. (n.d.-a). Ministry of New and Renewable Energy Retrieved 3.12.2010, from http://mnre.gov.in/

MNRE. (n.d.-b). Strategic Plan for New and Renewable Energy Sector for the Period 2011-17. New Delhi: Ministry of New and Renewable Energy.

Molle, F., Mollinga, P. P., \& Wester, P. (2009). Hydraulic Bureaucracies and the Hydraulic Mission: Flows of Water, Flows of Power. Water Alternatives, 2(3), 328-349.

Mollinga, P. P. (2003). On the Waterfront: Water Distribution, Technology and Agrarian Change in a South Indian Canal Irrigation System. New Delhi: Orient Longman Private Limited.

Mosse, D. (2003). The Rule of Water: Statecraft, Ecology, and Collective Action in South India. New Delhi: Oxford University Press.

msn-news. (2011). Angry villagers lock up engineers, other power dept employees. Retrieved 30.1.2012, from http://news.in.msn.com/national/article.aspx?cp-documentid $=4998417$

Nadkarni, M. (1987). Farmers' Movements in India. Ahmedabad: Allied.

Neher, C. D. (1994). Asian Style Democracy. Asian Survey, 34(11), 949-961.

Nishizawa, M. (2005). Citizen deliberation on science and technology and their social environments: Case study on the Japanese consensus conference on GM crops. Science and Public Policy, 32, 479-489.

Nohlen, D., Schultze, R.-O., \& Schüttemeyer, S. (Eds.). (1998). Polittische Begriffe. München: Verlag C.H. Beck.

Norris, P. (2001). Democratic Phoenix: Reinventing Political Activism. Cambridge, UK: Cambridge University Press.

Offe, C. (2003). Herausforderungen der Demokratie: Zur Integrationsfaebigkeit politischer Institutionen. Frankfurt am Main: Campus Verlag. 
Parry, G., Moyser, G., \& Day, N. (1992). Political participation and democracy in Britain. Cambridge: Cambridge University Press.

Patibanda, S. (2011). Reconceptualising Rights: A Study of Micro Social Movements in India. (PhD), Institute for Social and Economic Change through Mysore University, Mysore.

Patkar, M. (Ed.). (2004). River Linking: A Millenium Folly? Mumbai: National Alliance of People's Movement.

Pattenden, J. (2005). Trickle-Down Solidarity, Globalisation and Dynamics of Social Transformation in a South Indian Village. Economic and Political Weekly, 40(19), 1975+1977-1985.

Pattie, C., Seyd, P., \& Whiteley, P. (2003). Citizenship and Civic Engagement: Attitudes and Behaviour in Britain. Political Studies, 51, 443-468.

Patton, M. Q. (1990). Qualitative evaluation and research methods. Beverly Hills: Sage Publications.

Phadke, R. (2005). People's Science in Action: The Politics of Protest and Knowledge Brokering in India. Society and Natural Resources, 18, 363-375.

Polit, D., \& Beck, C. (2010). Generalization in quantitative and qualitative research: Myths and strategies. International Journal of Nursing Studies, 47, 1451-1458.

Prayas. (2001). Privatization or Democratization: The Key to the Crises in the Electricity Sector: The Case of Maharashtra. Pune: Prayas.

Prayas. (2008). Awareness and Action for Better Electricity Service. Pune: Prayas.

Prayas. (2009). An overview of Indian Energy Trends: Low Carbon Growth and Development Challenges. Pune: Prayas.

Putnam, R. (2000). Bowling Alone: The Collapse and Revival of American Community. New York: Simon \& Schuster.

Quartz, J. (2011). Constructing Agrarian Alternatives. (PhD), Maastricht University, Maastricht.

Ramana, M. V. (forthcoming). The Power of Promise? Examining Nuclear Energy in India. New Delhi: Penguin India.

Reddy, A. K. (2006). Technology and Development. In S. Reddy \& P. Balachandra (Eds.), Energy, Environment and Development: A Technological Perspective, Selected works of Prof. Amulya K. N. Reddy. New Delhi: Narosa Publishing House.

Rip, A. (2003). Constructing Expertise in a Third Wave of Science Studies? Social Studies of Science, 33(3), 419-434.

Rowe, G., \& Frewer, L. (2005). A Typology of Public Engagement Mechanisms. Science, Technology \& Human Values, 30(2), 251-290.

Rowe, G., Marsh, R., \& Frewer, L. (2004). Evaluation of a Deliberative Conference. Science, Technology \& Human Values, 29(1), 88-121.

Roy, A. (1999). The Greater Common Good. Mumbai: India Book Distributors.

Rudolph, L. I., \& Hoeber-Rudolph, S. (1987). In Pursuit of Lakshmi: The Political Economy of the Indian State. Delhi: Orient Longman. 
The Lokpal and Lokayuktas Bill 2011, Bill No. 134-C of 2011 C.F.R. (2011).

Sankar, T. L. (2004). Electricity Act 2003: Dark Shadows over a Bright Vision. Economic and Political Weekly, 39(8), 839-844.

Schultze, R.-O. (1995). Partizipation. In D. Nohlen \& R.-O. Schultze (Eds.), Politische Theorien (Vol. Band I). Muenchen: Verlag C.H. Beck.

Schumacher, E. F. (1973). Small is beautiful: a study of economics as if people mattered. London: Blond \& Briggs.

Scott, J. (1998). Seeing like a State: How Certain Schemes to Improve the Human Condition Have Failed. New Haven: Yale University Press.

Shah, E. (2003). Social Designs: Tank Irrigation Technology and Agrarian Transformation in Karnataka, South India. New Delhi: Orient Longman.

Shah, E. (2012). 'A life wasted making dust': affective histories of dearth, death, debt and farmers' suicides in India. The Journal of Peasant Studies, 1-21.

Sharma, A. (2008). Logics of Empowerment: Development, Gender, and Governance in Neoliberal India. Mineapolis: University of Minnesota Press.

Sharma, K. L. (1997). Rural Society in India. Jaipur: Rawat.

Sims, H. (2001). Moved, Left No Address: Dam Construction, Displacement and Issue Salience. Public Administration and Developement, 21, 187-200.

Singh, G. (1997). Understanding Political Corruption in Contemporary Indian Politics. Political Studies, 45(3), 626-638.

Singh, S. (1990). Evaluating Large Dams in India. Economic and Political Weekly, 25(11), 561-574.

Singh, S. (1997). Taming the Waters: The Political Economy of Large Dams in India. New Delhi: Oxford University Press.

Srinivas, M. N. (1972). Social Change in Modern India. New Delhi: Orient Longman.

Stein, B. (1989). Vijayanagara (Vol. 1.2). Cambridge: Cambridge University Press.

Task-Force. (2001). Report of the Task Force on Panchayati Raj Institutions (PRIs). New Delhi: Government of India.

TB-Board. (2006). Annual Report 2005-2006: Tungabhadra Dam. Hospet, Karnataka: Tungabhadra Board.

Tenhunen, S. (2003). Culture and political agency: Gender, kinship and village politics in West Bengal. Contributions to Indian Sociology 37(3), 495-518.

Thakkar, H. (2007). The Tryst with the Big Dam. Dams, Rivers \& People, 5(8-9), 7-14.

Thakkar, H. (2012). Why Inter-linking of Rivers is neither necessary, nor Desirable. Dams, Rivers \& People, 10(2), 1-4.

Thorpe, C. (2008). Political Theory in Science and Technology Studies. In E. J. Hackett, O. Amsterdamska, M. Lynch \& J. Wajcman (Eds.), The Handbook of Science and Technology Studies (Third Edition ed., pp. 63-82). Cambridge, MA: MIT Press. 
TIDE. (2009). Report of Study on Community Microhydro Systems in selected States. n.a.: Internal Report of the Swiss Agency for Development and Cooperation.

Times. (The New York Times) (2012). Anna Hazare. Retrieved 16.2.2012, from http://topics.nytimes.com/top/reference/timestopics/people/h/anna_hazare/index.html?offset $=0 \& \mathrm{~s}=$ newest

TOI. (The Times of India) (2010). Bescom employees locked in office. Retrieved 30.1.2012, from Times of India http://articles.timesofindia.indiatimes.com/2010-02-13/hubli/28139823_1_bescomtransformer-harihar

TOI. (The Times of India) (2012). SC directs Centre to implement interlinking of rivers project. Retrieved 10.4.2012, from http://articles.timesofindia.indiatimes.com/2012-0227/india/31103687_1_interlinking-social-activists-rivers

Topf, R. (1995). Beyond Electoral Participation. In H. Klingemann \& D. Fuchs (Eds.), Citizens and the State (Vol. 1, pp. 52-91). Oxford: Oxford University Press.

Transparency. (2005). India Corruption Study 2005: To Improve Governance (Vol. Volume-I: Key Highlights). New Delhi: Centre for Media Studies for Transparency International India

Turner, S. (2001). What is the Problem with Experts? . Social Studies of Science, 31(1), 123-149.

Uehlinger, H.-M. (1988). Politische Partizipation in der Bundesrepublik. Opladen: Westdeutscher Verlag.

UNDP. (1993). Human Development Report. New York: UNDP.

UNESCO. (2006). Water - a shared responsibility: UNESCO, World Water Assessment Programme

Vaghela, D. (2010). Transformative Participation in Community Micro Hydro: Gram Vikas’ Micro Hydro Projects. e-net Energy Network, 1, 3-5.

van Deth, J. W. (2003). Vergleichende politische Partizipationsforschung. In D. Berg-Schlosser \& F. Müller-Rommel (Eds.), Vergleichende Politikwissenschaft (Vol. 4, pp. 167-187). Opladen: Leske + Budrich.

van Deth, J. W., \& Maloney, W. (Eds.). (2012). New Participatory Dimensions in Civil Society: Professionalization and Individualized Collective Action. Milton Park: Routledge/ECPR Studies in European Political Science.

Verba, S., \& Nie, N. (1972). Participation in America: Political Democracy and Social Equality. New York: Harper \& Roy.

Verba, S., Schlozman, K., \& Brady, H. (1995). Voice and Equality: Civic Voluntarism in American Politics. Cambridge, MA: Harvard University Press.

Vijayalakshmi, V. (2005). Rent-Seeking and Gender in Local Governance: ISEC Working Paper 164. Bangalore: Institute for Social and Economic Change.

Visvanathan, S. (1997a). A Carnival for Science: Essays on Science, Technology and Development Oxford: Oxford University Press.

Visvanathan, S. (1997b). Gujral's Red Fort Doctrine. Political \& Econmical Weekly, 32(38), 2378-2379.

Vries, G. d. (2007). What is Political in Sub-politics?: How Aristotle Might Help STS. Social Studies of Science, 37(5), 781-809. 
Wade, R. (1982). The System of Administrative and Political Corruption: Canal Irrigation in South India. Journal of Development Studies, 18(3), 287-328.

Wade, R. (1984). Irrigation reform in the conditions of populist anarchy: An Indian case. Journal of Development Economics, 14(3), 285-303.

Wade, R. (1985). The market for public office: Why the Indian state is not better at development. World Development, 13(4), 467-497.

Walsh, D. (2004). Doing ethnography. In C. Seale (Ed.), Researching Society and Culture (2nd ed., pp. 225237). London: Sage Publications.

WB. (The World Bnak) (2010). Unleashing the Potential of Renewable Energy in India. Washington: The World Bank: South Asia Energy Unit, Sustainable Development Department.

WB. (The World Bank) (2011). India at a glance. Retrieved 9.4.2011, from http://devdata.worldbank.org/AAG/ind_aag.pdf

WB. (The World Bank) (2012). India Economic Update. Washington, DC: The World Bank.

WCD. (World Commission on Dams) (2000). Dams and Development: A New Framework for Decision-Making. London: Earthscan Publications Ltd.

Wida. (2004). Power to People: The Putsil Way, Community Response to Management of Local Resources and Appropriate Energy Options. Semiliguda: Wida.

Wida. (2007). Power of Change and the Catalysts: Local Solutions to Global Problems. Semiliguda: Wida.

Wilsdon, J. (2005). Paddling Upstream: New Currents in European Technology Assessment. In M. Rodemeyer, D. Sarewitz \& J. Wilsdon (Eds.), The Future of Technology Assessment (pp.22-29). Washington, DC: Woodrow Wilson International Center for Scholars.

Winner, L. (1980). Do Artefacts Have Politics? Daedalus, 109, 121-136.

Wynne, B. (1996). May the Sheep Safely Graze? A Reflexive View of Expert-Lay Knowledge Divide. In S. Lash, B. Szerzynski \& B. Wynne (Eds.), Risk, Environment and Modernity: Towards a New Ecology (pp. 44-84). London: Sage.

Wynne, B. (2003). Seasick on the Third Wave? Subverting the Hegemony of Propositionalism: Response to Collins and Evans (2002). Social Studies of Science, 33(3), 401-417.

Wynne, B. (2005). Risk as globalizing 'democratic' discourse? Framing subjects and citizens. In M. Leach, I. Scoones \& B. Wynne (Eds.), Science and Citizens: Globalization and the Challenge of Engagement (pp. 66-82). London: Zed Books.

Wynne, B. (2007). Public Participation in Science and Technology: Performing and Obscuring a PoliticalConceptual Category Mistake. East Asian Science, Technology and Society: an International Journal, 1, 99110 .

Zukin, C., Keeter, S., Andolina, M., Jenkins, K., \& Delli Carpini, M. X. (2006). A New Engagement?: Political Participation, Civic Life, and the Changing American Citizen. Oxford: Oxford University Press. 


\section{Samenvatting}

In dit boek bestudeer ik maatschappelijke betrokkenheid door de lens van elektriciteitsopwekking. Met deze focus pleit ik voor het behartigen van maatschappelijke belangen in de ontwikkeling van wetenschap en technologie. De technologieën die centraal staan in dit boek zijn kleinschalige waterkrachtcentrales in India, die elektriciteit opwekken door het gebruik van waterkracht. De maatschappelijke betrokkenheid bij deze technologieën is nog niet vaak bestudeerd. Tot nu toe kregen in de Indiase context meestal slechts technologieën de publieke aandacht, die elektriciteit op grote schaal opwekken. Dit ligt vooral aan de grootschalige gevolgen van deze technologieën voor de samenleving en de ecologie. Met het verkleinen van de schaal van de technologie lijkt echter de zichtbaarheid en de erkenning van de maatschappelijke betrokkenheid uit de publieke belangstelling te verdwijnen. Ik koos ervoor om maatschappelijke betrokkenheid bij kleine waterkrachtcentrales te bestuderen door drie aspecten empirisch te onderzoeken: vormen, inhoud en gevolgen. Dit onderzoekfocus zet impliciet vraagtekens achter algemene aannames, die van de sociaal-technische trivialiteit van deze kleinschalige, hernieuwbare energietechnologieën uitgaan. Door deze benadering probeer ik dus aan te tonen dat de empirische relevantie niet afhangt van schaal, noch van imago.

Mijn empirische analyse van vormen, inhoud en gevolgen van maatschappelijke betrokkenheid met kleinschalige waterkrachtcentrales in India begint in hoofdstuk 2, dat ons meeneemt naar de heuvels in het zuiden van Orissa. In dit eerste empirische hoofdstuk introduceer ik het concept "uitgenodigde betrokkenheid" (invited engagement) door het werk van twee NGOs te beschrijven. De NGO's Wida en Gram Vikas streven ernaar om door het faciliteren van micro hydel ${ }^{146}$ projecten aan de socio-economische ontwikkeling van arme plattelandsgemeenschappen bij te dragen.

De implementatie van micro hydel projecten binnen het kader van plattelandsontwikkeling heeft gevolgen voor de manier waarop maatschappelijke betrokkenheid plaatsvindt. In Orissa is maatschappelijke betrokkenheid bij micro hydel projecten gerelateerd aan de institutionalisering van bepaalde, vooraf gedefinieerde implementatiefasen en governance-structuren. Daardoor worden de activiteiten van de gemeenschap in lijn gebracht met de eisen van een ontwikkelingsproject. Beide NGOs volgen een gemeenschap-gebaseerde (community-based)

\footnotetext{
${ }^{146}$ Het woord "hydro-elektrische" wordt afgekort met "hydel".
} 
aanpak bij de uitvoering van micro hydro-elektrische projecten. Centraal in deze aanpak staan activiteiten, die leiden tot een gevoel van "project-eigenaarschap" bij de leden van de gemeenschap. Wida en Gram Vikas streven naar eigenaarschap door de mensen tot betrokkenheid bij de verschillende uitvoeringsfasen van het project uit te nodigen. Door hun betrokkenheid bij het initiëren, construeren en het beheer van de projecten kent de maatschappelijke betrokkenheid fysieke, technische, bestuurlijke en financiële aspecten.

Echter, beide NGOs zetten verschillende accenten bij het faciliteren van hun gemeenschapgebaseerde projecten, zodat de manier waarop mensen tijdens het implementatieproces betrokken worden verschilt. De toegang tot elektriciteit voor arme en gemarginaliseerde gemeenschappen kenmerkt Wida's interpretatie van gemeenschap-gebaseerde betrokkenheid. Bij Wida ligt de nadruk op de mogelijkheden die elektriciteitstoegang de gemeenschap biedt, bijvoorbeeld door productief gebruik of door het huishoudelijke werk van vrouwen (in dubbele zin) te verlichten. Gram Vikas ziet gemeenschap-gebaseerde betrokkenheid als een leermogelijkheid voor dorpelingen om apparatuur en expertise voornamelijk lokaal te verwerven, zodat ze in staat worden gesteld om micro hydel projecten zo veel mogelijk zelfstandig te implementeren. Door te focussen op het constructieproces, komt in de micro hydel projecten van Gram Vikas de toegang tot kennis naar voren. Actoren die micro-hydel projecten in Orissa faciliteren bepalen dus de vormen van betrokkenheid op basis van een bepaalde opvatting van empowerment. Als gevolg daarvan worden scenario's van empowerment gerealiseerd, waarbij de toegang tot elektriciteit of kennis consumenten, producenten, of ondernemers laat ontstaan.

Hoofdstukken 3 en 4 nemen ons mee naar een andere onderzoekslocatie, de staat van Karnataka. Twee kleine waterkrachtcentrales $\left(4.5 \mathrm{MW}^{147}\right.$ en $\left.6 \mathrm{MW}\right)$ in de buurt van het dorp Sugur (hoofdstuk 3) en het dorp Kenchanaguddam (hoofdstuk 4), beide gelegen langs de rivier Tungabhadra, vormen het uitgangspunt voor het onderzoek naar vormen, inhoud en gevolgen van maatschappelijke betrokkenheid. De context van de twee kleine hydro-elektrische projecten in Karnataka is heel anders dan die in Orissa. De kleine hydro-elektrische projecten in Karnataka zijn particuliere ondernemingen, die elektriciteit produceren voor het centrale elektriciteitsnetwerk. India's hervormingen sinds de jaren 1990 waren erop gericht de elektriciteitssector te liberaliseren. Kleine waterkrachtcentrales maken aldus deel uit van de inspanningen van de regering van India om de economische groei en de opwekking van elektriciteit te stimuleren, mede door het particuliere ondernemers mogelijk te maken aan de veelbelovende markt van hernieuwbare energie deel te nemen.

\footnotetext{
${ }^{147}$ MW is de afkorting van Megawatt.
} 
In Sugur (hoofdstuk 3) beschrijf ik gebeurtenissen die plaats vonden na de oprichting van een waterkrachtcentrale en laat zien hoe een lokale bewoner een cruciale rol speelde in de organisatie van activiteiten door de oprichting van een boerenorganisatie, de RHS. Betrokkenheid nam voornamelijk de vorm aan van protesten, die als gevolg van de overstroming van landbouwgrond ontstonden. Het management van de waterkrachtcentrale versterkte en verhoogde een oude dam (anicut) aanzienlijk om aldus meer water naar de centrale te leiden. Dit veroorzaakte herhaaldelijk overstromingen van de landbouwgronden. Het daaruit voortvloeiende conflict duurde meer dan vijf jaar en betrof het voorkomen van toekomstige overstromingen en de eis van boeren tot compensatievergoedingen.

Om de activiteiten die zich ontvouwden bij de Sugur-centrale te typeren, onderscheid ik "conventionele" en "onconventionele" vormen van maatschappelijke betrokkenheid. In het begin van het conflict bestaan de activiteiten uit verschillende vormen van conventionele betrokkenheid, zoals correspondentie met de overheid en het bijeenroepen van vergaderingen. Later werden deze vormen aangevuld met onconventionele activiteiten, in de vorm van het slopen van de anicut of het nemen van gijzelaars. Ik identificeer de verwijzing naar legaliteit en legitimiteit als verschillende normatieve kaders, die worden aangeroepen om deze activiteiten te rechtvaardigen.

Conventionele en onconventionele activiteiten rond de Sugur elektriciteitscentrale betroffen vraagstukken over water. Dit is verrassend, omdat men in het begin zou verwachten dat activiteiten verband houden met elektriciteitskwesties, zoals kwaliteit, prijzen, transmissie en distributie. Boeren verwachten niet dat een hydro-elektrisch project zich aanpast aan de omgeving zonder verdere verstoringen, maar dat de centrale henvoordelen oplevert die betrekking hebben op water, en niet elektriciteit.

Conventionele en onconventionele vormen van betrokkenheid spelen ook een rol in hoofdstuk 4 over de Kenchanaguddam elektriciteitscentrale. Maatschappelijke betrokkenheid met de Kenchanaguddam centrale uit zich in de uiteenlopende belangen van verschillende actoren, die zich bevinden in de nabijheid van de centrale, dat wil zeggen in Kenchanaguddam dorp, Vinaknagar Camp, en Deshnur dorp. De oprichting van de Kenchanaguddam elektriciteitscentrale veranderde de lokale waterstroom, hetgeen voordelen en nadelen bracht voor de omliggende dorpen. In alle gevallen is de waterstroom het referentiepunt voor de bewoners om uiteindelijk met hun eerdere activiteiten te stoppen en dus hun betrokkenheid opgaven. 
Drie belangrijke actoren spelen een belangrijke rol in het vormgeven van betrokkenheid bij de elektriciteitscentrale: Ten eerste fungeerde in Kenchanaguddam de lokale MLA ${ }^{148}$ als makelaar van een overeenkomst tussen boeren en het bedrijfsmanagement over de hoogte van de anicut. Dit had tot gevolg dat bewoners hun betrokkenheid bij de centrale opgaven. Ten tweede had de boerenlobby bij Kenchanaguddam een machtige positie in het conflict. Niet alleen had de onconventionele betrokkenheid van de lobby resultaat bij het bepalen van het ontwerp van het waterinnamekanaal van de centrale. Ook de beïnvloeding van verdeling van het water naar het Deshnur-kanaal komt voor rekening van de intimiderende protesten door de lobby. De terugtrekking van de boer Venkat en anderen van Vinaknagar Camp wordt veroorzaakt door de macht van de lobby, in combinatie met de beschikbaarheid van irrigatie-alternatieven.

Ten derde lieten de gebeurtenissen in Deshnur Village de belangrijke rol zien, die de GP ${ }^{149}$ speelt in de informatie- en goedkeuringprocessen van een elektriciteitscentrale. In deze processen zouden de professionele en persoonlijke belangen van de leden van de GP kunnen verstrengelen. De aanvaarding van steekpenningen wijst op de korte termijn- en winstgerichte aanpak van leden van de GP in Deshnur op dat moment. Bij het vernemen van de goedkeuring van het project door de GP begonnen mogelijk getroffen boeren tegen de centrale te protesteren door het schrijven van een brief aan de regionale overheidsinstantie. Daarna schortten zij hun betrokkenheid op, te wijten aan de stilstand van de bouw van het project.

Net als bij de Sugur case laat hoofdstuk 4 zien dat maatschappelijke betrokkenheid met de centrale in Kenchanaguddam gerelateerd is aan problemen met water. In Kenchanaguddam wordt echter duidelijk dat de bouw van de centrale ook leidt tot een stroom van geld, die de actoren proberen te beïnvloeden en uit te buiten. De machtige lokale positie die lobbyleiders genieten stelt hen in staat om in wisselende coalities geld af te persen van het management van de centrale.

De door de MLA bemiddelde overeenkomst en het onbetwiste gedrag van de boerenlobby zijn voorbeelden van creatie van sociale regelingen, waarin legitimiteit permanent voorrang krijgt boven legaliteit. Als gevolg daarvan wordt een nieuwe lokale orde gelegitimeerd, die parallel bestaat naast de openbare orde. In tegenstelling tot de Sugur case worden in Kenchanaguddam geen pogingen ondernomen om de lokale legitimiteit in lijn te brengen met de algemene openbare orde. Analytisch gezien verstoort het permanent verschil tussen lokale legitimiteit en openbare orde de categorieën van conventionele en onconventionele betrokkenheid zoals geïntroduceerd in het vorige hoofdstuk. De conventionele activiteiten van de MLA hebben een illegale dimensie, en de onconventionele activiteiten door de boerenlobby zijn onbetwist en

148 MLA is de afkorting van Member of the Legislative Assembly.

${ }^{149} \mathrm{GP}$ is de afkorting van Gram Panchayat. 
continu. Als gevolg daarvan worden de activiteiten de facto permanent gelegitimeerd. Hybride vormen van conventionele en onconventionele betrokkenheid zijn het resultaat.

In het afsluitende hoofdstuk 5 weef ik de bevindingen van de hoofdstukken 2 , 3, en 4 samen. In alle drie gevallen veroorzaakte de bouw van kleinschalige waterkrachtcentrales verschillende vormen van betrokkenheid, die ik getypeerd heb als uitgenodigde betrokkenheid (invited engagement), conventionele betrokkenheid en onconventionele betrokkenheid (conventional and unconventional engagement). Wynne's (2007) concept "invited engagement" was nuttig om de activiteiten met micro elektriciteitscentrales in Orissa te conceptualiseren. Het concept legt treffend uit hoe de NGOs gemeenschappen uitnodigden om deel te nemen in hun projecten. Voor de gemeenschappen betekende de aanvaarding van de uitnodiging de verbintenis om deel te nemen aan vooraf gedefinieerde activiteiten, die fysieke, technische, bestuurlijke en financiële aspecten kenden.

Verschillende facetten van betrokkenheid worden zichtbaar in de activiteiten van de bewoners die betrokken waren bij kleine elektriciteitscentrales langs de Tungabhadra rivier. De activiteiten hadden met name een protestkarakter en varieerden van contact zoeken en communiceren met overheidsambtenaren, via de oprichting van een boerenbelangenorganisatie, tot agressief gedrag. De gelijkenis van deze vormen met de vormen die beschreven worden in de participatie-literatuur, hebben mij ertoe geleid analytische inzichten uit dit vakgebied over te nemen. Vooral het analytische onderscheid tussen "conventionele" en "onconventionele" (Barnes \& Kaase, 1979) vormen van betrokkenheid bleek nuttig bij het begrijpen van de specifieke vormen van betrokkenheid in Karnataka. In lijn met Kaase en Barnes (Barnes \& Kaase, 1979; Kaase, 2003) bevestigt mijn analyse van de Karnataka case studies de belangrijke rol die legitimiteit speelt in de analyse van onconventionele vormen van betrokkenheid. Empirische gegevens in het geval van Kenchanaguddam wijzen echter op een situatie, waarin de categorieën van conventionele en onconventionele betrokkenheidactiviteiten vervormd worden. Analytisch leidt dit tot hybride vormen van deze categorieën.

De verschillende vormen van betrokkenheid hadden verschillende onderwerpen als inhoud. In Orissa werd de betrokkenheid met micro hydel projecten mogelijk gemaakt door de NGOs Wida en Gram Vikas. Het ging niet alleen over de opwekking van elektriciteit. De fysieke, technische en bestuurlijke betrokkenheid van de bewoners gaf hen ook toegang tot kennis. Dominante thema's in de betrokkenheid bij de twee elektriciteitsprojecten langs de Tungabhadra rivier in Karnataka waren gerelateerd aan de problematiek van water en geld. De constructie van de centrales zorgde niet alleen voor een verandering van de waterstroom, maar creëerde tevens 
een geldstroom. Beide kwesties leidden tot betrokkenheid en onbetrokkenheid. Het (on-) vermogen van actoren om de inhoud van de activiteiten te bepalen illustreerde vragen rond macht, die in alle drie de gevallen te voorschijn kwamen.

Betrokkenheid bij de elektriciteitscentrales in Orissa en Karnataka had verschillende consequenties. Afhankelijk van de conceptie van empowerment leidde de betrokkenheid van de bewoners in Orissa tot scenario's van empowerment, waarbij de toegang tot elektriciteit of kennis centraal stond. Als gevolg daarvan werden bewoners gesterkt in hun rol als consumenten, producenten of ondernemers. In de Sugur case namen activiteiten vooral de vorm aan van protest. Als gevolg van de langdurige betrokkenheid van de boeren in het kader van de RHS werden uiteindelijk toekomstige overstromingen voorkomen, $\mathrm{Zij}$ ervoeren dus dat hun betrokkenheid een verschil maakte. Dit lijkt echter dubbelzinnig, zo niet cynisch, door de wanverhouding tussen de afloop en de prijs die boeren moesten betalen in de vorm van geïnvesteerde tijd, verloren oogst en de ervaren verwaarlozing.

In Kenchanaguddam en omgeving leidde betrokkenheid tot een scenario van wantrouwen, met als kern beschuldigingen van corruptie. De situatie was doordrongen van wantrouwen tussen de dorpen ${ }^{150}$, tussen dorpelingen ${ }^{151}$, en tussen de bedrijven en de dorpelingen ${ }^{152}$. De activiteiten van de boerenlobby leidden tot de oprichting van machtsstructuren naast die van de overheidsinstellingen. Als gevolg daarvan werden die overheidsinstellingen verzwakt en daarmee ook de mogelijkheden van bewoners voor het eisen van verantwoording en rechtzetting.

Om de geïdentificeerde vormen, inhoud en gevolgen van maatschappelijk betrokkenheid uit te leggen onderscheid ik de variabelen "situationele elementen", "organisatie", "randvoorwaarden" en "technologiedesign". De verklarende kracht van de variabelen verschilt per case, zodat steeds andere variabelen op de voorgrond treden. In Orissa kwam het technologieontwerp naar voren als belangrijkste variabele voor het verklaren van vormen, inhoud en gevolgen van betrokkenheid. Het idee van gemeenschap-gebaseerde (community-based) betrokkenheid was wezenlijk voor de manier hoe Wida en Gram Vikas hun micro hydel projecten conceptualiseerden. De technologie was zodanig ontworpen dat zij mensen in staat stelde deel te nemen aan de bouw en het beheer van de centrales.

Hoewel de verandering van de waterstroom door de bouw van een elektriciteitscentrale het uitgangspunt was voor activiteiten in Sugur en Kenchanaguddam, domineren verschillende variabelen de redenen waarom de activiteiten werden ontplooid. De betrokkenheid die plaatsvond in de Sugur case werd vooral beïnvloed door de manier waarop Rao de activiteiten

\footnotetext{
150 van Kenchanaguddam en Vinaknagar

151 in Deshnur

152 uit Kenchanaguddam en van Vinaknagar 
organiseerde. Dientengevolge bepaalde de betrokkenheid onder leiding van de RHS het verloop van de gebeurtenissen. In Kenchanaguddam vormde corruptie in combinatie met de aanwezigheid van invloedrijke leiders, georganiseerd in een boerenlobby, de belangrijkste randvoorwaarden voor de ontplooiing van betrokkenheid. Terwijl "technologiedesign" dus dominant is in de Orissa case study, domineert de variabele "organisatie" de uitleg van betrokkenheid in de Sugur case. Ten slotte komen zowel "randvoorwaarden" als ook "organisatie" naar voren als belangrijke verklarende variabelen in Kenchanaguddam. Toch betekent het identificeren van dominante variabelen in elke afzonderlijke case niet dat de andere variabelen onbelangrijk zijn. In feite helpt juist het samenspel van dominante en minder dominante variabelen om vormen, inhoud en gevolgen van maatschappelijk betrokkenheid bij kleinschalige waterkrachtcentrales in India te verklaren. 


\section{Curriculum Vitae}

Johanna Irene Höffken (December 1978) was born in Berlin and started her academic career at the Dresden University of Technology (TUD), where she graduated as M.A. in International Relations. During this time, she could broaden and enrich her studies at the TUD with study and work stays in Madrid, Geneva and Brussels.

After moving to the Netherlands, she ventured into the field of Science and Technologies Studies (STS) and graduated as M.A. in the ESST program at Maastricht University in 2006. She then worked temporarily for the Dutch Ministry of Foreign Affairs and the Dutch Provincial Government of Noord-Brabant, before she started her PhD project about Civic Engagement with Small-scale Hydroelectric Plants in India at the Faculty of Arts and Social Sciences at Maastricht University.

During her time as $\mathrm{PhD}$ candidate she was trained within the Faculty's Graduate School as well as the Netherlands Graduate Research School of Science, Technology and Modern Culture (WTMC). She also had the privilege to participate as fellow in the Program on Science, Technology and Society at Harvard University in the fall semester in 2010.

She currently works as a lecturer at the Eindhoven University of Technology (TUe), where she follows her interests in STS, development, and sustainability issues within the School of Innovation Sciences. 